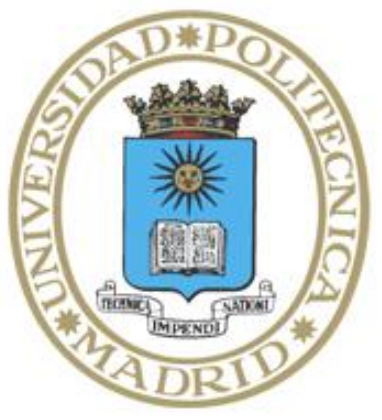

UNIVERSIDAD POLITÉCNICA DE MADRID

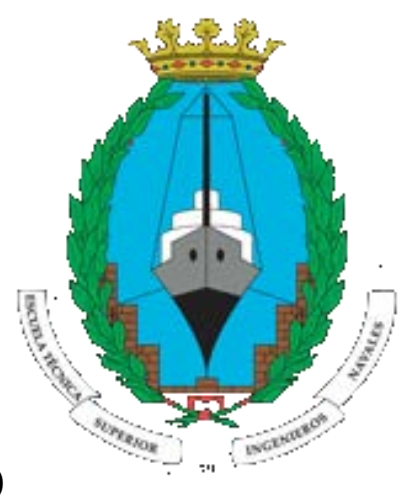

ESCUELA TÉCNICA SUPERIOR DE INGENIEROS NAVALES

\title{
COMPORTAMIENTO A IMPACTO DE MATERIALES COMPUESTOS SOMETIDOS A FENÓMENOS DE SLAMMING EN EMBARCACIONES DE ALTA VELOCIDAD
}

TESIS DOCTORAL

D. Patrick Townsend Valencia (Máster Universitario en Ciencias y

Tecnología de Polímeros/Ingeniero Naval)

Director de Tesis: D. Juan Carlos Suárez (Doctor en Ciencia de los Materiales e Ingeniería Metalúrgica) 


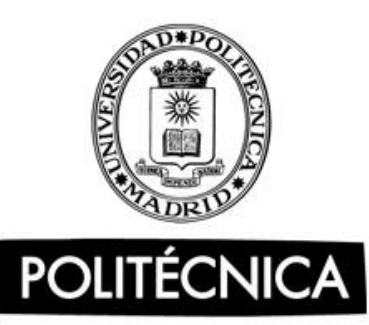

Tribunal designado por la Comisión de Doctorado de la Universidad Politécnica de Madrid, en su reunión del día de. .de $20 \ldots . .$.

Presidente:

Vocal:

Vocal:

Vocal:

Secretario:

Suplente:

Suplente:

Realizado el acto de defensa y lectura de la Tesis el día. de. .de 20 ... en la E.T.S.I. /Facultad.

Calificación

EL PRESIDENTE

LOS VOCALES

EL SECRETARIO 


\section{AGRADECIMIENTOS}

Debo mencionar que sin la invaluable ayuda de mi director Juan Carlos Suárez, no hubiese sido posible esta investigación. Sus enseñanzas y los criterios compartidos, han permitido que culmine este proyecto y aplique las mismas en el desarrollo de esta investigación.

Gracias a Ana García, por la orientación y compañerismo en el trabajo del laboratorio que fue necesario para la consecución de la presente investigación.

A Estela Sanz, por su valiosa colaboración en la ejecución de los trabajos y por la constancia para poder acompañar mi ritmo de trabajo.

Y no puedo dejar de menciona a mi familia, a mi esposa Carlota y a mis hijos Patrick y Carlita, quienes sin su apoyo no hubiese podido ausentarme del hogar para venir a esta institución como lo es la UPM, a cursar mis estudios Doctorales. 
RESUMEN

ABSTRACT

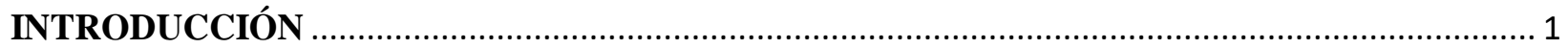

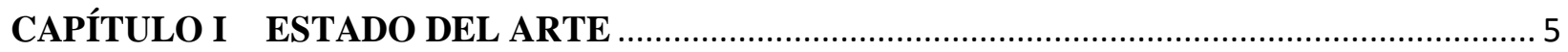

1.1. Aspectos fundamentales del fenómeno de slammig ............................................................... 5

1.2. Los materiales compuestos en la construcción naval..................................................... 9

1.3. Materiales compuestos con curado fuera de autoclave ..................................................... 11

1.4. Comportamiento a impacto de materiales compuestos ................................................... 14

1.5. Estrategias para mitigar el daño en paneles de materiales compuestos .............................. 20

CAPÍTULO II METODOLOGÍA EXPERIMENTAL I: PANELES GFRP SIN MODIFICAR 24

2.1. Fabricación de paneles GFRP con preimpregnado OoA .................................................... 24

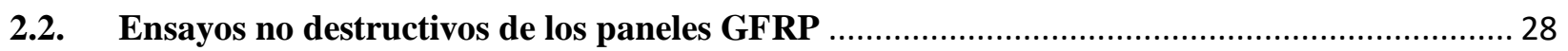

2.3. Ensayos mecánicos de caracterización de los paneles GFRP ................................................ 32

2.4. Ensayos de impacto por caída de peso ............................................................................... 34

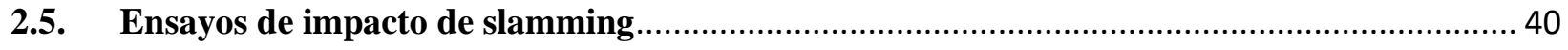

2.6. Evaluación del daño en los paneles impactados ................................................................ 46

2.7. Determinación de la resistencia residual de los paneles impactados ................................. 50

CAPÍTULO III RESULTADOS EXPERIMENTALES I: PANELES GFRP SIN MODIFICAR 51

3.1. Inspección mediante ultrasonido en inmersión mediante la técnica de pulso-eco y

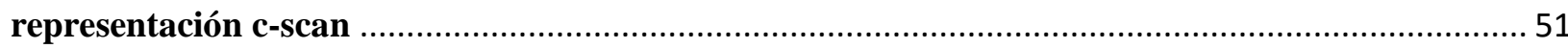

3.2. Resultados de los ensayos de tracción y flexión de los paneles GFRP …............................. 53

3.3. Evaluación no destructiva del daño tras los impactos por caída de peso …........................... 55

3.4. Observación microestructural del daño en paneles GFRP no modificados tras el impacto por

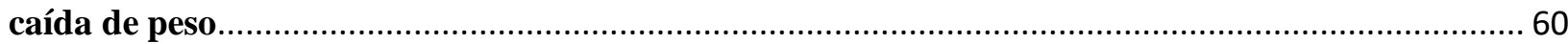

3.5. Distribución del daño en los laminados. Análisis de secciones delgadas en la zona de impacto 63

3.6. Evaluación no destructiva del daño a lo largo de los ensayos de slamming, en función del

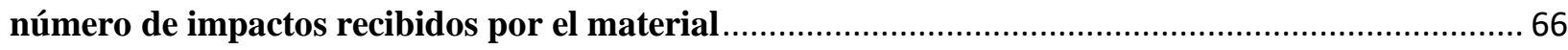

3.7. Distribución del daño en los laminados tras los ensayos de slamming …............................. 70

3.8. Observación microestructural del daño producido por los impactos de baja energía en los ensayos de slamming 
3.9. Ensayos de compresión tras impacto en paneles impactados

CAPÍTULO IV DISCUSIÓN DE LOS RESULTADOS EXPERIMENTALES I: PANELES GFRP SIN MODIFICAR

4.1. Correlaciones experimentales entre energía de impacto y daño producido en el material.... 83

4.2. Mecanismo de daño interlaminar e intralaminar en los paneles impactados 84

4.3. Evolución del daño y pérdida de propiedades mecánicas de los paneles. Resistencia residual de los paneles impactados.

4.4. Estrategias para mitigar la progresión del daño y diferir el fallo del material 87

CAPÍTULO V METODOLOGÍA EXPERIMENTAL II: PANELES GFRP MODIFICADOS

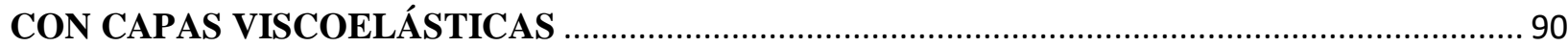

5.1. Fabricación de capas viscoelásticas mediante fabricación aditiva ..................................... 90

5.2. Integración de las capas viscoelásticas en los paneles de GFRP de preimpregnados OoA .... 93

5.3. Ensayos de impacto por caída de peso en paneles GFRP modificados con capas viscoelásticas 96

5.4. Ensayos de impactos repetidos de baja energía en ensayos de slamming ..... 97

CAPÍTULO VI RESULTADOS EXPERIMENTALES II: PANELES GFRP MODIFICADOS CON CAPAS VISCOELÁSTICAS

6.1. Daño producido en paneles GFRP modificados con capas viscoelásticas por impactos por caída de peso. 98

6.2. Daño producido en paneles GFRP modificados con capas viscoelásticas por impactos repetidos de baja energía en ensayos de slamming...

CAPÍTULO VII DISCUSIÓN DE LOS RESULTADOS EXPERIMENTALES II: PANELES GFRP MODIFICADOS CON CAPAS VISCOELÁSTICAS. 108

7.1. Comparación entre el comportamiento frente a impactos por caída de peso de paneles GFRP sin modificar y modificado mediante la introducción de capas viscoelásticas.

7.2. Comparación entre el comportamiento frente a impactos repetidos de baja energía en ensayos de slamming de paneles GFRP sin modificar y modificados mediante la introducción de capas viscoelásticas . 


\section{LISTA DE TABLAS}

Tabla 1 Condiciones de los ensayos de impacto por caída de peso a paneles no modificados .................. 55

Tabla 2 Características de la embarcación a condición de máxima carga .............................................6 66

Tabla 3 Resumen de análisis con ultrasonidos realizados luego de los ensayos de slamming a paneles no

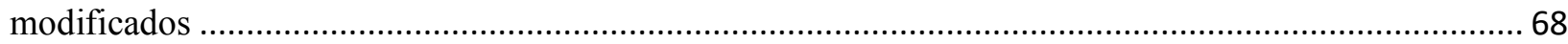

Tabla 4 Condiciones de los ensayos de slamming a paneles no modificados ........................................ 70

Tabla 5 Condiciones de los ensayos de impacto por caída de peso a paneles modificados ..................... 98

Tabla 6 Condiciones de los ensayos de slamming a paneles modificados ........................................... 105

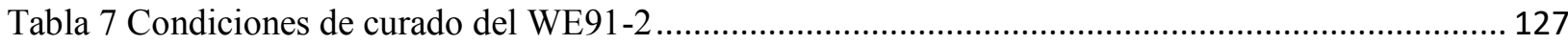

Tabla 8 Características mecánicas de la resina WE91-2 …................................................................. 128

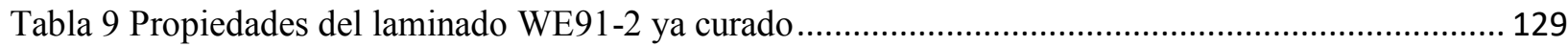

Tabla 10 Análisis de los paneles de GFRP con ultrasonido sumergido ................................................. 134

Tabla 11 Resultados de los ensayos de slamming sobre el panel \# A ................................................ 152

Tabla 12 Resultados de los ensayos de slamming sobre el panel \# B ................................................. 155

Tabla 13 Resultados de los ensayos de slamming sobre el panel \# C.................................................... 160

Tabla 14 Resultados de los ensayos de slamming sobre el panel \# D .................................................. 163

Tabla 15 Resultados de los ensayos de slamming sobre el panel \# E ................................................... 166 


\section{LISTA DE FIGURAS}

Figura 1 Navegación de la lancha "Bite Me" ............................................................................... 6

Figura 2 Ángulos de astilla muerta considerados para el slamming ................................................... 8

Figura 3 Defectos por vacío en laminados .................................................................................. 12

Figura 4 Daño producido por slamming en el peak de proa de la lancha "Bite Me" .............................. 14

Figura 5 Evolución del daño en un panel laminado ...................................................................... 17

Figura 6 Equilibrio entre las energías de la prueba de impacto de un material compuesto biaxial ............ 18

Figura 7 Energías de impacto por caída vertical de peso ................................................................... 19

Figura 8 Modelo presentado por Blake sobre la inserción del material viscoelástico dentro de una

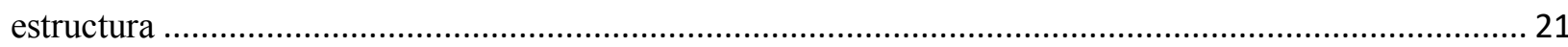

Figura 9 Efecto de la presión de slamming dentro de un panel de GFRP modificado viscoelásticamente

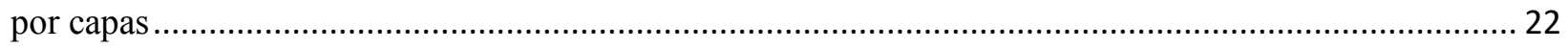

Figura 10 Rollo de preimpregnado a temperatura ambiente ............................................................ 26

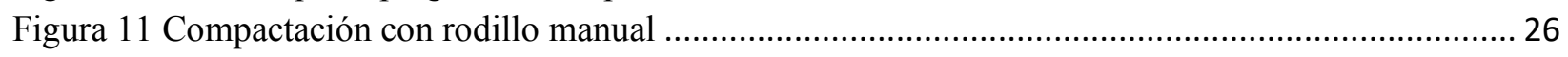

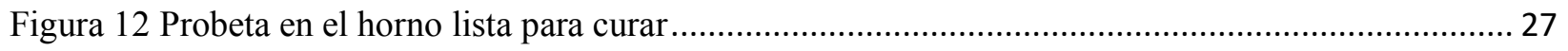

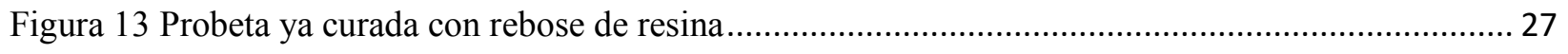

Figura 14 Probeta con Galgas lista para ensayos ......................................................................... 27

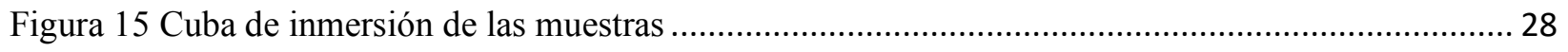

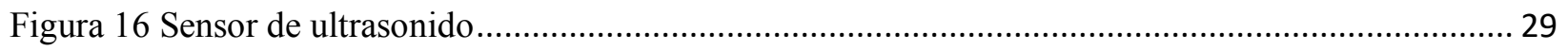

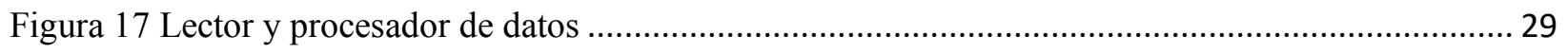

Figura 18 Conversión de imagen de 32 bits a 2 bits de un panel ensayado ........................................... 30

Figura 19 Comparación con ultrasonido de un panel sin impactar y luego de $1.8 \times 10^{5}$ ciclos de impacto

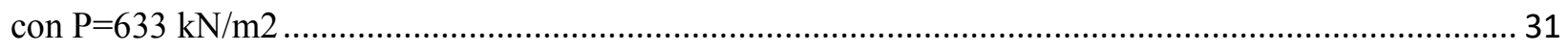

Figura 20 Máquina universal de ensayos con útil de flexión en 3 puntos ............................................. 32

Figura 21 Configuración de la máquina de impacto por caída de peso .................................................. 34

Figura 22 Parte inferior de la estructura de soporte....................................................................... 35

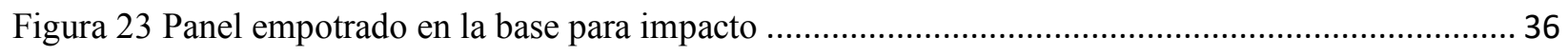

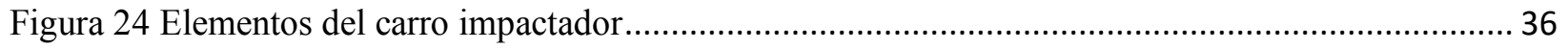

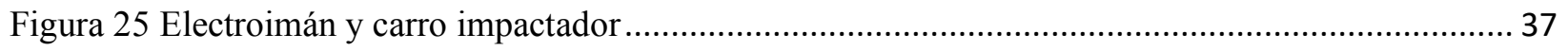

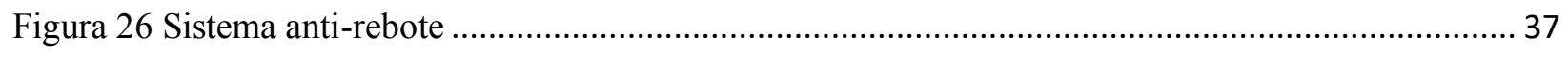

Figura 27 Esquema de aplicación de la carga se slamming ............................................................. 41

Figura 28 Equipo de reproducción de slamming ......................................................................... 42

Figura 29 Detalle de la leva y la ubicación del panel ................................................................... 42

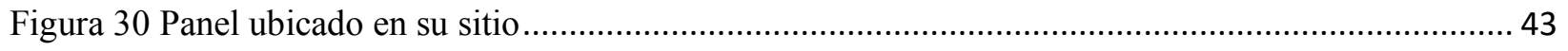

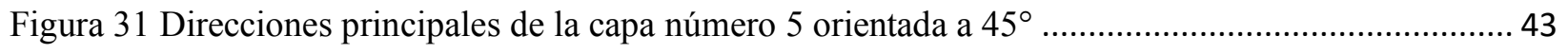

Figura 32 Detalle de la deformación en la sección central del modelo FEM ........................................ 44

Figura 33 Medición de la temperatura en la cara opuesta al impacto .................................................. 45

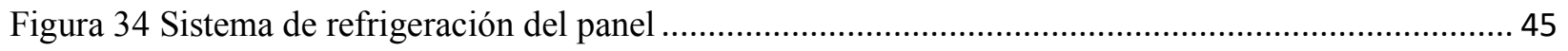

Figura 35 Equipo para líquidos penetrantes .............................................................................. 46

Figura 36 Panel observado bajo luz fluorescente luego de la aplicación de la tinta penetrante ................. 47

Figura 37 Equipo de corte con diamante lubricado con aceite .......................................................... 47

Figura 38 Secuencia de secciones que muestran la penetración de la tinta por capas bajo la luz

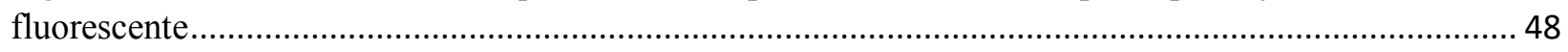

Figura 39 Secuencia de evaluación de daño por impacto .............................................................. 48 
Figura 40 Probetas extraídas de un panel ensayado en la zona del daño .............................................. 49

Figura 41 Útil fabricado para el ensayo de compresión restringido .................................................... 50

Figura 42 Evaluación ultrasónica del ensayo de impacto por caída de peso ........................................... 51

Figura 43 Probetas empleadas en el ensayo de flexión en tres puntos................................................. 53

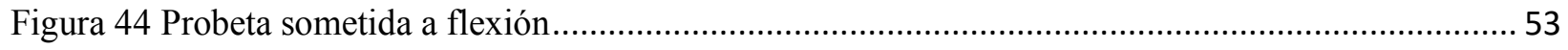

Figura 45 Resultados del ensayo de flexión zona elástica ................................................................. 54

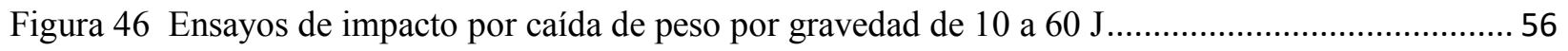

Figura 47 Panel sometido a dos impactos de 130 joules cada uno .................................................... 57

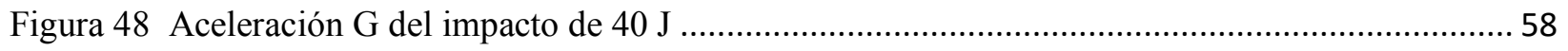

Figura 49 Fuerza versus desplazamiento de 30 y 50 joules............................................................. 58

Figura 50 Energía de impacto vs Energía absorbida de los ensayos.................................................... 59

Figura 51 Energía devuelta luego del impacto vertical ................................................................... 59

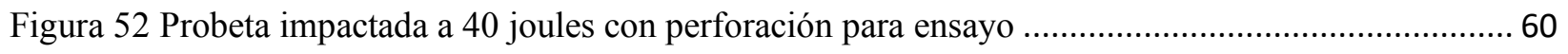

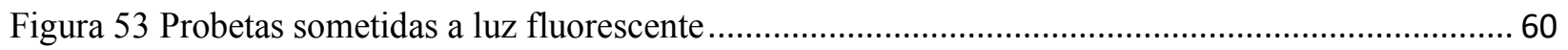

Figura 54 Probetas cortadas en laminillas para exposición de sección transversal .................................. 61

Figura 55 Secciones transversales bajo luz fluorescente de probeta impactada a 40J ............................. 61

Figura 56 Detalle de una sección transversal de la probeta impactada a $40 \mathrm{~J}$ con las marcas de las

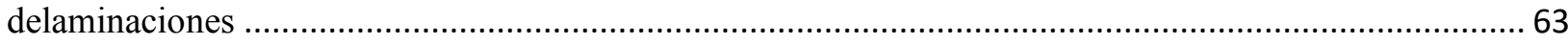

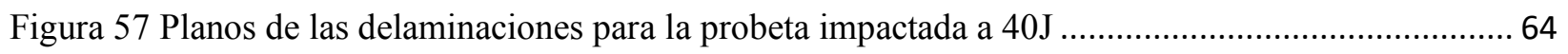

Figura 58 Plano de delaminaciones a 30 joules comparado con la fuerza vs desplazamiento .................. 64

Figura 59 Plano de delaminaciones a 50 joules comparado con la fuerza vs desplazamiento .................. 65

Figura 60 Presiones para el ensayo de slamming ........................................................................ 67

Figura 61 Resultado de Inspección con ultrasonido del panel $\mathrm{C}$ a los $1.8 \times 10^{5}$ ciclos de impacto con

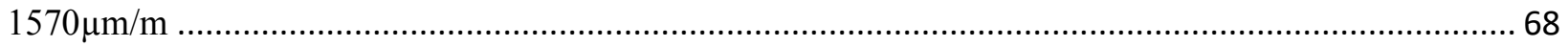

Figura 62 Comparación de porcentajes de bits dañados en paneles de preimpregnado sin modificar ....... 69

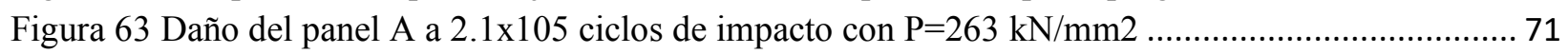

Figura 64 Daño del panel B a 1.5x105 ciclos de impacto con $\mathrm{P}=404 \mathrm{kN} / \mathrm{mm} 2$.................................. 71

Figura 65 Daño del panel $\mathrm{C}$ a 1.8x105 ciclos de impacto con $\mathrm{P}=633 \mathrm{kN} / \mathrm{mm} 2$ ….............................. 72

Figura 66 Evolución del daño del panel D hasta alcanzar $2.1 \times 10^{4}$ ciclos de impactos con $\mathrm{P}=812 \mathrm{kN} / \mathrm{m} 273$

Figura 67 Porcentaje de daño/ciclo con las presiones aplicadas en los paneles..................................... 74

Figura 68 Evolución de la flexibilidad del panel $\mathrm{F}$ hasta alcanzar $2.2 \times 10^{4}$ ciclos de impactos con $\mathrm{P}=427$

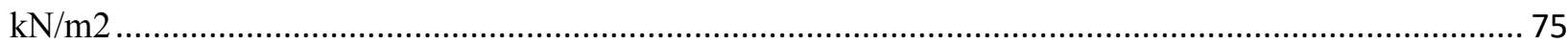

Figura 69 Microscopia del panel $\mathrm{C}$ a $1.8 \times 10^{5}$ ciclos de impacto con $\mathrm{P}=633 \mathrm{kN} / \mathrm{mm} 2$....................... 76

Figura 70 Microscopia del panel $\mathrm{C}$ a $1.8 \times 10^{5}$ ciclos de impacto con $\mathrm{P}=633 \mathrm{kN} / \mathrm{mm} 2 \ldots \ldots \ldots \ldots \ldots \ldots \ldots \ldots . . . . . . . . . . . . .77$

Figura 71 Microscopia del panel $\mathrm{C}$ a $1.8 \times 10^{5}$ ciclos de impacto con $\mathrm{P}=633 \mathrm{kN} / \mathrm{mm} 2$........................ 77

Figura 72 Microscopia del panel D a 2.1x $10^{4}$ ciclos de impacto con $\mathrm{P}=812 \mathrm{kN} / \mathrm{mm} 2$........................ 78

Figura 73 Microscopia del panel D a 2.1x $10^{4}$ ciclos de impacto con $\mathrm{P}=812 \mathrm{kN} / \mathrm{mm} 2$........................ 78

Figura 74 Microscopia del panel D a 2.1x $10^{4}$ ciclos de impacto con $\mathrm{P}=812 \mathrm{kN} / \mathrm{mm} 2$......................... 79

Figura 75 Probeta dañada luego el ensayo de compresión restringida ............................................... 80

Figura 76 Probetas varias impactadas por caída de peso ensayadas por compresión ............................... 81

Figura 77 Resultados de las probetas al ensayo de compresión .......................................................... 81

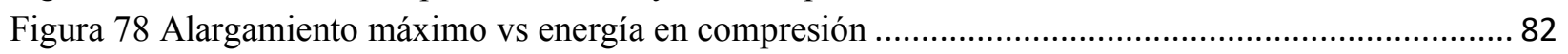

Figura 79 Flexibilidad de paneles dañados por impacto................................................................. 82

Figura 80 Modelo de elementos fínitos de celda viscoelástica ............................................................. 88 


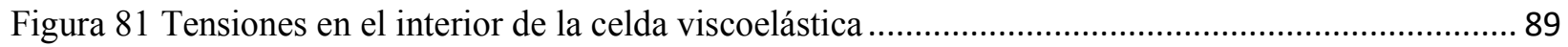

Figura 82 Tensión en el interior del material viscoelástico y del material ABS ..................................... 89

Figura 83 Impresora 3D doble extrusión fabricando la capa viscoelástica ............................................. 90

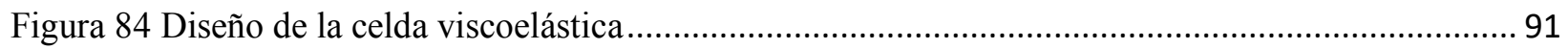

Figura 85 Vista interior de la celda viscoelástica ......................................................................... 91

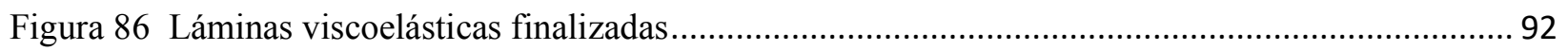

Figura 87 Capa viscoelástica colocada durante el laminado ............................................................ 93

Figura 88 Panel ya curado con la capa viscoelática vista del lado del impacto ..................................... 94

Figura 89 Capa viscoelástica con tratamiento con resida y tela de fibra de vidrio .................................. 94

Figura 90 Capa viscoelástica tratada con fibra de vidrio colocada en el laminado ................................. 95

Figura 91 Panel ya curado con capa viscoelástica tratada con fibra de vidrio ........................................ 95

Figura 92 Impacto a $30 \mathrm{~J}$ de un panel modificado sin tratamiento superficial con fibra de vidrio............. 96

Figura 93 Ensayo de slamming a panel con lámina viscoelástica tratada superficialmente con hebras de

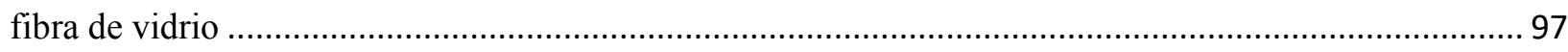

Figura 94 Paneles modificados luego del impacto por caída de peso con láminas viscoelásticas sin tratar

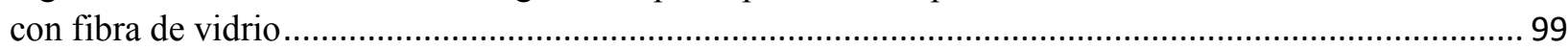

Figura 95 Curva de Fuerza vs Desplazamiento con impacto a 40 Joules con deslizamiento del

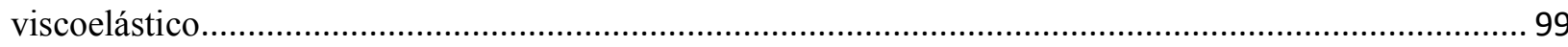

Figura 96 Caracterización con tinta penetrante a panel impactado a 80 Joules .................................... 100

Figura 97 Detalle de la lámina en el punto del impacto a 80 joules .................................................... 101

Figura 98 Delaminaciones del impacto a 40 joules de un panel modificado ......................................... 102

Figura 99 Delaminaciones del impacto a 80 joules de un panel modificado ........................................ 102

Figura 100 Porcentaje de energía devuelta luego de los ensayos de impacto por caída de peso a paneles

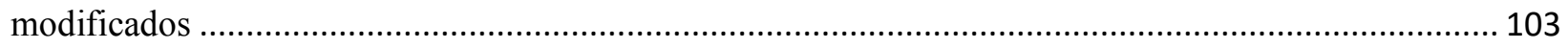

Figura 101 Panel sometido a 3 impactos de 130 Joules cada uno .................................................... 104

Figura 102 Evolución del daño del panel G impactado a 2.2x10 ciclos y presión de $801 \mathrm{kN} / \mathrm{m}^{2} \ldots \ldots \ldots \ldots .106$

Figura 103 Cambio de flexibilidad durante el ensayo del panel H a 2.7x $10^{4}$ ciclos con una presión de 343

$\mathrm{kN} / \mathrm{m}^{2}$

Figura 104 Comparación de la sección de impacto por caída de peso a 40 joules caracterizado con tintas penetrantes fluorescentes . 108

Figura 105 Comparación de la fuerza versus desplazamiento a impacto por caída de peso de 30 joules 109 Figura 106 Comparación de la curva de fuerza versus desplazamiento por impacto por caída de peso a

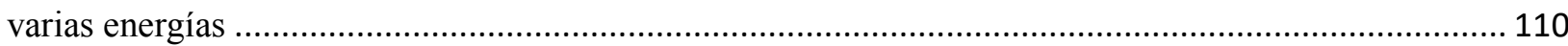

Figura 107 Comparación de energía devuelta tras impactos por caída de peso ..................................... 110

Figura 108 Comportamiento de la galga extensiométrica al slamming ............................................. 111

Figura 109 Comparación del cambio de la flexibilidad durante el ensayo de slamming con $2.7 \times 10^{4}$ ciclos

Figura 110 Viscosidad Compleja del Prepreg WE91-2 ............................................................. 127 


\section{RESUMEN}

Se propone la inserción de una capa viscoelástica en un panel laminado de GFRP de una embarcación planeadora, con el propósito de disminuir la propagación del daño producido por el impacto repetitivo del fenómeno de slamming. Se realizaron ensayos de laboratorio destructivo y no destructivo a paneles no modificados y a paneles modificados. Mediante los ensayos de impacto por caída de peso, flexión en tres puntos, comprensión restringida y reproducción de slamming, realizados a probetas de GFRP a base de preimpregnado, curado en horno fuera de autoclave "OoA", se confirma el beneficio de la modificación con capa viscoelástica. También se realizaron caracterizaciones con ultrasonido sumergido, microscopia SEM y exposición a luz fluorescente de secciones impactadas para corroborar estos resultados. Para los ensayos se fabricó una máquina de impacto por caída de peso por gravedad con acelerómetro. Los resultados de las fuerzas de aceleración se manejaron matemáticamente para obtener las diferentes energías que rigen el comportamiento de los paneles a los impactos. También se fabricó un equipo de reproducción de slamming compuesto por una leva de impacto. Se propone una metodología de impacto a bajas energías. La evolución del daño por slamming es observable físicamente y va diferenciado en grupos de impacto de altos ciclos y de bajos ciclos. En la discusión y las conclusiones se muestran las ventajas de la modificación en cuando a cantidad de energía devuelta y el beneficio en la vida útil del panel laminado. 


\begin{abstract}
It is proposed the insertion of a viscoelastic layer in a laminated panel of GFRP of a glider, in order to reduce the propagation of the damage caused by the repetitive impact of the slamming phenomenon. Destructive and non-destructive laboratory tests were performed on unmodified panels and on modified panels. Through the tests of drop weight tear, three-point flexion, restricted understanding and reproduction of slamming, performed on pre-impregnated, oven-cured GFRP samples outside the "OoA" autoclave, confirm the benefit of the viscoelastic layer modification. Characterizations with submerged ultrasound, SEM microscopy and exposure to fluorescent light of impacted sections were also performed to corroborate these results. A drop weight tear test machine with accelerometer was manufactured for the tests. The results of the acceleration forces were mathematically managed to obtain the different energies that govern the behavior of the panels to the impacts. Also a slamming reproduction equipment composed by an impact cam was made. A low impact energy methodology is proposed. The evolution of slamming damage is physically observable and differentiated into high cycle and low cycle impact groups. The discussion and conclusions show the advantages of the modification in when to amount of energy returned and to benefit in the life of the laminated panel.
\end{abstract}




\section{INTRODUCCIÓN}

La presente investigación busca mitigar el daño producido por el impacto de las olas a los paneles que conforman el fondo de una nave construida con materiales compuestos del tipo GFRP a base de preimpregnado curado fuera de autoclave.

El impacto de una embarcación planeadora contra las olas durante su navegación, se conoce como fenómeno de slamming y es el producto de la velocidad de la nave, la cual por el efecto de la sustentación hidrodinámica planea elevándose sobre el agua para luego al romperse el equilibrio caer verticalmente sobre la superficie. Dentro del campo de la investigación de la hidrodinámica y de los materiales usados en construcción naval, se han desarrollado numerosos escritos y ensayos de laboratorio durante décadas para comprender el fenómeno de slamming y poder predecir el daño que causa en la nave. Y pese a este, todavía hay mucho que hacer para mejorar su vida útil,

Si las condiciones del mar son favorables al incremento de este golpe haciendo que la caída vertical sea mayor, los daños son catastróficos produciendo roturas en el interior del material del casco de la nave, ya que la mayoría de las embarcaciones planeadoras se construyen de plástico reforzado con fibra de vidrio o GFRP.

En la actualidad se están desarrollando mejoras en sus prestaciones a estos materiales y una de ellas es la aparición de los preimpregnados, los cuales son GFRP que vienen en láminas listas para curar, con la resina inerte inyectada en fábrica haciendo gala de un porcentaje casi cero de porosidad. Para la construcción naval por el tema de bajar los costos de producción y aprovechar las altas cualidades de los preimpregnados, los fabricantes han desarrollado los de tipo OoA o Curado fuera de la Autoclave, los cuales requiren un procedimiento de presión en bolsa de vacío luego del laminado y un proceso de secado dentro de horno o estufa durante el tiempo recomendado por el fabricante. Este tipo de proceso ha permitido que sean más asequible al empleo de la fabricación de embarcaciones planeadoras.

El material ya curado y sometido a los impactos verticales de la carga cíclica de slamming, pese a sus elevadas prestaciones a lo largo de su vida útil presentará daños conocidos como 
delaminaciones y micro roturas de la matriz los cuales deben estudiar y reproducirse, las cuales dentro de un panel laminado van incrementándose a medida de que aumentan los ciclos cambiando las prestaciones de la estructura de la embarcación.

Por esta razón se ha propuesto una metodología de reproducción y caracterización de resultados, con el propósito de demostrar una modificación denominada "viscoelástica" en el interior de un panel laminado de preimpregnado sometido al fenómeno de slamming.

Como el daño del impacto con las olas está referido a un impacto vertical de la nave, primero se realizó la investigación sometiendo paneles a los que se ha llamado "sin modificar" a ensayos de impacto verticales por caída de peso. Esto se realizó con un equipo construido para esta investigación dotada de un acelerómetro o gravitómetro que proveerá la información suficiente para el análisis de las energías implicadas en el impacto. Los paneles se llaman "sin modificar", porque corresponden a probetas de laminados de material preimpregnado OoA, normales empleados actualmente en la construcción de las naves planeadoras.

Se diseñó una lámina a la que se la ha llamado "lámina viscoelástica" la cual está compuesta de un conjunto de celdas que en su interior tienen un material elastomérico, encapsulados en un plástico rígido. Este diseño ha considerado el mínimo espesor y una forma moldeable, con el propósito de que pueda insertarse en el laminado hacia la cara de impacto de las olas y permita que el daño que evoluciona dentro del material por los golpes, se difumine y no pase hacia las láminas siguientes del material compuesto. El diseño se comprueba empleando un modelo no lineal de elementos finitos, en la cual se observa como las tensiones que se inducen en la lámina viscoelástica es absorbida por el elastómero pasando en menor grado a la cápsula rígida y por ende al resto del laminado.

De tal forma, que con estas láminas viscoelásticas, se fabrican los paneles llamados "modificados", para ser sometidos a los mismos ensayos realizados a los "no modificados". La comparación obtenida con la caracterización de las probetas impactadas por caída vertical de peso con ensayos de tintas penetrantes, flexión en tres puntos, compresión restringida, modelación de delaminaciones, análisis de energías, umbral de daño y ultrasonido sumergido, dejan ver en los 
resultados de una forma muy clara de que la modificación protege al panel del impacto, y el daño pasa en menor grado al resto del laminado. Incluso el manejo matemático de daños permite comparar la fuerza interior que va delaminando el panel durante la deformación por impacto observándose claramente el efecto de la lámina viscoelástica la cual consume esta fuerza disminuyendo su valor. Incluso para mostrar mejor la propiedad de absorción de daño de la modificación, se presenta un ensayo del tipo destructivo en la cual un panel "sin modificar" puede penetrarse luego del impacto mientras que el "modificado" no se consigue bajo las mismas condiciones de laboratorio.

Pero el daño por slamming no solo es producto de un impacto vertical sino de los golpes repetidos durante la navegación, los cuales, de acuerdo con el estado del arte presentado para la investigación, resultan acertados reproducirlos sobre el material estudiado. Para esto se diseñó y construyó un equipo compuesto por una leva que induce al material a ser impactado cíclicamente como si estuviese navegando sobre un mar de diferentes condiciones de olas. Este impacto se lo presenta como presión sobre los paneles ensayados y mediante una estimación con las reglas de una Sociedad Clasificadora de buques, se lo relaciona para establecer los valores de presión a ensayar de acuerdo con el umbral de daño obtenido por los resultados anteriores y que corresponden a impactos de baja energía. La reproducción a diferentes presiones, se realiza a los paneles "sin modificar" y "modificados", con el propósito de observar la evolución del daño.

La evolución de daño de los "sin modificar" mediante el empleo de ultrasonido sumergido, permite evaluar la aparición de las micro grietas y su incremento marcando la diferencia entre ensayos de altos ciclos y ensayos de bajos ciclos. De tal forma que al repetir los ensayos con los paneles "modificados", se los ajustó a las mismas condiciones de presión de slamming y se observó su evolución de daño. Como el equipo de ultrasonido no permitió observar la aparición de micro grietas porque lo caracteriza como un defecto a la lámina viscoelástica, el control de la pendiente de flexibilidad de la curva de deformación medida con el empleo de galgas extensiométricas, fue una buena opción para comparar como los paneles van cambiando a medida que se van dañando interiormente. La lámina viscoelástica protege definitivamente al material, y los ensayos realizados fueron buena fuente de resultados para conocer el comportamiento del material. 
El futuro de la construcción naval de embarcaciones planeadoras de GFRP está aquí, en las láminas viscoelásticas, las cuales deben ser colocadas en los puntos de mayor presión de slamming en el fondo de la nave de acuerdo con la forma y el diseño de la misma. Esto mitigará el daño y permitirá que se prologue la vida útil, así como de acuerdo con la habilidad del diseñador, la fabrique con paneles más ligeros disminuyendo su desplazamiento, aumentando su velocidad y capacidad de carga.

Adicional, esta investigación deja una puerta abierta a futuros trabajos sobre mejoras en el diseño de la lámina viscoelástica en cuanto a su adherencia, forma y otros patrones para beneficio de su principal propiedad de absorber el daño en un panel laminado. 


\section{CAPÍTULO I ESTADO DEL ARTE}

\subsection{Aspectos fundamentales del fenómeno de slammig}

El slamming es un evento importante durante la navegación del buque y se presenta como una repentina fuerza que golpea verticalmente el buque en proa y genera energía por el impacto entre el casco de una embarcación en navegación y la superficie libre del agua. Esta fuerza se traduce en pulsos de muy corta duración (típicamente del orden de unos pocos milisegundos) que actúan sobre una superficie muy pequeña y que da lugar, consecuentemente, a elevados picos de presión. La gravedad de este impacto y su daño en la nave es tan impredecible, que los operadores son muy cautos y reducen la velocidad para no sufrir daños adicionales durante las travesías, situación que se ve agravada en el caso de embarcaciones planeadoras de alta velocidad. La importancia del slamming sobre la seguridad e integridad de los vehículos marinos ha tenido como consecuencia una intensa actividad investigadora desde los pioneros en estudiar este fenómeno como Von Karmman en 1929 [1] hasta nuestros días.

La complejidad del fenómeno se debe a que en el fondo de la nave, ingresa al fluido por la diferencia angular entre la superficie del cuerpo y la superficie del mar, haciendo que la región de contacto se expanda a alta velocidad independiente de la velocidad de la nave como lo analizó Wagner en 1932 [2] y Kabsengerg 2011 [3] quien recopila la investigación realizada en los últimos años, y confirma que el estudio de este problema, no está concluido, se debe hacer más simulación, mejorar los modelos matemáticos y probar con modelos o reproducciones a escala en una perspectiva del futuro del slamming y el estado actual de las investigaciones. Debe también considerarse que el estado del mar como la altura de las olas influye en el golpe de presión ejercido sobre la embarcación durante el impacto cíclico.

En la Figura 1 se presentan tres instantes de navegación de la LP "Bite Me", una embarcación planeadora de fondo en "V" construida de GFRP, los cuales fueron observados durante una prueba de mar para conocer su comportamiento ante el impacto de slamming producido por la velocidad y el estado de mar. En el instante a), la embarcación va ganando sustentación hidrodinámica, para luego en el instante b) llega al punto crítico de elevación de la proa. Luego de esto cae sobre su 
fondo, golpeando el mar en fracciones de segundo debido a que la presión hidrodinámica ya está sustentándola para elevarla.

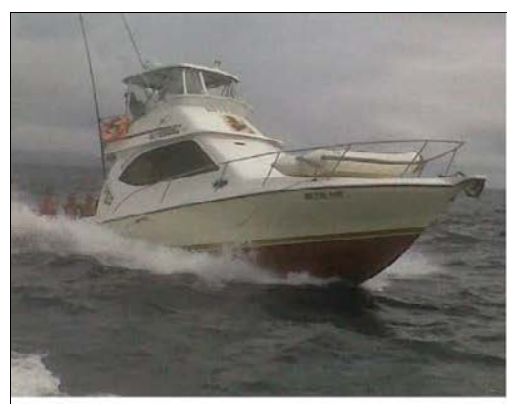

a) Antes del planeo

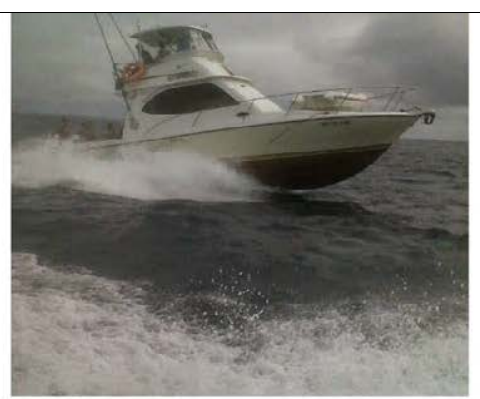

b) Planeo

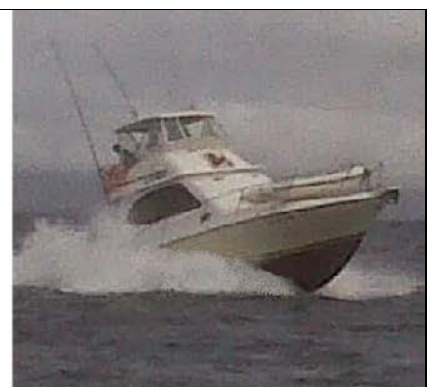

c) Golpe de slamming

Figura 1 Navegación de la lancha "Bite Me"

Las respuestas sobre este fenómeno y su influencia en la estructura de las embarcaciones no han podido ser dadas todavía con mucha claridad y hay mucha investigación al respecto. El problema del efecto local sobre la estructura de la nave, se complica todavía más cuando se consideran las inclusiones de burbujas de aire en el agua que impacta el fondo lo cual cambia la compresibilidad y aparece la cavitación. Este efecto ha sido demostrado por experimentos que golpean naves contra el agua a diferentes ángulos de astilla muerta como los de Mattias [4] y Rousset [5]. La ola que golpea el fondo es un fenómeno muy complejo y no lineal, y se define por los parámetros de la cinemática del barco, la reproductibilidad del golpe, la dinámica de la superficie libre alrededor de la nave y cargas locales introducidas por el diseño del casco. Bajo los $5^{\circ}$ de astilla muerta se produce inclusión de aire y cavitación contra el fondo de la embarcación. El efecto del volumen de aire con la presión ejercida sobre la nave, tiene un papel importante ya que al escapar se suma a los efectos de compresibilidad del agua causando cavitación y una respuesta elástica-plástica a la estructura. Faltisen [6] sugiere que esto se puede representar como la respuesta dinámica de una placa plana endurecida que puede causar Cavitación local. Para ángulos mayores a $5^{\circ}$, de acuerdo con Kapsenberg [7] la ley de similitud de Froude es válida y se consideran impactos normales.

Las pruebas con modelos realizadas para buscar estas respuestas, van desde modelos localizados de ciertas porciones de la nave, hasta modelos completos del buque que intentan reproducir la escala real del efecto del slamming sobre la embarcación. A esto hay que sumarle los modelos 
computacionales y las simulaciones a largo plazo que intentan explicar el daño que produce el golpe de presión en el material de la nave y su envejecimiento prematuro. Kvålsvold y Faltinsen [8] presentaron los resultados de las pruebas de caída de una placa sobre una cresta de la ola. Los resultados se compararon con una teoría de dos dimensiones utilizando un modelo de viga para la placa en tiempos de impacto menores a 0.008 segundos y una viga dinámica no lineal desarrollado por Zhao y Faltinsen [9]. En cuanto al problema de simular el corto tiempo del pico de presión, que actúa sobre el fondo de la nave es muy difícil estimar el tiempo real del impacto en el fondo de las naves planeadoras, y ya investigadores como Lewis [10] trataron de simularlo y observarlo con impactos de fluidos, concluyendo que la duración del impacto estaba en el orden de $2.5 \mathrm{mseg}$ hasta 10 mseg en los casos más críticos que dan una buena idea de los tiempos y las presiones actuantes en el fenómeno de slamming.

Los experimentos con modelos completos de barcos buscan la respuesta global, es bastante caro y sirve para buscar problemas en partes de la estructura de la nave simulado una viga como rígida con conexiones flexibles como lo hizo por Hermundstad [11], Lavroff [12] y Drummen [13], o como una viga con flexión continua como los experimentos de McTaggart [14], Dessi [15] y Iijima [16]. La ventaja del primer método es que la conexión flexible puede hacerse ajustable mientras que calibrar el haz es más complicado, sin embargo, ambos métodos parecen dar buenos resultados en comparación con los métodos de cálculo.

Las Reglas de las Sociedades Clasificadoras en este caso el American Bureau of Shipping -ABS [17], hacen especial énfasis en el diseño de las naves planeadoras a los ángulos de astilla muerta conocidos como $\beta_{s x}$ para el ángulo del costado de la nave y $\beta_{b x}$ para el ángulo del fondo de la nave como se ve en la Figura 2. En la actualidad son una buena referencia para los cálculos de la presión de slamming en el fondo de embarcaciones planeadoras de alta velocidad. 


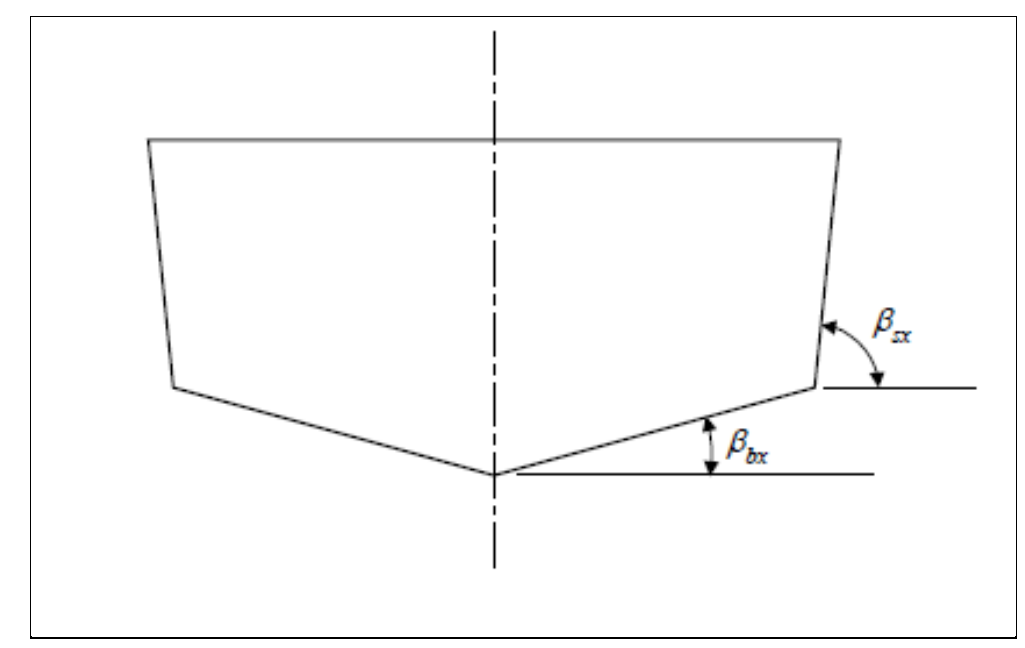

Figura 2 Ángulos de astilla muerta considerados para el slamming

Estos fenómenos complejos crean un problema en la predicción de los valores de escala, e incluso el empleo de una escala completa no es suficiente como lo indica Bogaert [18], lo cual obliga a que la simulación del fenómeno en rangos de diferentes presiones sea una buena alternativa para medir sus efectos y minimizar la predicción de valores a escala.

Las cargas hidrodinámicas indicadas sobre el casco del buque, definitivamente son de naturaleza dinámica, y estas fuerzas se transfieren de esta manera a la estructura del casco. Para estudiar la transferencia de esta fuerza y su distribución de tensiones, sumándole la carga vertical de slamming, es necesario realizar una reproducción para observar el daño del material examinándolo numéricamente mediante el uso de una metodología de daño progresivo y obtener resultados experimentales en forma cualitativa y cuantitativa de la disipación de la energía dentro del material. 


\subsection{Los materiales compuestos en la construcción naval}

La aplicación de los materiales compuestos de Glass Fiber Reinforced Plastic - GFRP en embarcaciones fue impulsado inicialmente por una necesidad de obtener embarcaciones más ligeras, fuertes, resistentes a la corrosión, resistencia al medio ambiente, capacidad de moldear estructuras con geometrías complejas, capacidad de adaptar su resistencia mecánica de acuerdo a las condiciones de carga, excelente resistencia mecánica en relación a su bajo peso, facilidad de reparación y excelente durabilidad, Selvaraju [19] y Recuero [20]. Una de las desventajas más importantes es el alto costo inicial excepto para las aplicaciones pequeñas o en serie, seguido de la necesidad de protección contra incendios así como el bajo módulo de elasticidad que hace que el diseño de conexiones sea complicado [21-22].

Desde 1930 se ha estado experimentando con buques ligeros, siendo el astillero Herreshoff en Rhode Island que experimentó con una yola de plástico reforzado con fibra de vidrio, y el prototipo fue una construcción de baja tecnología de material pesado y quebradizo. En 1966 la construcción laminada de GFRP tuvo un gran impulso ya que los ingenieros George Cuthbertson y el constructor aeronáutico George Cassian mejoran el método de laminación [23]. De allí, el desarrollo de los materiales ha sido imparable, y se tiene en la actualidad materiales compuestos hechos a base de laminados unidireccionales, bidireccionales y trenzados para conseguir altas prestaciones. Las razones para emplear estos materiales más ligeros incluyen también la mayor capacidad de carga y lograr velocidades mayores con su consecuente ahorro en el consumo de combustible.

Las aplicaciones son variadas en monocascos, catamaranes, trimaranes, buques de pesca, yates de pasajeros, botes a velas, superestructuras mixtas para buques de acero. Desde la década de los ochenta, se amplió, cubiertas, mamparos, avanzados sistemas de mástiles, hélices, ejes de propulsión, timones, tuberías, bombas, válvulas, maquinaria, fragatas, destructores, portaaviones, uso en propulsores, superficies de control, accesorios, patrulleros rápidos, buques de caza de minas y corvetas [24]. Algunas reglas de clasificación como la Norske Veritas, recomienda no superar los 50 metros de eslora [25]. 
El GFRP está compuesto de dos o más materiales y elementos constitutivos, y se obtiene por la combinación de componentes que si interactuaran por separado y que no tienen las mismas cualidades y destrezas. Existen en su composición dos fases claramente definidas, la fase continúa y la fase dispersa. La fase continua corresponde a la resina o al líquido que va a solidificar dentro del compuesto y por lo general es termoestable.

La relación esfuerzo-deformación de los materiales GFRP en la construcción de las naves, se ha comparado en múltiples ocasiones con la del acero estructural con la diferencia que por sí solos no son dúctiles y exhiben un comportamiento lineal hasta la falla. Aunque esto podría interpretarse como una desventaja severa, las estructuras tales como cuadernas, vagras, longitudinales y otros pueden conservar su ductilidad si se diseña adecuadamente [26-28].

Otra de las grandes ventajas del empleo de los GFRP, es el moldeo, lo que permite construir embarcaciones de formas complejas, principalmente las planeadoras de alta velocidad, ya que su sección en "V" requiere la adecuación de aristas y solapas para el mejoramiento hidrodinámico durante su navegación [29-30]. Las estructuras se construyen en una sola operación de moldeo como es el caso de los materiales compuestos denominados preimpregnados. De este tipo de GFRP a base de prepreg, se han construido naves como el M/S Delfín, el cual es un pesquero de 35 metros de eslora con un diseño que aprovecha las cualidades del material y sus prestaciones [31]. También El Lake Génova el cual es una embarcación de cabotaje que hace gala de su lujo, acabado y resistencia [32]. Si la espiral de diseño sigue avanzando, definitivamente ya no hay porqué quedarse en el pasado y se debe seguir investigando la mejora de las prestaciones de los materiales de GFRP. 


\subsection{Materiales compuestos con curado fuera de autoclave}

Los GFRP a base de preimpregnados según Johnson [33] y Centea [34], son compuestos de matriz dispersa y de matriz continua ralentizada para retardar su proceso de curado bajo condiciones ambientales indicadas por el fabricante. Son materiales preparados bajo condiciones de porosidad menores al 2\% del volumen total del compuesto lo que aumenta la resistencia y rigidez, siendo el foco principal el combinado de la fibra para que los termoplásticos empleados en la fabricación tengan el mismo rango de la matriz termoestable según la recopilación presentada por Largber [35] para preimpregnados fabricados con diferentes tipos de fibras y matriz, en forma de láminas de fibra de vidrio unidireccionales.

Cytec [36], principal fabricante de este material, recomienda al igual que los otros fabricantes preparar la estructura laminada sobre un molde, la cual se secuencia con telas aireadoras y bolsas para vacío previo su proceso de curado. Con esto puede ser introducido en el horno o en la autoclave de acuerdo con los requisitos del material entregados por el fabricante y desarrollada por los investigadores para logar una estructura de buen acabado y de gran resistencia estructural.

Los primeros materiales empleaban para el proceso de curado la autoclave con elevadas presiones y temperaturas en su interior, siendo muy costoso su empleo ya que tiene poca disponibilidad y la energía que emplea implica costos elevados y requiere de infraestructura adicional para poder funcionar como lo menciona Schlimbach [37]. Esta es la causa que desde sus inicios el empleo de los preimpregnados sea casi en su totalidad en la aeronáutica y la aeroespacial, las cuales corresponden a industrias con prestaciones de alto valor agregado. A partir de esto, es que nace la idea de desarrollar materiales preimpregnados que no se curen en autoclave para al menos eliminar este alto costo de producción, Brosius [38], se realiza actualmente mucha investigación para curarlos al horno o estufa, siendo llamados estos preimpregnados OoA o "Out of Autoclave". Calder [39] presenta la necesidad de seguir desarrollando estos materiales por su facilidad de empleo, Hou [40] evalúa sus propiedades y Sutter [41] así mismo compara las ventajas y desventajas de esta transición del uso o no de la autoclave. 
El 2006 la compañía Umeco [42] introdujo en el mercado la tecnología MTM45 que entregaba preimpregnados OoA cuyas propiedades en cuanto a calidad, nivel de porosidad y resistencias mecánicas eran muy similares a los materiales curados en la autoclave. Estos productos disponen de ciclos flexibles de curado, que requieren tiempos de curado más largos a $70^{\circ} \mathrm{C}$ consiguiendo una temperatura de transición vítrea del material en estado húmedo a más de $150^{\circ} \mathrm{C}$. Todas estas variaciones en el tratamiento corresponden a evitar las porosidades debido a la falta de presión del horno versus la autoclave que influye en la salida de gases dentro de la matriz según el modelo de Hou [43]. Cuando se cura en horno la presión existente en el panel es la presión de vacío, y la evacuación de los gases y vapores depende exclusivamente de ello de acuerdo con los estudios de Hubert [44-45] y Pelhman [46].

Resulta importante el control de la presión de vacío, pues tal como se observa en la Figura 3, la humedad durante el proceso de montaje del laminado y los gases que tienen algunos prepregs en su impregnación, o simplemente aire entrampado mientras se colocaban las láminas forman las burbujas entre las capas.

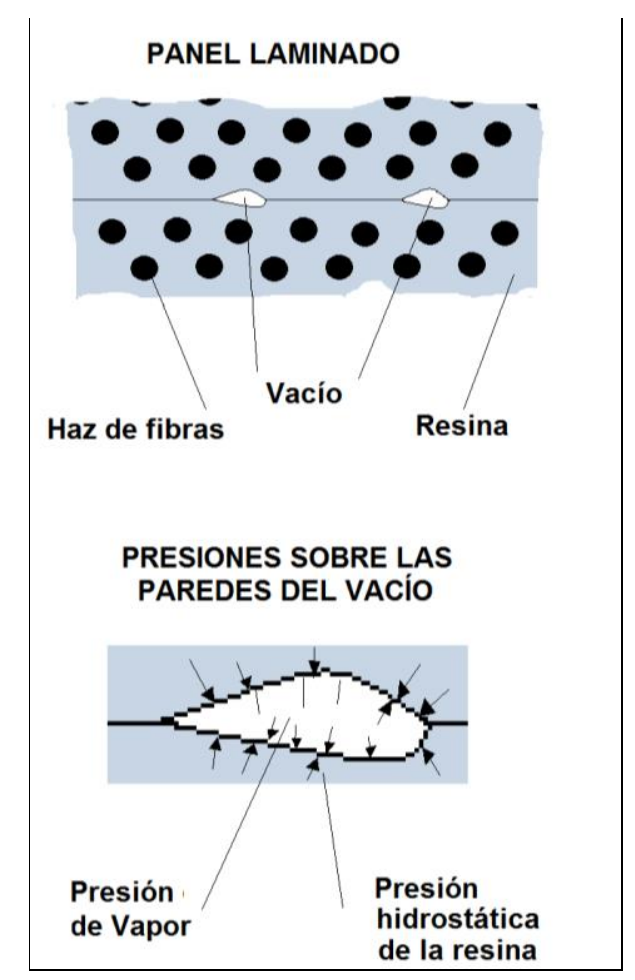

Figura 3 Defectos por vacío en laminados 
El esfuerzo interno de la resina mientras penetra el prepreg en la fabricación, no permite que las burbujas se desplacen entre las fibras quedando atrapadas durante el estado inerte de almacenaje del material. La presión hidrostática de la resina no alcanza a romper la burbuja de vapor durante el proceso de curada, producido porque dicha presión interna llega ser mayor que la presión de vacío dentro de la bolsa en la cual se prepara el panel para el horno. Esto ocurre frecuentemente cuando hay elementos volátiles, como en el caso de resinas epóxicas. Arafath [47] mediante un modelo matemático de gases en el laminado estimó el tiempo que debe mantenerse el vacío en función de la permeabilidad en el plano y la masa de aire.

Los materiales compuestos han inaugurado una nueva generación de barcos en la construcción naval según Balckington [48], lo que indica que los arquitectos navales están construyendo buques con un rendimiento superior en las prestaciones de su estructura. Las fibras de vidrio, basalto e incluso de carbono pueden competir con éxito con los materiales tradicionales de construcción naval en estructuras marinas portadoras de carga cuando se fabrican con procesos OoA con la típica colocación manual de capas secuenciales. 


\subsection{Comportamiento a impacto de materiales compuestos}

En el caso de las embarcaciones de GFRP, el fenómeno de slamming tiene la particularidad de que el golpe del mar se convierte en energía que se disipa en un material compuesto, produciendo distintos niveles de daño lo que lo vuelve un problema de impacto físico muy complejo de estudiar [49-51]. Este fenómeno llega a ser uno de los más importantes en el diseño de la nave afectando directamente su costo, su capacidad de carga y su confort tal como lo discute Shen [52] y que afectan considerablemente su resistencia.

En la Figura 4 se observa el peak de proa hacia la roda de la lancha de pasajeros "Bite Me", hecha de GFRP, la cual durante una inspección realizada el 31 de agosto de 2015 se pudo observar el daño prematuro por el fenómeno de slamming. Luego de un año de operación en un ritmo de 10 días al mes, las fuerzas de presión generadas en el fondo del casco, habían producido delaminaciones en la zona crítica de la astilla muerta, sobre las capas interiores del laminado. Es decir, sobre la cara sometida a tracción durante el golpe de la ola.

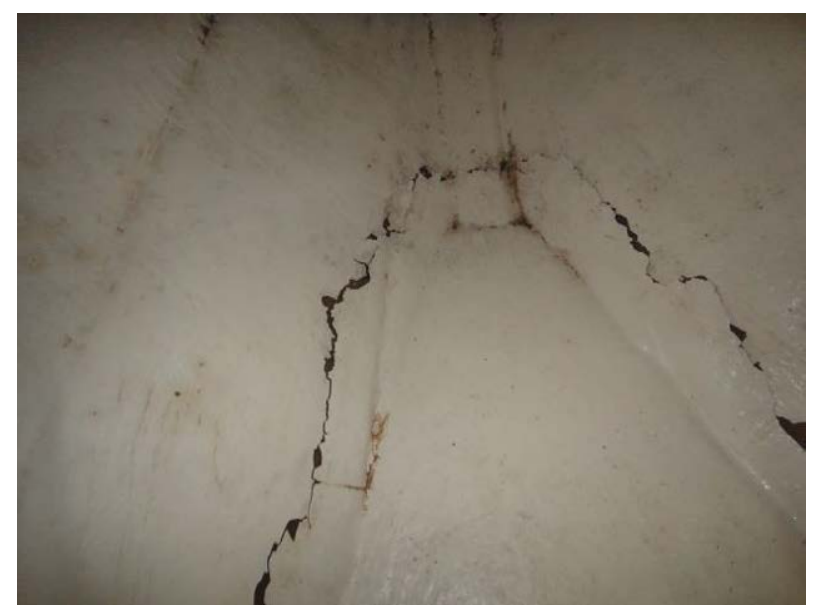

Figura 4 Daño producido por slamming en el peak de proa de la lancha "Bite Me"

La estructura de la embarcación al componerse de un laminado, relaciona la disipación de la energía en las capas que lo componen tal como ocurre en los paneles de los buques planeadores [53]. Esto se complica cuando aparecen los GFRP, ya que la energía que se disipa en el material 
luego del impacto, no se distribuye en forma uniforme, sino que la ortotropía del material permite que las solicitaciones impuestas al material hagan que tenga diferente comportamiento dentro del mismo. Las tensiones y deformaciones sobre el laminado no son uniformes y varían en dirección de la superficie del mismo, así como transversalmente saltando entre capas y dependiendo del tipo de compuesto y sus solicitaciones haciendo que este tipo de daño se vuelva impredecible [54-55]. Dentro de las capas los impactos como los producidos por la presión durante el fenómeno de slamming en primera instancia hace que la matriz se rompa en forma aleatoria, para luego producir las delaminaciones entre capas las cuales a medida que aumenta la deformación del panel se unen con las grietas de la matriz y forma escalones continuos.

El empleo de nuevos materiales preimpregnados "out of autoclave"-OoA para curados en horno en las estructuras de GFRP, requiere una especial consideración en el estudio de la disipación de la energía de impactos cíclicos como el del slamming discutido por Shim [56] quien lo asocia con las variaciones de sus propiedades. Los impactos, durante los milisegundos que dura la deformación van dejando un daño residual en el laminado que se va acumulando en el material a nivel micro estructural.

Numerosos tipos de ensayos se realizan basados en el principio de la conservación de la energía, en el cual un equipo impactador es lanzado desde una altura sobre la muestra a estudiar cayendo libremente a una aceleración de la gravedad (g). De acuerdo con las investigaciones de Lopes y Seresta [57] esta técnica proporciona resultados muy completos sobre la observación de que toda la energía potencial, se convierta en energía cinética y esta al transferirse a la muestra produce un daño que se transmite sobre la superficie de la misma. Los materiales de GFRP cuando se someten a este tipo de ensayo de impacto disipan la energía recibida a través del laminado, la cual dependiendo de su intensidad se traduce en daño de diferentes tipos.

En la Figura 5, se muestran las etapas de daño que puede hacer el impactador sobre el material compuesto en el laminado de GFRP según las observaciones hechas por Choi [58-59], y luego repetidas experimentalmente por Ahmed [60]. Al momento del impacto en la etapa a), el panel comienza a flexionarse elásticamente generando tensiones y deformaciones internas producto de la respuesta a las deferentes energías que se transfieren desde el impactador. Luego de que se ha 
superado el límite elástico o umbral de daño del material, ya el laminado no puede devolver toda la energía de impacto y comienzan a aparecer las primeras grietas intralaminares o etapa b), en la cual dependiendo de la orientación de las fibras, de las solicitaciones impuestas por la deflexión del panel que genera tensiones de tracción y compresión se rompe la matriz. Estas por lo general se observan en una sección transversal, como marcas normales a la superficie del laminado, las cuales no siguen un mismo orden saltando de capa a capa. Si el impactador sigue actuando sobre el panel e introduciendo más energía en el laminado, se pasa a la etapa c), la cual aparecen las delaminaciones intercapas, las cuales se van orientando en forma de escalera uniendo las grietas en la matriz. Estas delaminaciones generalmente rodean la zona del impacto y corresponden a la zona de tracción de la flexión. Si la energía entregada por el impactador al momento del impacto continúa actuando en la deformación, se tiene una etapa c), en la cual se rompen las fibras y comienza a verse por el exterior. En esta última etapa se vuelve muy completo cuantificar el tipo de daño. El estudio del slamming es de baja energía ya que una embarcación dañada por este fenómeno, rara vez exhibe las fibras en los paneles que conforman el casco de la nave.

La energía absorbida se considera como un parámetro representativo del comportamiento de los materiales compuestos al ser sometidos a cargas de impacto, y por ello de acuerdo a las demostraciones de Jang [61] y Catwell [62] esta es entonces una variable importante para cuantificar y comparar resultados. La representación de la energía aplicada durante el impacto se relacionan como un perfil de energías tal como se ve en la Figura 6, correspondiente a un material compuesto biaxial en el cual la línea discontinua diagonal representa la relación de equienergías entre la energía de impacto y la energía absorbida cuyos valores fueron revisados por Lopes y Cammanho [63] y Abrate [64]. En este perfil energético típico para este tipo de material se pueden diferenciar tres regiones $\mathrm{AB}, \mathrm{BC}, \mathrm{CD}$. En la región $\mathrm{AB}$ la probeta permanece sin penetración. La cantidad de daño que sufre la probeta y la superficie total de área dañada depende de la energía de impacto. En esta región la curva se encuentra por debajo de la curva de equienergía, lo que implica que la probeta no es capaz de absorber toda la energía (la diferencia entre la curva y la línea de equienergía). El exceso de energía se acumula en el impactador y produce el rebote del mismo tras el impacto como lo presenta Belingardini [65] quien discute la importancia de estos impactos a baja energía y su acumulación de daño. 
a) Panel intacto $\bigcirc$ Esfera de impacto

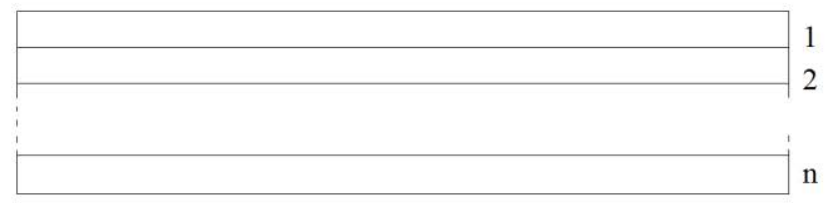

b) Agrietamiento de la matríz
polimérica

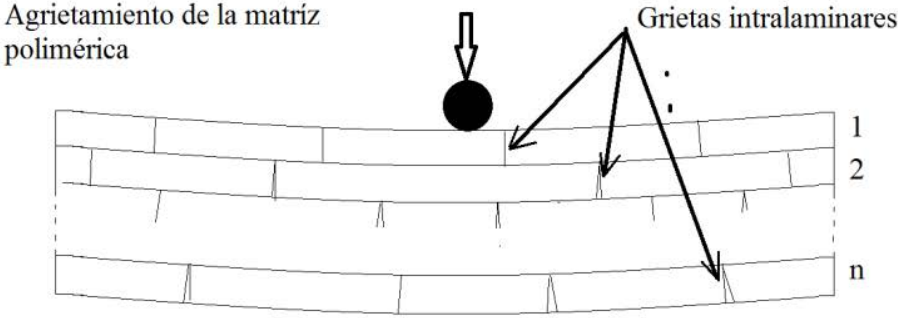

c) Delaminación

Delaminaciones

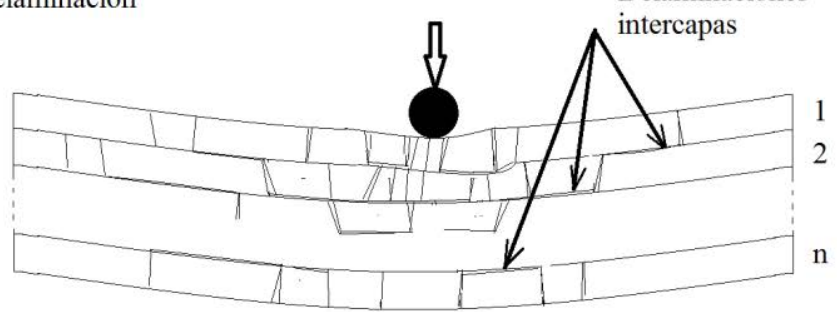

d) Penetración y rotura de fibras

Hilachas de fibras

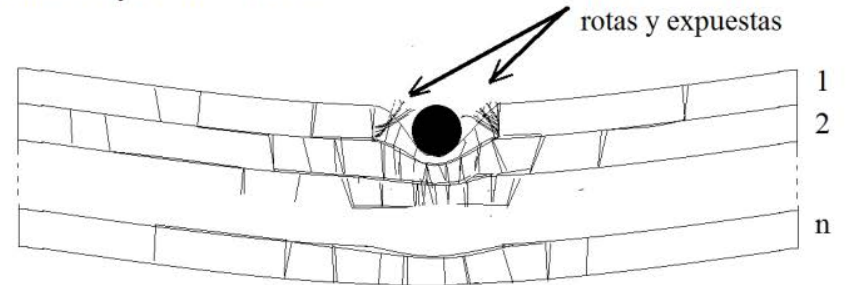

$\mathrm{n}=$ número de capa

Figura 5 Evolución del daño en un panel laminado

A la región $\mathrm{BC}$ se le denomina como región de penetración, en esta región probablemente el total de la energía de impacto es absorbida por la probeta. Por último, la región CD se denomina como región de perforación. Además, el punto $\mathrm{B}$ y C representan el umbral de penetración y perforación respectivamente. El umbral de penetración se puede definir como el punto donde la energía absorbida iguala a la energía de impacto por primera vez. Al alcanzar el umbral de penetración, el 
impactador se queda adherido dentro del laminado y no rebota. A partir del umbral de perforación, la energía absorbida permanece más o menos constante. Esto implica que no produce más daño en la probeta y ni siquiera aumentando la energía de impacto

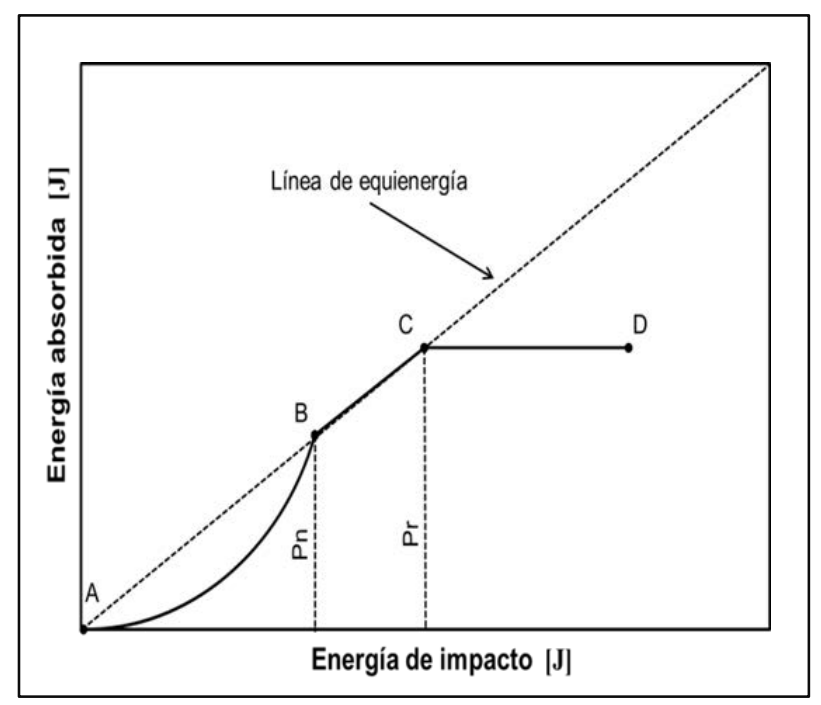

Figura 6 Equilibrio entre las energías de la prueba de impacto de un material compuesto biaxial

El comportamiento energético durante el impacto, ha sido estudiado empleando un acelerómetro con un sistema de adquisición de datos informáticos obteniendo buenos resultados de parámetros tales como fuerza, desplazamiento y energía devuelta tal como lo demuestran Baucom [66] y Svenson [67]. Estos datos se utilizan para generar las curvas característica de Fuerza y energías presentes en el ensayo de impacto versus el tiempo presentadas en la Figura 7, y que han sido desarrolladas en múltiples investigaciones de materiales GFRP como los de Elavenil [68] y Grasso [69] en los cuales desarrolla a partir de los datos obtenidos por el acelerómetro, las variables indicadas.

La energía inicial aplicada por el peso a la probeta (Eo) se descompone en energía almacenada o elástica (Ea), la energía viscoelástica que corresponde a la capacidad del material en disipar la energía recibida durante el impacto y que propaga el daño o energía devuelta (Ed) y la energía consumida asociada con la velocidad de deformación o energía cinética (Ek). La fuerza que produce la primera delaminación $(\mathrm{Fd})$ es también la Energía crítica (Ecri) y está relacionada con 
el umbral de daño del material o umbral de delaminación. Los impactos bajo el umbral se consideran subcríticos y los que están sobre el daño supercríticos. La fuerza máxima registrada en el impacto se conoce como (Fp).

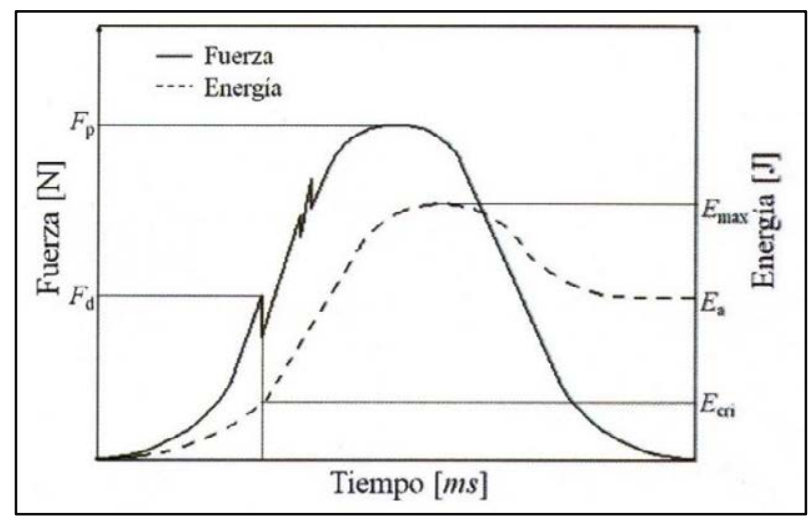

Figura 7 Energías de impacto por caída vertical de peso

Para integrar toda la información obtenida experimentalmente y poder utilizarla en el diseño de nuevas embarcaciones, es necesario proponer modelos de daño que permitan caracterizar el comportamiento del material. Una revisión sobre este tema puede encontrarse en Liu y Zheng [70] y Zhou [71]. Los modos de fallo que se producen en material, son los causantes de los modos en los cuales se producen las delaminaciones y la pérdida de rigidez. [72-74]. La delaminación o separación de las capas individuales es un defecto importante que no permite mantener un laminado estructuralmente sólido. Como la tenacidad interlaminar de laminados es la dureza más baja, una grieta se propaga fácilmente bajo esfuerzos de tracción en la interfaz.

Un informe completo que revisa la resistencia al daño impuestos por impacto de un GFRP fue publicado por Tomblin [75], del cual Zilong [76] y Sánchez [77] confirman que la evaluación de la resistencia residual es un complemento importante en la investigación de una secuencia de impactos a diferentes alturas, y permite obtener una relación exponencial entre las energías que decrece con la fuerza de compresión previo al fallo en el ensayo, sometiendo una probeta impactada a una presión sobre el plano de las delaminaciones para obtener una tendencia de como el impacto ha ido cambiando la flexibilidad del GFRP. 


\subsection{Estrategias para mitigar el daño en paneles de materiales compuestos}

La reproducción considerada a escalas reales, permite mediante los planos de separación interlaminares, conocer la cantidad de energía devuelta que no se convierte en daño y tener una idea de lo que ocurre con los GFRP a medida que avanza el tiempo versus el número de impactos aplicados. Y si la cantidad de energía cinética disipada durante la deformación se debe mitigar para disminuir el daño el laminado, es fundamental modificar este laminado para disminuir el agrietamiento de la resina, la separación de la fibra y la delaminación los cuales afectan dramáticamente la fuerza global y la integridad de la estructura[78].

El empleo de los materiales viscoelásticos, ha sido una opción para tratar de amortiguar el ruido y el impacto en superficies de estructuras tal como la patente presentada por Varela [78] y el laminado propuesto por Maly [79], quienes diseñan un material compuesto con varias capas de viscoelásticos en múltiples direcciones. Ellos aprovechan que los materiales compuestos tienen relaciones de rigidez elevada [80] pero poca amortiguación combinando los altos niveles de disipación de energía con una rigidez estructural mínima, y curándolos dentro del laminado observando que el proceso modificó el comportamiento del viscoelástico manteniendo en cierto grado la amortiguación.

No resulta útil en el caso de las embarcaciones planeadoras este tipo de compuesto por el elevado espesor del laminado, ya que una modificación debe considerar la disminución del volumen y peso a la estructura del casco con el propósito de que la energía cinética impuesta se transforme en menor daño interno. Blake [81] propone una solución con la introducción de material viscoelástico en uniones de refuerzos en el casco como se observa en la Figura 8, y corresponde a una estructura de GFRP con compuesto de balsa a la cual se le ha incluido una capa viscoelástica como núcleo adicional en el espacio entre el casco y el refuerzo. 


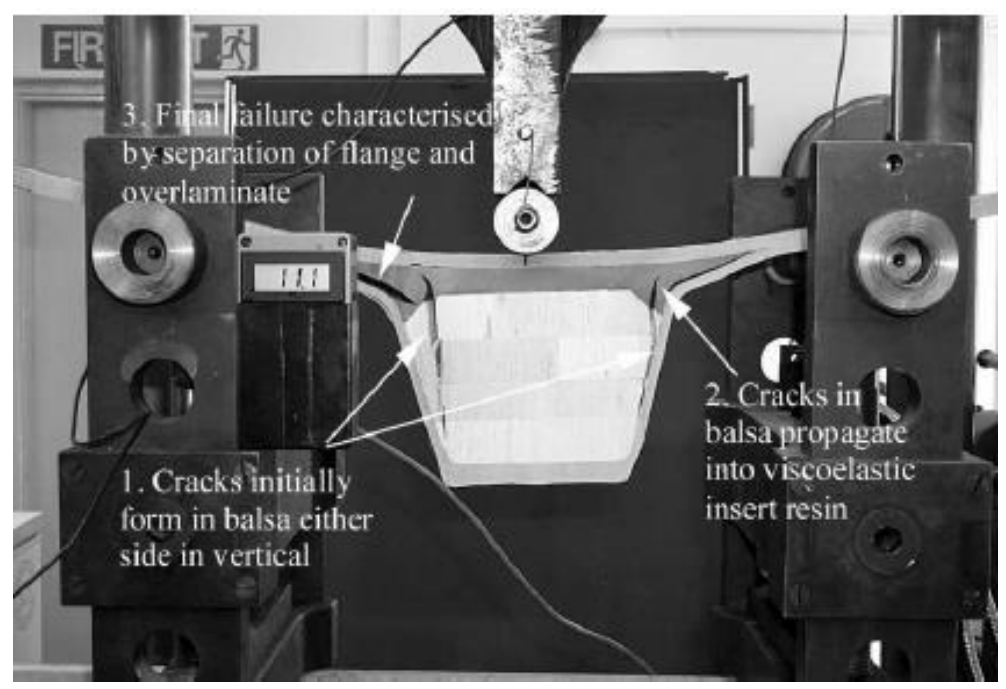

Figura 8 Modelo presentado por Blake sobre la inserción del material viscoelástico dentro de una estructura

El empleo de los viscoelásticos en los laminados de los materiales compuestos tiene el amortiguamiento supeditado orientación de las fibras de acuerdo a numeroso estudios con impacto de caída de peso por gravedad que muestran su tolerancia al daño como los comentados por House [82] quien concluye que aunque no existen análisis teóricos, la naturaleza viscoelástica de la matriz y su optimización sobre las típicas frecuencias de impacto perjudiciales, es un factor importante para absorber la energía de impacto de la misma manera que para absorber energía vibratoria, y considera el impacto como una forma extrema de vibración.

La amortiguación de un compuesto de fibras continuas modificado con capas viscoelásticas, en cuanto a la flexión y la cizalla transversal se determina usando asunciones y ecuaciones que sugieren que la disipación se produce en la resina a un valor intermedio entre el material viscoelástico y la matriz según Lavanya [8382]. Ocurre en los GRFP que los micro daños tienden a unirse para formar una grieta macroscópicas llamadas grietas transversales o intralaminares producto de la tensión cuasi-estática y la tensión de fatiga comentadas por Rajesh [84] para modelos viscoelástico e identificadas por Crowther [85] como la degradación de su fuerza por fatiga estática y dinámica y que debe ser atenuada. 
En la Figura 9 se observa una comparación de lo que eventualmente ocurriría dentro de un laminado de $\mathrm{n}$ capas cuando se lo modifica con capas viscoelásticas y se lo impacta repetidas veces lo que equivaldría al fenómeno de slamming de acuerdo con las teorías presentadas.

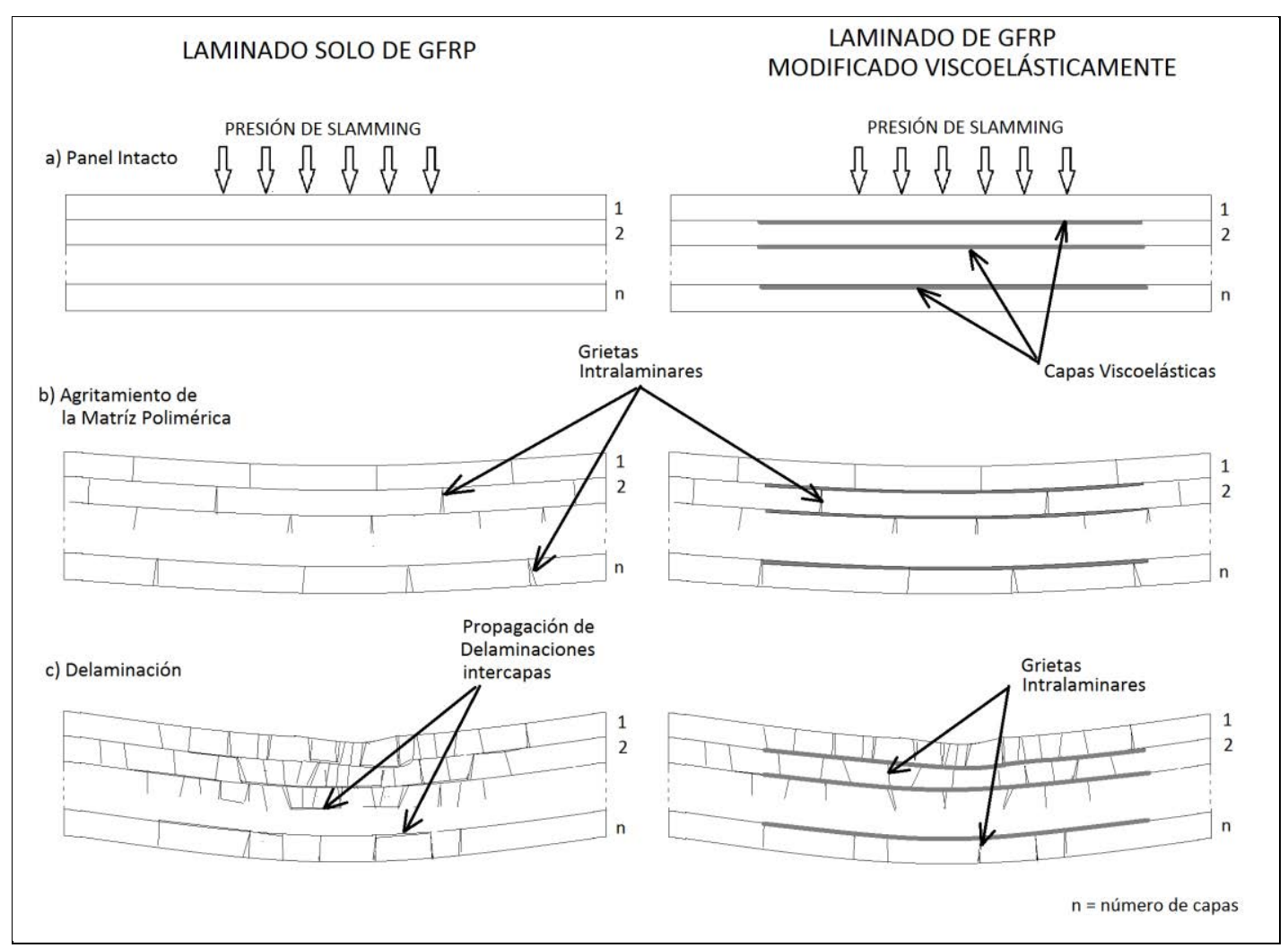

Figura 9 Efecto de la presión de slamming dentro de un panel de GFRP modificado viscoelásticamente por capas

Se observa que, en un panel sin modificar cuando se impacta con el pico de presión de slamming, en la primera etapa de la deformación por acción de la fuerza sobre la superficie, aparecen las grietas verticales intralaminares, que corresponden a la rotura de la matriz. Estás van en aumento a medida que sigue deformándose el panel creando tensiones que en la siguiente etapa de daño se propagan dentro entre capas como delaminaciones intercapas, que van uniéndose con las grietas intralaminares creando formas como de escalera saltando de capa a capa.

De tal forma que estas grietas están espaciadas en las capas y con el aumento de la carga de impacto se nuclea una nueva grieta entre dos existentes tendiendo a un estado de saturación denominado 
característica de estados de daños por Reifsnider [86], lo cual puede llegar al rompimiento de la fibra. Moore y Dillard [87) observaron el crecimiento dependiente del tiempo de las grietas transversales en laminados de capas cruzadas a temperatura ambiente. Raghavan y Meshii [88] observaron la dependencia de la velocidad de agrietamiento transversal en capas cruzadas de laminados. Se ha observado en estos estudios que bajo cargas constantes, las grietas transversales se limitaron a la su aparición en los bordes mientras que en las pruebas de velocidad de carga constante, estas grietas abarcaban toda la anchura del laminado. Zocher [89-90], Kumar [91] y Arvin [92] estudiaron los materiales laminados en un estado de daño con micromecánica analítica y modelos matemáticos que se limitan a patrones de daño que se pueden identificar en este tipo de modificación.

La propuesta de inserción de capas viscoelásticas va definitivamente a amortiguar esta propagación de daño debido a las energías que se quedan en el panel luego del impacto y que producen daño. La confección de una lámina con material viscoelástico debe hacerse de tal forma que no influya significativamente en el espesor del laminado del casco de la embarcación y permita aligerar el peso de la nave para beneficio de su potencia y desplazamiento de manera esencial.

La confección de la lámina, debe aprovechar la propiedad de los elastómeros de que cuando se restringen en dos direcciones, permite que el módulo de elasticidad efectivo sea más grande que el módulo de elasticidad real del material por el factor de Posison cercano a 0.5 de acuerdo con la Ley de Hooke en tres dimensiones para compresión de un bloque restringido en dos direcciones.

Está lámina para que absorba el amortiguamiento de la energía de daño, debe laminarse con el panel y ser incluida entre las capas previo al curado, de tal forma que el envejecimiento prematuro del material debido a la aparición de las meso grietas en los cascos de las embarcaciones, debería amortiguarse su propagación y obtener una mejor vida útil del mismo. Para observar los resultados de esto, se propone impactar por caída de peso por gravedad y reproducir el fenómeno de slamming en paneles de GFRP modificado y sin modificar, con el propósito de estudiar su comportamiento energético interior, como se propaga el daño en ambos casos y establecer las bondades y deficiencias de la modificación propuesta. 


\section{CAPÍtUlo II METODOLOGÍA EXPERIMENTAL I: PANELES GFRP SIN MODIFICAR}

\subsection{Fabricación de paneles GFRP con preimpregnado OoA}

El término sin modificar, es representativo de la no aplicación de capas viscoelásticas en las probetas. El material utilizado Gurit WE-91 triaxial viene en telas de $1 \mathrm{~mm}$ de espesor con láminas de 3 capas de fibra de vidrio unidireccional orientadas en 3 direcciones $\left(0^{\circ} / 45^{\circ} /-45^{\circ}\right)$ siendo este un GFRP a base de preimpregnado con matriz epóxica cuyas características se indican en el ANEXO 1. Se prepararon paneles con 3 láminas compactadas de 270 x $270 \mathrm{~mm}$ que se orientaron en forma cruzada y dieron un total de nueve capas $\left(45^{\circ} /-45^{\circ} / 90^{\circ} /-45^{\circ} / 45^{\circ} / 0^{\circ} / 90^{\circ} /-45^{\circ} /+45^{\circ}\right)$, siendo la primera capa la que va a resistir el impacto en los ensayos y la última la que será testada su deformación mediante el empleo de una galga extensiométrica. El espesor promedio de los paneles ya curados es de $3 \mathrm{~mm}$.

Para la confección se emplearon los siguientes materiales.

- Útil de metal.

- Válvula de cierre de vacío con empaque para bolsa.

- Cinta de cierre.

- Corcho.

- Cera desmoldable con resistencia mayor a $120^{\circ} \mathrm{C}$.

- Bolsa de vacío de polietileno.

- Tela respiradora.

- Pelable.

- Tela impermeable Daltex.

- Equipo de vacío.

- Horno para rampa de temperatura.

Para su confección de acuerdo con las recomendaciones del fabricante, se retira el material del refrigerador el cual lo mantiene a $-18^{\circ} \mathrm{C}$ para que su consistencia y pegajosidad no disminuyan cambiando sus propiedades. Esto se hace 24 horas antes con el propósito de que el material llegue 
a temperatura ambiente muy lentamente y no absorba humedad. Luego de las 24 horas, el material desenrollado puede presentar ondulaciones debido al manipuleo y debe ser compactado previamente. El aspecto del prepreg al ser estirado es el que se observa en la Figura 10.

Para apilar las 3 capas de prepreg, estas se van pegando unas con otras retirando la tela protectora., compactándolas con un rodillo de presión manual, tal como se lo ve en la Figura 11, y luego se coloca la tela respiradora o pelable en la parte superior en inferior, así como las tiras de corcho en los extremos, los cuales deben tener una altura superior a la de la probeta, con el propósito de que cuando se cure el material al vacío, los gases del proceso de curado escapen por este respiradero y no así la resina, para tener la menor cantidad de pérdidas posibles. Debido a que la resina escapa por la tela respiradora, se coloca una pequeña lámina de teflón bajo la válvula de vacío con entremedio el Daltex y la tela respiradora. Se coloca la bolsa de vacío de polietileno, dejando una holgura para que pueda realizarse el vacío de forma uniforme. Los bordes se sellan con masilla. La válvula para vacío, se coloca una llave, con el propósito de cerrar el vacío y el equipo pueda ingresar al horno.

Se procede a hacer el vacío, y es necesario durante este proceso, verificar con un medidor acústico de que se haya sellado completamente los bordes. Se mantiene el vacío mediante un compresor que permite que la manguera de vacío ingrese al horno y los gases o volátiles del proceso de curado puedan escapar de la bolsa de vacío y disminuir las porosidades durante el tiempo de curado.

A continuación, se lleva al horno deberá calentarse de $1^{\circ}$ a $2^{\circ} \mathrm{C}$ por minuto hasta llegar a $120^{\circ} \mathrm{C}$, temperatura que se escogió para tratarlo 90 minutos de acuerdo a la rampa de temperatura dada por el fabricante. Cabe destacar, que el equipo de horno empleado, no permite llevar a cabo el ascenso de temperatura a la velocidad recomendada, sino que esta se elevó a $6^{\circ} \mathrm{C}$ por minuto. El prepreg listo colocado en el horno, se aprecia en la Figura 12.

Una vez concluido el tiempo de curado, se apaga el horno y se lo deja enfriar hasta que se constate que está a la temperatura ambiente. En la Figura 13, se observa la probeta ya curada antes del desmolde. La resina ha escapado por las tiras de corcho y regado sobre el panel. Esta resina no se pega al panel, ya que la tela Daltex impermeable se lo impide. 
El desmolde se hace retirando destructivamente todas las partes, para que quede libre solo el panel compuesto. En la Figura 14 se observa la probeta con la galga lista para las pruebas.

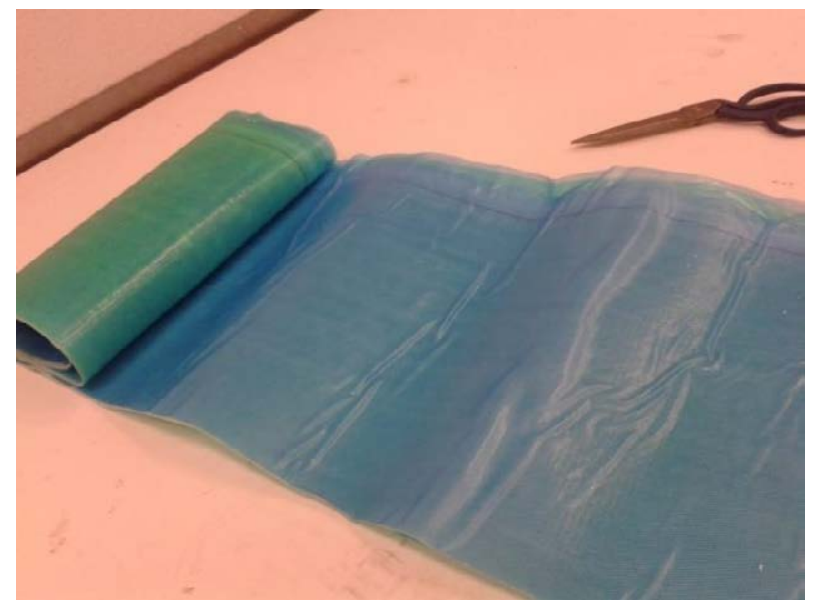

Figura 10 Rollo de preimpregnado a temperatura ambiente

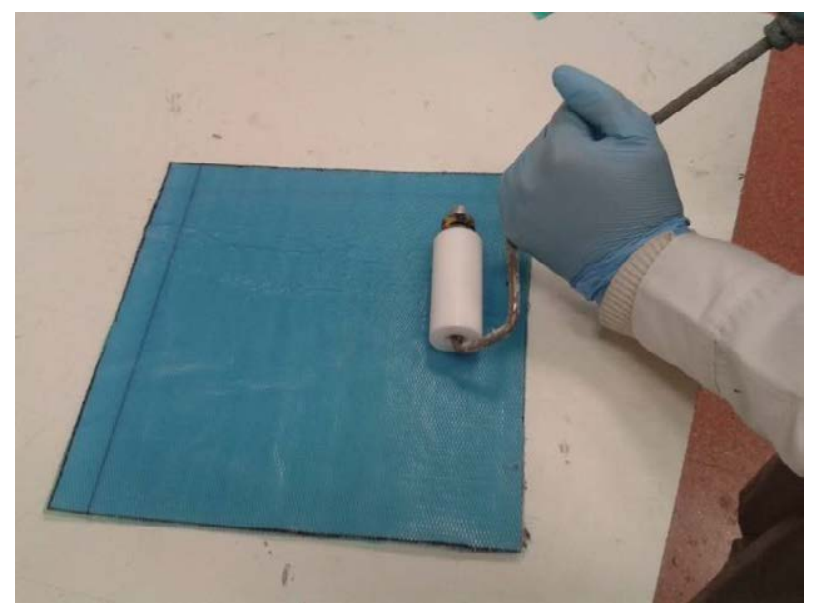

Figura 11 Compactación con rodillo manual 


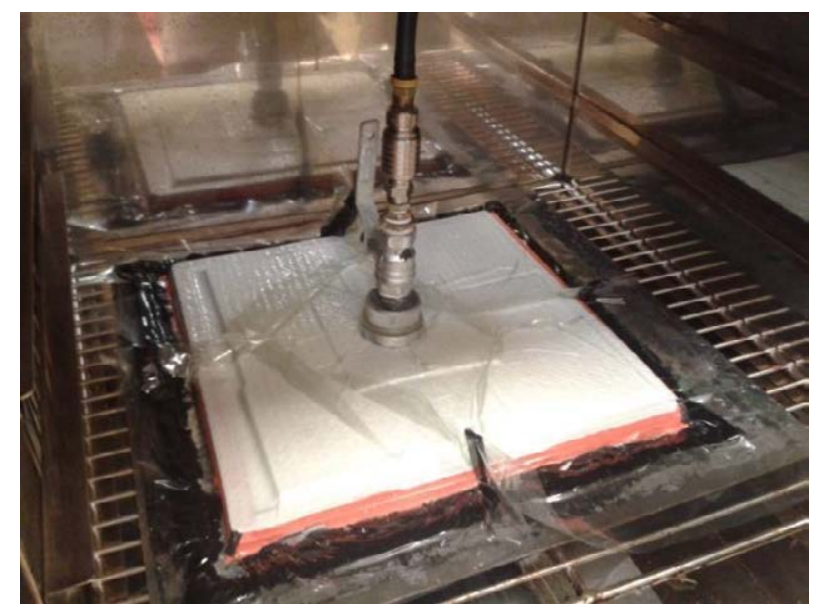

Figura 12 Probeta en el horno lista para curar

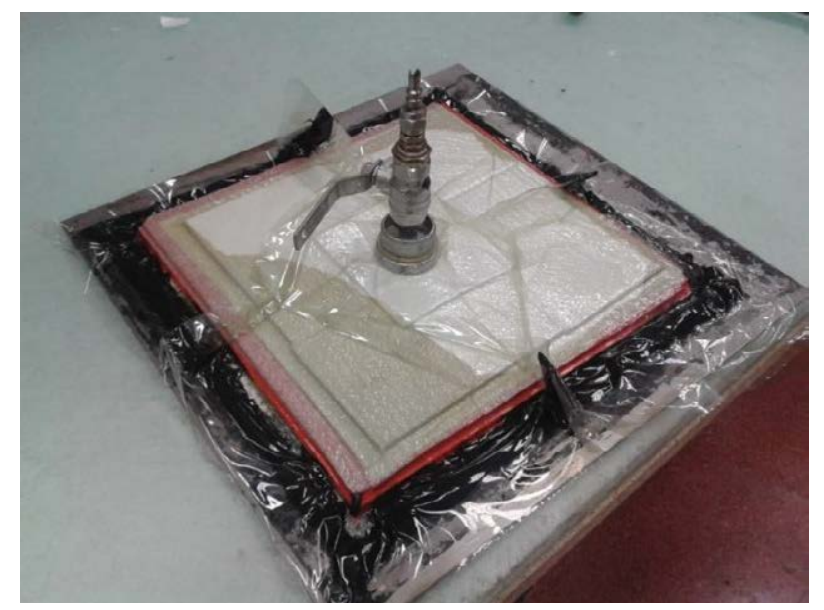

Figura 13 Probeta ya curada con rebose de resina

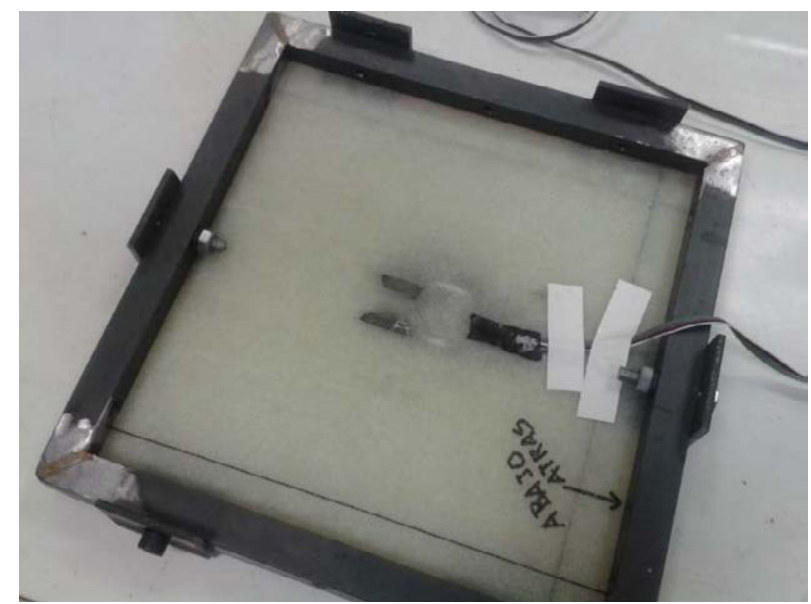

Figura 14 Probeta con Galgas lista para ensayos 


\subsection{Ensayos no destructivos de los paneles GFRP}

El tipo de ensayo aplicado es el de inspección por ultrasonido en inmersión y se va a emplea un equipo denominado "Sistema Automático de Inspección por Ultrasonidos en inmersión" que tiene una velocidad máxima de inspección de $100 \mathrm{~mm} / \mathrm{s}$, y una precisión del barrido de $(0.1 \mathrm{~mm}, 0,2$ $\mathrm{mm})$. El equipo es emisor y receptor a la vez y se basa en la propagación del sonido para analizar este tipo de material compuesto. Las ondas barren sobre todo el material, para cubrir la superficie y buscar imperfecciones, en la cual la discontinuidad que puede ser una porosidad, una fisura, una delaminación o un defecto que cambia la densidad del material, produce que la onda se regrese antes de tiempo, testando el equipo la ubicación de la falla.

El equipo a emplear, fabricado por TecniTest, consta de un ordenador de control, módulo de potencia adosado a la estructura de la cuba para mover los equipos de barrido tal como se muestra en la Figura 15 y en la Figura 16. Para la adquisición de datos, el software está basado en el equipo Mastersan 335 para la generación y tratamiento de las señales ultrasónicas cuyo detalle se observa en la Figura 17. El programa VisualScan bajo el sistema Windows presenta en tiempo real los resultados.

El medio empleado para sumergir la muestra es agua corriente y el equipo está diseñado para operar a una temperatura ambiente de $22^{\circ}$ Celsius.

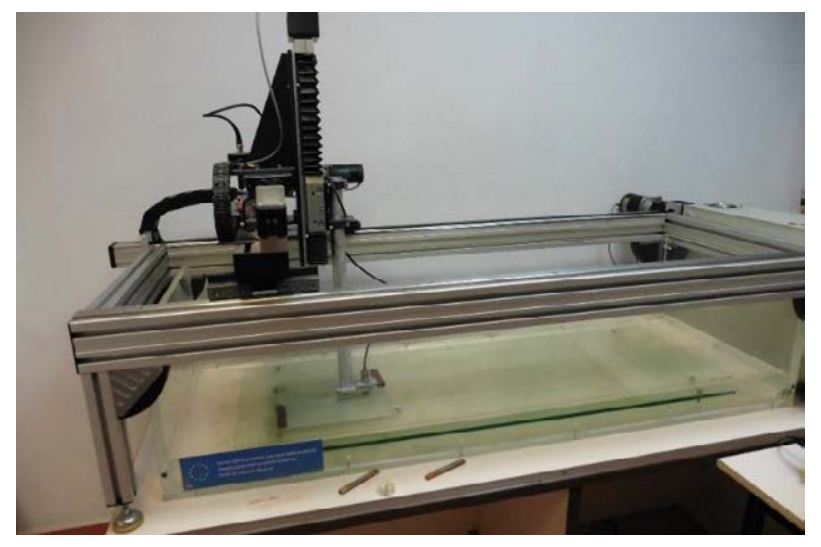

Figura 15 Cuba de inmersión de las muestras 


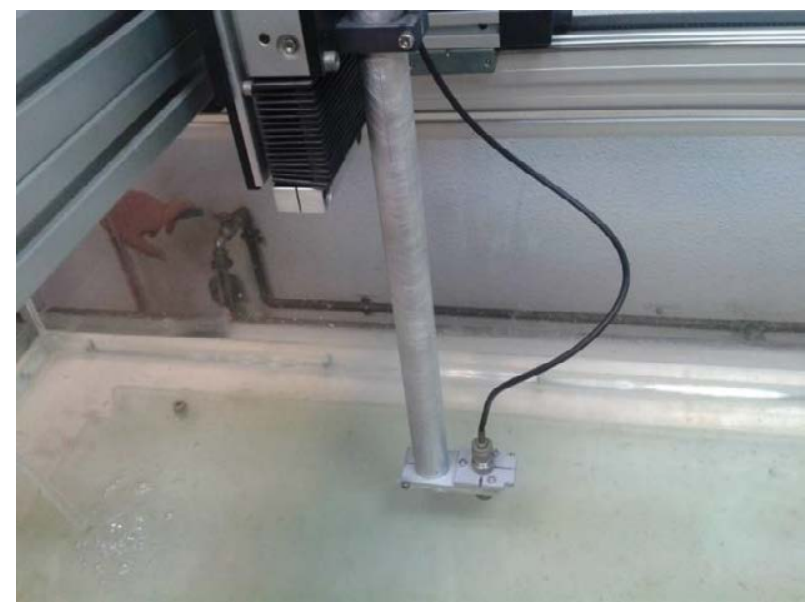

Figura 16 Sensor de ultrasonido

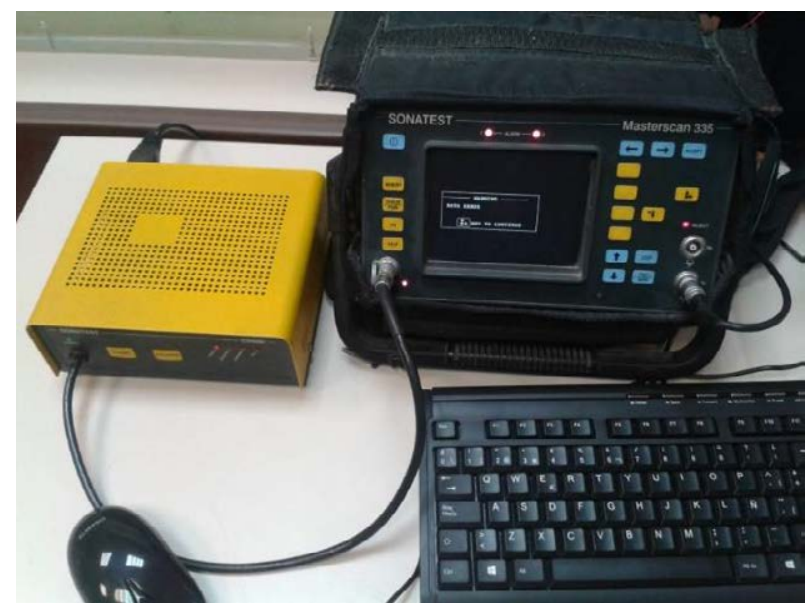

Figura 17 Lector y procesador de datos

Durante los ensayos, las imágenes obtenidas en 32 colores, se convirtieron a blanco y negro para separar los bits mayores a 18 decibelios y poder cuantificar el daño. En la Figura 18 , se observa la imagen de un panel dañado con ultrasonidos y su correspondiente imagen binaria en blanco y negro que muestra las zonas dañadas luego de uno de los ensayos. 


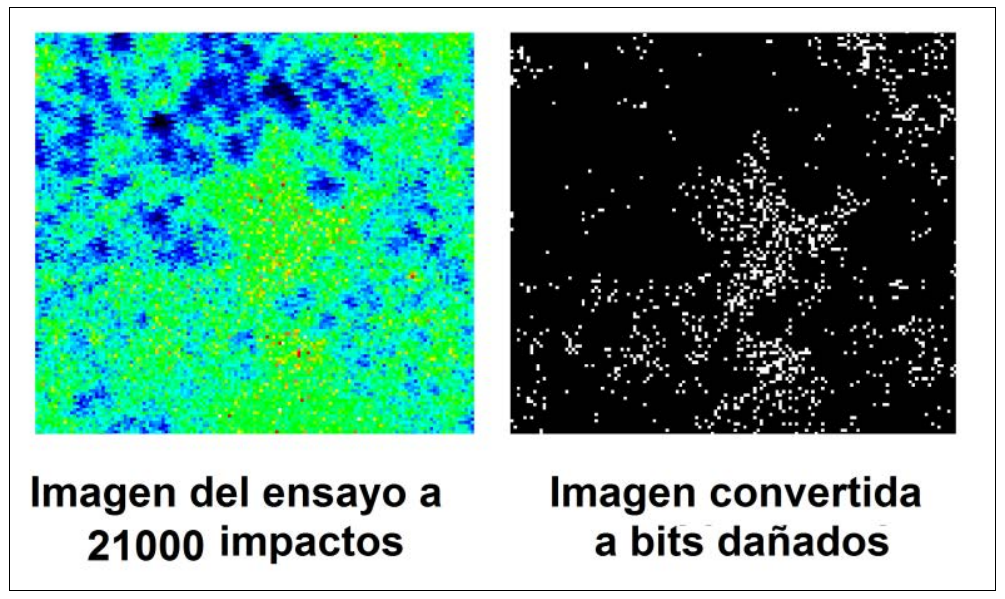

Figura 18 Conversión de imagen de 32 bits a 2 bits de un panel ensayado

El nivel de daño introducido se cuantificó mediante un software de análisis de imagen (ImageJ) que permitió contar el número de pixeles correspondientes a cada nivel de atenuación ultrasónica. En el caso de los ensayos de impacto por caída de peso, se obtuvo la imagen con ultrasonido luego del impacto por única vez. En los ensayos de slamming, se desmontaron por bloques de ciclos de impacto para llevar el control del avance del daño. En la Figura 19 se observa un ejemplo de un panel golpeado en la reproducción de slamming, en la cual se tiene la comparación del \% de bits dañados luego de ser procesado por el software ImageJ. Las áreas de barrido en ambos casos correspondieron a las zonas ensayadas. 


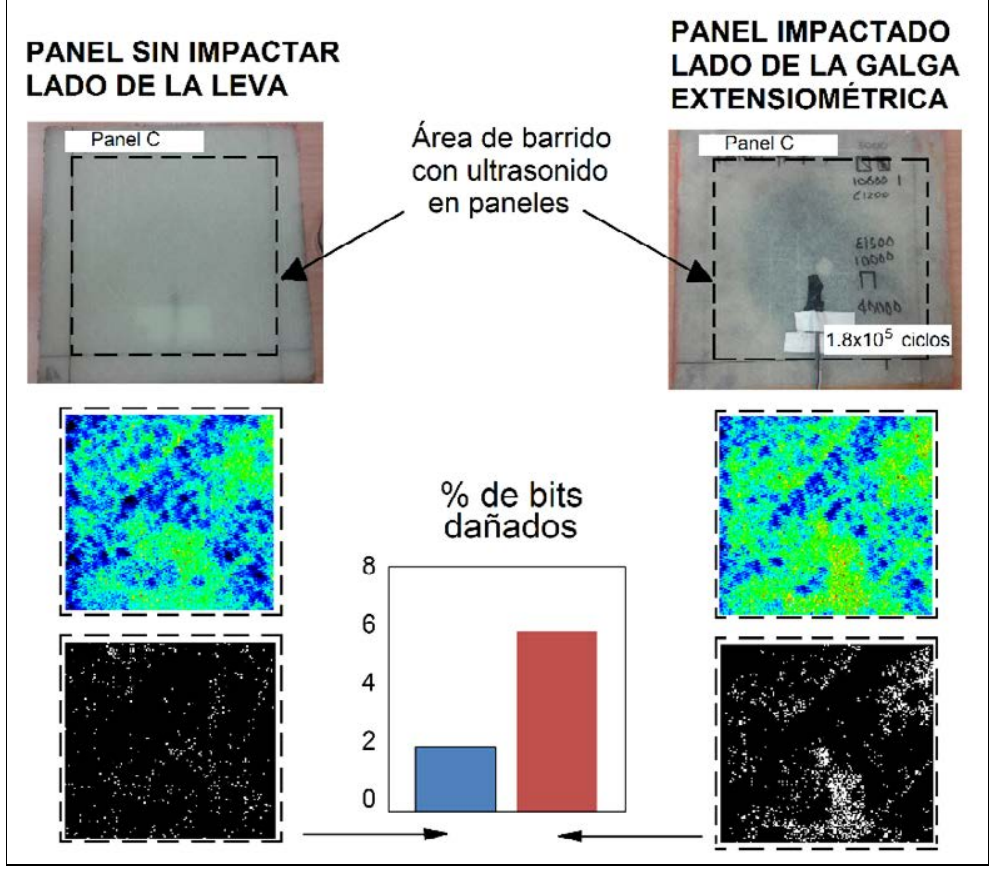

Figura 19 Comparación con ultrasonido de un panel sin impactar y luego de $1.8 \times 10^{5}$ ciclos de impacto con $\mathrm{P}=633 \mathrm{kN} / \mathrm{m} 2$ 


\subsection{Ensayos mecánicos de caracterización de los paneles GFRP}

Se empleó la máquina universal de ensayos Ibertest, a la cual se le adaptó un útil de 3 rodillos para realizar la prueba de flexión en 3 puntos. A partir de paneles construidos de material preimpregnado, se extrajeron probetas con un ancho de $15 \mathrm{~mm}$, las cuales fueron flexionadas obteniéndose como resultado la curva de fuerza versus flecha de deformación. Esto permitió calcular las microdeformaciones respectivas para estimar el umbral de daño del material, es decir se cuantificaron los valores en los cual termina el límite elástico de la flexión porque se producen las primeras micro fracturas en la matriz. El equipo se observa en la Figura 20.

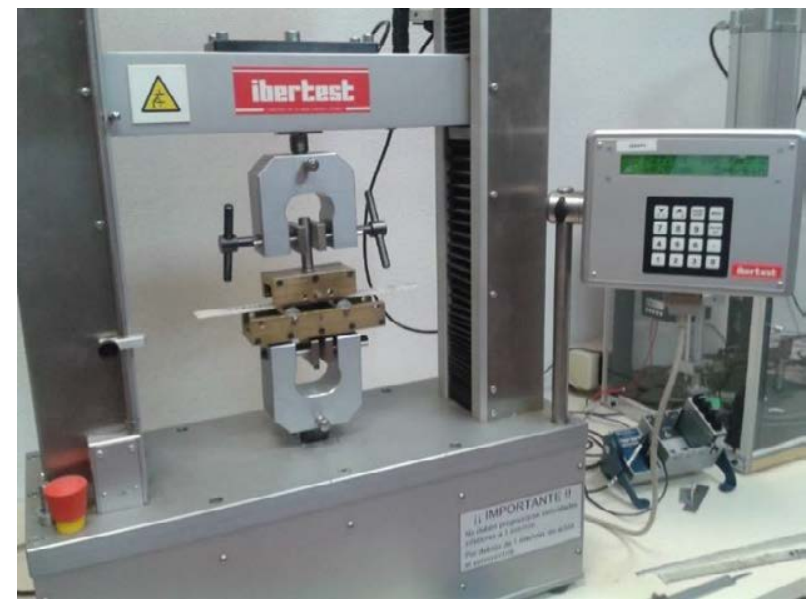

Figura 20 Máquina universal de ensayos con útil de flexión en 3 puntos

La formulación empleada en el ensayo, corresponde a las ecuaciones indicadas en la Ecuación 2.3-1 y la Ecuación 2.3-2 siendo $\rho$ el radio de curvatura y y la distancia al eje neutro en la cara de tensión. El valor del módulo de Young, se calculó con al obtenido con el valor de la flecha en el límite elástico.

Ecuación 2.3-1

$$
\varepsilon_{x}=-\frac{y}{\rho}
$$

Ecuación 2.3-2

$$
\frac{1}{\rho}=-\frac{E}{E I_{x}}
$$


El valor de las microdeformaciones que marca el umbral de daño, sirvió para relacionarlo con las microdeformaciones aplicadas a los ensayos impacto por caída de peso y de golpe de slamming realizados, con el propósito de uniformizar y controlar los valores de energía de impacto y presiones aplicados respectivamente. 


\subsection{Ensayos de impacto por caída de peso}

La máquina de impacto por caída de peso, que fue fabricada para la presente investigación en el laboratorio de Ensayos destructivos de la ETSIN Navales, está configurada para trabajar bajo las condiciones indicadas en la Figura 21.

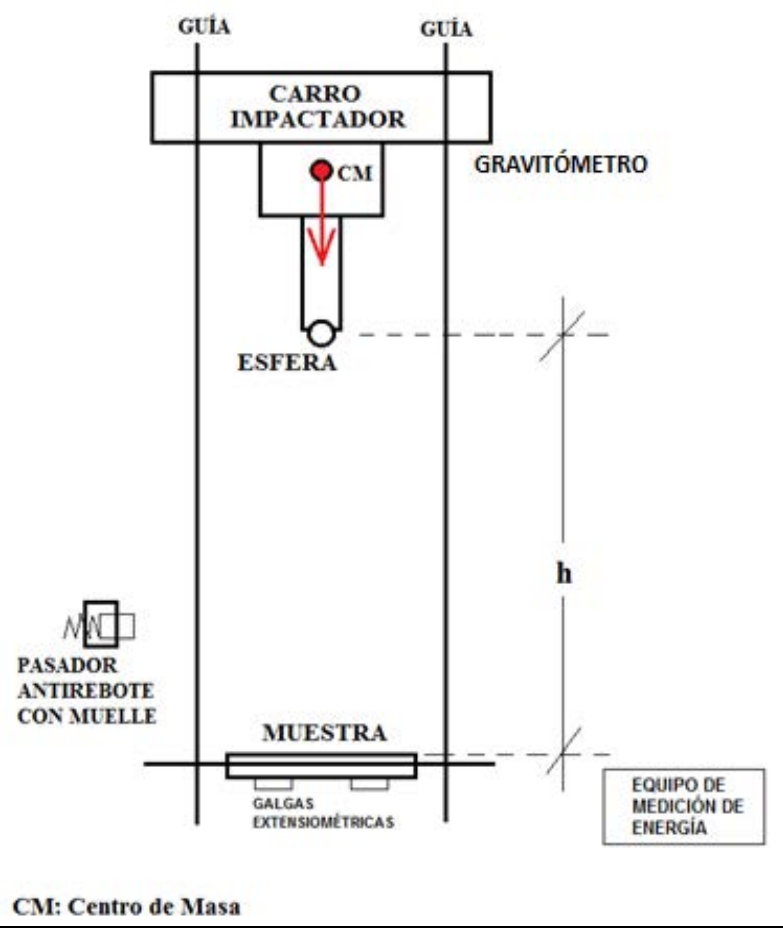

Figura 21 Configuración de la máquina de impacto por caída de peso

Para el caso del ensayo a realizar, no se va a considerar el coeficiente de restitución, ya que el equipo impide que de un segundo golpe y se ha construido con los siguientes elementos.

- Estructura de soporte. En la Figura 22 aparece la parte inferior de esta estructura. La parte superior está constituida por un marco. 


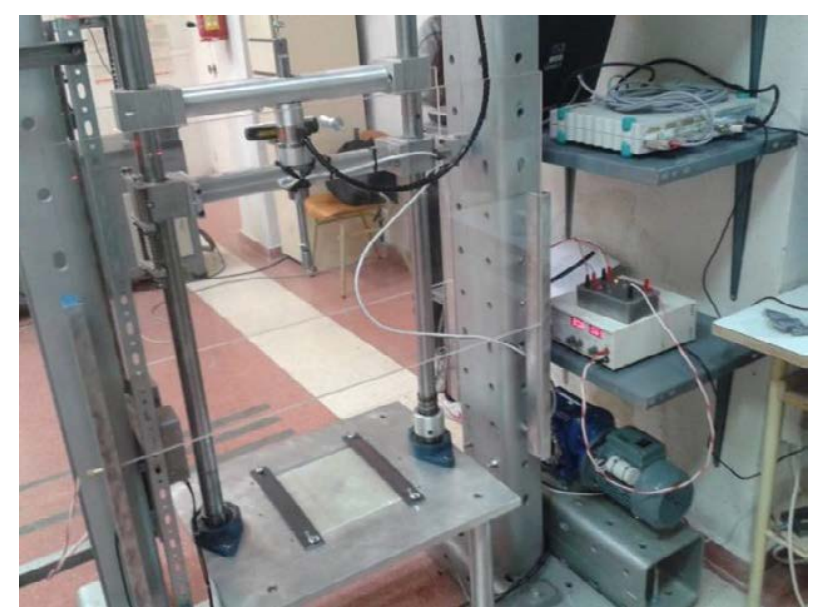

Figura 22 Parte inferior de la estructura de soporte

- Base de impacto. Plataforma baja y horizontal, la cual dispone de un aligeramiento donde se sitúa la probeta para asegurar que el impacto recibido sea en su centro. Este aligeramiento tiene dimensiones de $25 \times 25 \mathrm{~cm}$ y a $\operatorname{los}$ costados se sitúan las platinas de sujeción para considerarlo como de extremos empotrada la probeta y en los otros extremos simplemente soportada. En Figura 23 se puede observar una probeta de PRFV ya instalada en su base correctamente.

- Columnas guía. Por ellas se deslizan los carros verticalmente. Durante los ensayos se va a considerar que la fricción es despreciable, debido a la magnitud del peso que cae y ya que las columnas se encuentran engrasadas.

- Carros. Piezas unidas al impactador que permiten su movimiento vertical.

- Impactador. Está constituido por varias piezas: Imán superior, barra central, barra vertical y esfera de impacto. El imán superior no permite la caída mientras el electroimán esté conectado, la barra central conecta los dos carros y aporta la posibilidad de añadir más pesos, la barra vertical es un elemento cilíndrico que conecta la barra horizontal con la esfera de impacto, la cual se encuentra sujeta mediante un imán. Esta esfera impacta contra la probeta con una energía establecida, provocando un determinado daño en ésta. En la Figura 24 se observa el impactador unido a los carros, además de las columnas guía. 


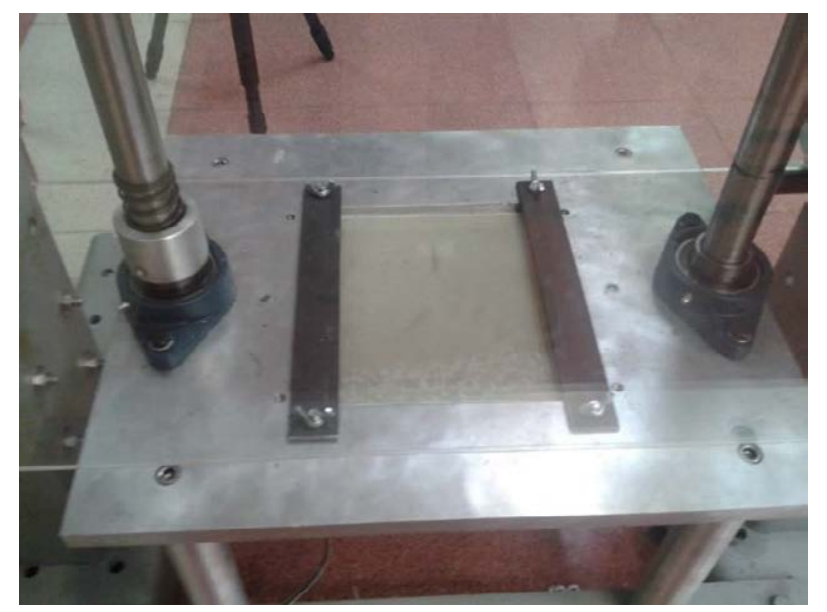

Figura 23 Panel empotrado en la base para impacto

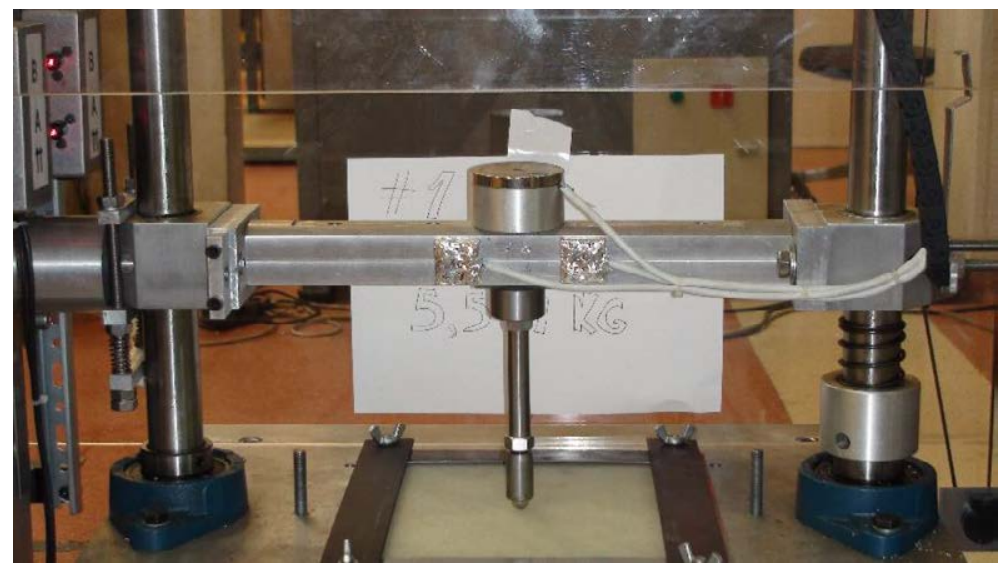

Figura 24 Elementos del carro impactador

- Electroimán. Sujeta el impactador mientras está conectado y al desconectarlo, el impactador baja en caída libre para golpear la probeta. En la Figura 25 se observa, en la parte superior, el electroimán con su soporte y en la parte inferior en el carro impactador. 


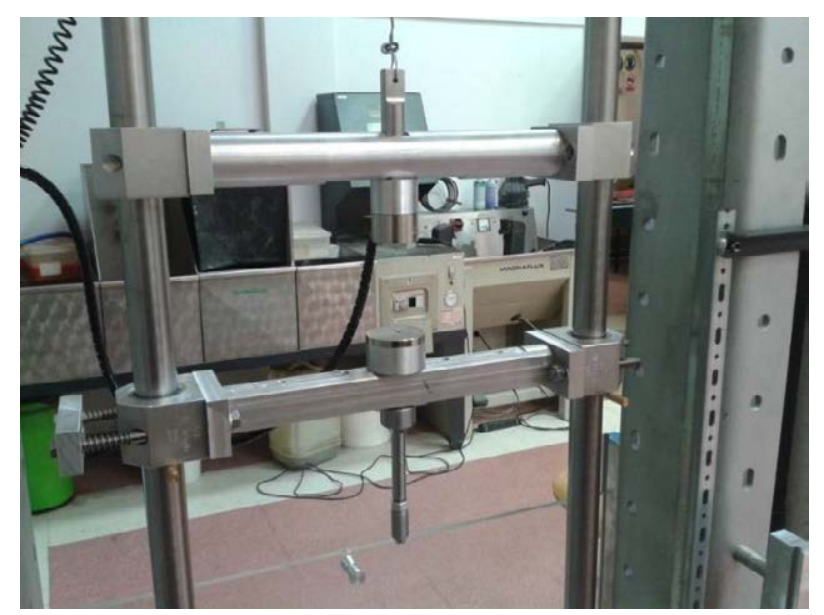

Figura 25 Electroimán y carro impactador

- Sistema anti-rebote. Evita que el carro impactador caiga por segunda vez sobre la probeta. Este equipo incluye un pasador que sale, impulsado por un muelle, al desconectar el electroimán que lo mantiene oculto, impidiendo el paso del carro impactador. En la Figura 26 se muestra este sistema.

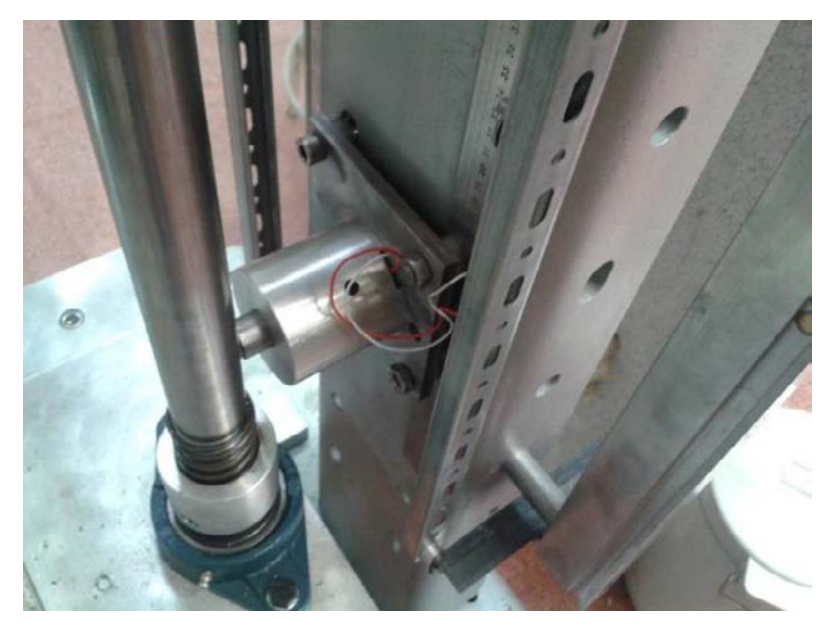

Figura 26 Sistema anti-rebote

- Sistema láser. Mide la velocidad que lleva el carro impactador justo antes de impactar la probeta.

- Sistema medidor de energía o gravitómetro. Obtiene el espectro de fuerzas G o gravedades obtenidas durante el transcurso del impacto. 
Para el cálculo y el manejo de las energías de acuerdo con la información entregada por el gravitómetro o acelerómetro instalado en la máquina de ensayos de impacto por gravedad, se desarrolló la formulación matemática que rige el cálculo de la energía devuelta por el panel. El software instalado para el gravitómetro permite obtener datos en microsegundos de lo que ocurre a medida que la esfera va rompiendo el panel y luego cuando rebota hasta que deja de tocar el panel.

Las variables manejadas para la valoración y cuantificación de resultados son las siguientes.

G: número adimensional de gravedad dado por el gravitómetro.

g: aceleración del impactador $(\mathrm{m} / \mathrm{s} 2)$

t: Tiempo del impacto testado por el gravitómetro (s)

T: tiempo relativo al inicio del impacto (s)

W: Peso impactado $(\mathrm{kg})$

F: Fuerza de impacto $(\mathrm{N})$

$\mathrm{v}$ : velocidad en un instante de tiempo $(\mathrm{m} / \mathrm{s})$

$\mathrm{V}$ : velocidad total relativo al impacto $(\mathrm{m} / \mathrm{s})$

$\mathrm{x}$ : desplazamiento del impactador $(\mathrm{m})$

$\mathrm{X}$ : desplazamiento total desde el inicio del impacto (m)

e: energía unitaria recibida por el impactador (J)

E: energía total del impacto recibida por el impactador (J)

ek: energía cinética unitaria entregada por el impactador (J)

Ek: energía cinética total entregada por el impactador (J)

Eo: energía inicial del impactador (J)

Ea: energía absorbida por el material (J)

Ed: energía devuelta por el material (J)

Para diferentes instantes i de t, se aplicó la siguiente formulación para obtener los datos para la curva de la energía devuelta $E_{d}$ que corresponde a una diferencia de la $E_{a}$ con la energía máxima 
producida por el impacto. De tal forma que los resultados de los ensayos de impacto se han procesado para estimar la energía devuelta, y valorar hasta que niveles el panel comienza a absorber daño luego del impacto.

\begin{tabular}{|c|c|}
\hline Ecuación 2.4-1 & $g(t)=G(t) * 9.81$ \\
\hline Ecuación 2.4-2 & $F(t)=W * g(t)$ \\
\hline Ecuación 2.4-3 & $v(t)=g(t) * \Delta t$ \\
\hline Ecuación 2.4-4 & $V(t)=v_{0}+\int_{0}^{t} v(t) d t$ \\
\hline Ecuación 2.4-5 & $x(t)=v(t) * \Delta t+1 / 2 g(t) *(\Delta t)^{2}$ \\
\hline Ecuación 2.4-6 & $X(t)=\int_{0}^{t} x(t) d t$ \\
\hline Ecuación 2.4-7 & $e(t)=F(t) * x(t)$ \\
\hline Ecuación 2.4-8 & $E(t)=\int_{0}^{t} e(t) d t$ \\
\hline Ecuación 2.4-9 & $k(t)=1 / 2 W *(V(t))^{2}$ \\
\hline Ecuación 2.4-10 & $K(t)=\int_{0}^{t} k(t) d t$ \\
\hline Ecuación 2.4-11 & $E_{a}=E_{o}-(|E(t)|-|K(t)|)$ \\
\hline
\end{tabular}

Otra curva importante presentada en los resultados, corresponde a la fuerza dada por la Ecuación 2.4-12 versus el desplazamiento total del impactador a medida que va rompiendo las diferentes capas del laminado y que se calcula con la Ecuación 2.4-13.

Los ensayos de impacto, se realizaron en diferentes rangos de energía, variando el peso impactador y la altura. 


\subsection{Ensayos de impacto de slamming}

El equipo fabricado para la prueba de impacto por slamming en el laboratorio de la ETSIN Navales, consiste en las siguientes partes.

- Un motor eléctrico marca Black Thunder de $0.75 \mathrm{Kw}$ a $220 \mathrm{~V} 50 \mathrm{~Hz} 1380 \mathrm{RPM}$ y de 0.8 Kw a 240 V $60 \mathrm{~Hz} 1680$ RPM.

- Una leva de impacto excéntrica.

- Un contador de revoluciones.

- Base y cuadro para probeta.

El equipo de reproducción de slamming tiene el conjunto variador-motor eléctrico, conectado mediante un eje apoyado sobre dos rodamientos. La leva de acero que va ajustada con chaveta al eje, tiene devastado aligeramientos en su masa para que se encuentre balanceada con el centro del eje y evitar cargas inerciales por su forma excéntrica. El variador instalado permite al motor trabajar a una frecuencia de 200 a 320 RPM, valores en los cuales el conjunto es más eficiente y las vibraciones que produce el equipo al girar no afectan al montaje de las partes. Se colocaron juntas de caucho en las bases de los rodamientos que sostenían el eje, para disipar la energía de reacción de la leva contra el panel y no afecte esta carga lateral al conjunto motor variador. El diseño de la leva hace que la deformación y relajación del panel presionen en forma gradual sobre la cara de contacto y se eviten cargas de golpe de martillo. A un costado del eje se adaptó un interruptor para contar los ciclos que se aplicaban.

El equipo se lo empotró en medio de dos bases de acero, para que sirvan de anclaje al marco donde va ubicado el panel a ensayar. Los paneles se montaron con prensas atornilladas al mismo, para evitar la traslación y rotación en sus extremos con el propósito de que durante la prueba sus condiciones de contorno sean de empotramiento, con todos sus grados de libertad restringidos.

Una de las características del equipo diseñado para el ensayo, es la distancia de ajuste de la leva que se graduaba moviendo el marco sobre guías perpendiculares al eje del sistema. Esto permitió que se apliquen diferentes deformaciones $(\delta)$ correspondiente a la flecha de la probeta y que está directamente relacionada con la deformación unitaria $(\varepsilon)$ sobre una de sus caras. Para controlar la 
$\varepsilon$ a la cual se ajustó cada uno de los paneles, se colocó en cada uno, una galga extensiométrica del lado contrario a la presión de la leva. No se ubicó en la parte central porque la presión de la leva la despegaría, sino a una distancia de $40 \mathrm{~mm}$ del centro de carga de la misma. En el equipo se pueden aplicar entre 0 a $2050 \mu \mathrm{m} / \mathrm{m}$ medidos en la ubicación de la galga extensiométrica correspondientes al mínimo y máximo alejamiento del panel contra la leva. La forma excéntrica de la leva y la curvatura del panel tal como se ve en la Figura 27, permite una superficie de contacto de $825 \mathrm{~mm} 2$ en promedio.

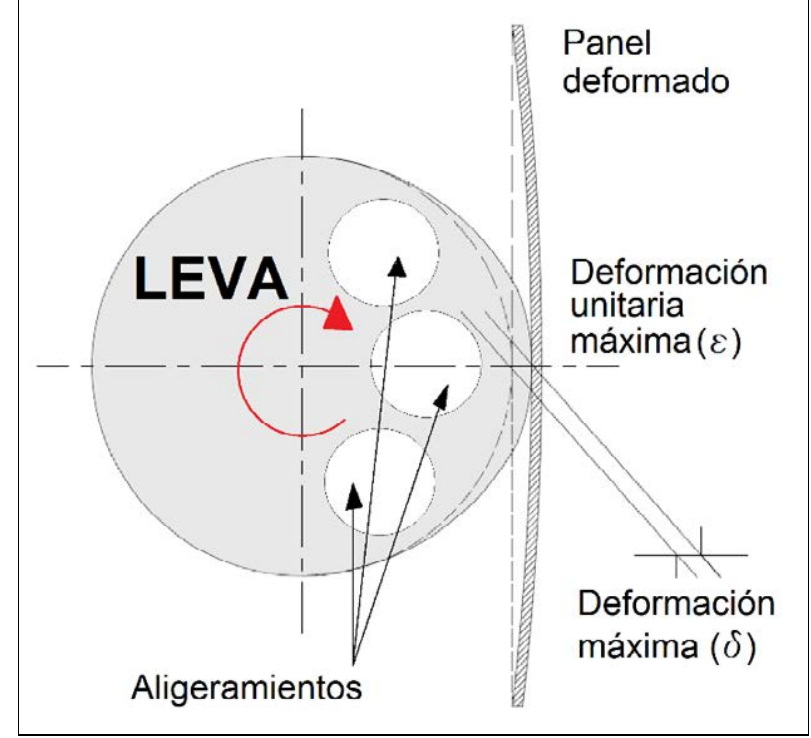

Figura 27 Esquema de aplicación de la carga se slamming

En la Figura 28 se observa el equipo con todas sus partes. La leva se encuentra firmemente soportada por dos chumaceras, lo que permite que no tenga desplazamiento y toda la energía de la leva se quede en el panel a golpear. Esto se observa en la Figura 29 donde se aprecia el sitio donde se coloca el panel y los pernos que sirven de calibración. 


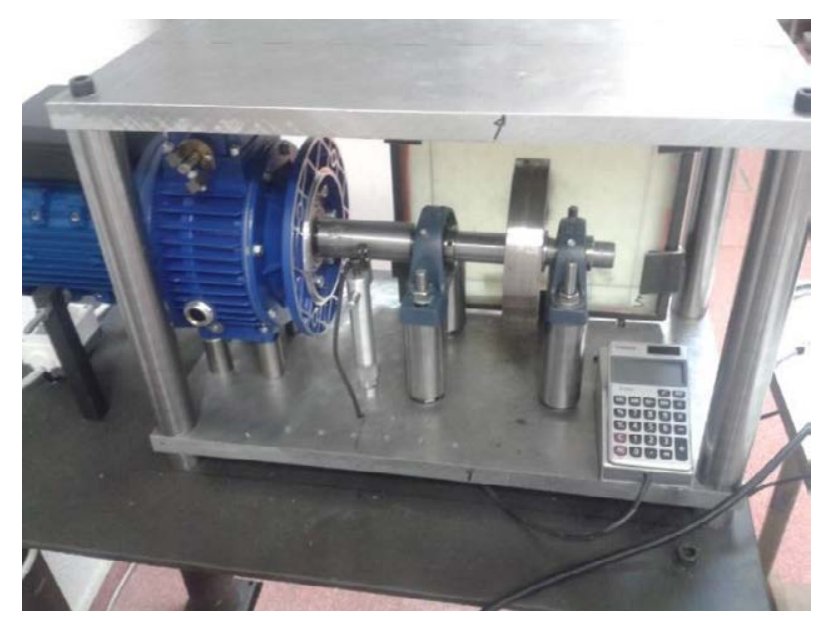

Figura 28 Equipo de reproducción de slamming

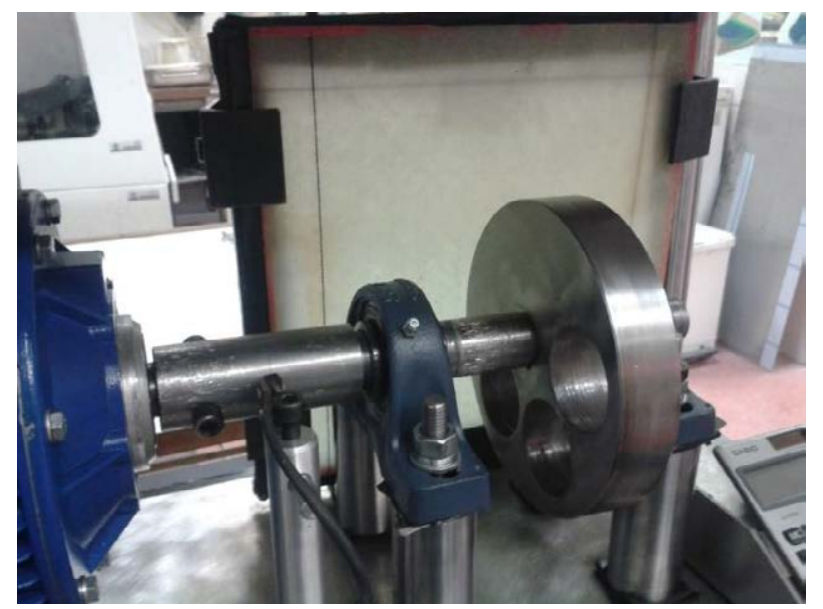

Figura 29 Detalle de la leva y la ubicación del panel

En la Figura 30, se un panel listo para los ensayos. Cabe destacar que, a este nivel de revolución y golpe, el equipo no entró en resonancia con la base y los niveles de vibración de la inercia de la leva con el conjunto motor eléctrico fueron razonables. 


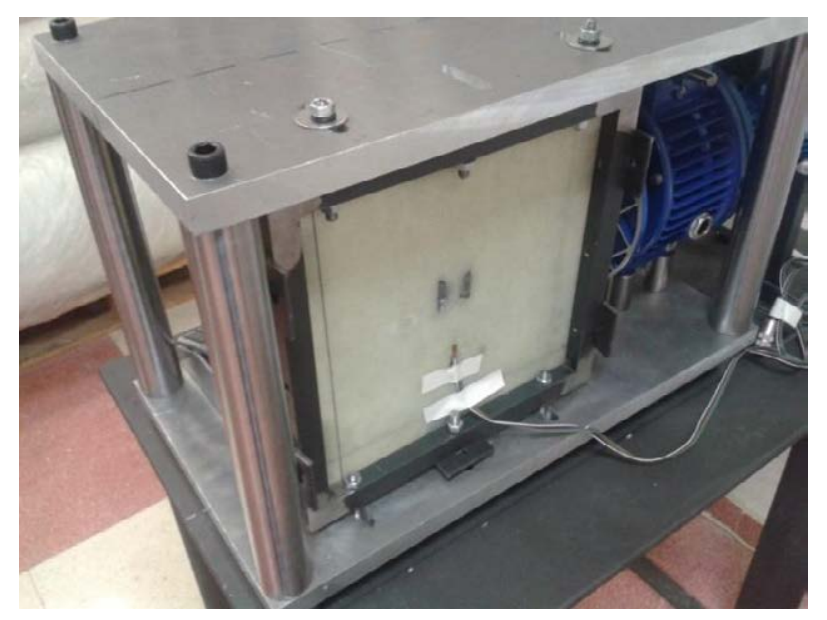

Figura 30 Panel ubicado en su sitio

Para calcular las presiones máxima y mínima del equipo, así como la presión del umbral de daño y las que se aplicaron a los paneles, se confeccionó un modelo empleando el método de elementos finitos con el programa Ansys. Se consideró que el laminado se apilaba en la dirección $+Y$, y las fibras se orientaban sobre el plano XZ. A cada capa se le dio su orientación y se empleó elementos sólidos del tipo SOLSH190 con 8, nodos adecuados para el modelado de estructuras delgadas. Se observa a modo de ejemplo en la Figura 31, la capa número 5 que tiene una dirección a $45^{\circ}$ y la normal del elemento es perpendicular a la cara del panel. Se modeló el panel completo y se restringieron los 4 bordes en traslación y rotación para que se considere empotrado. La carga normal que ejerce la leva sobre el panel, se aplicó sobre la primera capa en una superficie equivalente a 16 elementos que corresponden al área de contacto.

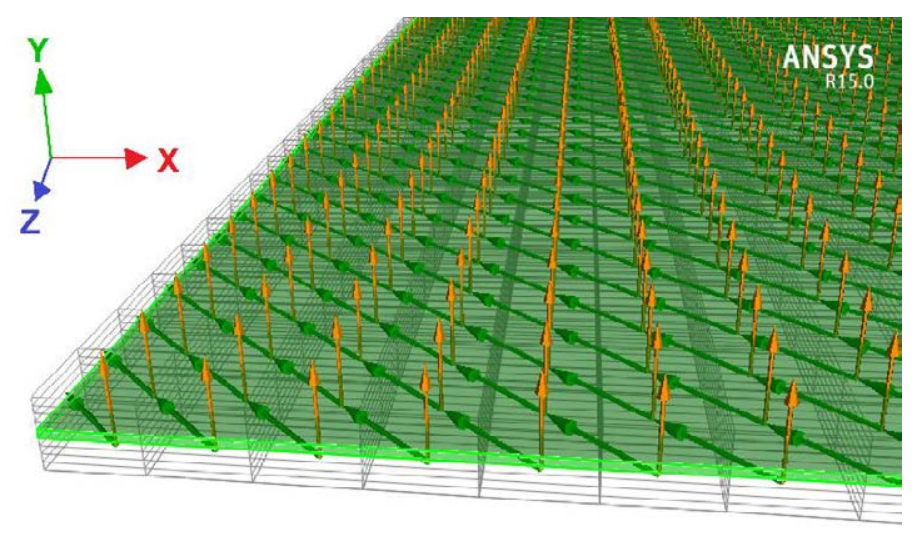

Figura 31 Direcciones principales de la capa número 5 orientada a $45^{\circ}$ 
En el análisis del comportamiento del panel compuesto analizado con el MEF, se asumió que las secciones planas ortogonales al plano medio de un laminado delgado, permanecen planas y ortogonales a la directriz después de la deformación, y que el panel no experimentó deformación en la dirección transversal a través del espesor. Además, según el tipo de modelo el campo de desplazamientos y rotaciones en los planos de referencia estaba definido por el plano medio del elemento. La deformación en el modelo varió en forma continua y lineal a través del espesor, mientras que las tensiones fueron discontinuas debido a que la matriz rigidez reducida es función de la orientación de cada lámina. Se lo deformó hasta un valor igual a las microdeformaciones registradas por la galga extensiométrica en dicho punto, con lo cual se obtuvo la fuerza, el valor de la deformación unitaria y la presión aplicada en la zona de la leva. En la Figura 32 se observa una sección transversal cortada en la zona de la leva del modelo MEF deformado por una de las cargas que muestra como varió $\varepsilon$ en el apilamiento de las capas.

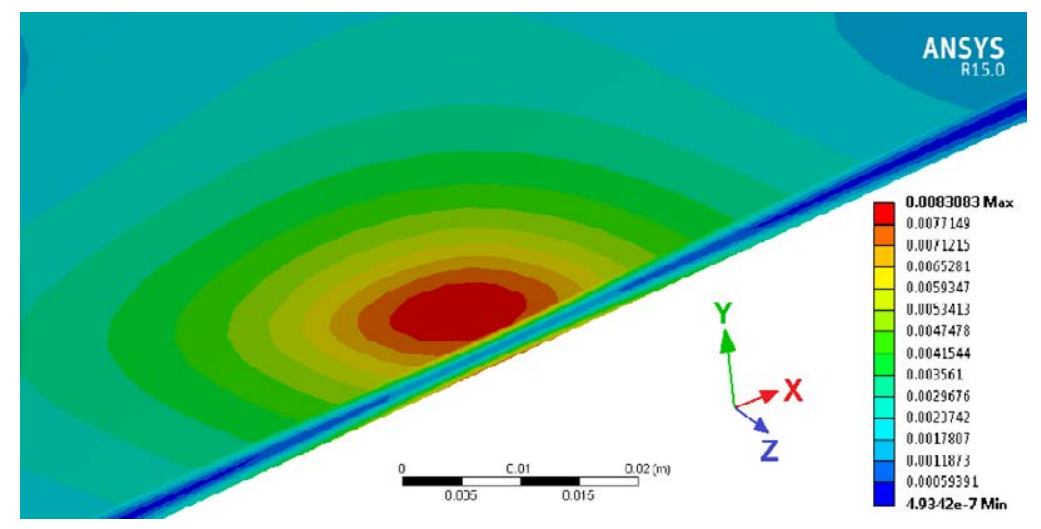

Figura 32 Detalle de la deformación en la sección central del modelo FEM

Cuando se realizaron los ensayos de slamming, se fijaron las revoluciones del equipo de acuerdo con el rendimiento del motor-variador y se aplicaron presiones desde el umbral de daño del material hasta el máximo de ajuste del equipo. Para minimizar la fricción entre la leva y el panel, se colocó grasa de Litio sobre la superficie del panel. Los ciclos de impacto de slamming se agruparon en bloques, con un número total de ciclos que se iban ajustando en función del daño medido mediante la inspección por ultrasonido y permitiendo el enfriamiento de la leva entre dos bloques de ensayos. Se usó un equipo de aire acondicionado para ventilar la cara del panel donde estaba la galga extensiométrica y paños fríos húmedos para bajar rápidamente la temperatura. El chequeo de la temperatura durante la experimentación se controló con un equipo de termografía 
infrarroja portátil, para garantizar que en ningún punto se superaba la temperatura de transición vítrea (Tg) de la matriz polimérica como se ve en la Figura 33. En ciertos ensayos se utilizó un equipo de aire acondicionado portátil para mantener frío el ambiente en la prueba tal como se observa en la Figura 34.

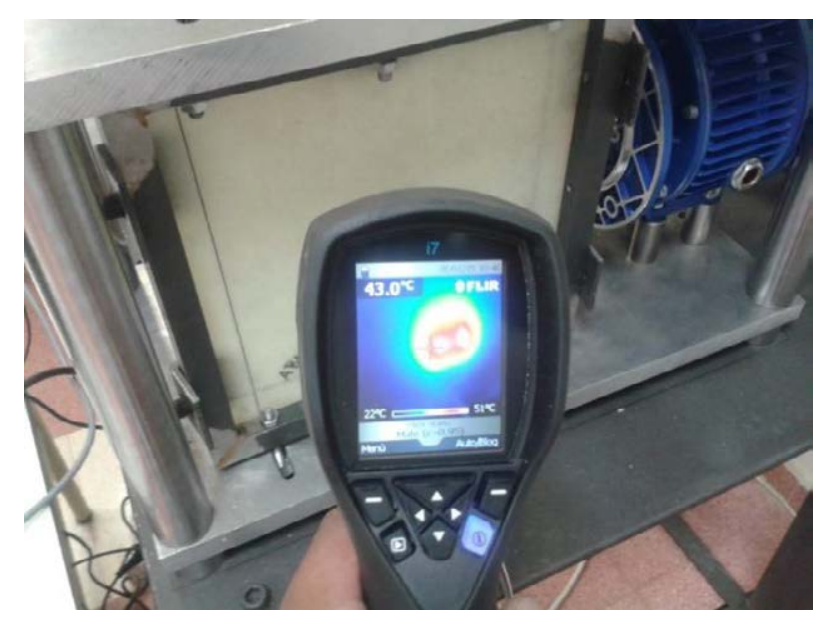

Figura 33 Medición de la temperatura en la cara opuesta al impacto

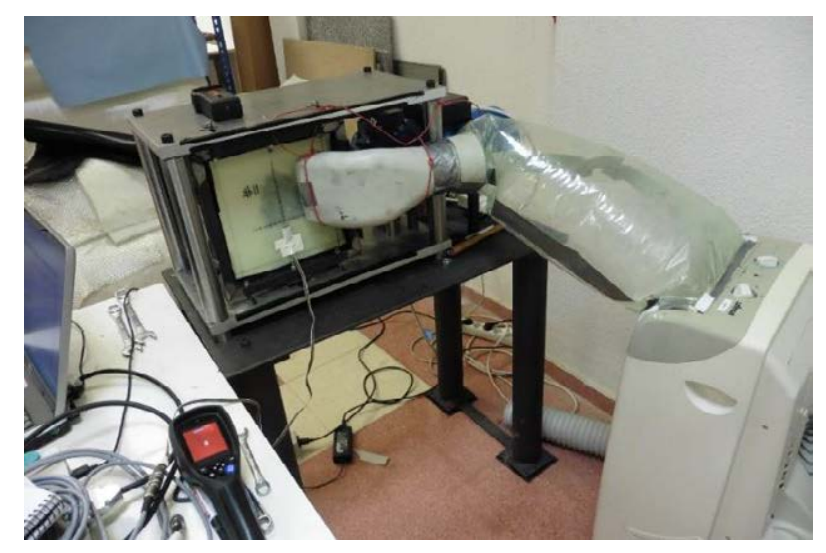

Figura 34 Sistema de refrigeración del panel 


\subsection{Evaluación del daño en los paneles impactados}

\section{$\underline{\text { Inspección con tintas penetrantes para observación con luz fluorescente }}$}

Para este ensayo, los paneles en la zona del impacto se cortaron de 60 x $60 \mathrm{~mm}$ y se perforaron con taladro con una broca de $0.5 \mathrm{~mm}$, con el propósito de sumergirlos en un líquido penetrante fluorescente para que la tinta penetre por las delaminaciones interlaminares e intralaminares y puedan ser observados bajo la luz fluorescente. En la Figura 35 se observan los paneles cortados luego de ser sumergidos en el líquido penetrante.

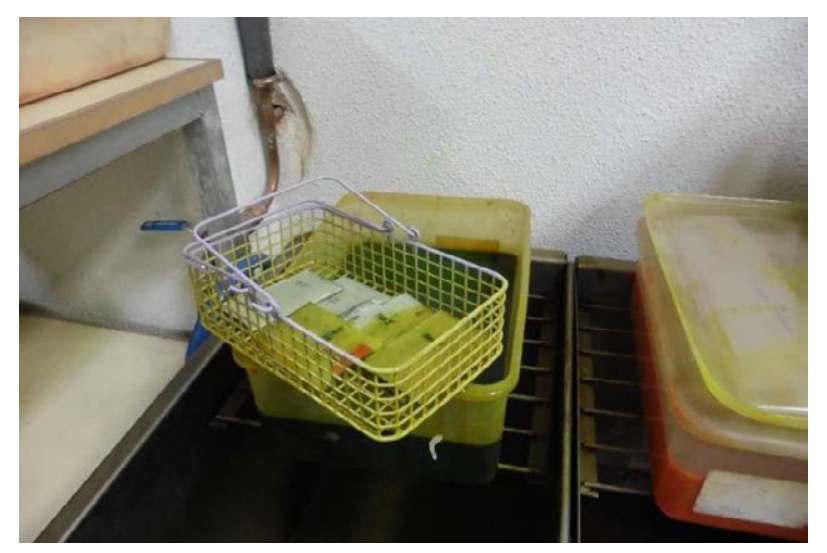

Figura 35 Equipo para líquidos penetrantes

Luego de ello se sumergieron en un líquido solvente que retira la tinta del exterior, y no tiene la capacidad de penetración. Se debían lavar con abundante agua para luego ser expuestos a la luz fluorescente, en la cual se puede observar como la tinta ha penetrado y ha dejado marcada las roturas y fallas del material en el interior. En la Figura 36 se observa un panel impactado bajo la luz fluorescente.

Con un equipo de disco fino de diamante, se procedió a cortar las secciones trasversales de las muestras en la zona del impacto, El equipo empleado que se observa en la Figura 37, lubrica con aceite el corte, con el propósito de que no se produzcan quemaduras en el corte y no se arrastre mucho material del compuesto, y las secciones puedan exhibirse en la luz fluorescente. 


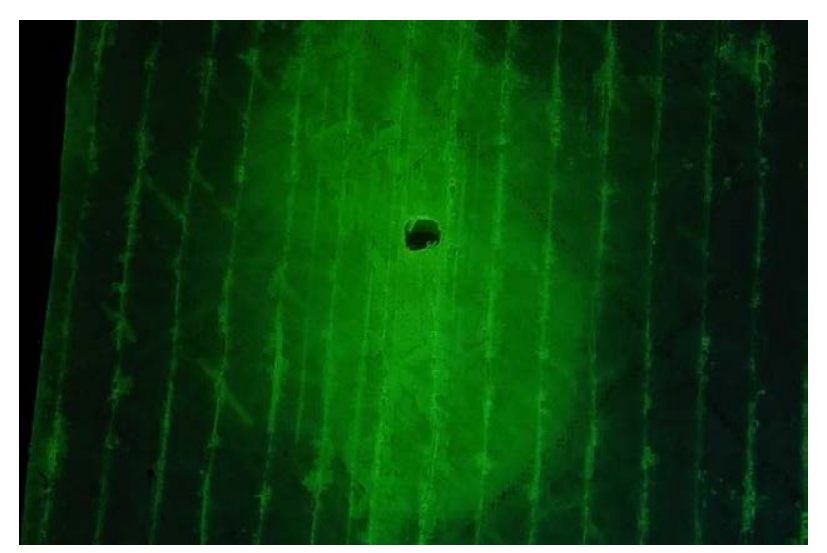

Figura 36 Panel observado bajo luz fluorescente luego de la aplicación de la tinta penetrante

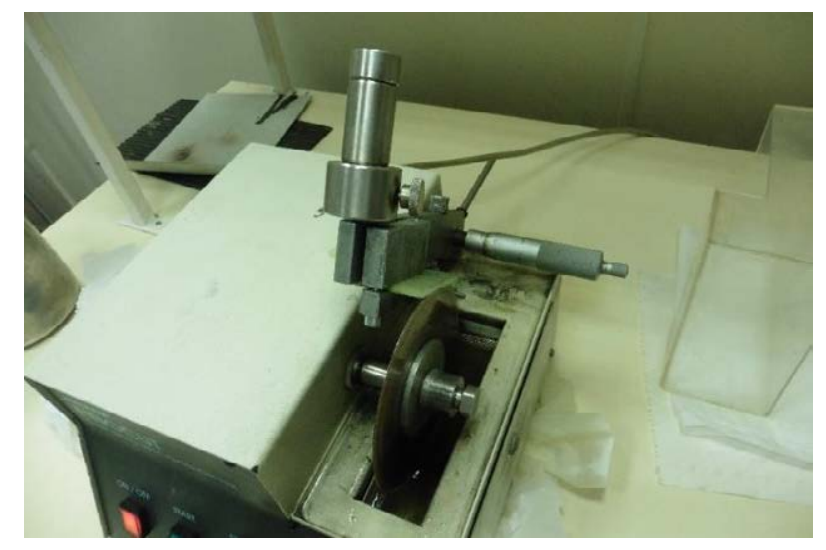

Figura 37 Equipo de corte con diamante lubricado con aceite

Finalmente, las secciones en forma secuencial se exponen a la luz fluorescente como se ve en la Figura 38, en la cual pueden ser fácilmente observables las delaminaciones para poder extraer los planos de daño intercapas. 


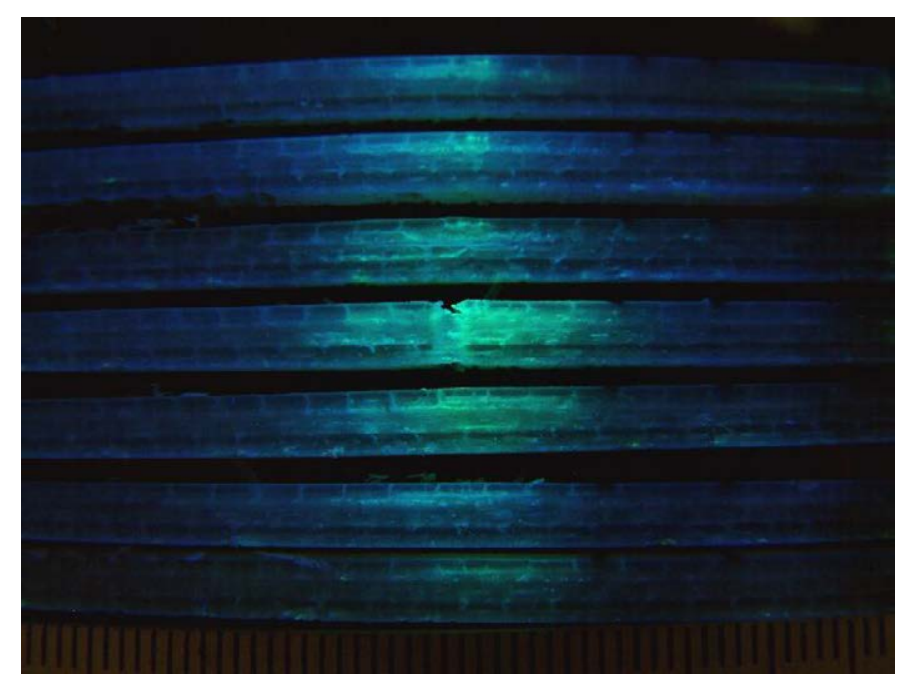

Figura 38 Secuencia de secciones que muestran la penetración de la tinta por capas bajo la luz fluorescente

Se empleó el software Rinhoceros, para dibujar en 3D las delaminaciones o separaciones entre las capas, de acuerdo con las líneas marcadas bajo la luz fluorescente en cada sección, en la Figura 39 , se observa a modo de resumen el proceso completo de la evaluación de daño realizada.

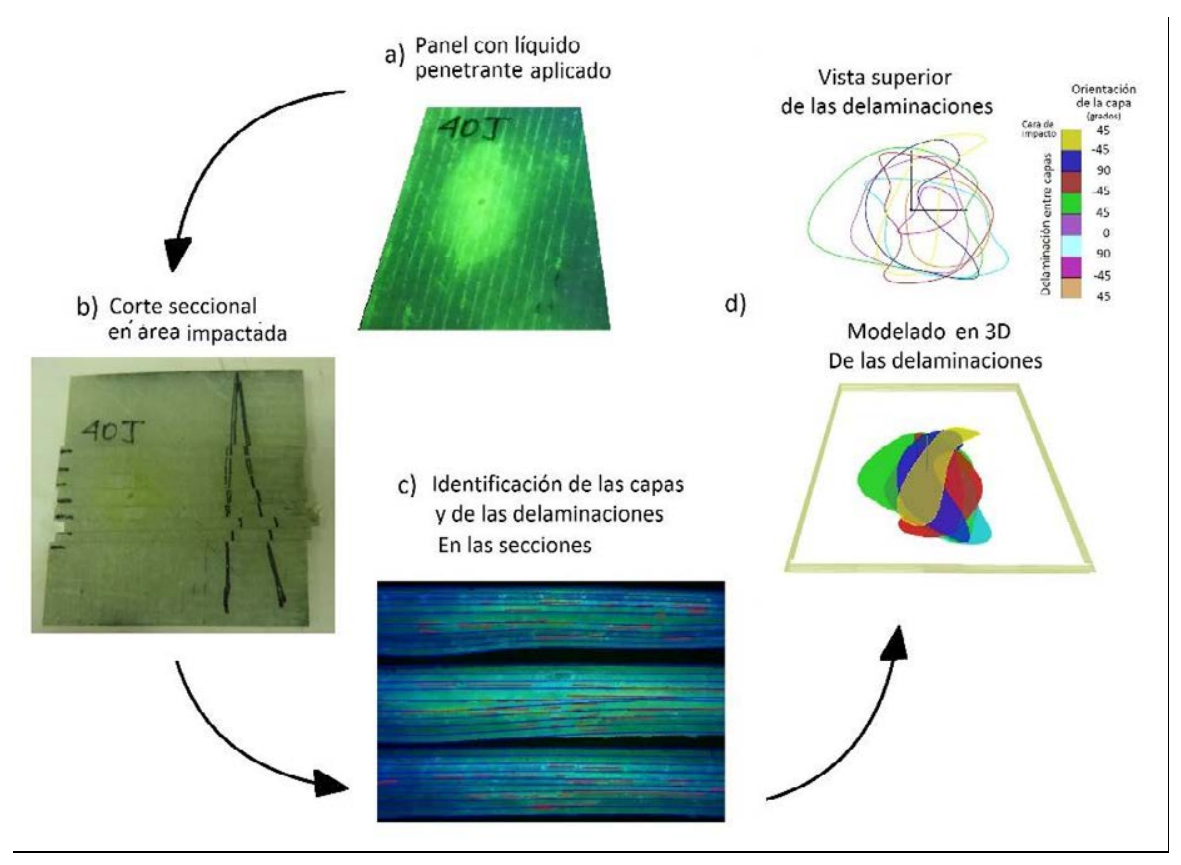

Figura 39 Secuencia de evaluación de daño por impacto 


\section{Microscopia electrónica de barrido (SEM)}

Para analizar el tipo de daño dentro de la matriz de los paneles, se realizó la microscopía electrónica de barrido (SEM) la cual es una técnica que se basa en el principio de la microscopia óptica en la cual se sustituye el haz de luz por un haz de electrones sobre una muestra bañada con una capa fina de carbón que le proporciona propiedades conductoras. El equipo empleado permitía observar hasta 3000 veces el tamaño de la muestra, y para ello era necesario cortar los paneles luego de los ensayos, para obtener secciones expuestas de las zonas dañadas. En la Figura 40 se observan 2 cortes extraídos de una probeta ensayada con el propósito de observar su microestructura para observar delaminaciones, porosidades, efectos de la temperatura y estado de curado de la resina.

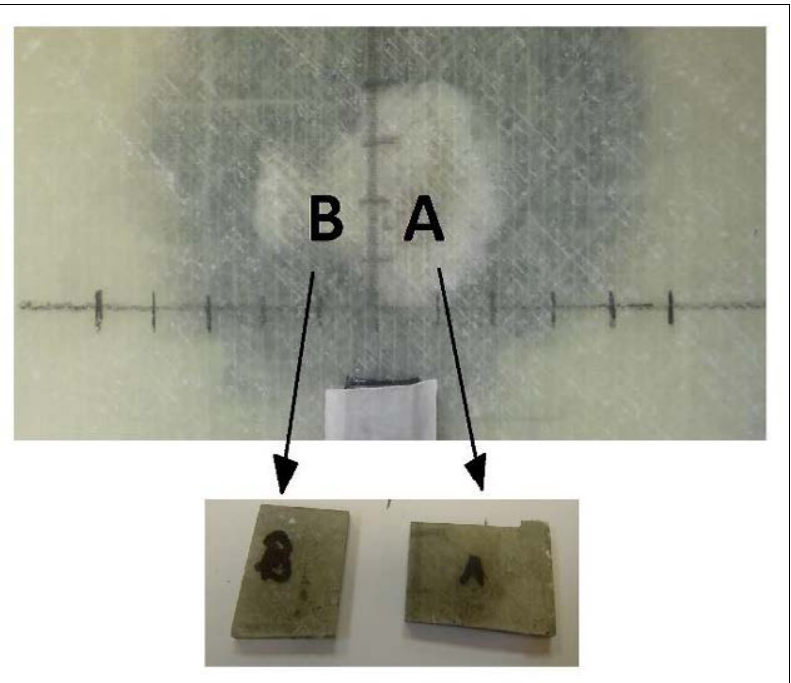

Figura 40 Probetas extraídas de un panel ensayado en la zona del daño 


\subsection{Determinación de la resistencia residual de los paneles impactados}

Para la realización de este ensayo, se fabricó un útil de compresión tras impacto tipo Airbus AITM0010 en los talleres del laboratorio de materiales de la UPM, el cual consta de 4 bloques que forman un marco. Estos bloques tienen guías laterales regulables, que sirven de alojamiento de las caras laterales del panel para evitar la deformación por pandeo.

Adicional, para que la cara superior de las muestras no se despostille y se deslice fallando en el extremo. Para prevenir este modo de falla erróneo, se colocó unas laminillas de acero con pegamento en el extremo superior y presente la falla por compresión en los extremos sino en la zona del impacto. El software instalado medirá la fuerza aplicada en Newtons versus la carrera en milímetros. Un panel montado sobre el útil se observa en la Figura 41.

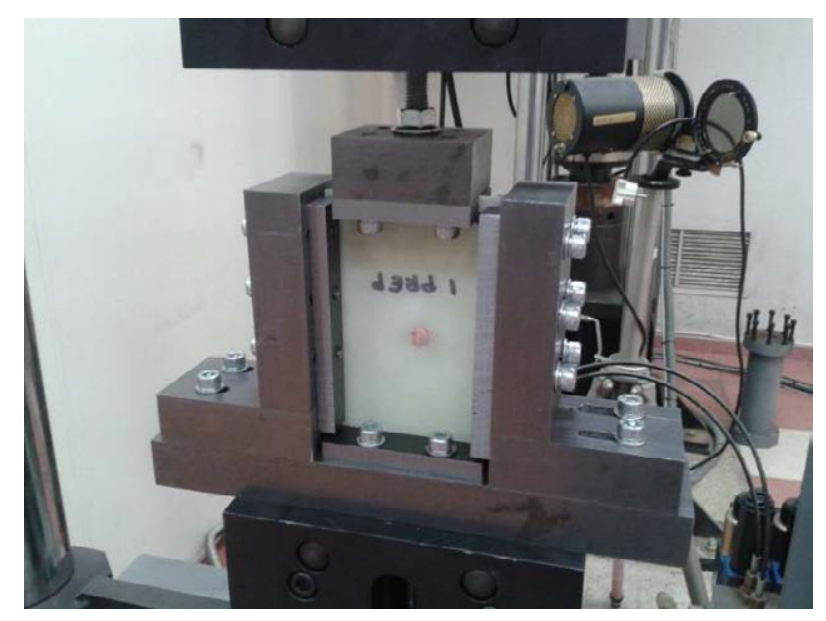

Figura 41 Útil fabricado para el ensayo de compresión restringido

Los resultados obtenidos por el software, se procesaron para obtener la pendiente de la curva antes del fallo y poder evaluar el cambio de flexibilidad de los paneles con el propósito de conocer la resistencia residual luego del impacto. 


\section{CAPÍTULO III RESULTADOS EXPERIMENTALES I: PANELES GFRP SIN MODIFICAR}

\subsection{Inspección mediante ultrasonido en inmersión mediante la técnica de pulso-eco y representación c-scan}

Las inspecciones realizadas, en el caso de los ensayos de impacto por caída de peso, mostraron la evolución del daño de una forma fácilmente identificable de acuerdo con las energías aplicadas. En la Figura 42, se observan los resultados de los ensayos de 10 a 60 joules, en la cual se muestran las imágenes a 32 bits de cada impacto, las imágenes binarias en blanco y negro que presenta claramente los defectos en el material y por el impacto, con su correspondiente evaluación de bits dañados del software ImageJ.

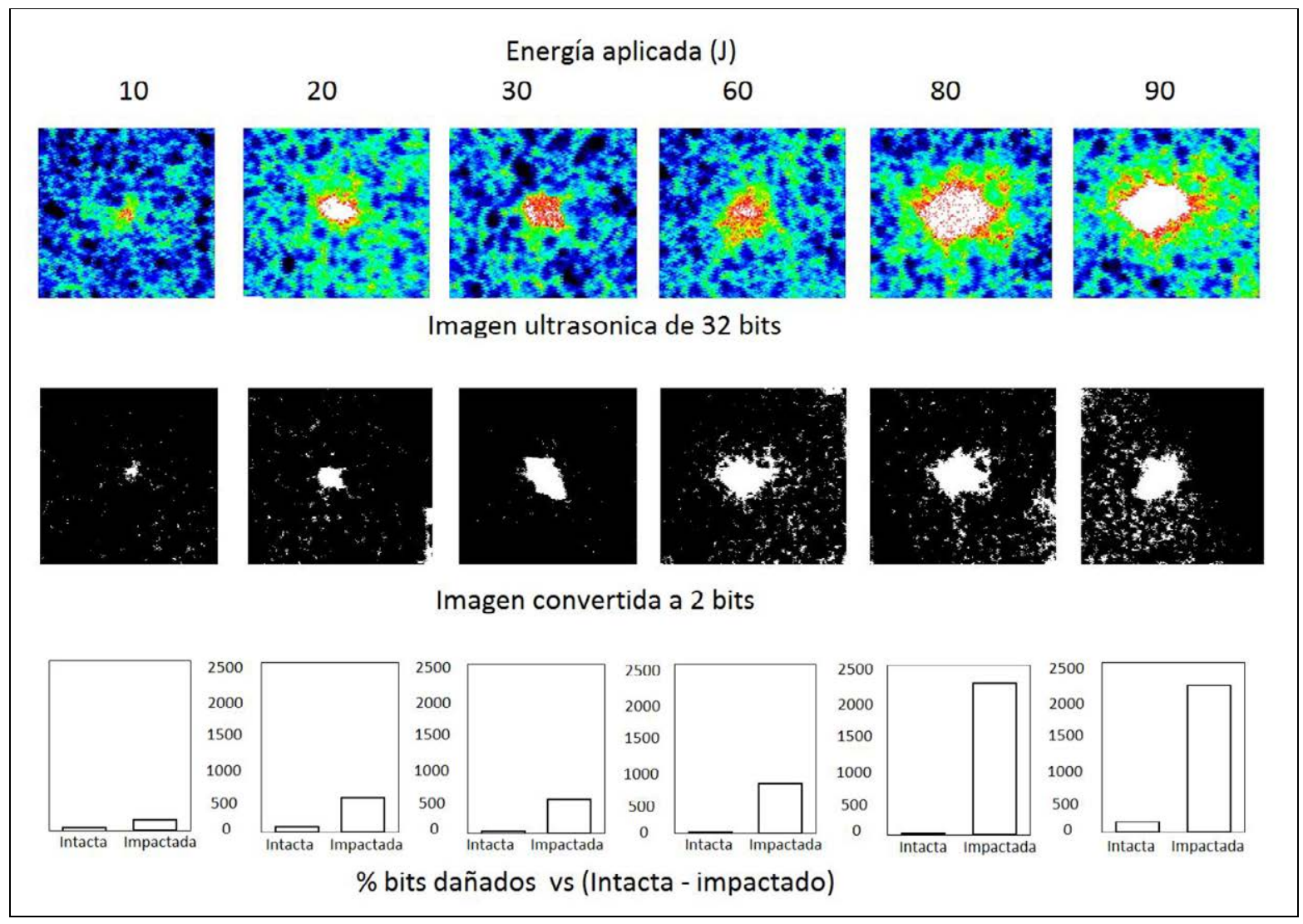

Figura 42 Evaluación ultrasónica del ensayo de impacto por caída de peso 
Si existe una delaminación se la ve reflejada en parte de la señal del haz que regresa marcando un defecto antes de atravesar la siguiente capa del laminado, de $1027 \mathrm{Db}$ que se emitieron para el caso de este material compuesto, aproximadamente un bajo porcentaje retornó. Aunque existió una una atenuación muy pronunciada dicha señal fue suficiente para poder ser detectada por el receptor de ultrasonidos. La onda reflejada y transmitida, si permitió empleando elevadas frecuencias e intensidades determinar las porosidades y las delaminaciones. En el ANEXO 2 se muestran los resultados de los ensayos de ultrasonido sumergido a los paneles impactados sin modificar realizados luego de su confección 


\subsection{Resultados de los ensayos de tracción y flexión de los paneles GFRP}

Cuando se realizó el ensayo, se cortaron 4 probetas ya curadas de un panel sin impactar en forma de tiras de $15 \mathrm{~mm}$ de ancho por $250 \mathrm{~mm}$ de largo para flexionarlas más allá de su límite elástico. En la Figura 43 se observa las probetas ya cortadas, las cuales dos corresponden al corte paralelo a la dirección inicial de $+45^{\circ}$ y dos al a dirección perpendicular a misma dirección inicial.

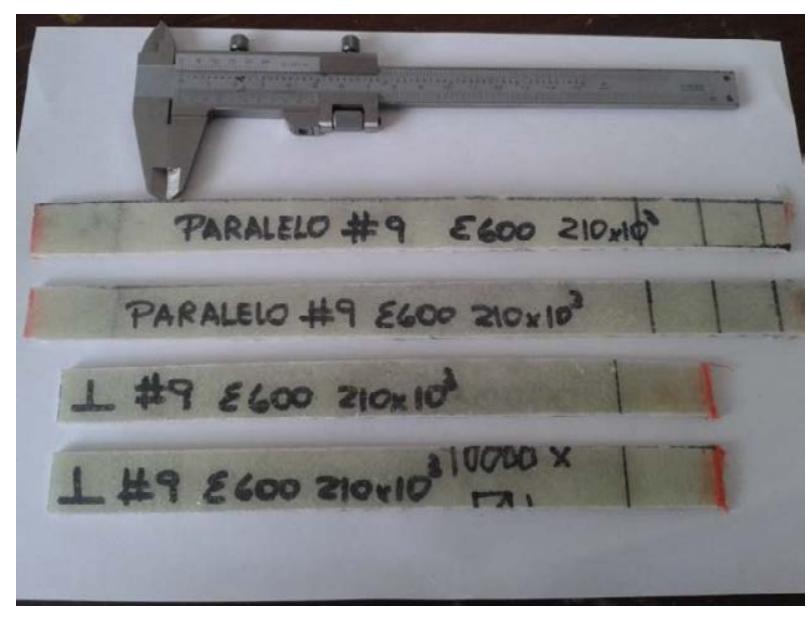

Figura 43 Probetas empleadas en el ensayo de flexión en tres puntos

Durante el ensayo, las probetas se flexionaron hasta lo máximo que permitió el útil tal como se muestra en la Figura 44 con una de las probetas flexionadas.

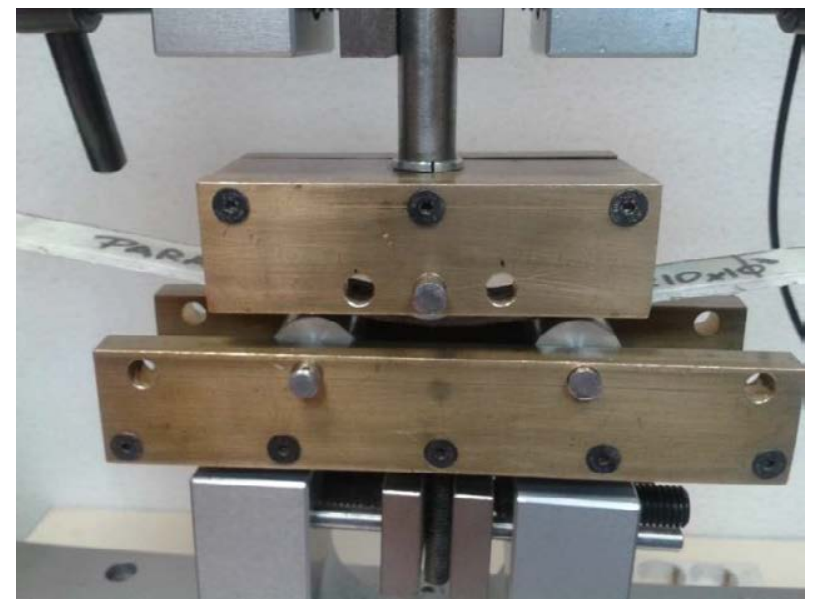

Figura 44 Probeta sometida a flexión 
De acuerdo a los cálculos realizados con la formulación, se observa en la gráfica de la Figura 45, que en $2314 \mu \mathrm{m} / \mathrm{m}$ se produce el primer cambio de pendiente, con lo cual a este valor de microdeformaciones el panel laminado seleccionado tiene el umbral de daño el cual se empleará para los ensayos de slamming.

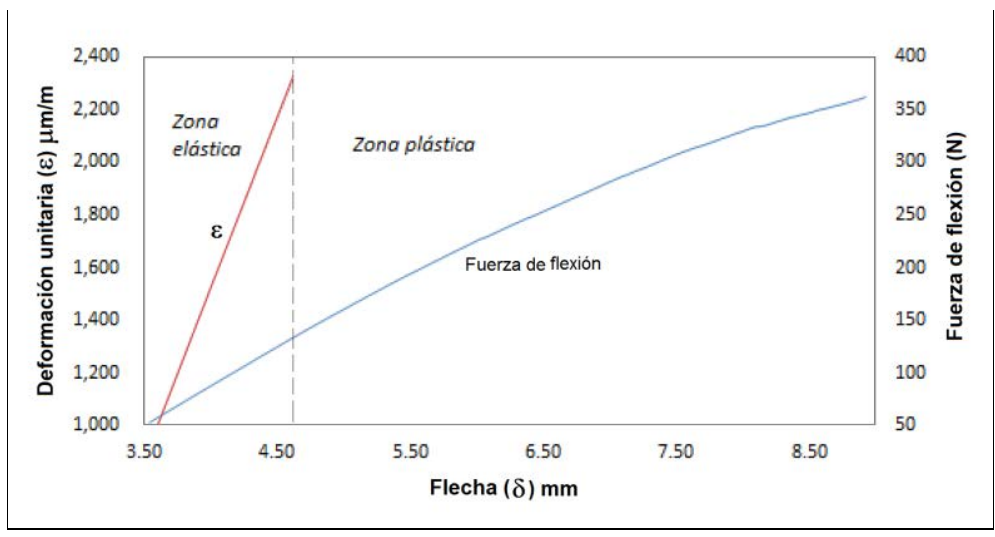

Figura 45 Resultados del ensayo de flexión zona elástica 


\subsection{Evaluación no destructiva del daño tras los impactos por caída de peso}

Se realizó un grupo de ensayos aplicando diferentes energías que van desde 10 a 60 joules con un solo impacto, y una prueba a 130 joules con 2 impactos. Las condiciones del ensayo fueron las indicadas en la Tabla 1 y se obtuvieron variando el peso a impactar y su altura, registrando las microdeformaciones con la correspondiente galga extensiométrica. La lectura de datos, el sistema antirebote para definir el número de impactos y el nivel de medición de altura, respondieron bien a las condiciones de los ensayos.

\begin{tabular}{|c|c|c|c|c|}
\hline $\begin{array}{c}\text { Valor nominal } \\
\text { de Energía }(\mathrm{J})\end{array}$ & $\begin{array}{c}\text { Altura del impacto } \\
(\mathrm{m})\end{array}$ & $\begin{array}{c}\text { Peso } \\
(\mathrm{kg})\end{array}$ & $\begin{array}{c}\text { Microdeformaciones } \\
\text { obtenidas } \\
(\mu \mathrm{m} / \mathrm{m})\end{array}$ & \# de impactos \\
\hline 10 & 0.18 & 5.549 & 502 & 1 \\
\hline 20 & 0.37 & 5.549 & 749 & 1 \\
\hline 30 & 0.55 & 5.549 & 1130 & 1 \\
\hline 40 & 0.73 & 5.549 & 1401 & 1 \\
\hline 50 & 0.36 & 13.829 & 1710 & 2 \\
\hline 60 & 0.44 & 13.829 & 1828 & 1 \\
\hline 130 & 0.97 & 13.829 & 3250 & 1 \\
\hline
\end{tabular}

Tabla 1 Condiciones de los ensayos de impacto por caída de peso a paneles no modificados

En la Figura 46 se observa la secuencia de daño en los paneles en la cara de impacto y en la cara contraria al impacto para las diferentes energías aplicadas a un sol impacto. Los impactos de acuerdo al tramado del preimpregnado de los paneles, presentan las direcciones de las manchas de las delaminaciones en las orientaciones principales de la urdimbre del laminado. 


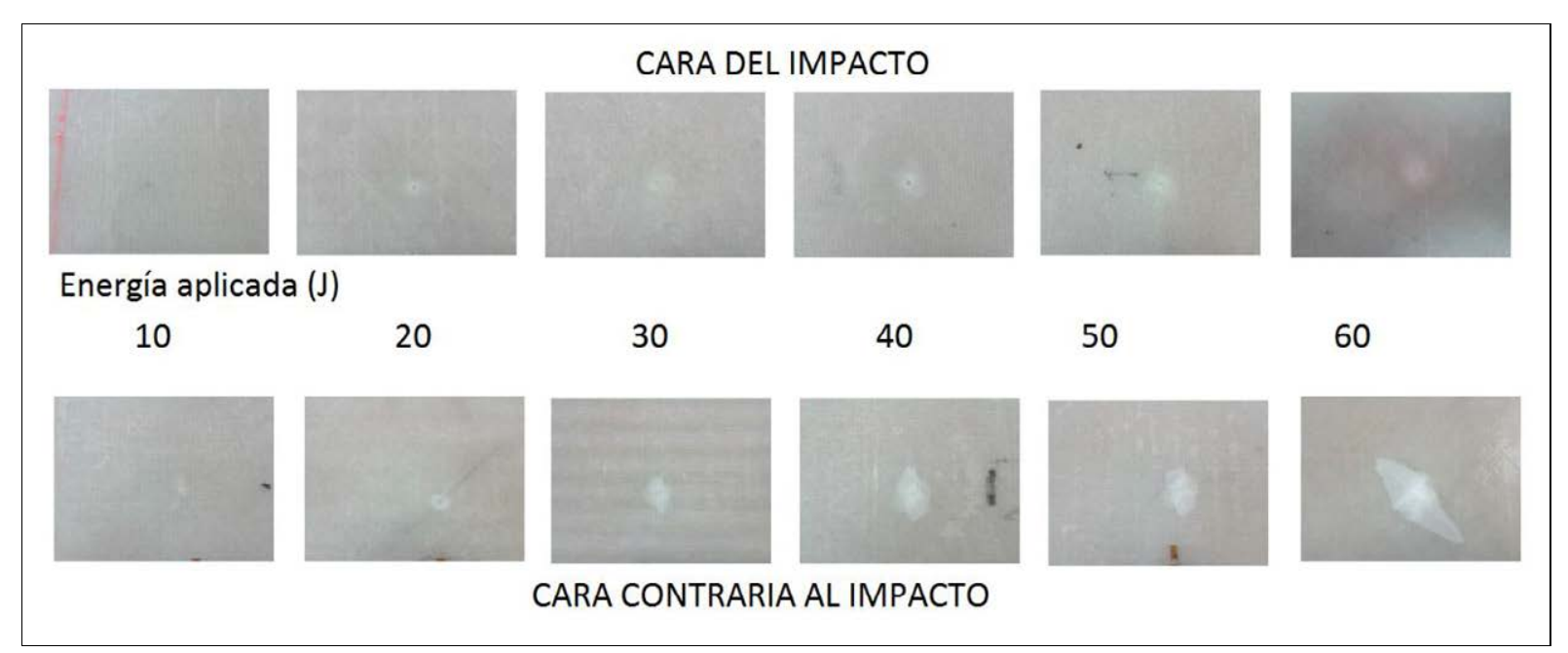

Figura 46 Ensayos de impacto por caída de peso por gravedad de 10 a $60 \mathrm{~J}$

En la Figura 47, se observan los resultados del ensayo de dos impactos seguidos a 130 Joules, en las cuales se aprecia que el primer impacto es completamente destructivo, ya que perfora el material sin llegar a traspasarlo, produciendo un daño considerable en la cara posterior la cual se delamina en gran forma sobre la dirección de la urdimbre. El segundo impacto hecho sobre el mismo punto, a la mista energía de 130 Joules, con el estado del daño del anterior impacto, es un golpe de penetración completa, e incluso se observa que el puntero de la máquina de caída de vertical se quedó prensado dentro del laminado y es fácilmente observable por los dos lados. La delaminación es considerable y el ensayo muestra pulverización de la matriz en los alrededores del impacto. 


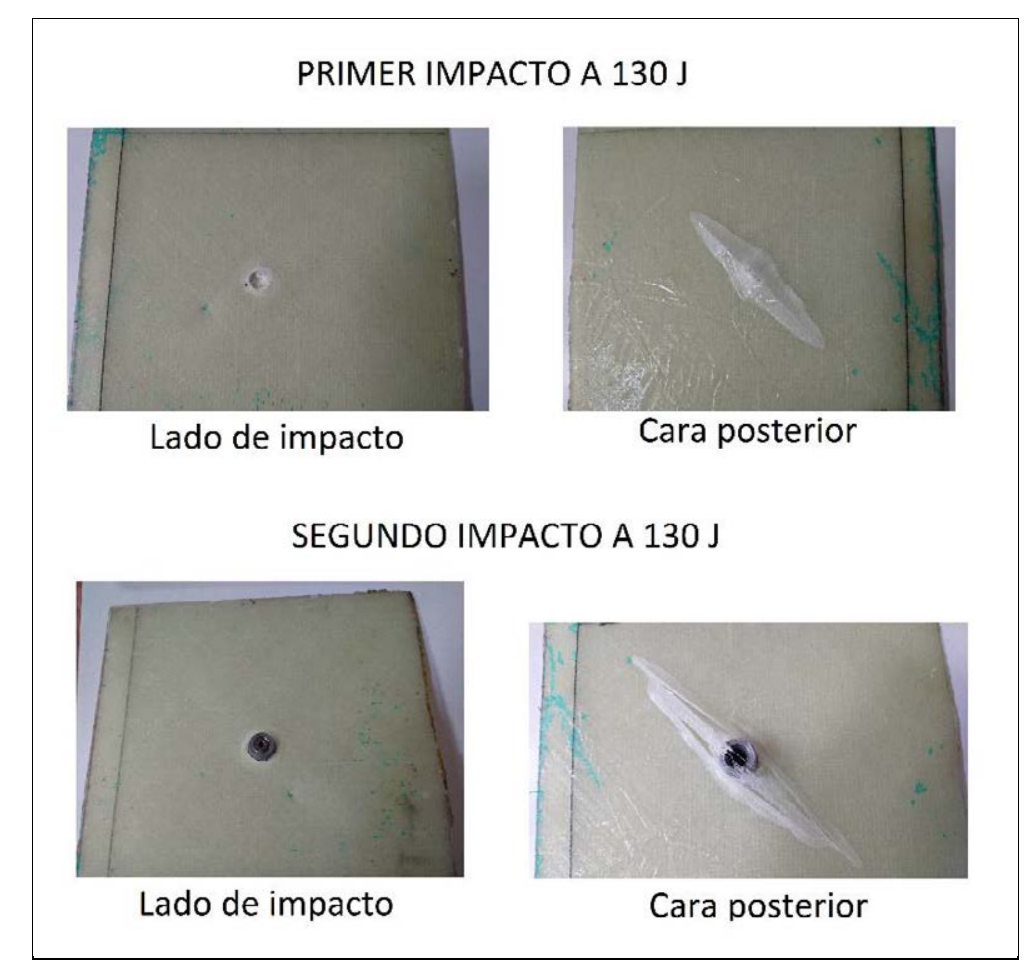

Figura 47 Panel sometido a dos impactos de 130 joules cada uno

Los datos generados por el gravitómetro, el cual entrega como información de las fuerzas G que van rompiendo el panel durante los instantes del golpe y luego durante la restitución, se obtuvieron con una frecuencia de $10^{4} \mathrm{~Hz}$. En la Figura 52 se observa el perfil de deformación de la aceleración entregada por el equipo para la prueba de $30 \mathrm{~J}$, y en ella se aprecian los picos de aceleración que se dan entre la rotura de cada una de las capas, es decir, como el peso va acelerando y desacelerando a medida que encuentra las orientaciones del laminado para luego decrecer mientras el panel comienza a relajarse a medida de que el peso impactador es empujado de regreso dando lugar al rebote. 


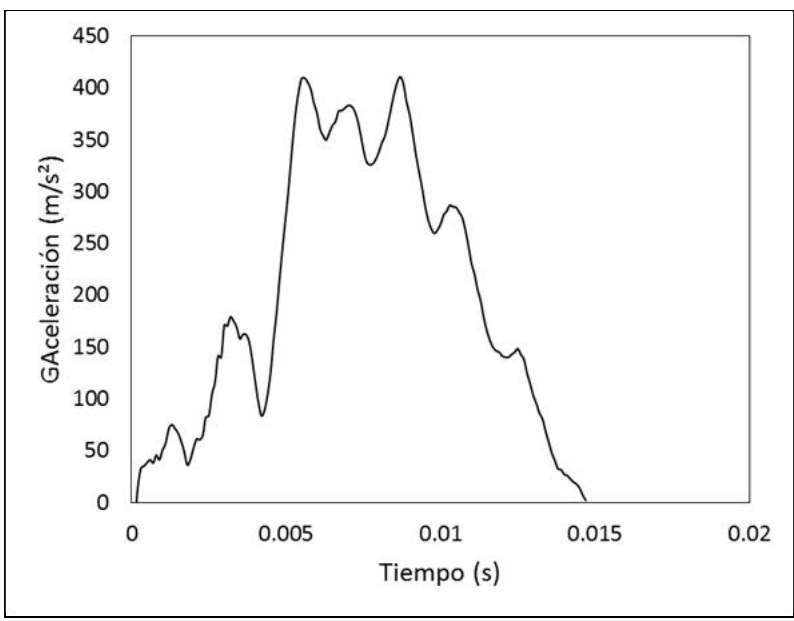

Figura 48 Aceleración $\mathrm{G}$ del impacto de $40 \mathrm{~J}$

El diagrama de fuerzas versus desplazamiento obtenido mediante el cálculo con la formulación matemática desarrollada, se observa como en la Figura 49, en la cual se aprecian las curvas de impacto a 30 y 50 joules. El impacto a baja energía tiene una curva con área interior mayor, representativo del valor de la energía devuelta ya que el panel es observado que tiene un dañó mucho menor que en el de 50 joules, en la cual el área de la curva Fuerza versus Desplazamiento para todo el evento es mucho menor.

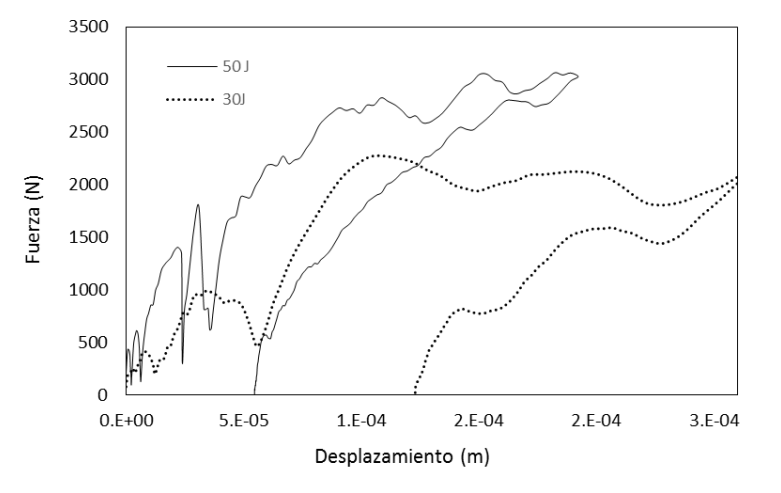

Figura 49 Fuerza versus desplazamiento de 30 y 50 joules

De acuerdo con los cálculos del manejo de resultados, todos presentados en el ANEXO 3, considerando la Energía Absorbida para todos los ensayos, se observa en la Figura 50 que muestran una tendencia no lineal a medida que aumenta la energía de impacto lo cual según la observación del tipo de daño presentado en los paneles está acorde a la curva. 


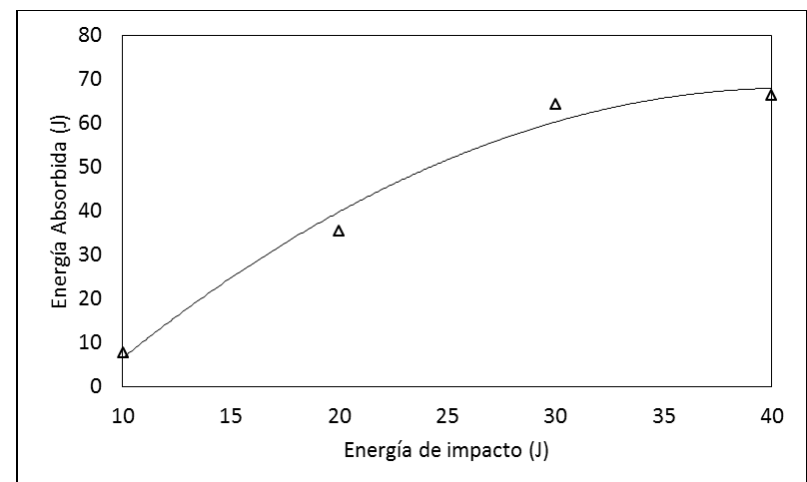

Figura 50 Energía de impacto vs Energía absorbida de los ensayos

El porcentaje de energía devuelta por los paneles de acuerdo con la energía de impacto aplicada, muestra según la Figura 51, que sobre los 30 joules la capacidad del material decrece en devolver la energía cinética impuesta y consecuentemente la va a consumir en mayor daño para el material.

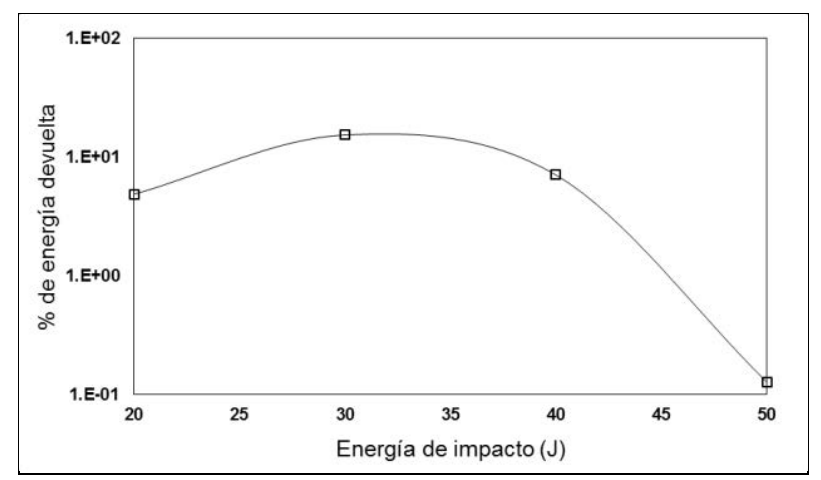

Figura 51 Energía devuelta luego del impacto vertical 


\subsection{Observación microestructural del daño en paneles GFRP no modificados tras el impacto por caída de peso}

A las probetas luego del impacto, se les realizó en ensayo con tintas penetrantes fluorescentes y su correspondiente corte seccional para exponerlo a la luz ultravioleta. En la Figura 52, se observa como ejemplo la placa de GFRP impactada a $40 \mathrm{~J}$, con la perforación del taladro para que ingrese el líquido penetrante. Esta perforación se ha realizado en el punto del impacto, con el propósito de que no afecte la visualización de la expansión del daño en el laminado.

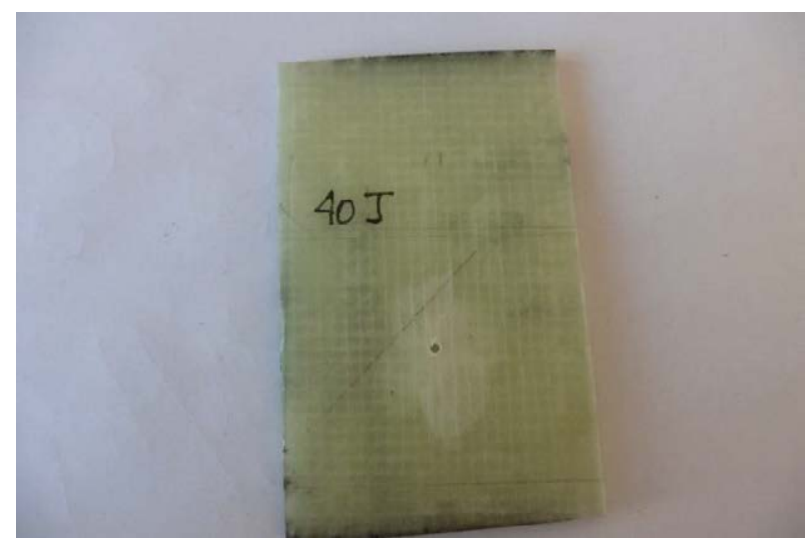

Figura 52 Probeta impactada a 40 joules con perforación para ensayo

En la Figura 53 se observan todas las probetas impactadas bajo la luz fluorescente, en las cuales se sombrean las delaminaciones. De allí en la Figura 54 se tienen las mismas probetas pero ya cortadas para la observación de la sección transversal

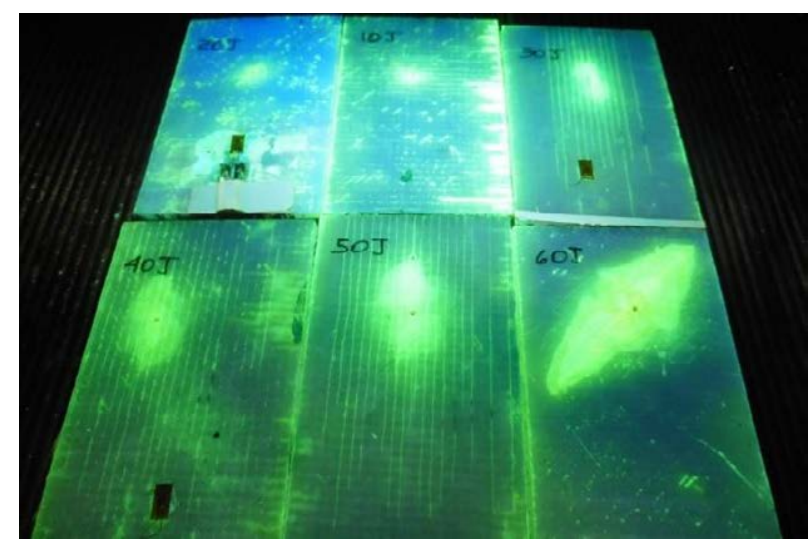

Figura 53 Probetas sometidas a luz fluorescente 


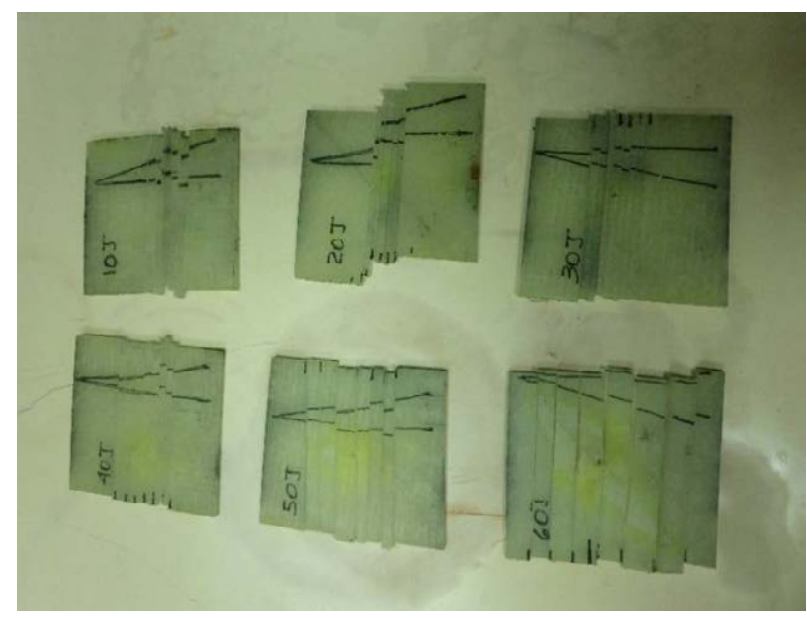

Figura 54 Probetas cortadas en laminillas para exposición de sección transversal

Luego del corte, se puedo observar tal como se ve en la Figura 55, que la tinta había penetrado en las grietas intralaminares verticales, y en las delaminaciones interlaminares. En ciertas secciones el corte estaba difuso por el efecto de la cuchilla de corte que había arrastrado penetrante a la matriz. Esta placa impactada a $40 \mathrm{~J}$, permite ver bien el daño en todas las capas del compuesto. Las marcas verdes verticales entre capas, corresponden a las roturas de la matriz dentro de cada una de las capas, mientras las líneas verdes horizontales son las delaminaciones en las cuales se aprecia la forma escalonada del avance del daño.

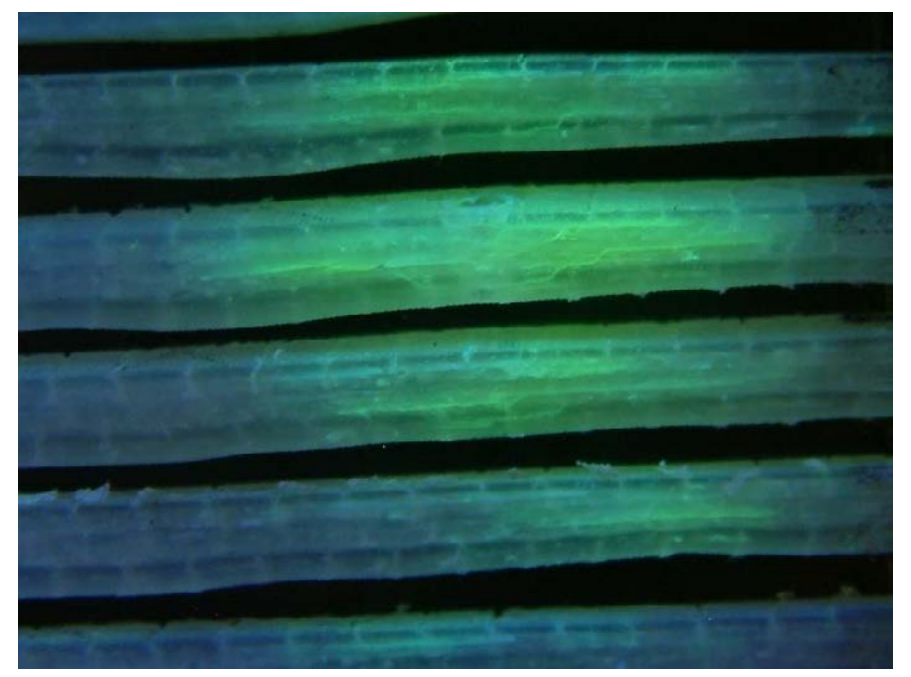

Figura 55 Secciones transversales bajo luz fluorescente de probeta impactada a 40J 
En el ANEXO 4 se observan todos los cortes de los impactos bajo la luz fluorescente de acuerdo a las energías de impacto. 


\subsection{Distribución del daño en los laminados. Análisis de secciones delgadas en la zona de impacto}

Con las secciones fotografiadas bajo la luz fluorescente, se dibujaron las delaminaciones con el programa Rhinoceros con el propósito de establecer la posición en el espacio 3D de las separaciones interlaminares. Se observa en la la Figura 56 el impacto a $40 \mathrm{~J}$ en el cual se han identificado las 9 capas del compuesto con líneas azules y con líneas rojas las delaminaciones marcadas por la tinta penetrante. Se hizo lo mismo para todos los cortes de sección del compuesto con lo cual se obtuvo el plano 3D de las separaciones entre capas luego del impacto.

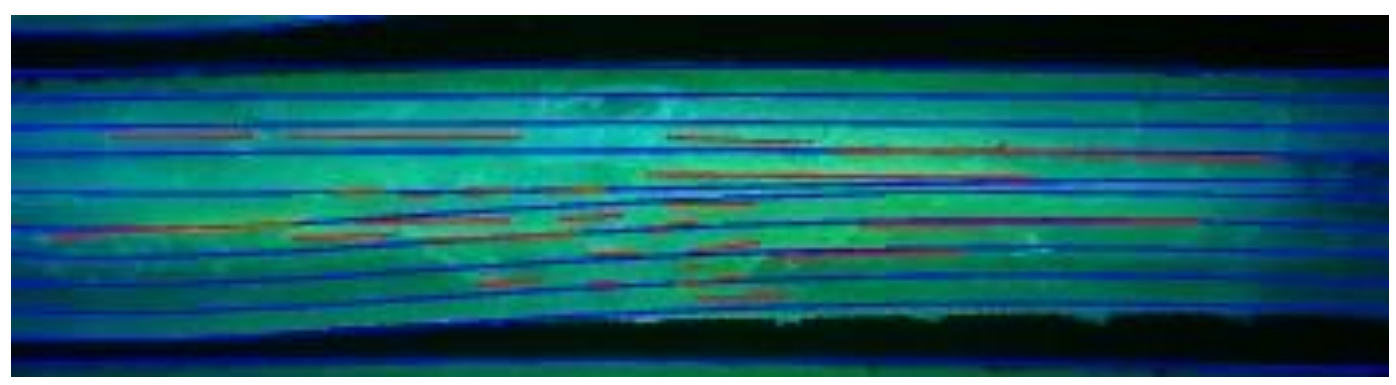

Figura 56 Detalle de una sección transversal de la probeta impactada a 40 J con las marcas de las delaminaciones

Para cada panel, se dibujaron las capas en 3D, tal como se observa en la Figura 57, en la cual se tiene en a) la perspectiva en 3D de las capas, siendo la cara de impacto la superior. En b) se tiene el plano de vista superior, en la cual se observan todas las capas, la cual tiene una figura similar a la observada en los paneles bajo la luz fluorescente antes del corte. El ejemplo mostrado corresponde al panel de $40 \mathrm{~J}$.

En el ANEXO 5, se presentan todas las vistas en plano y 3D de los impactos realizados de 10 a 60 joules. Estos planos de delaminaciones, se relacionaron con las curvas típicas de la Fuerza versus desplazamiento registradas durante las pruebas de impacto, de acuerdo con el espesor seleccionado de 9 capas. Se observa en el caso de la Figura 58 y Figura 59 correspondientes al ensayo de $30 \mathrm{~J}$ y $50 \mathrm{~J}$ respectivamente. Se observan las oscilaciones dinámicas durante el impacto, así como también caídas repentinas de carga durante el inicio y la propagación del daño las cuales tienen un intensidad que va relacionada con el tamaño de la delaminación y se presentó en forma de diamante 
en cada uno de los paneles ensayados. Se han identificada los picos que corresponden a la variación de la fuerza para delaminar cada una de las capas.

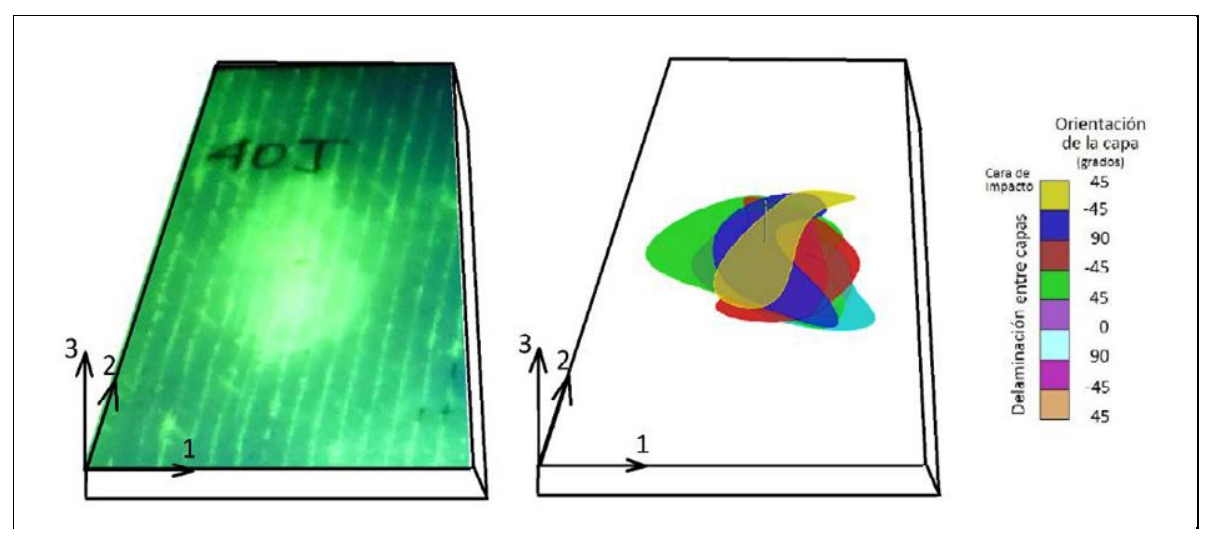

Figura 57 Planos de las delaminaciones para la probeta impactada a 40J

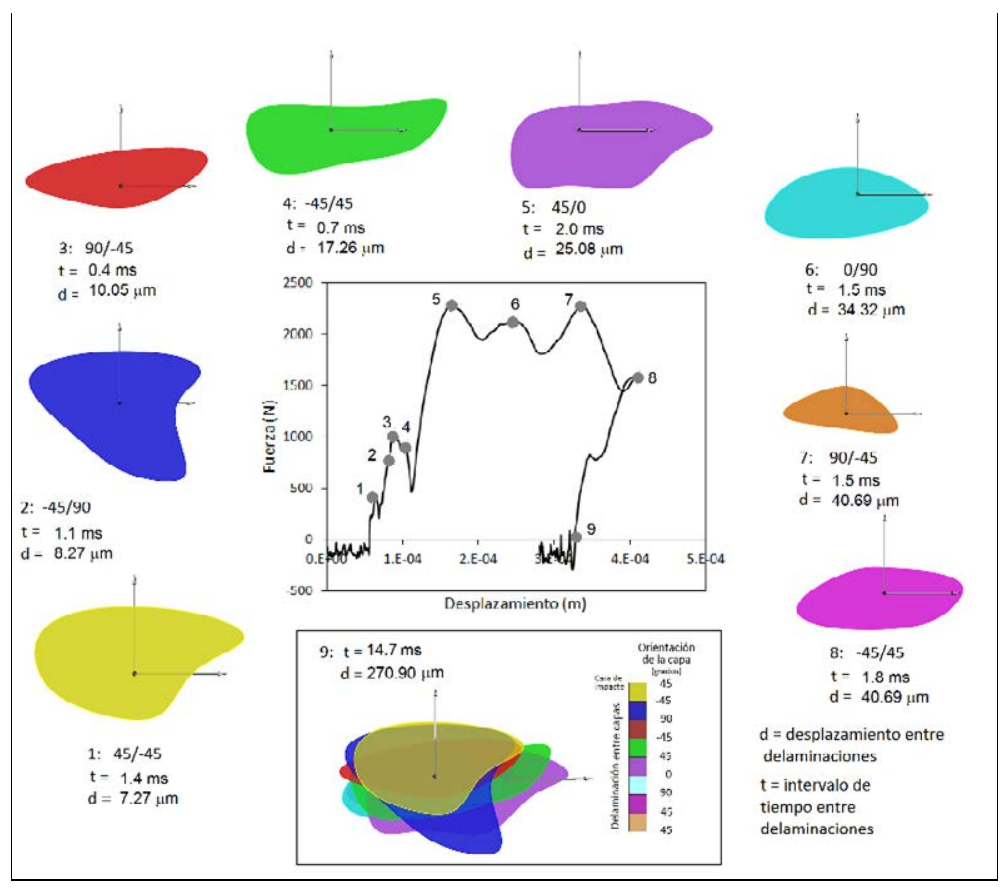

Figura 58 Plano de delaminaciones a 30 joules comparado con la fuerza vs desplazamiento 


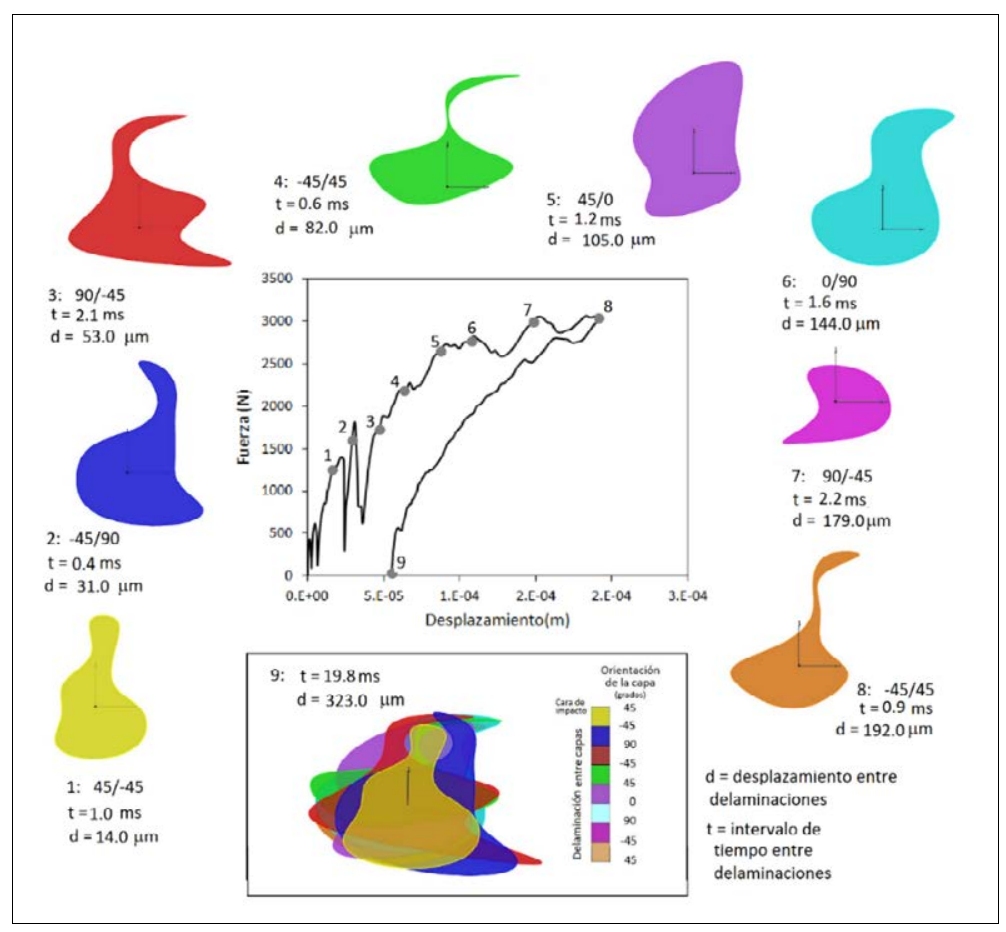

Figura 59 Plano de delaminaciones a 50 joules comparado con la fuerza vs desplazamiento 


\subsection{Evaluación no destructiva del daño a lo largo de los ensayos de slamming, en función del número de impactos recibidos por el material}

Para el cálculo de las presiones de slamming empleando las reglas de clasificación ABS se consideró la embarcación cuyas características se muestran en la Tabla 2, y que corresponden a la condición crítica de operación a plena carga. Se consideró un estado de mar en la zona de operación de la nave en las Islas Galápagos ubicadas en el Océano Pacífico frente a las costas de América del sur en el Paralelo $0^{\circ}$, y que tiene olas de alcance de altura 1,5 a 1,8 m con frecuencias de 14 a 19 segundos de mar de fondo. Según el registro publicado en el web del Instituto Nacional Oceanográfico de la Armada - INOCAR, de la República del Ecuador para los meses de mayo a julio.

\begin{tabular}{|l|l|}
\hline Material & GFRP \\
\hline L (eslora) & $12400 \mathrm{~mm}$ \\
\hline$\Delta$ (desplazamiento) & $7700 \mathrm{~kg}$ \\
\hline $\mathrm{B}$ (manga) & $4000 \mathrm{~mm}$ \\
\hline T (ángulo de astilla muerta) & $4^{\circ}$ \\
\hline V (velocidad máxima) & $22 \mathrm{Kn}$ \\
\hline
\end{tabular}

Tabla 2 Características de la embarcación a condición de máxima carga

La presión máxima de diseño en el fondo de la embarcación resultó entre $1800 \mathrm{kN} / \mathrm{m} 2$ a 1050 $\mathrm{kN} / \mathrm{m} 2$ para los valores de astilla muerta de $14^{\circ}$ a $38^{\circ}$ respectivamente, a lo largo de la eslora de la sección media a proa. Cabe destacar que el valor de $38^{\circ}$ es mayor al máximo permitido por las ecuaciones de las reglas ABS y se ha tomado como frontera para presentar el rango de la escala de presiones de la nave.

Mediante el modelo FEM del panel se estimaron los valores de presiones y microdeformaciones equivalentes en los diferentes rangos de trabajo experimental del ensayo de Slamming. Se determinó que el intervalo de presiones en el cual se podía realizar los ensayos de acuerdo a la máxima y mínima microdeformación que se obtenía ajustando el panel a la máquina de reproducción era de 260 a $820 \mathrm{kN} / \mathrm{m} 2$. Se aplicó el mismo procedimiento para calcular la presión 
del umbral de daño, la cual se obtuvo de $358 \mathrm{kN} / \mathrm{m} 2$. En la Figura 60 se esquematiza la presión recomendada sobre el fondo de la embarcación, el ángulo de astilla muerta, el intervalo de presiones de ajuste de la máquina de slamming y la presión del umbral de daño. Estos valores se han representado medidos desde la sección media hacia proa de la embarcación seleccionada.

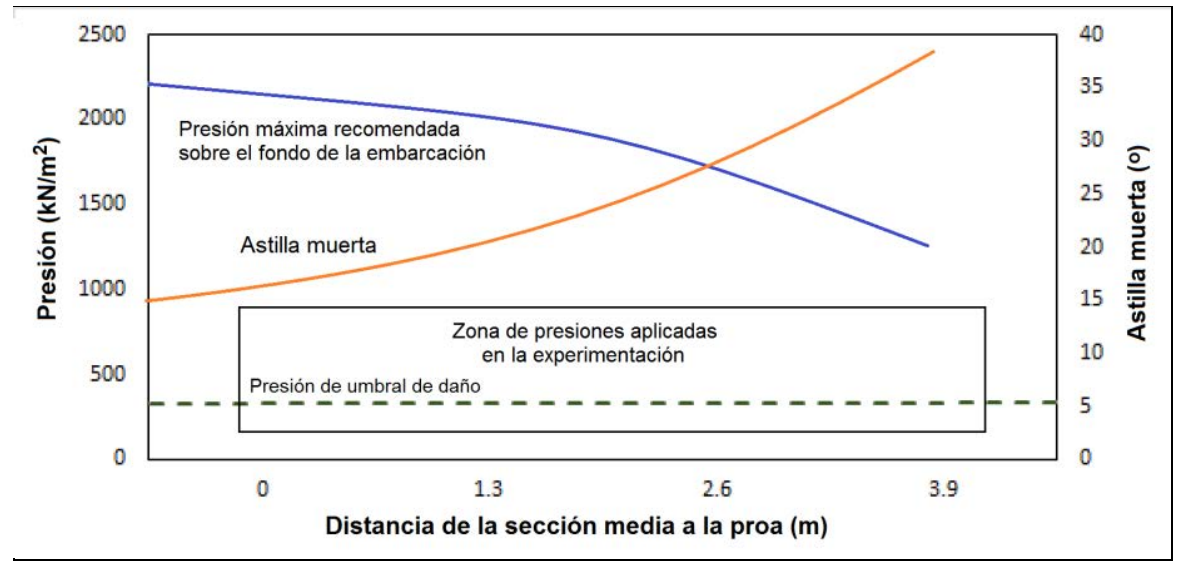

Figura 60 Presiones para el ensayo de slamming

De acuerdo al total de ensayos de slamming realizados, y a las evaluaciones no destructivas realizadas con ultrasonido sumergido, se tienen los grupos experimentales presentados en la Tabla 3, en la cual se observa el nombre del panel, la presión que se aplicó durante los ensayos con la leva, la cantidad de ciclos en los cuales se detuvo el ensayo para llevar el panel a la inspección ultrasónica y la cantidad de veces que se repitió esto.

\begin{tabular}{|l|l|l|l|l|}
\hline Panel \# & $\begin{array}{l}\text { Presión } \\
\text { aplicada } \\
\text { sobre } \\
\text { panel } \\
(\mathrm{kN} / \mathrm{m} 2)\end{array}$ & $\begin{array}{l}\text { Total de ciclos } \\
\text { aplicados }\end{array}$ & $\begin{array}{l}\text { Grupos de ciclos } \\
\text { de ensayo x } \\
\text { cantidad ejecutada }\end{array}$ & $\begin{array}{l}\text { Número de } \\
\text { ensayos de } \\
\text { ultrasonido } \\
\text { realizado en los } \\
\text { ensayos }\end{array}$ \\
\hline A & 263 & 210,020 & $\begin{array}{l}10000 \times 6 \\
30000 \times 3 \\
20000 \times 1 \\
40020 \times 1\end{array}$ & 11 \\
\hline B & 404 & 150,018 & $\begin{array}{l}10003 \times 6 \\
30000 \times 3\end{array}$ & 9 \\
\hline C & 633 & 181,916 & $\begin{array}{l}5000 \times 10 \\
10000 \times 4\end{array}$ & 16 \\
\hline
\end{tabular}




\begin{tabular}{|l|l|l|l|l|}
\hline & & & $40440 \times 1$ & \\
& & $51476 \times 1$ & \\
\hline D & 812 & 21608 & $7516 \times 1$ & 2 \\
& & & $2100 \times 1$ & \\
& & & & \\
& & & & \\
& & $5042 \times 1$ & $\times 1$ & \\
& & 21000 & $3000 \times 3$ & 2 \\
& 833 & 27000 & $5000 \times 2$ & \\
\hline F & 427 & & $1000 \times 2$ & 0 \\
& & & $2000 \times 1$ & \\
& & & $3000 \times 4$ & \\
& & & $4000 \times 1$ & \\
\hline
\end{tabular}

Tabla 3 Resumen de análisis con ultrasonidos realizados luego de los ensayos de slamming a paneles no modificados

A modo de ejemplo en la Figura 61 se observa para el panel C el resultado de la inspección ultrasónica realizado a $1.8 \times 10^{5}$ ciclos, en la cual se muestra el perfil de deformación que entrega la galga extensiométrica para la presión aplicada, y la evolución de todas las inspecciones con ultrasonido realizadas hasta ese número de ciclos.

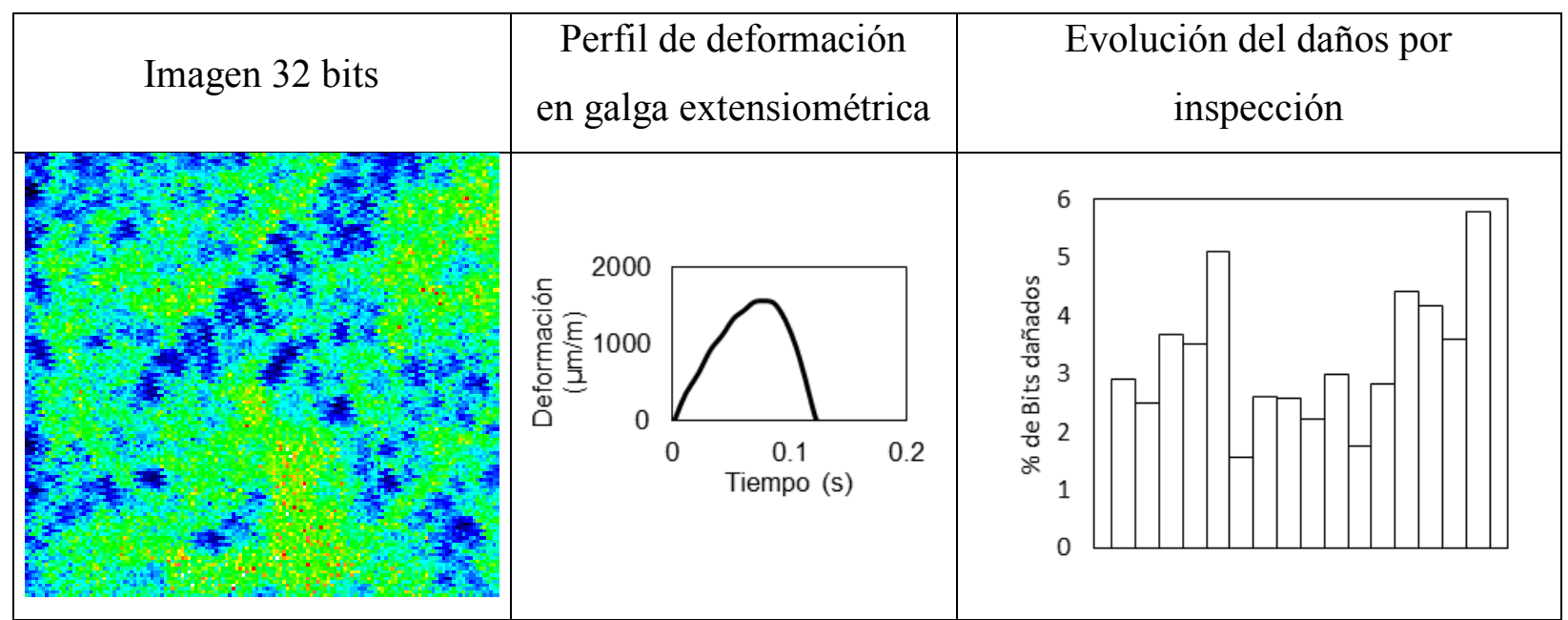

Figura 61 Resultado de Inspección con ultrasonido del panel C a los 1.8x10 ciclos de impacto con $1570 \mu \mathrm{m} / \mathrm{m}$ 
En el ANEXO 9 se adjuntan todas las caracterizaciones que se le hicieron a los paneles por ultrasonido, así como su análisis de imagen del porcentaje de bits dañado de acuerdo con los ciclos de impacto aplicados.

En la Figura 62 se observa el nivel de daño de los paneles impactados con golpe de slamming versus el número de impactos recibidos, de cada una de las pruebas de ultrasonido. Se observa que los paneles $\mathrm{A}$, B y C de ciclo de régimen de progresión de daño de altos ciclos, no superan el 6\% de los bits dañados. El panel D, pese a ser de régimen de progresión de bajos ciclos, el ensayo de ultrasonido no es representativo para el daño recibido puntual en la zona de contacto con la leva en relación con el área total de barrido como lo es el caso del panel E.

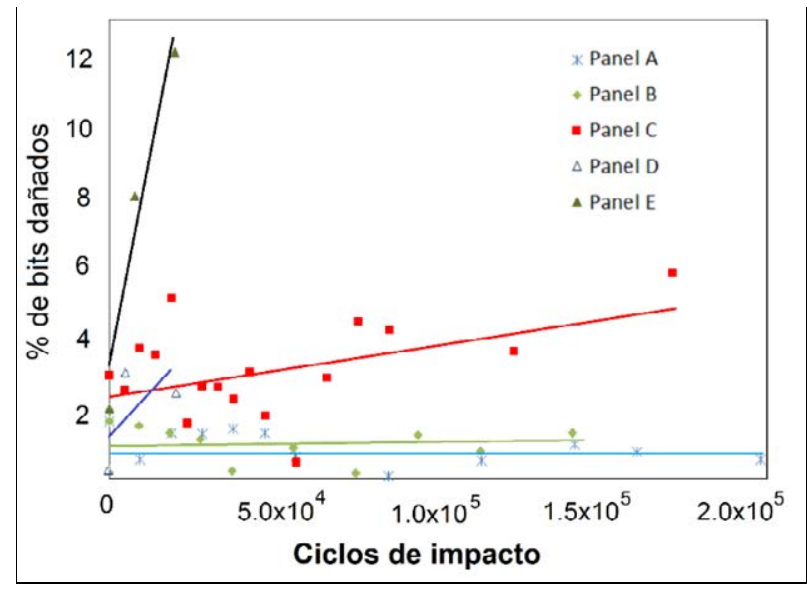

Figura 62 Comparación de porcentajes de bits dañados en paneles de preimpregnado sin modificar 


\subsection{Distribución del daño en los laminados tras los ensayos de slamming}

De acuerdo con los ensayos realizados, se tomaron en cuenta las siguientes consideraciones para realizar la reproducción de slamming.

\begin{tabular}{|c|c|c|c|c|c|c|}
\hline $\begin{array}{c}\text { Panel } \\
\#\end{array}$ & $\begin{array}{c}\text { Presión } \\
\text { aplicada } \\
\text { sobre el } \\
\text { panel } \\
\left(\mathrm{kN} / \mathrm{m}^{2}\right)\end{array}$ & $\begin{array}{c}\varepsilon \text { medida con } \\
\text { extensiométrica } \\
(\mu \mathrm{m} / \mathrm{m})\end{array}$ & $\begin{array}{c}\varepsilon \text { estimada } \\
\text { en el centro } \\
\text { del panel } \\
(\mu \mathrm{m} / \mathrm{m})\end{array}$ & $\begin{array}{c}\text { Frecuencia } \\
(\mathrm{RPM})\end{array}$ & Ciclos & $\begin{array}{c}\text { Tiempo } \\
\text { de } \\
\text { aplicación } \\
\text { de la } \\
\text { carga por } \\
\text { ciclo } \\
(\mathrm{mseg})\end{array}$ \\
\hline A & 263 & 650 & 1659 & 211 & 210,020 & 51.68 \\
\hline B & 404 & 1000 & 2660 & 219 & 150,018 & 66.10 \\
\hline C & 633 & 1570 & 4800 & 222 & 181,916 & 68.33 \\
\hline D & 812 & 2000 & 5250 & 310 & 21608 & 71 \\
\hline E & 833 & 2050 & 5340 & 309 & 21000 & 68.43 \\
\hline F & 427 & 1050 & 2690 & 310 & 27000 & 76.12 \\
\hline
\end{tabular}

Tabla 4 Condiciones de los ensayos de slamming a paneles no modificados

El cálculo de las presiones de slamming aplicadas se realizó de acuerdo con los resultados del modelo de elementos finitos relacionando las presiones máximas y mínimas del equipo con las deformaciones unitarias medidas por la galga extensiométrica, con lo cual se seleccionó valores cercanos al umbral de daño. Los paneles A, B y C, se ensayaron con ciclos del orden de $10^{5}$ y los paneles $\mathrm{C}$ y D, se ensayaron con ciclos del orden de $10^{4}$. Los intervalos de golpes de 5000, 10000 o más ciclos se definieron de acuerdo a como se fueron observando los resultados en las probetas. Por la limitación del par del motor solo se pudo ensayar en un rango de 160 a 310 ciclos por minuto su velocidad de rotación. La grasa de litio lubricó muy bien el panel y disminuyó la fricción con la leva, así mismo el método de refrigeración empleado ayudó a bajar la temperatura pero no fue suficiente.

El panel A que se ensayó con la presión bajo el valor del umbral de daño no presentó variaciones hasta los $1.5 \times 10^{5}$ ciclos, luego del cual se observó en la zona de presión de la leva la aparición de las micro grietas. Al final de la prueba a los $2.1 \times 10^{5}$ ciclos, el daño en el área de contacto llegó a representar el 15\% de la superficie. Las micro grietas tomaron la orientación de la penúltima capa 
del lado de tracción $\left(-45^{\circ}\right)$, alineándose y separándose las fibras de esta capa tal como se ve en la Figura 63. En la última capa del mismo lado correspondiente a la cara de tracción, se observó daño. El calentamiento de la leva y de la placa durante el ensayo, fue controlable y se mantuvo por el orden de $\operatorname{los} 55^{\circ} \mathrm{C}$

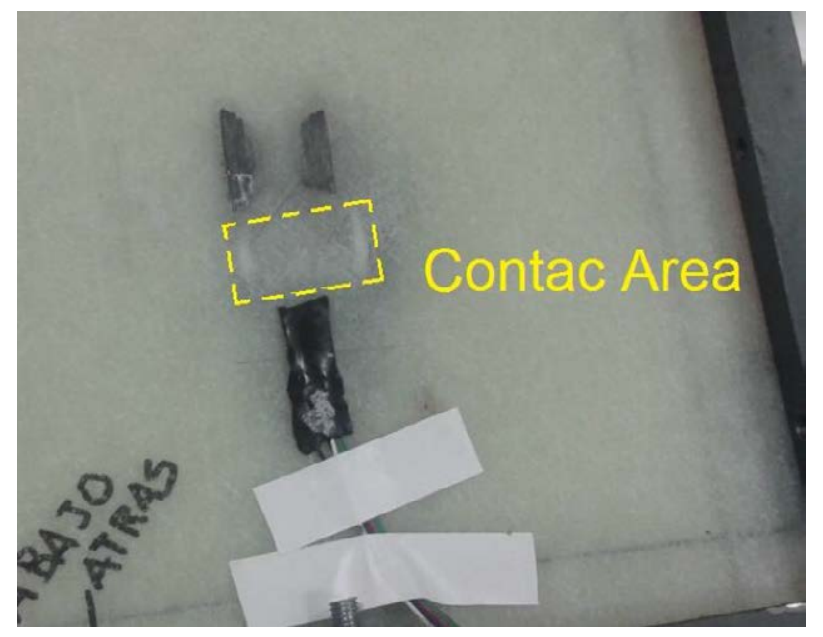

Figura 63 Daño del panel A a 2.1x105 ciclos de impacto con $\mathrm{P}=263 \mathrm{kN} / \mathrm{mm} 2$

El panel B que se ensayó con una presión $404 \mathrm{kN} / \mathrm{m} 2$, se obtuvo un daño correspondiente al 30\% de la superficie de contacto con $1.5 \times 10^{5}$ ciclos tal como se ve en la Figura 64.

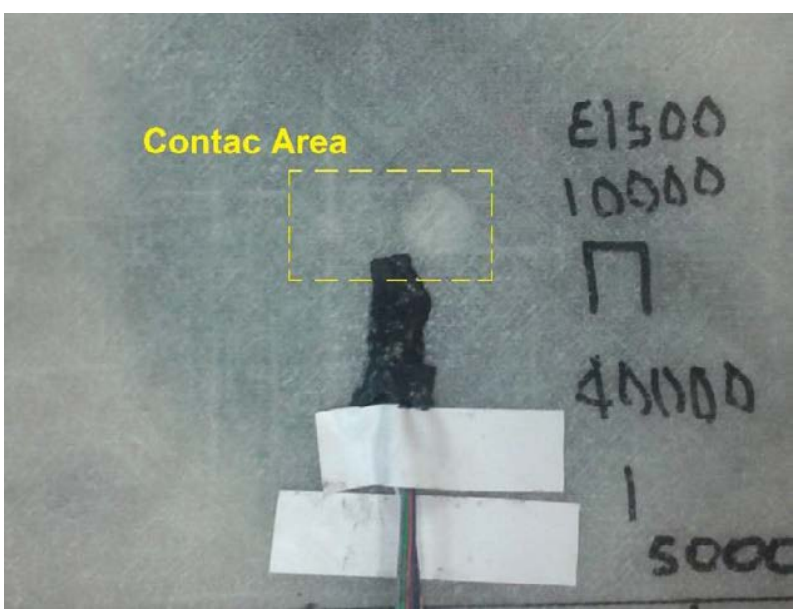

Figura 64 Daño del panel B a 1.5x105 ciclos de impacto con $\mathrm{P}=404 \mathrm{kN} / \mathrm{mm} 2$ 
En el panel C presentado en la Figura 65, se observó que las micro grietas se agruparon aleatoriamente en el centro de la zona de contacto y tomaron la orientación de la penúltima capa del lado de tracción $\left(-45^{\circ}\right)$ con $1.8 \times 10^{5}$ ciclos y el $25 \%$ de daño en la zona de contacto con la leva, con una temperatura promedio de $70^{\circ} \mathrm{C}$ durante el ensayo.

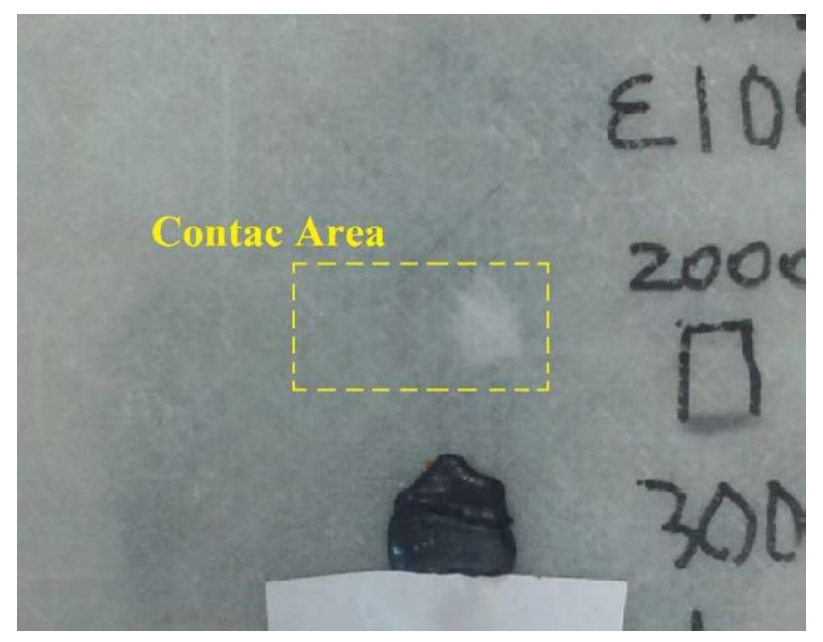

Figura 65 Daño del panel C a 1.8x105 ciclos de impacto con $\mathrm{P}=633 \mathrm{kN} / \mathrm{mm} 2$

Las reproducciones realizadas a los paneles $\mathrm{D}$ y E corresponden al orden de $10^{4} \mathrm{y}$ al ser un ensayo de bajo número de ciclos, permite seguir el proceso de observación fotografía del daño creciendo en forma continua.

El número de ciclos de cada grupo en estos paneles dependía de la temperatura de la leva, ya que por la fricción llegaba a los $70^{\circ} \mathrm{C}$. Como los métodos aplicados de refrigeración no fueron suficientes, había que detener el ensayo y esperar a que se enfríe la leva. El gradiente de elevación de temperatura varió entre $10^{\circ}$ a $20^{\circ}$ por minuto. La aplicación de paños húmedos fríos bajaba la temperatura del panel en el orden de $\operatorname{los} 20^{\circ} \mathrm{C}$ instantáneamente, lo que permitía ensayar unos ciclos más el panel sin detener el equipo de slamming.

El panel D, llegó al 85\% de daño en la zona del contacto con la leva. Se observó que las primeras micro grietas aparecieron a los 200 impactos, y ya eran muy visibles a los 1000 ciclos. Los primeros daños observados como leves sombras de color blanco, se ubicaron en las zonas donde 
topan los costados de la leva, para luego irse alineando hacia el centro de la superficie de contacto como se observa en la secuencia presentada en la Figura 66 que muestra la evolución del daño a medida que se incrementan los ciclos de golpes de slamming. La propagación del daño pudo ser observado en tiempo real a este nivel de presión, y se expandió primero por la penúltima capa de $-45^{\circ}$ laminada del lado de la galga. Al término del ensayo se constató que se habían formado ya roturas en el panel que pasaban de lado a lado en el laminado. En el panel E, se observó el mismo comportamiento del daño y se tuvo un daño de $88 \%$ en la zona de contacto con la leva.

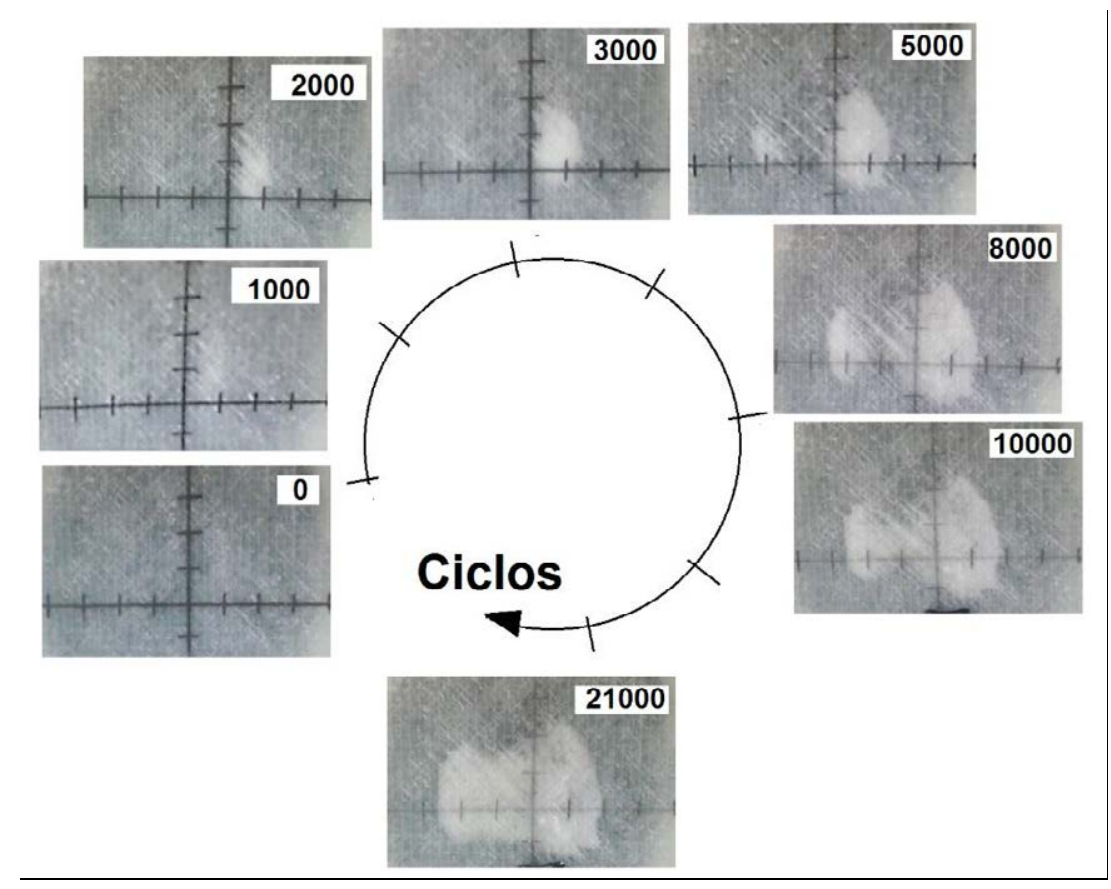

Figura 66 Evolución del daño del panel D hasta alcanzar 2.1 $110^{4}$ ciclos de impactos con $\mathrm{P}=812 \mathrm{kN} / \mathrm{m} 2$

De acuerdo con la relación de porcentaje de daño para el total de ciclos por panel en las diferentes presiones ensayadas, se observa en la Figura 67 la tendencia de daño que se obtuvo con el equipo de slamming. Para presiones mayores a $700 \mathrm{kN} / \mathrm{mm} 2$ el daño por ciclo que se impone al material tiene un régimen de progresión de daño de bajos ciclos o del orden de $10^{4}$ golpes de impactos de slamming. Para presiones menores a este valor, los ensayos son de régimen de progresión de daño de bajos ciclos o del orden de $10^{5}$ golpes. 


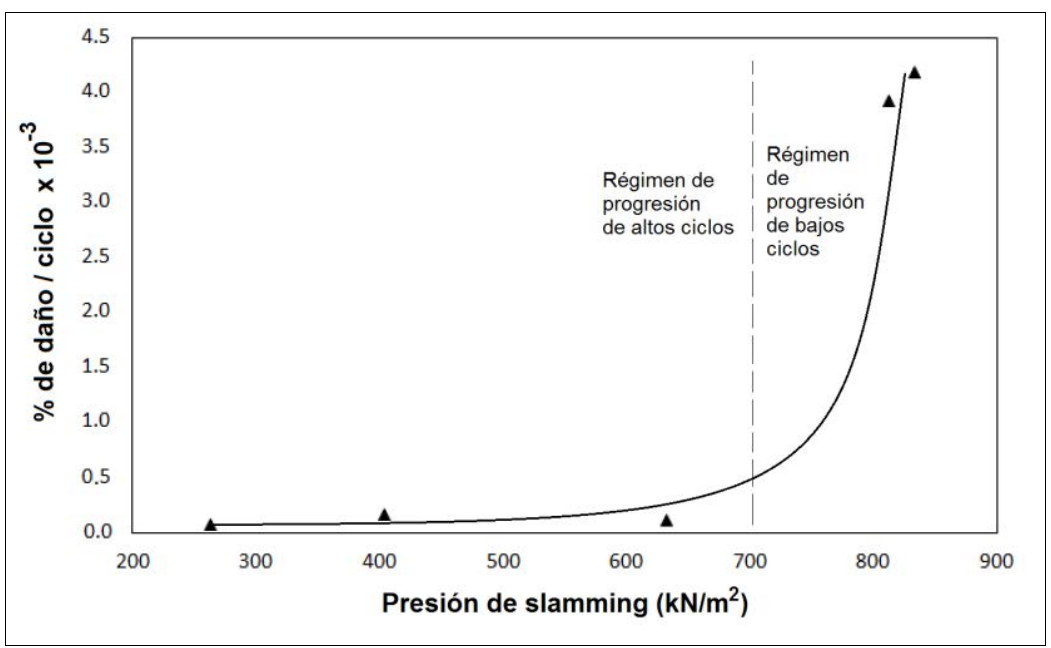

Figura 67 Porcentaje de daño/ciclo con las presiones aplicadas en los paneles

También se realizó un ensayo de bajos ciclos, en el cual se controló el cambio de flexibilidad del panel medido a través de la pendiente de entrada de la curva de la galga extensiométrica. Este ensayo se hizo con lecturas de galga a igual temperatura ambiente. Los bloques de ciclos se ejecutaban hasta que el panel sobrepasaba $\operatorname{los} 70^{\circ} \mathrm{C}$, y luego se dejaba enfriar todo el conjunto

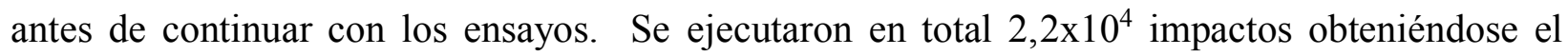
cambio de flexibilidad y el daño presentado en la

Figura 68. Cabe destacar que en este ensayo se aumentó la frecuencia con relación al ensayo de altos ciclos de igual microdeformación, cambiando considerablemente el modelo del daño. 


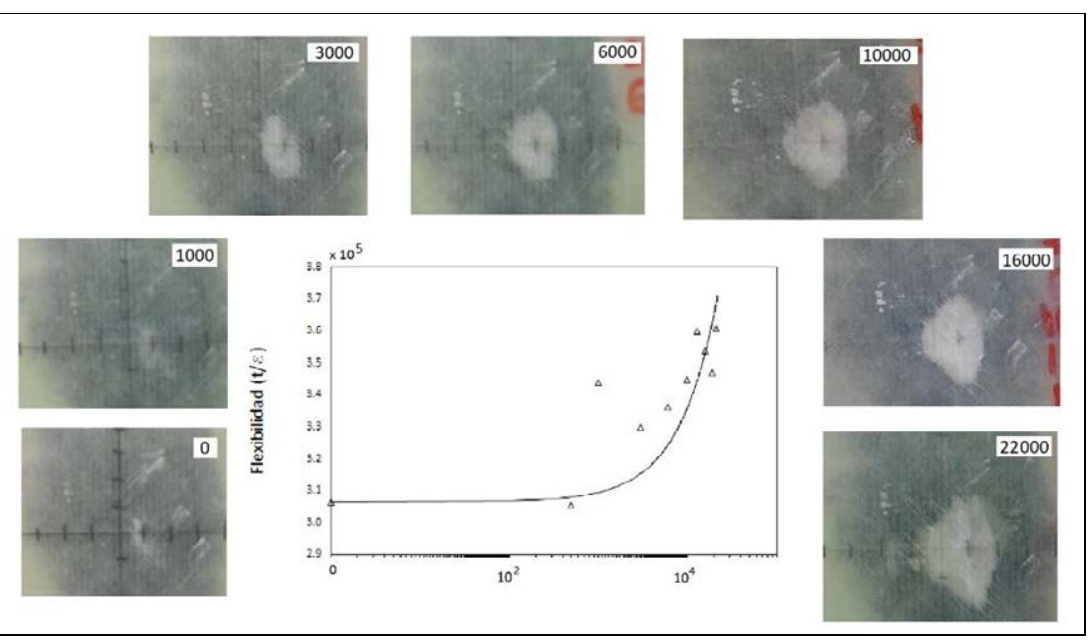

Figura 68 Evolución de la flexibilidad del panel F hasta alcanzar 2.2x10 ciclos de impactos con $\mathrm{P}=427 \mathrm{kN} / \mathrm{m} 2$ 


\subsection{Observación microestructural del daño producido por los impactos de baja energía en los ensayos de slamming}

De las muestras extraídas del panel C que se observaron con microscopía electrónica de barrido tal como se aprecia en la Figura 69, a 100 de aumento, se aprecia porosidad interlaminar que ha resultado en una delaminación por efecto de los impactos de baja energía. Aumentado a 300 veces se tiene una serie de poros interlaminares que van enlazándose unos con otros para formar una delaminación continua en algunas zonas bajo la acción de los impactos repetidos que reproducen el slamming. Observando por 1000 veces de aumento, se aprecia el detalle de un poro con fibras alineadas bajo una delgada película de polímero. Este mismo sitio a 3000 veces de aumento deja ver la sección transversal de tres fibras que afloran al exterior de la matriz polimérica, notándose que existe una buena adherencia en la interfase fibra-matriz.

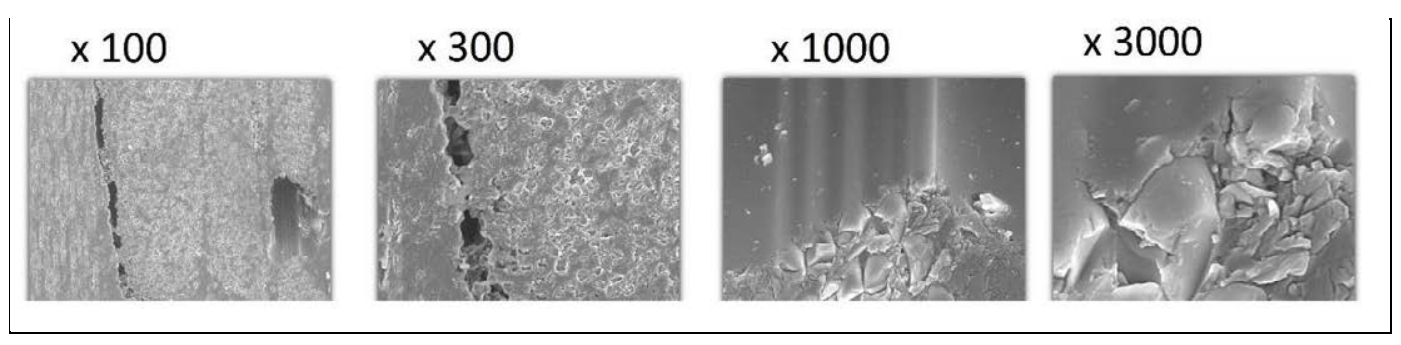

Figura 69 Microscopia del panel C a $1.8 \times 10^{5}$ ciclos de impacto con $\mathrm{P}=633 \mathrm{kN} / \mathrm{mm} 2$

En la Figura 70, observando de la muestra del compuesto en la capa con fibras paralelas al plano de corte, a 300 aumentos apenas se aprecia daño inducido por los impactos de slamming. La adherencia entre fibra y matriz ha soportado la energía de los impactos sin que se despeguen fibra y matriz a lo largo de la interfase. Aumentando esta zona por 1000 veces y aplicando el análisis de imagen EDS para detectar la distribución de Silicio, se apreciaron las distintas fibras presentes, incluso por debajo de la capa de polímero. A 2000 veces de aumento, se observaron dos fibras con matriz adherida y sin aparición de microgrietas o huecos debidos a daño alguno creado por los impactos 


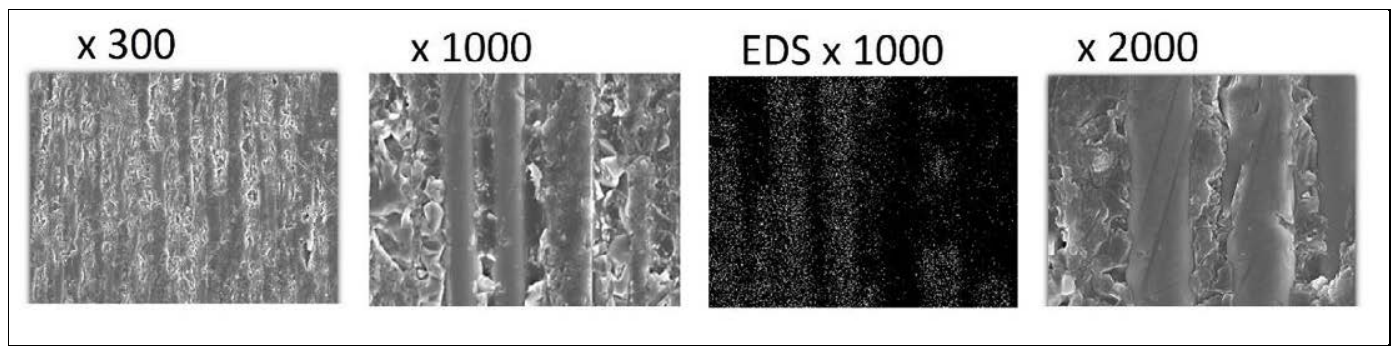

Figura 70 Microscopia del panel C a $1.8 \times 10^{5}$ ciclos de impacto con $\mathrm{P}=633 \mathrm{kN} / \mathrm{mm} 2$

En la Figura 71, en la cual se observó la capa de fibras orientadas perpendicularmente a la superficie de corte de la probeta, tanto a 1000 veces como a 2000 veces aumentada, no se observó aparición de zonas despegadas en la interfase entre la matriz polimérica y las fibras. De la imagen aumentada 2000 veces se seleccionó un área aplicar el análisis de imagen EDS y detectar la distribución de Silicio y observar las distintas fibras presentes.

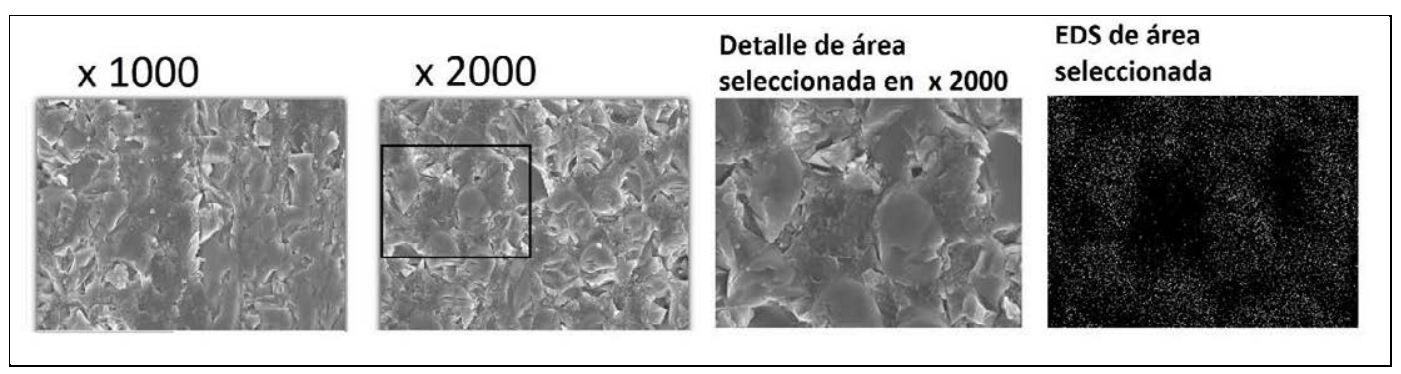

Figura 71 Microscopia del panel C a $1.8 \times 10^{5}$ ciclos de impacto con $\mathrm{P}=633 \mathrm{kN} / \mathrm{mm} 2$

De las muestras extraídas del panel D que se observaron con microscopía electrónica de barrido tal como se aprecia en la Figura 72, a 100 veces de aumento se aprecian varias láminas de material compuesto en la cara opuesta a la zona de impacto de la leva, en la cual hay porosidad intralaminar especialmente en la capa con fibras orientadas en dirección paralela al plano de corte. Prácticamente no se aprecia porosidad interlaminar. A 300 veces de aumento en la misma zona, se observan despegues en la fibra/matriz, porosidad intralaminar y microgrietas. No se aprecia daño en la unión entre las dos láminas del material compuesto. 


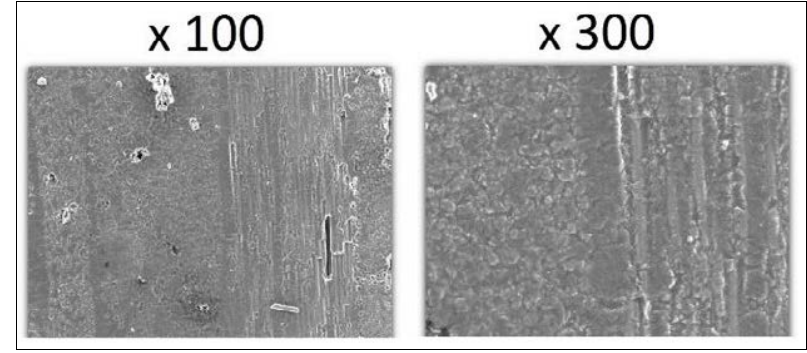

Figura 72 Microscopia del panel D a $2.1 \times 10^{4}$ ciclos de impacto con $\mathrm{P}=812 \mathrm{kN} / \mathrm{mm} 2$

En la Figura 73 la cual corresponde a la probeta de la zona más próximas a las de impacto de la leva, aumentado 100 veces se observa también algo de porosidad intralaminar y prácticamente nada de daño interlaminar. Se lo aumentó 300 veces para tener un detalle mayor, y a esta amplitud muestra una zona de separación entre la matriz polimérica y las fibras alineadas longitudinalmente en la imagen. Aumentado a 500 veces se apreció una curiosa estructura de la matriz polimérica. Aparecen arrugas, que pueden estar relacionadas con los mecanismos de deformación a las elevadas temperaturas que alcanza el material durante los ensayos. A 200 veces, la estructura de fluencia plástica de la matriz polimérica bajo la acción de los impactos repetidos aparece claramente y se observa cómo la matriz se ha separado a ambos lados de la fibra, dejando un hueco, pero sin llegar a desprender por completo.

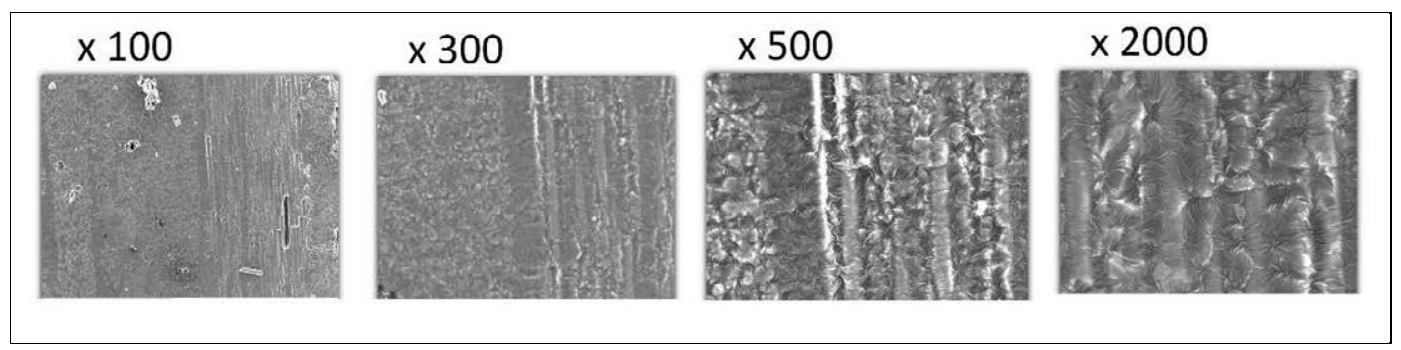

Figura 73 Microscopia del panel D a $2.1 \times 10^{4}$ ciclos de impacto con $\mathrm{P}=812 \mathrm{kN} / \mathrm{mm} 2$

Un detalle más con la estructura producida por la fluencia plástica de la matriz polimérica bajo la acción de los impactos de slamming se observa en la Figura 74. 


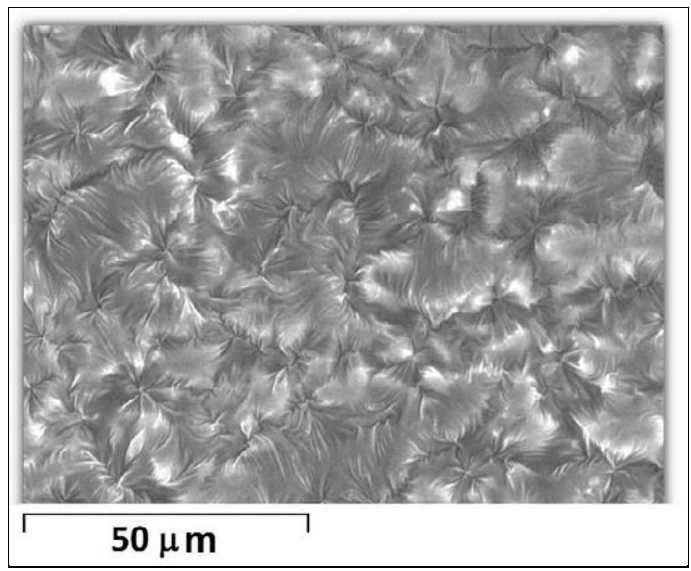

Figura 74 Microscopia del panel D a $2.1 \times 10^{4}$ ciclos de impacto con $\mathrm{P}=812 \mathrm{kN} / \mathrm{mm} 2$ 


\subsection{Ensayos de compresión tras impacto en paneles impactados}

Este tipo de ensayo también conocido como CAI es exitoso cuando la falla en el material se produce dónde está el impacto, ya que así está el equipo testando la resistencia residual del panel de las zonas no impactadas con las impactadas. En el caso de la muestra intacta, la primera falla apareció en un punto aleatorio de la superficie del panel. En la Figura 75 se aprecia un panel comprimido, en la cual la zona dónde falló en el ensayo está efectivamente pasando por el punto del impacto. Esta es la línea de primera falla, pues sobre el resto de la superficie del panel no se observan grietas o fisuras.

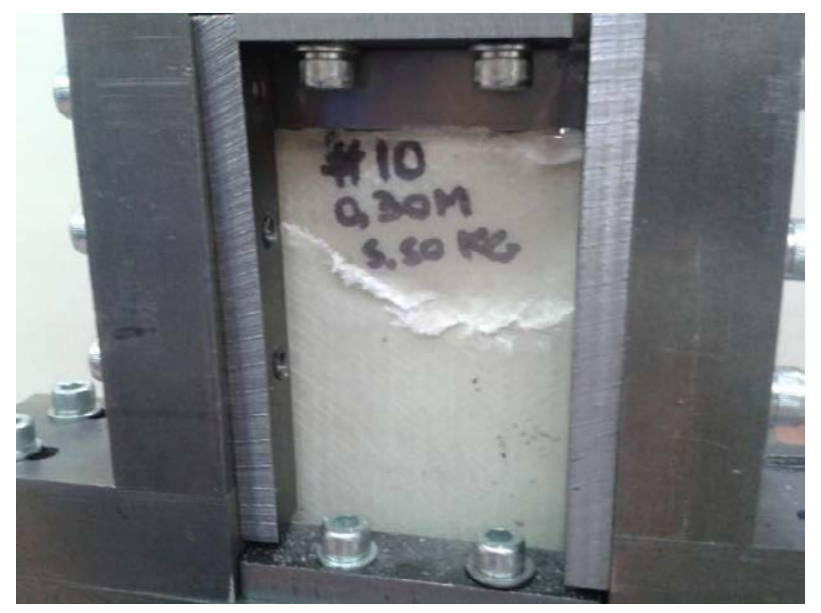

Figura 75 Probeta dañada luego el ensayo de compresión restringida

En la Figura 76, se tiene una vista de todos los paneles ya probados por compresión restringida. En el panel ensayado a baja energía no se produjo la rotura pasando por el punto de impacto, sino en su vecindad siendo esto debido a que la energía de impacto acumulada es muy baja de 17.14 joules, y en cambio con valores mayores a 30 joules inclusive se produce la rotura en la zona esperada. La muestra intacta, también presentó su rotura hacia el lado de una de las caras, pero no sobre el borde de las laminillas, lo cual indica que se obtuvieron buenos resultados en esta probeta. 


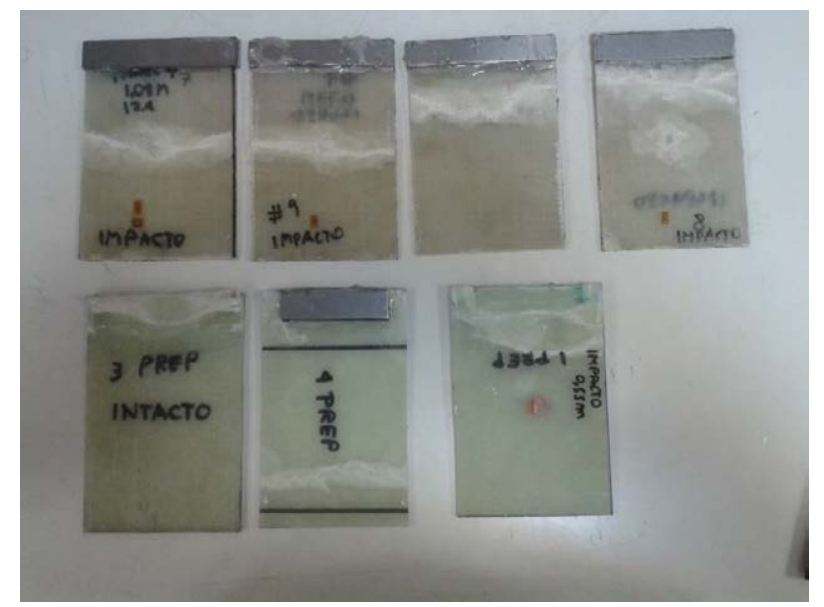

Figura 76 Probetas varias impactadas por caída de peso ensayadas por compresión

Para procesar los resultados de este ensayo, se calculó las diferentes pendientes de las curvas de Fuerza de compresión $(\mathrm{F})$ versus alargamiento $(\delta)$ registrados por el software del equipo de medición. Estas se observan en la Figura 77, en la cual se aprecia que hasta el límite elástico, las pendientes disminuyen a medida de que el panel tenía mayor energía de impacto mostrando mayor daño en la zona central de las probetas identificándose dónde se produce la primera falla en el material

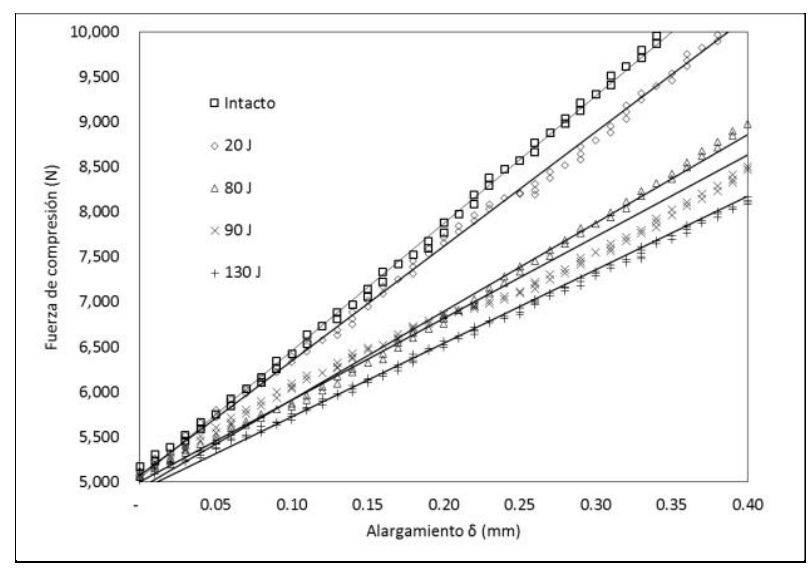

Figura 77 Resultados de las probetas al ensayo de compresión

Esto permite procesar los resultados obteniendo con los valores de cada una de las pendientes del ensayo, la tendencia de la flecha de compresión o alargamiento versus la energía de impacto aplicada. Esta tendencia se observa en la Figura 78, en la cual se tiene el valor mayor cerca de los 40 joules. 


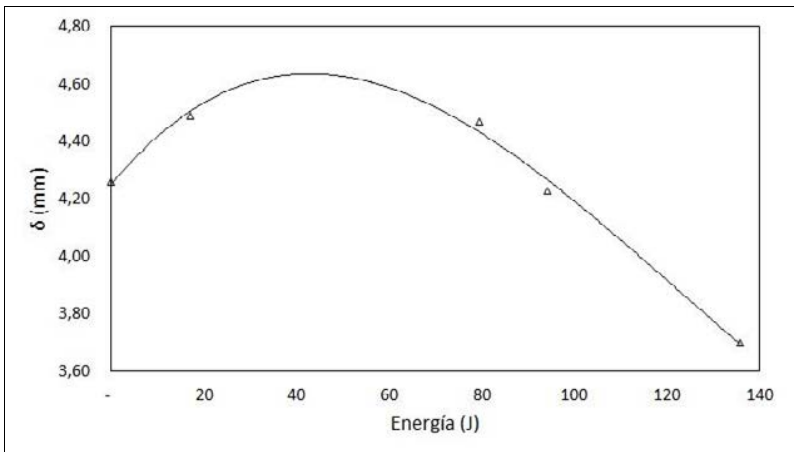

Figura 78 Alargamiento máximo vs energía en compresión

Con estos estos resultados se calcula el inverso de este valor que corresponde a la flexibilidad del material. En la Figura 79 se observa claramente, que la flexibilidad aumenta con la deformación unitaria aplicada en los diferentes impactos.

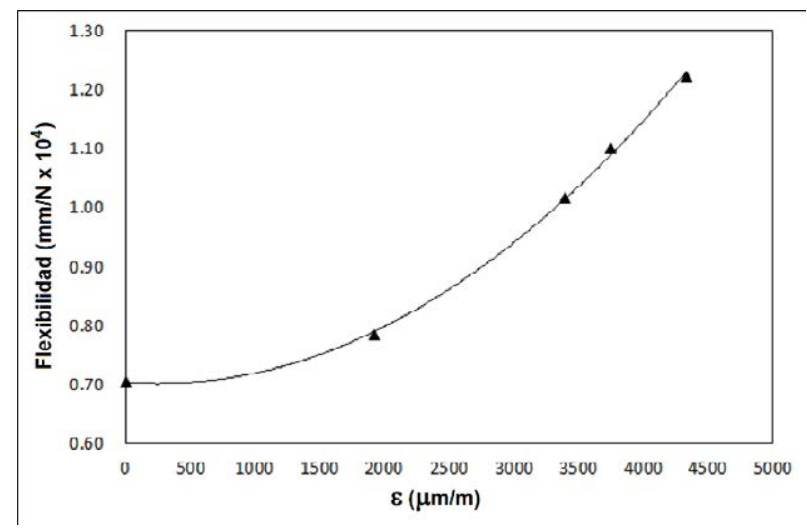

Figura 79 Flexibilidad de paneles dañados por impacto 


\section{CAPÍTULO IV DISCUSIÓN DE LOS RESULTADOS EXPERIMENTALES I: PANELES GFRP SIN MODIFICAR}

\subsection{Correlaciones experimentales entre energía de impacto y daño producido en el material}

La metodología aplicada mediante la observación del daño por impacto de caída de peso, la comparación con la evolución de los bits dañados cuantificados por el software ImageJ luego del barrido a las probetas con ultrasonido sumergido, y la tendencia de las curvas de fuerza versus desplazamiento en el manejo matemático de los resultados, permite claramente tener una idea de lo que ocurre durante la deformación del material y su comportamiento.

El GFRP recibe una energía que no es devuelta en su totalidad, y a medida que devuelve menos por el incremento de la carga de impacto, esta se convierte en daño llegando a ser destructivo. Para el caso del tipo de laminado ensayado, el umbral de daño queda establecido entre los 30 y 40 joules porque allí cambia la capacidad del material en devolver energía marcando la diferencia entre impactos de baja y alta energía. Cabe destacar que, de acuerdo con los datos obtenidos por el acelerómetro, la respuesta del material no es sensible a la velocidad y se calcula la energía absorbida irreversiblemente de acuerdo con la formulación correspondiendo al área encerrada entre de la curva fuerza versus desplazamiento. 


\subsection{Mecanismo de daño interlaminar e intralaminar en los paneles impactados}

De los resultados experimentales obtenidos, varios modos de fallo interno se pudieron observar dentro del laminado del material compuesto a partir de una perspectiva de la micromecánica. Esto permitió predecir la aparición de las mesogrietas, la microfisuración en la matriz, la desunión de las fibras, la retirada de la fibra, y la delaminación. En los ensayos, el rompimiento de las fibras durante la aplicación de carga sobre el material compuesto ha sido el que define el comportamiento a las tensiones críticas e induce una redistribución de la tensión ejerciendo una influencia en la evolución de las grietas

Este fenómeno es la base fundamental de lo observado en la exposición de las delaminaciones con tintas penetrantes y su mapeo 3D, el cual permite ver la relación directa con las fuerzas que van rompiendo el panel a medida que el impactador lo va deformando y se va acumulando el daño en cada una de sus láminas. Así como observar su comportamiento anisotrópico ya que la dependencia del estado direccional de las tensiones, permite que se vayan acoplando las microgrietas en forma perpendicular entre las capas de $45^{\circ}$ para el caso de los paneles ensayados creando tensiones tangenciales. 


\subsection{Evolución del daño y pérdida de propiedades mecánicas de los paneles. Resistencia residual de los paneles impactados}

El seguimiento del daño con el análisis de ultrasonido y de imagen, permitió cuantificar el incremento de las microgrietas, para poder evaluar el nivel de daño en los paneles luego de los impactos cíclicos. Con el ultrasonido queda claro que el equipo no produce un fenómeno de delaminación directa porque el nivel de presión de slamming equivalente a un impacto de baja energía, genera micro fracturas en la matriz que están directamente relacionadas con la vida útil del compuesto y por ende con su resistencia residual. La observación SEM de la matriz, dejó en claro que la temperatura influyó en la delaminación, ya que durante la aparición de los esfuerzos residuales se volvió a fundir el compuesto aumentado su resistencia intralaminar.

Las presiones de slamming sobre el compuesto y su relación con el porcentaje de daño producido por ciclo, tiene un aumento brusco de intensidad sobre un cierto valor de presión. Esto es porque las microgrietas que se alinean rápidamente con las fibras de mayor tensión se orientan para llegar a la fractura por la disminución de rigidez y aumento de fragilidad de preimpregnado.

La predicción de fallos usando modelos micromecánicos en materiales compuestos puede ser exacta a nivel local en la descripción de inicio del fallo, en los puntos críticos. La microscopia ha demostrado que el equipo permite diferenciar el daño que pasa de interlaminar a intralaminar, medir la degradación de la rigidez a lo largo de la aplicación de los ciclos de la carga y la rotura del laminado a presiones menores que su límite estático, que están siempre relacionados con la deformación plástica según los resultados. La microestructura observada para ensayos de bajos ciclos, el incremento de temperatura que produce la disipación de las tensiones en el material no puede ser estimada porque la fricción de la leva durante los ensayos eleva la temperatura más de este nivel ya que el equipo de reproducción de slamming no es adiabático.

A este nivel de presiones del cambio del porcentaje del daño por ciclo el equipo de slamming permite observar físicamente en un corto intervalo de tiempo la dinámica de la redistribución del esfuerzo y explica la presencia de discontinuidades. Los ensayos de tal forma pasaron de impactos de slamming de baja energía en la cual las microgrietas se van alineando en forma interlaminar, a impactos de mediano nivel de energía, en la cual el daño interlaminar produce también daño 
intralaminar, lo cual fue confirmado por la observación microscópica SEM. La fragmentación de la fibra en el vértice de una macro grieta en desarrollo, conduce a un incremento de la tenacidad de la fractura del compuesto y a una disipación adicional de la energía.

La configuración estructural del casco de una embarcación planeadora ha sido investigado mediante el estudio de la evolución del daño por slamming en un panel compuesto de GFRP tipo OoA en condiciones controladas de laboratorio con fuerzas de impacto equilibradas por la inercia del panel, lo que implica que la elasticidad estructural es poco importante durante esta etapa. Este tipo de material OoA emplea una matriz más ligera que sacrifica en parte su rigidez, la cual es una condición que está directamente relacionada al fenómeno de slamming.

La relación de tendencia de los resultados, indica que los ensayos de compresión restringida se realizaron de forma adecuada, por lo cual confirmó y presentó de forma clara como el material ha ido cambiando la resistencia residual del laminado luego de los impactos y el tipo de daño puede relacionarse mediante el esfuerzo irreversible no-lineal que mide el daño en un material compuesto que depende de la tensión efectiva de daño en sus componentes principales ortotrópicos.

Bajo la carga de compresión a lo largo de la dirección de la fibra, se observó el modo de fractura transversal a la tracción en el cual la deformación excede la capacidad de deformación del material compuesto en forma de micro buckling y el esfuerzo cortante por las fibras cuando el compuesto se carga en la dirección perpendicular a la orientación de las fibras. 


\subsection{Estrategias para mitigar la progresión del daño y diferir el fallo del material}

Durante el fenómeno de slamming, el bajo peso estructural es uno los factores más importantes que se consideran en el diseño de las embarcaciones de alta velocidad, el cual va unido a la posibilidad de reducción del tamaño del sistema de propulsión de la nave, disminuir costes de fabricación y reducir el consumo de energía durante el servicio.

De acuerdo con el daño observado tanto en los diferentes ensayos, este progresivamente va delaminando las capas contrarias a los impactos sumándose a la tensión ejercida por la flexión del material. La inserción de la capa viscoelástica como se discutió en el capítulo 1, es la opción seleccionada para poder frenar el daño y que pase en menor grado a las capas inferiores del laminado.

Los elastómeros con su propiedad de constante de Poisson cercano a 0.5 les permite grandes elongaciones y absorción de energía cuando se restringen, y son la clave para el diseño de la lámina viscoelástica. De tal forma que encapsular el elastómero dentro de un polímero rígido permitiría jugar con el peso de la lámina, su capacidad de adherencia y su espesor. Considerando que se va a colocar en el casco de las embarcaciones y que sus beneficios están entre disminuir el peso de la nave al colocar menos capas luego del viscoelástico y poder adaptarse a la curvatura de la nave. Se propone un diseño en forma hexagonal, que permita crear un conjunto de celdas que se agrupen unas con otras al ser fabricadas y puedan formar un conjunto. La forma circular no permitiría formar grupos uniformes y una forma cuadrática crearía concentración de tensiones en las aristas de la cápsula.

Para comprobar esta aseveración, se desarrolló un modelo de elementos finitos de una cápsula hexagonal con un elastómero en su interior. En la Figura 80 se observa el modelo discretizado con elementos sólidos de tipo se empleó elementos sólidos del tipo SOLSH190 con 8 nodos adecuados para el modelado de estructuras delgadas en Ansys. Al conjunto formado por la cápsula rígida y el elastómero interior se le denominará como el viscoelástico. 


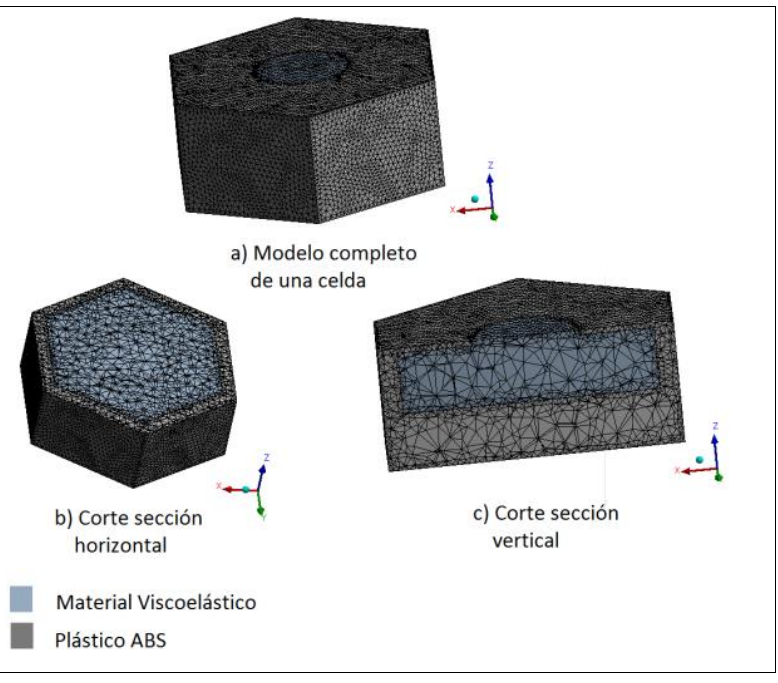

Figura 80 Modelo de elementos fínitos de celda viscoelástica

Aprovechando las propiedades mencionadas en el capítulo 1 sobre la Ley de Hooke en tres dimensiones, el viscoelástico debe tener una superficie expuesta y libre para la compresión. Por ello en a), se observa que el modelo propuesto tiene expuesto el material elastomérico para ser comprimido dentro de la cápsula. Como plástico rígido se escoge el material $\mathrm{ABS}$, muy común en el mercado y el elastómero lineal de tipo TPU también muy empleado en la actualidad. En b) se muestra un corte horizontal de la celda en la cual se ve encapsulado el elastómero, y en c) un corte vertical que permite ver la parte inferior de la cápsula que servirá para observar el comportamiento de las tensiones.

Al someter el modelo a una presión de compresión en la cara libre del elastómero se observa en la Figura 81 que la tensión equivalente dentro del modelo se concentra en el elastómero, amortiguándose y pasando en menor medida a la parte inferior de la cápsula. 


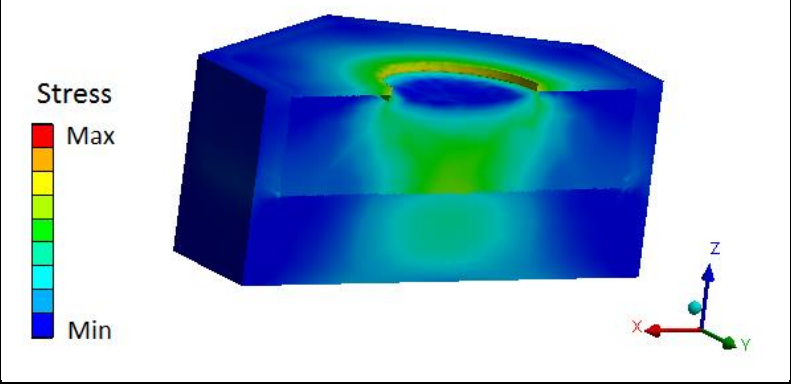

Figura 81 Tensiones en el interior de la celda viscoelástica

El modelo es no lineal y permite grandes elongaciones en el elastómero. Este amortiguamiento de la energía se visualiza para valores normalizados de presión referencial aplicada en la Figura 82, que corresponde a la tensión normalizada de un nodo dentro del viscoelástico en el centro del modelo y de la tensión de un nodo en el centro del ABS en la parte inferior de la cápsula. La presión aplicada en función del tiempo, permite observar que las escalas de tensión normalizada tienen 10 veces menos de tensión el ABS.

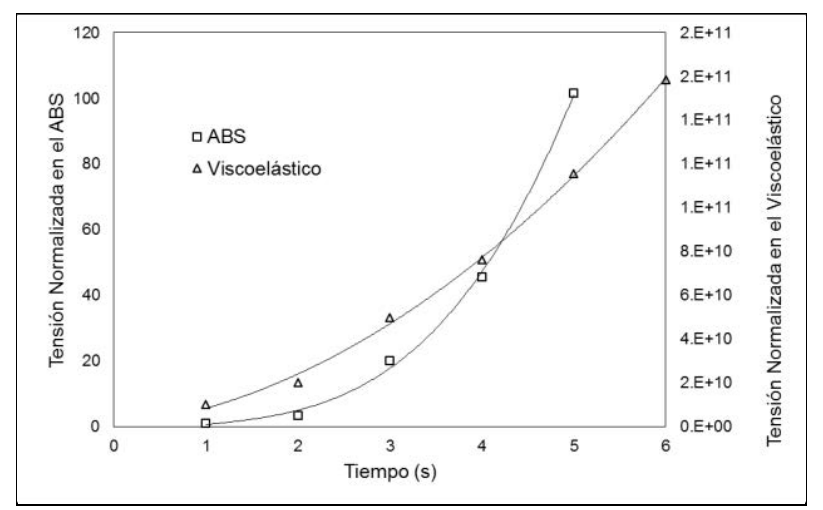

Figura 82 Tensión en el interior del material viscoelástico y del material ABS

De tal forma, que el diseño de la cápsula viscoelástica amortigua la tensión y la concentra no dejando que pase en gran forma a la capa inferior. 


\section{CAPÍTULO V METODOLOGÍA EXPERIMENTAL II: PANELES GFRP MODIFICADOS CON CAPAS VISCOELÁSTICAS}

\subsection{Fabricación de capas viscoelásticas mediante fabricación aditiva}

Para la fabricación de las láminas viscoelásticas, se empleará la impresión en tres dimensiones o impresión 3D mediante la superposición de capas de material. El equipo empleado es del tipo de inyección de polímeros con modelado por deposición fundida y ablanda el material para producir las capas, las cuales son muy precisas y su acabado es casi perfecto. Su principal ventaja es que permite la utilización de dos materiales diferentes en un mismo objeto.

La impresora que se empleó es marca Sirius con dos extrusores independientes para que no haya contaminación entre los materiales, e imprime sobre una cama temperada de $20 \mathrm{~cm} \times 30 \mathrm{~cm}$ tal como se observa en la Figura 83.

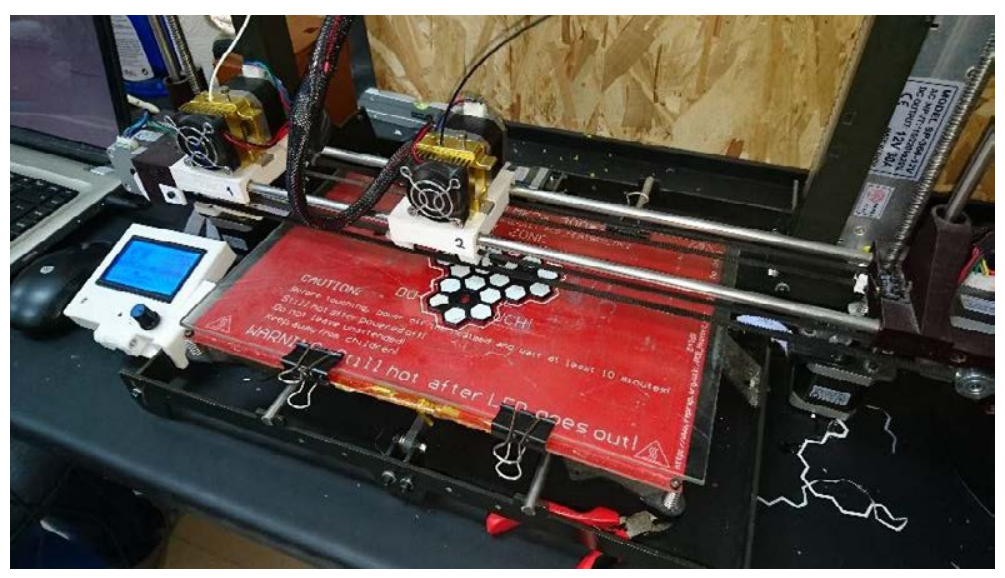

Figura 83 Impresora 3D doble extrusión fabricando la capa viscoelástica

Para la fabricación de la cápsula exterior, se empleó el acrilonitrilo butadieno estireno o ABS de $3 \mathrm{~mm}$, el cual es un plástico muy resistente al impacto compuesto por tres bloques, acrilonitrilo, butadieno y estireno por lo que se le denomina terpolímero. El acrolonitrilo da rigidez, resistencia a ataques químicos, dureza y estabilidad a las altas temperaturas. El butadieno le proporciona tenacidad para temperaturas bajas y resistencia a impacto, y el estireno que le da resistencia mecánica, rigidez, brillo y dureza. 
Para el elastómero interior se empleó un poliuretano termoplástico lineal o TPU, el cual entre sus propiedades tiene alta resistencia al desgaste, a la abrasión, a la tracción y al desgarre. Tiene muy buena capacidad de amortiguación y es tenaz, excelente recuperación elástica.

Las láminas fueron fabricadas por celdas de acuerdo con el diseño presentado en la Figura 84, siendo un conjunto de celdas hexagonales que se acoplan entre sí.

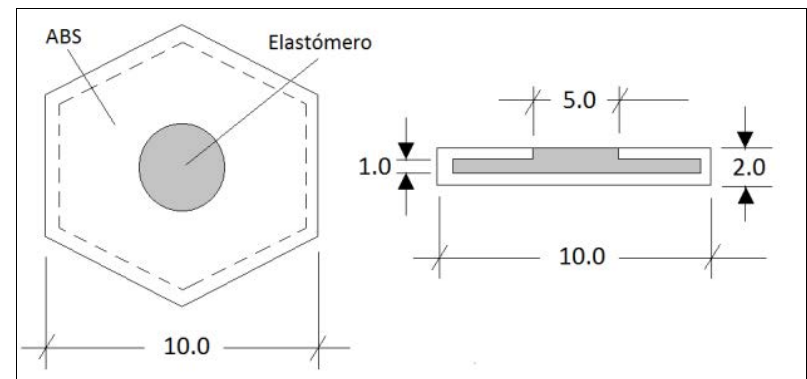

Dimensiones en milímetros

Figura 84 Diseño de la celda viscoelástica

En la Figura 84 se observa la parte interior de una de las láminas fabricadas, en la cual el elastómero está adherido a las paredes de la cápsula. Se intercalaron celdas sin elastómero, para en ellas hacer una perforación con el propósito de que los gases durante el proceso de curado no se queden produciendo porosidades.

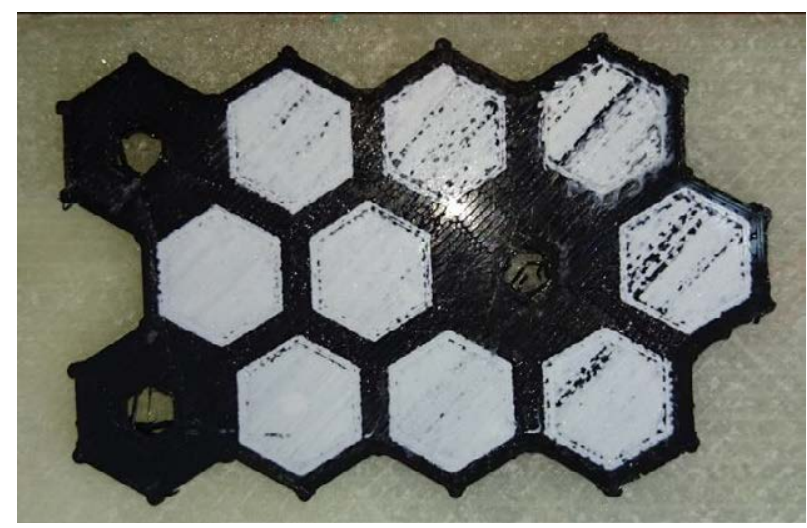

Figura 85 Vista interior de la celda viscoelástica 
En la Figura 84 se observa una lámina ya terminada, en la cual en la cara de impacto el elastómero está expuesto para ser comprimido, mientras que en la cara posterior el elastómero está encapsulado. También se aprecian los agujeros para el flujo de gases durante el curado.
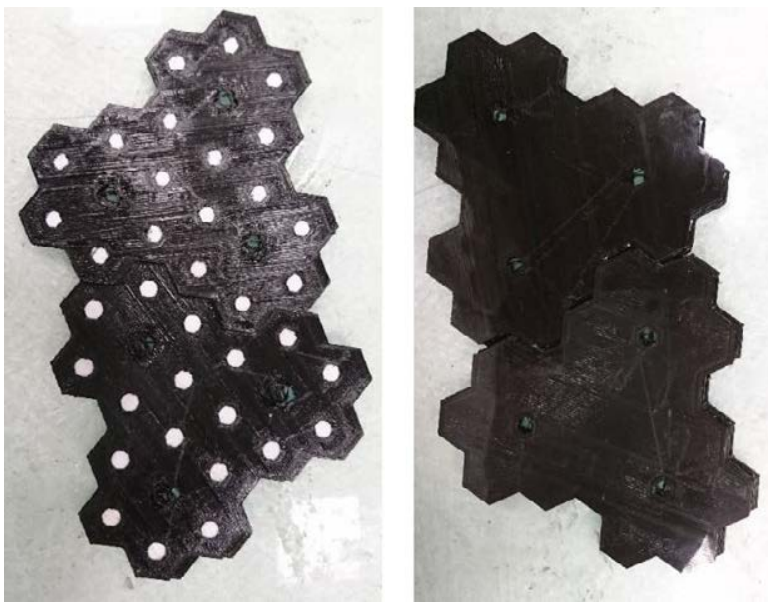

Figura 86 Láminas viscoelásticas finalizadas 


\subsection{Integración de las capas viscoelásticas en los paneles de GFRP de preimpregnados OoA}

Para la fabricación de los paneles, se siguió la misma secuencia de los no modificados de 9 capas en las orientaciones $\left(45^{\circ} /-45^{\circ} / 90^{\circ} /-45^{\circ} / 45^{\circ} / 0^{\circ} / 90^{\circ} /-45^{\circ} / 45^{\circ}\right)$, solo que la lámina viscoelástica se introdujo luego de la tercera capa del lado del impacto. Es decir los paneles modificados confeccionados quedaron con la secuencia $\left(45^{\circ} /-45^{\circ} / 90^{\circ} /\right.$ viscoelástico/ $-45^{\circ} / 45^{\circ} / 0^{\circ} / 90^{\circ} /$ $45^{\circ} /+45^{\circ}$ ), La lamina colocada tenía el tamaño suficiente para cubrir las zonas de impacto a ensayar.

Un primer grupo de paneles se fabricaron con la adherencia que proporcionaba únicamente la resina sobre la lámina viscoelástica como se observa en la Figura 87 en la cual se observa la lámina colocada durante el montaje de las capas. En la Figura 88 se aprecia un panel ya curado con laminado en el interior visto del lado de la cara de impacto. Estos paneles cuando fueron ensayados presentaron problemas de adherencia, separándose del laminado luego del impacto.

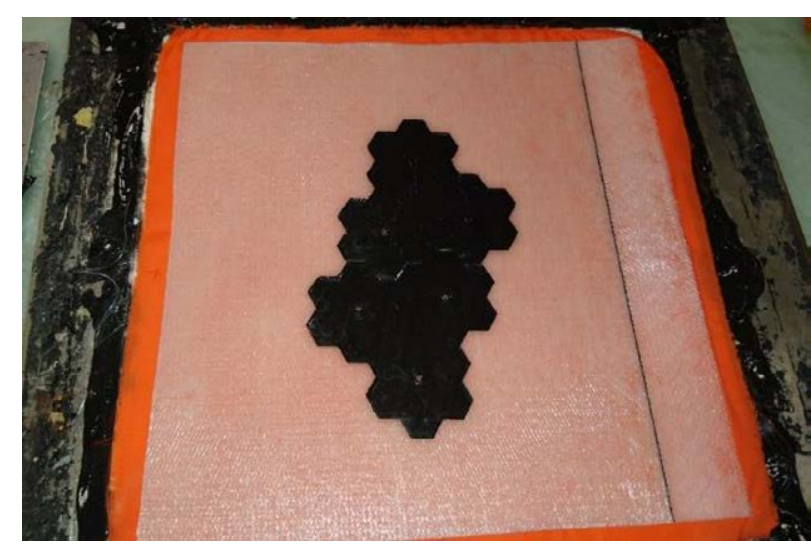

Figura 87 Capa viscoelástica colocada durante el laminado 


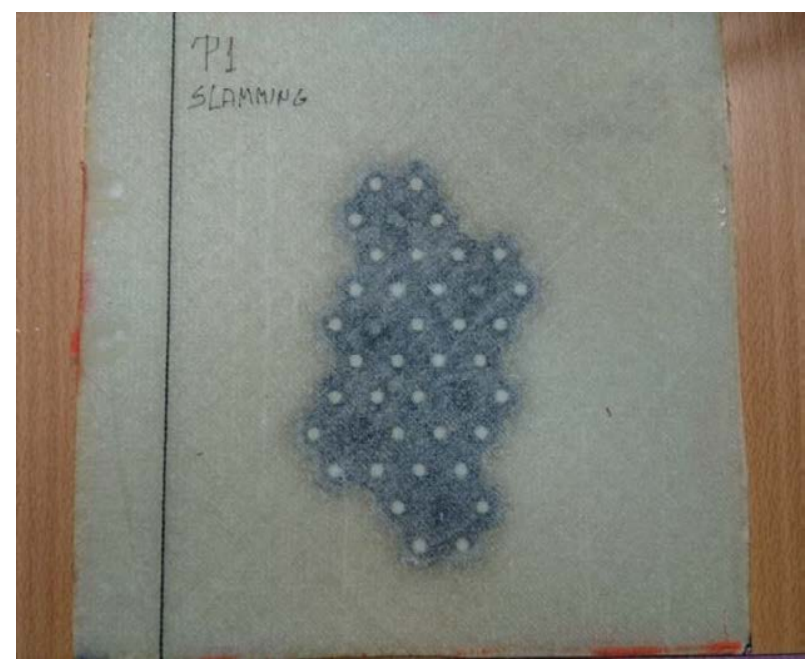

Figura 88 Panel ya curado con la capa viscoelática vista del lado del impacto

Para mejorar la adherencia, se pegó con poliuretano líquido, hebras de tejido de fibra de vidrio en ambas caras de las láminas, previo darles rugosidad superficial con lija. En la Figura 89 se tiene la vista de los ambos lados de una lámina viscoelástica con las hebras adheridas.

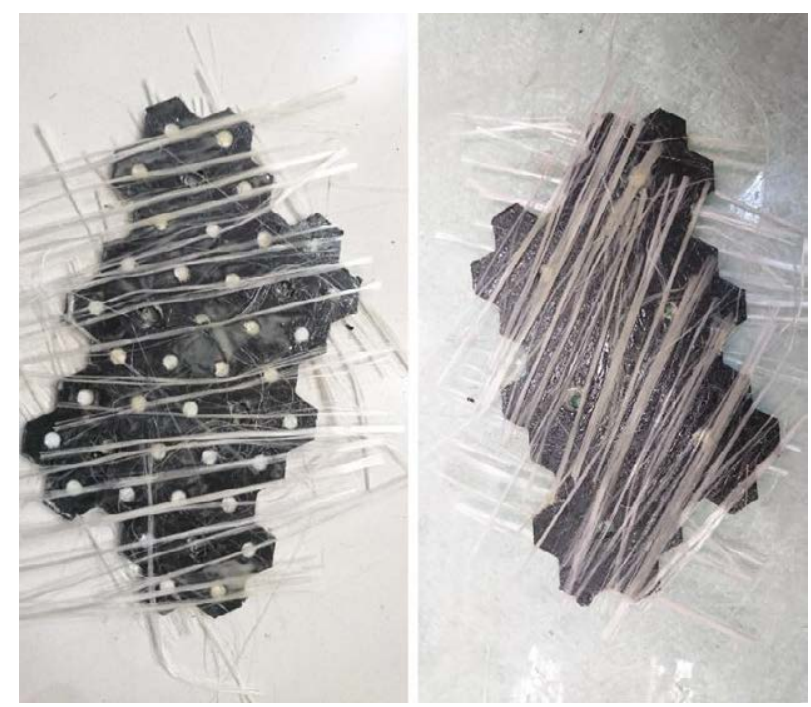

Figura 89 Capa viscoelástica con tratamiento con resida y tela de fibra de vidrio

Como se observa en la Figura 90, se laminaron de igual forma los paneles con las capas viscoelásticas, quedando finalmente curados como se observa en la Figura 91. Las hebras de tela de fibra, se observan claramente bajo la superficie del laminado. 


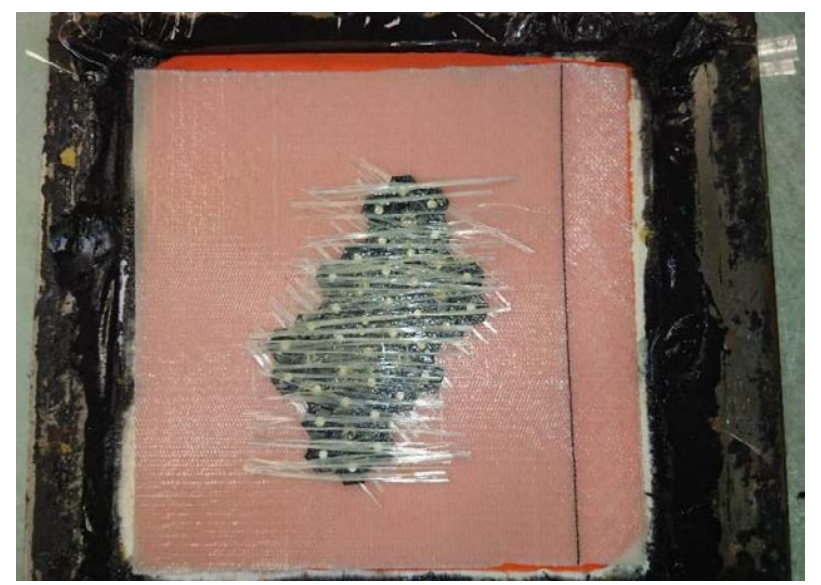

Figura 90 Capa viscoelástica tratada con fibra de vidrio colocada en el laminado

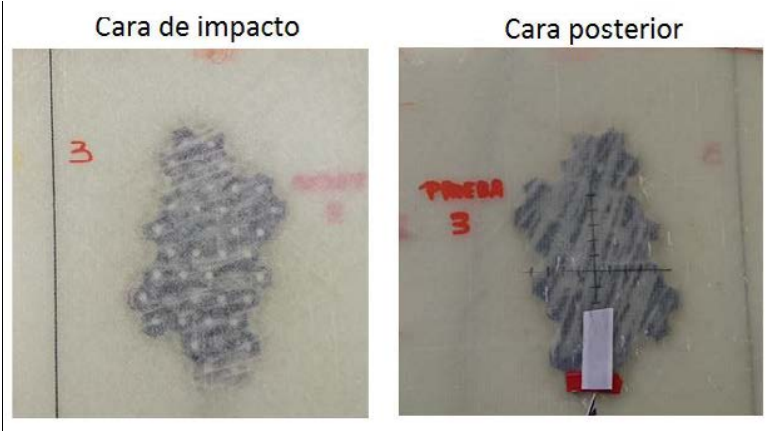

Figura 91 Panel ya curado con capa viscoelástica tratada con fibra de vidrio 


\subsection{Ensayos de impacto por caída de peso en paneles GFRP modificados con capas viscoelásticas}

Se aplicó la misma metodología experimental que se empleó en los paneles no modificados, llevando el control de los impactos con la galga extensiométrica y la toma de datos con el gravitómetro. Los ensayos en los cuales se observó que la lámina viscoelástica se despegó dentro del panel, fueron repetidos con las láminas tratadas superficialmente con hebras de tela de fibra de vidrio. En la Figura 92 se observa va el ensayo de impacto de 30 joules.

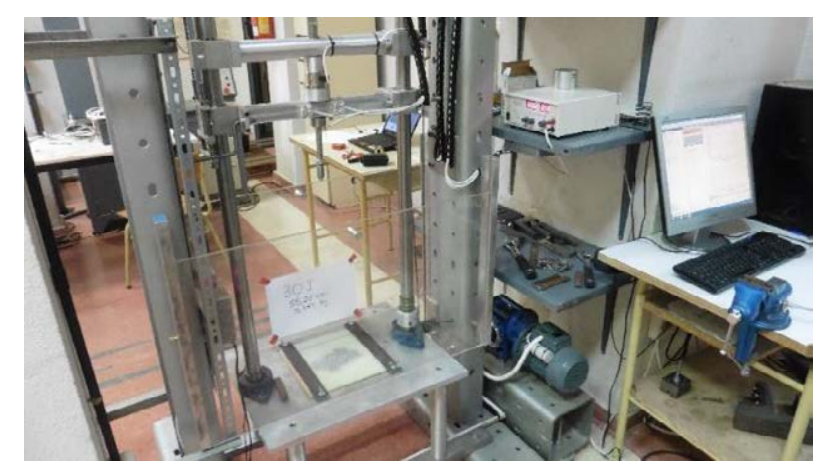

Figura 92 Impacto a $30 \mathrm{~J}$ de un panel modificado sin tratamiento superficial con fibra de vidrio.

Adicional se realizaron ensayos para obtener penetración del impactador en el material viscoelástico, con el propósito de establecer comparaciones con los paneles no modificados en los resultados.

Estos ensayos no pudieron ser controlados con ultrasonido sumergido porque el equipo a la frecuencia de ensayo del material GFRP, cuando barre la onda de sonido la lámina viscoelástica la toma como un defecto. De tal forma que no se puede observar el daño que se produce en las capas subsiguientes a la modificación. 


\subsection{Ensayos de impactos repetidos de baja energía en ensayos de slamming}

Los ensayos de slamming, se realizaron bajo los mismos parámetros experimentales de los paneles no modificados. Se tuvo especial cuidado de acoplar los paneles de la misma forma en los diferentes ensayos, de lubricar con la grasa de litio para disminuir la fricción y de controlar la frecuencia de aplicación de presión de la leva para comparar luego los resultados.

En la Figura 93 se observa un panel modificado con capa viscoelástica y tratado superficialmente con hebras de fibra de vidrio, al cual se lo ensayó con impactos cíclicos de slamming.

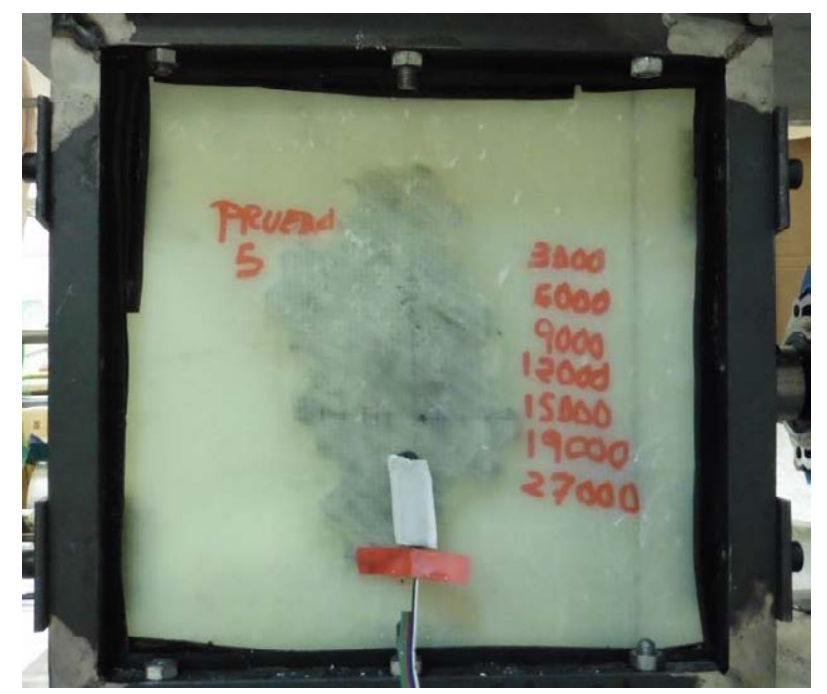

Figura 93 Ensayo de slamming a panel con lámina viscoelástica tratada superficialmente con hebras de fibra de vidrio

De igual forma se controló la temperatura sobre todo en los ensayos que controlan la flexibilidad del modelo mediante la galga extensiométrica, ya que debió detenerse el ensayo cuando superaba los $70^{\circ} \mathrm{C}$ y esperar hasta que regrese a la temperatura ambiente, con el propósito de que las microdeformaciones medidas estén bajo los mismos parámetros. 


\section{CAPÍTULO VI RESULTADOS EXPERIMENTALES II: PANELES GFRP MODIFICADOS CON CAPAS VISCOELÁSTICAS}

\subsection{Daño producido en paneles GFRP modificados con capas viscoelásticas por impactos por caída de peso}

Se realizó un grupo de ensayos aplicando diferentes energías y número de impactos. Las condiciones de los ensayos fueron las indicadas en la Tabla 5 y se obtuvieron variando el peso a impactar y su altura, registrando las microdeformaciones con la correspondiente galga extensiométrica. La lectura de datos, el sistema antirebote para definir el número de impactos y el nivel de medición de altura, respondieron bien a las condiciones de los ensayos. Se diferencia en la tabla los paneles en los cuales se colocaron las láminas sin o con el tratamiento superficial que se dio con tela de fibra de vidrio.

\begin{tabular}{|c|c|c|c|c|c|}
\hline $\begin{array}{c}\text { Valor } \\
\text { nominal } \\
\text { de Energía } \\
(\mathrm{J})\end{array}$ & $\begin{array}{l}\text { Altura del } \\
\text { impacto } \\
\text { (m) }\end{array}$ & $\begin{array}{c}\text { Peso } \\
(\mathrm{kg})\end{array}$ & $\begin{array}{l}\text { Microdeformaciones } \\
\text { obtenidas } \\
(\mu \mathrm{m} / \mathrm{m})\end{array}$ & $\begin{array}{c}\text { \# de } \\
\text { impactos }\end{array}$ & $\begin{array}{l}\text { Observación si tenía } \\
\text { tratamiento } \\
\text { superficial con tela } \\
\text { de fibra de vidrio }\end{array}$ \\
\hline $20(2)$ & 0.37 & 5.549 & 252 & 1 & No \\
\hline $30(2)$ & 0.55 & 5.549 & 514 & 1 & No \\
\hline $30(3)$ & 0.55 & 5.549 & 480 & 1 & $\mathrm{Si}$ \\
\hline $40(2)$ & 0.73 & 5.549 & 669 & 1 & No \\
\hline $40(3)$ & 0.73 & 5.549 & 655 & 1 & $\mathrm{Si}$ \\
\hline $60(2)$ & 0.44 & 13.829 & 991 & 1 & No \\
\hline $80(3)$ & 0.44 & 13.829 & 1040 & 1 & $\mathrm{Si}$ \\
\hline $120(3)$ & 0.85 & 13.829 & 1273 & 1 & $\mathrm{Si}$ \\
\hline $130(3)$ & 0.97 & 13.829 & 1338 & 3 & $\mathrm{Si}$ \\
\hline
\end{tabular}

Tabla 5 Condiciones de los ensayos de impacto por caída de peso a paneles modificados

Los ensayos de impacto con los paneles sin tratamiento con fibra de vidrio, mostraron desprendimiento de la capa luego del golpe en todos los niveles de energía. En la Figura 94 se 
observan los impactos a 20, 3040 y 60 joules en la cara posterior al golpe, en las cuales hubo delaminación en forma de diamante y desprendimiento en casi su totalidad en el impacto mayor de 60 joules.

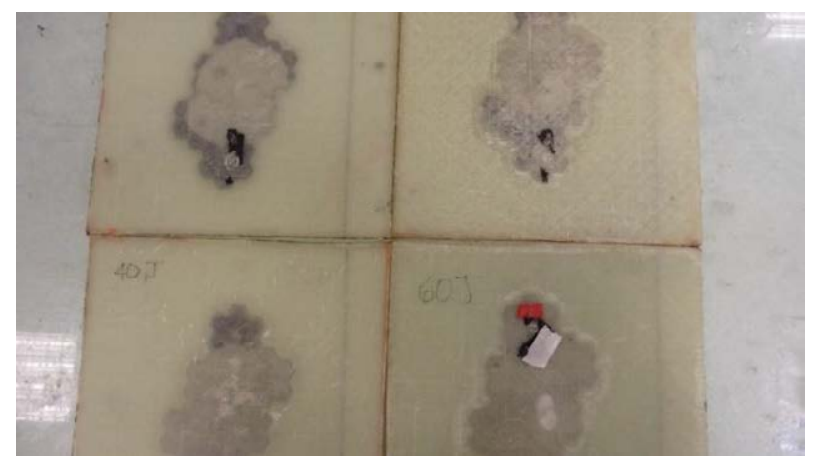

Figura 94 Paneles modificados luego del impacto por caída de peso con láminas viscoelásticas sin tratar con fibra de vidrio

Debido al desprendimiento y el deslizamiento del viscoelástico dentro del laminado, el procesamiento de resultados mediante la formulación para el cálculo de la Fuerza vs Desplazamiento muestra una variación que produce datos erróneos. En la Figura 95 se observa para el ensayo de 40 joules el resultado de este cálculo, en el cual sobre los 4x105 m de desplazamiento del panel durante la deformación, el viscoelástico resbala dando valores negativos disipando la energía no en la dirección del golpe sino como deslizamiento. Las curvas mostradas en el ANEXO 7, muestran este mismo comportamiento para todos los otros 3 ensayos mencionados.

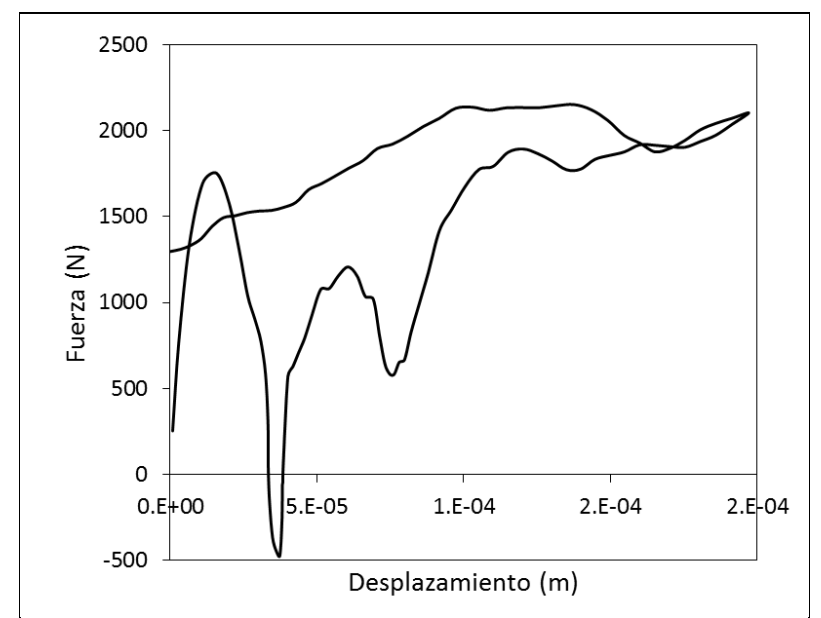

Figura 95 Curva de Fuerza vs Desplazamiento con impacto a 40 Joules con deslizamiento del viscoelástico 
Los paneles que cuya lámina viscoelástica fue tratada con fibra de vidrio, al ser sometidos a impacto no presentaron desprendimiento de la capa viscoelástica. La Figura 96 muestra el resultado de la caracterización con tinta penetrante fluorescente para el panel impactado a 80 joules. Se observa que las capas superiores al viscoelástico se encuentran rotas por el golpe con el impactador, el viscoelástico se ha deformado permanentemente pero no se observa daño, y las capas inferiores tienen las delaminaciones característica.

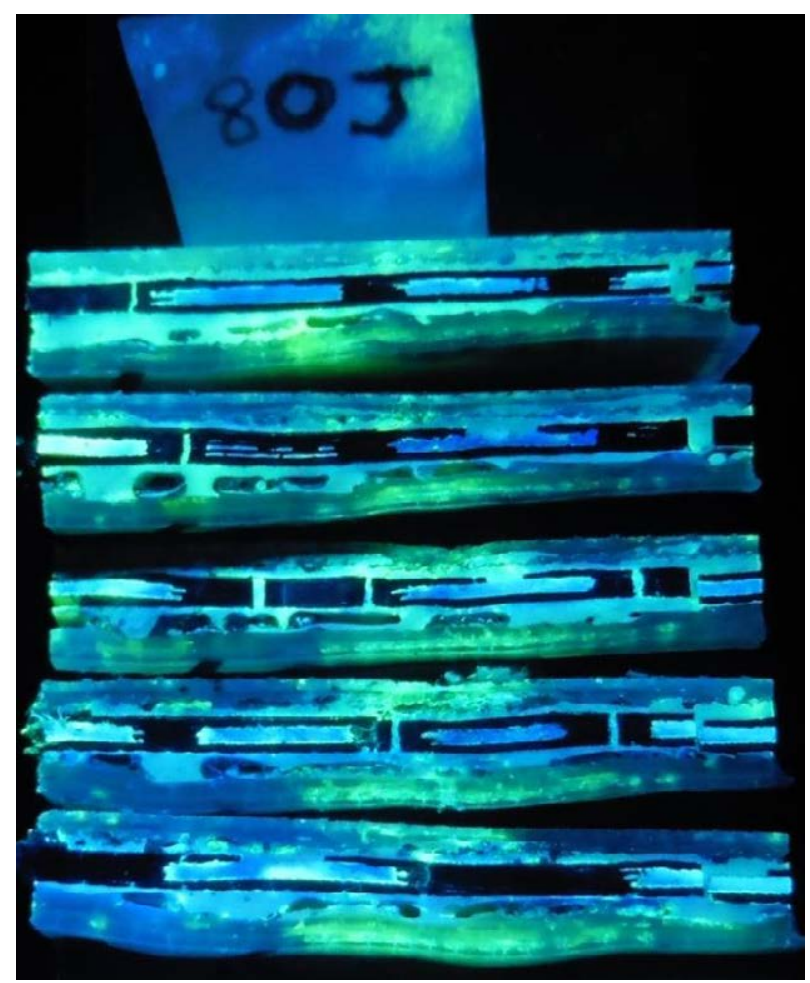

Figura 96 Caracterización con tinta penetrante a panel impactado a 80 Joules

En la Figura 97 se observa el detalle de la lámina en el punto del impacto en la cual se aprecian porosidades por el no acoplamiento de la lámina de preimpregnado a las hebras de fibra de vidrio colocadas para el tratamiento superficial. 


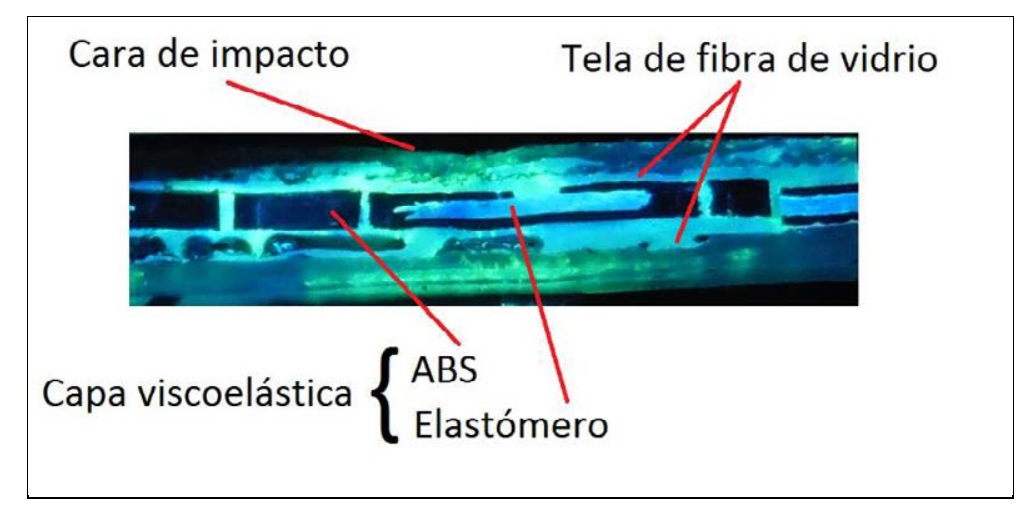

Figura 97 Detalle de la lámina en el punto del impacto a 80 joules

La modelación en 3D empleando el programa Rinhoceros, mostró la forma como se delaminaron las capas en los diferentes impactos y se relacionaron con las gráficas de Fuerza vs Desplazamiento. En la Figura 98 se observa el impacto a 40 joules, en la cual se identifica claramente la acción del viscoelástico que produce una variación en la fuerza de delaminación. Esta es disipada antes y después de la capa 3 y la capa 4 del preimpregnado, destacando que este resultado muestra que la delaminación es mínima en la cara superior del viscoelástico, y si existe delaminación en la cara inferior del mismo.

En el impacto a 80 joules, la fuerza en el viscoelástico produce daño luego de la capa 3, ya que se registra una magnitud de valores que continua con la delaminación. Esto resultado indica que la capa del viscoelástico se delaminó por ambos lados luego del impacto en la zona del golpe tal como se observa en la Figura 99. 


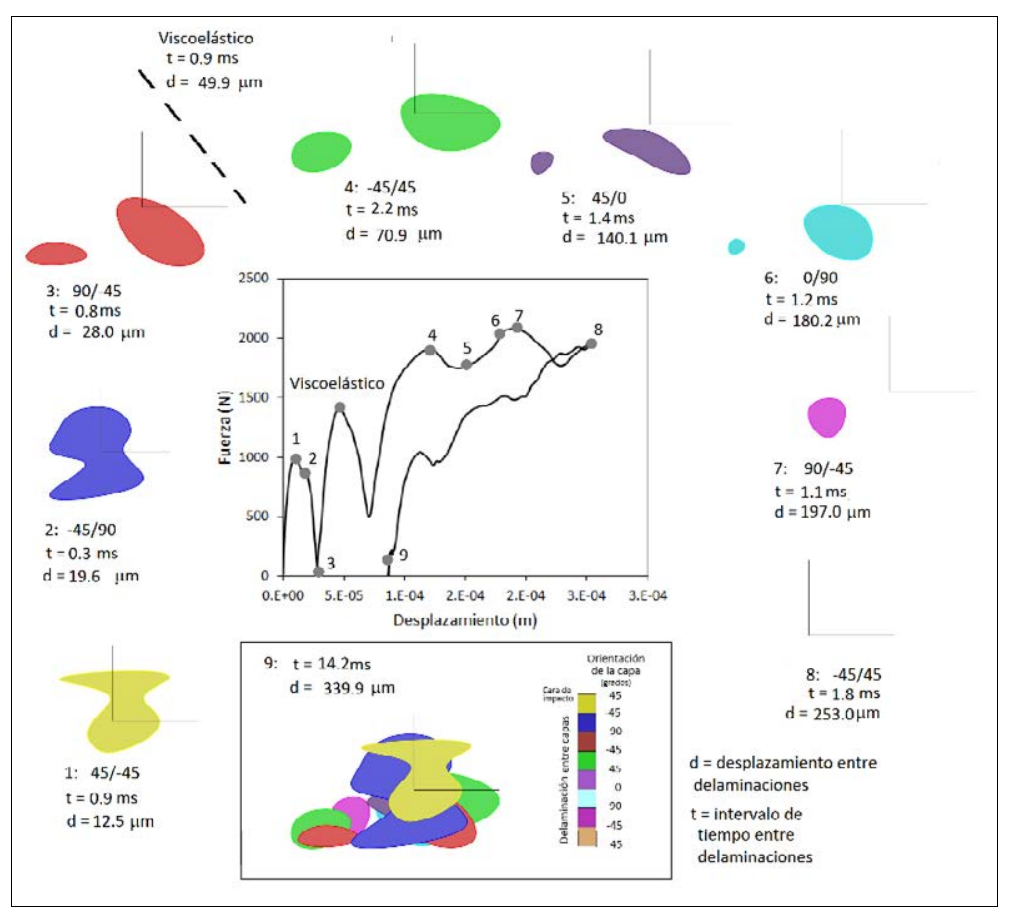

Figura 98 Delaminaciones del impacto a 40 joules de un panel modificado

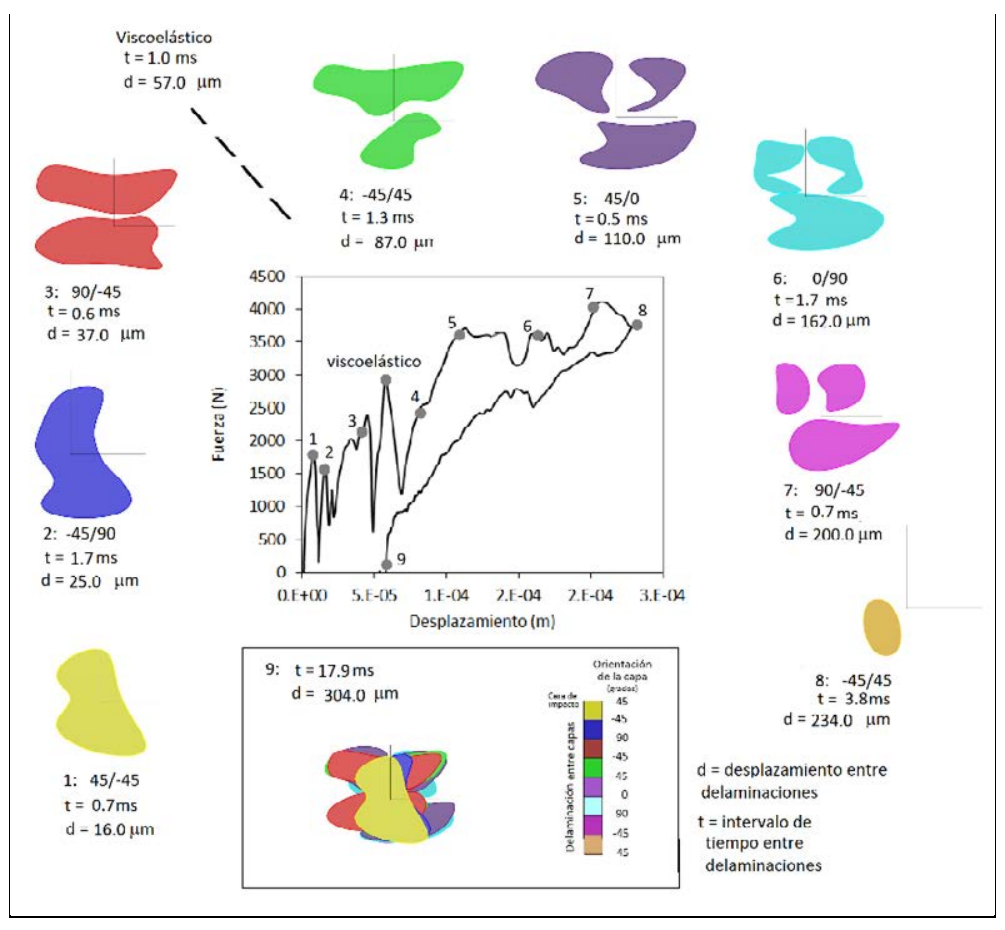

Figura 99 Delaminaciones del impacto a 80 joules de un panel modificado 
De los ensayos realizados en los cuales no hubo desprendimiento de la lámina viscoelástica por el tratamiento con hebras de fibra de vidrio, se calculó la energía devuelta luego del impacto, y este resultado se muestra en la Figura 100, en la cual se observa que el panel luego de los 40 joules va perdiendo su capacidad de devolver esta energía y se consume en mayor daño. Sobre los 130 joules todavía el panel puede devolver energía convertida en rebote.

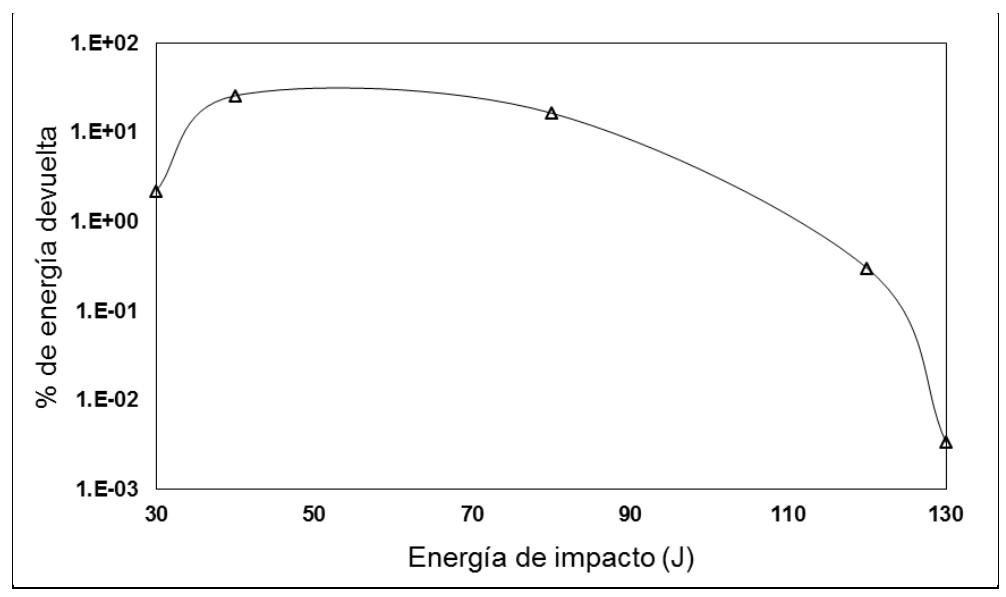

Figura 100 Porcentaje de energía devuelta luego de los ensayos de impacto por caída de peso a paneles modificados

Cabe destacar que en el ensayo a 130 joules se realizaron 3 impactos repetidos sobre el mismo punto con el propósito de conseguir la penetración del impactador, lo cual no se produjo. Estos impactos fueron cada uno de 130 joules en los cuales la altura del rebote fue disminuyendo por el daño absorbido por el material. En la Figura 101 se aprecian los resultados de los 3 impactos, en los cuales la lámina viscoelástica no se deslizó dentro del panel por el tratamiento con fibra de vidrio para anclaje del mismo. Al tercer impacto se observa rotura en la cara del impacto, y una delaminación en la cara opuesta tiene la forma de diamante y se orienta en la dirección de la capa exterior. 


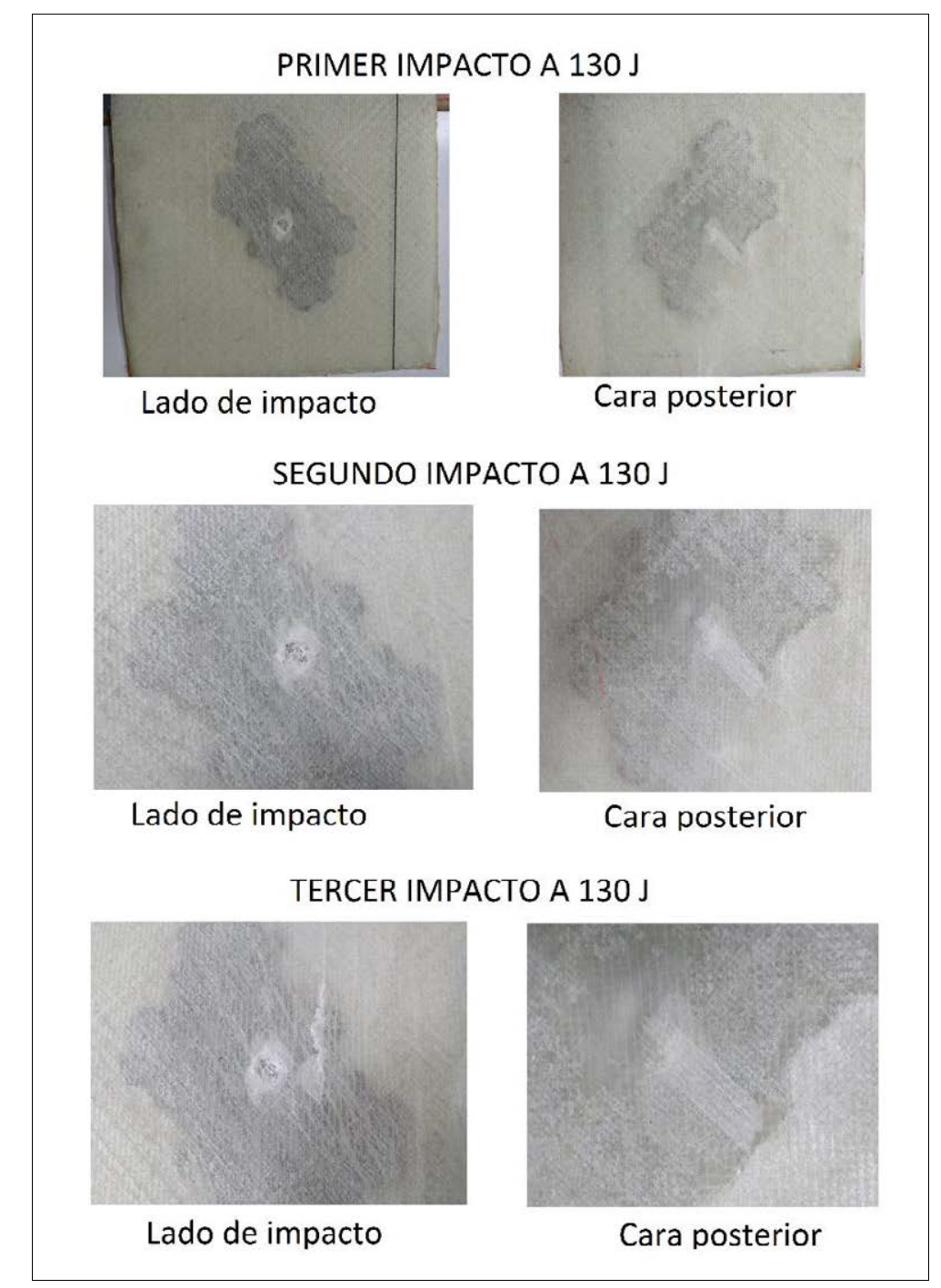

Figura 101 Panel sometido a 3 impactos de 130 Joules cada uno 


\subsection{Daño producido en paneles GFRP modificados con capas viscoelásticas por impactos repetidos de baja energía en ensayos de slamming}

Los ensayos realizados de slamming se muestran en la Tabla 6, y corresponden al ensayo del panel G con alta energía de slamming cuya microdeformación está próximo al umbral de daño y al ensayo del panel $\mathrm{H}$, con una microdeformación que produce la misma flexibilidad en la lectura de la galga extensiométrica que el panel F no modificado y es de baja energía.

\begin{tabular}{|c|c|c|c|c|c|c|c|}
\hline $\begin{array}{c}\text { Panel } \\
\#\end{array}$ & $\begin{array}{c}\text { Presión } \\
\text { aplicada } \\
\text { sobre el } \\
\text { panel } \\
\left(\mathrm{kN} / \mathrm{m}^{2}\right)\end{array}$ & $\begin{array}{c}\varepsilon \text { medida con } \\
\text { galga } \\
\text { extensiométrica } \\
(\mu \mathrm{m} / \mathrm{m})\end{array}$ & $\begin{array}{c}\varepsilon \\
\text { estimada } \\
\text { en el } \\
\text { centro } \\
\text { del panel } \\
(\mu \mathrm{m} / \mathrm{m})\end{array}$ & $\begin{array}{c}\text { Frecuencia } \\
(\mathrm{RPM})\end{array}$ & $\begin{array}{c}\text { Ciclos } \\
\text { Tiempo } \\
\text { de } \\
\text { aplicación } \\
\text { de la } \\
\text { carga por } \\
\text { ciclo } \\
(\mathrm{mseg})\end{array}$ & $\begin{array}{c}\text { Grupos } \\
\text { de ciclos } \\
\text { de } \\
\text { ensayo x } \\
\text { cantidad } \\
\text { ejecutada }\end{array}$ \\
\hline $\mathrm{G}$ & 801 & 1950 & 5315 & 302 & 22000 & 81.20 & $\begin{array}{c}1000 \times 1 \\
3000 \times 3 \\
2000 \times 6\end{array}$ \\
\hline $\mathrm{H}$ & 343 & 850 & 2324 & 309 & 27000 & 69.90 & $3000 \times 9$ \\
\hline
\end{tabular}

Tabla 6 Condiciones de los ensayos de slamming a paneles modificados

No se realizó inspección por ultrasonido sumergido, debido a que la frecuencia de barrido hacia que el haz de sonido al pasar por el viscoelástico lo tome como un defecto.

Los resultados del ensayo del panel G se muestran en la Figura 102, en la cual se observa que sobre los 2000 ciclos pese al tratamiento con hebras de fibra de vidrio, el viscoelástico se comienza de separar del laminado y durante la prueba físicamente se podía notar el deslizamiento de la lámina en ciertas partes de la superficie de contacto con la leva. La temperatura se incrementaba rápidamente y este regulaba el número de ciclos a realizar. 


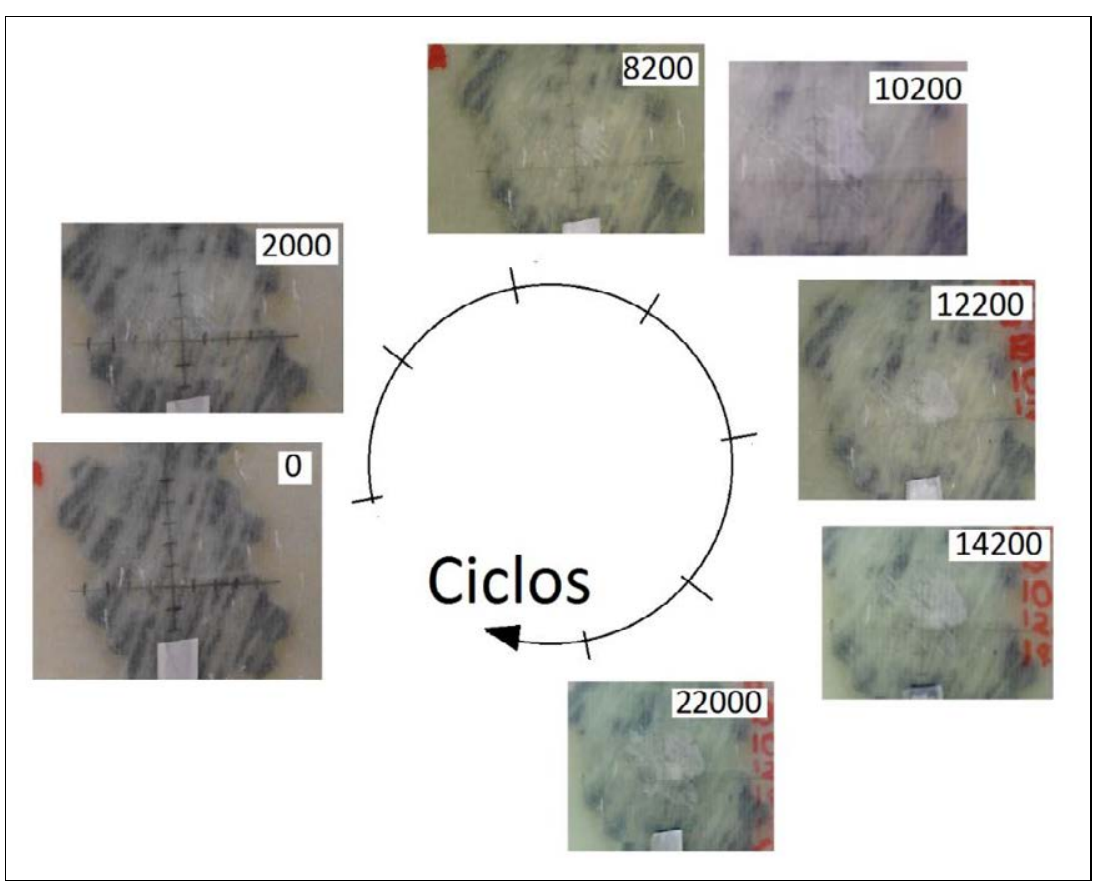

Figura 102 Evolución del daño del panel G impactado a 2.2×10 ciclos y presión de $801 \mathrm{kN} / \mathrm{m}^{2}$

En el ensayo de baja energía, con una flexibilidad observable igual a la del panel $\mathrm{F}$ sin modificar, se observó que el daño producido sobre la cara de tensión contraria al impacto de slamming no era observable durante la prueba, pero si se registró el cambio de flexibilidad en las pendientes de las curvas de microdeformación tal como se observa en la misma Figura 103. El panel se ensayó hasta los $2.7 \times 10^{4}$ ciclos obteniendo una mínima zona observable de separación entre las fibras. La lámina viscoelástica durante la prueba no presentó desprendimiento ni deslizamiento entre capas. 


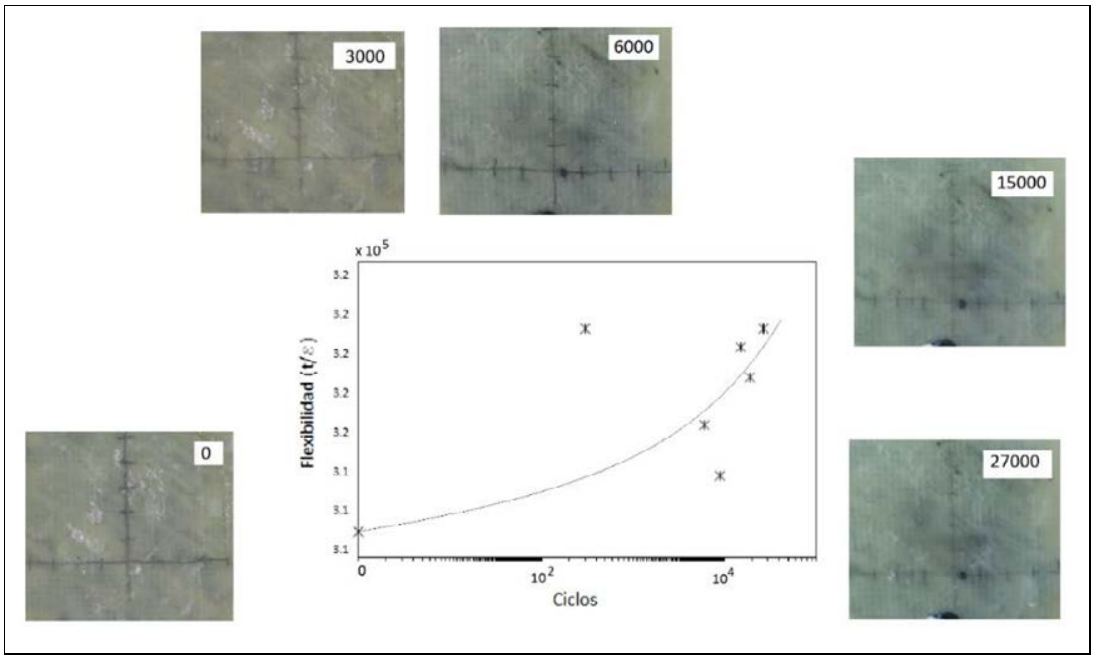

Figura 103 Cambio de flexibilidad durante el ensayo del panel $\mathrm{H}$ a $2.7 \times 10^{4}$ ciclos con una presión de $343 \mathrm{kN} / \mathrm{m}^{2}$ 


\section{CAPÍTULO VII DISCUSIÓN DE LOS RESULTADOS EXPERIMENTALES II: PANELES GFRP MODIFICADOS CON CAPAS VISCOELÁSTICAS}

\subsection{Comparación entre el comportamiento frente a impactos por caída de peso de paneles GFRP sin modificar y modificado mediante la introducción de capas viscoelásticas}

La caracterización por tintas penetrantes fluorescentes, permitió observar físicamente como el daño no se propaga de igual forma bajo las capas de la lámina viscoelástica, mezclándose este daño entre el golpe de impacto y la tensión normal por la flexión del panel en la cara de tracción. En la Figura 104 se muestran dos secciones de corte en la zona del impacto ya caracterizadas de un panel sin modificar y uno modificado, impactados ambos a 40 Joules. En el panel sin modificar los daños interlaminares e intralaminares se enlazan produciendo roturas interiores en el laminado y separaciones importantes a la matriz. La influencia de la tensión en la cara de tracción se difumina y prevalece la fuerza del impactador que va rompiendo en forma vertical el compuesto.

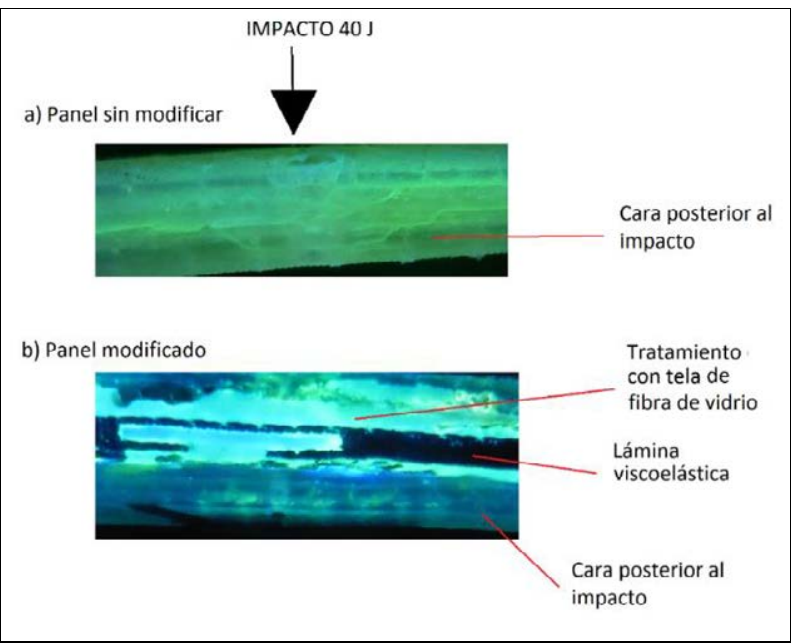

Figura 104 Comparación de la sección de impacto por caída de peso a 40 joules caracterizado con tintas penetrantes fluorescentes

En cambio en el impacto del panel modificado viscoelásticamente, se observa que el nivel de daño en la parte superior del laminado donde fue el golpe vertical de impacto, tiene una diferencia de daño mucho mayor que la cara inferior donde las grietas interlaminares e intralaminares no 
pudieron llegar a enlazarse para formar los típicos escalones. La energía de impacto definitivamente fue absorbida por la lámina viscoelástica y esta concentró las tensiones dando lugar a un perfil de tensiones obtenidos mediante el modelo no lineal de elementos finitos presentado anteriormente.

Considerando un impacto de más baja energía cercano al umbral de la máxima capacidad del panel de devolver energía, se muestra en la Figura 105, la curva de fuerza versus desplazamiento de un impacto a 30 joules sin modificar y modificado. Las fuerzas que se generan a medida que se van rompiendo las capas resultan ser aproximadamente 35\% mayores para el panel sin modificar, lo cual es el indicativo de que los daños se propaguen más al interior del laminado. Se puede observar claramente como la presencia de la lámina viscoelástica alrededor de los $5 \times 10^{-5}$ metros de desplazamiento del impactador hace que decaiga la fuerza bajando su valor total. La influencia de la dirección de las capas también está presente ya que hay similitud de variaciones en ambas curvas, pero variando su magnitud.

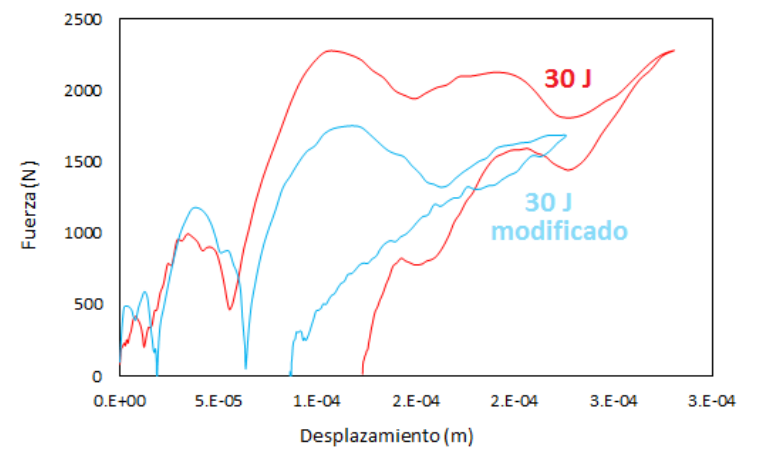

Figura 105 Comparación de la fuerza versus desplazamiento a impacto por caída de peso de 30 joules

A nivel de impactos considerados como destructivos se presentan las curvas de fuerza versus desplazamiento en la cual a 50 joules el panel no solamente tiene delaminaciones sino desgarramiento de las capas en la cara del impacto, mientras que el panel modificado viscoelásticamente no presenta daños con desgarramiento en las capas luego de la lámina indicada. Así mismo se observa claramente la influencia de la modificación en la curva no solo en los valores 
de tensión, sino en el tiempo que demora la deformación y la restitución del panel. Esto permite que las tensiones se distribuyan de mejor forma en la cara de tracción.

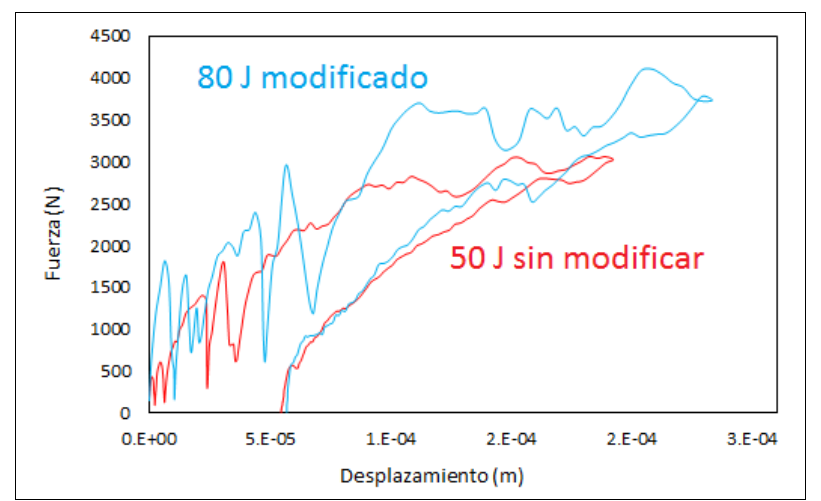

Figura 106 Comparación de la curva de fuerza versus desplazamiento por impacto por caída de peso a varias energías

De acuerdo con estos resultados, al comparar el perfil de energías devueltas como lo es el caso de las curvas presentadas en la Figura 107, el pico de máxima energía que devuelve el panel es mayor en el modificado con alrededor a 10 joules, mientras que la capacidad de resistir el impacto equivale que un impacto a 50 joules no modificado devuelva similar energía que un impacto a 125 joules para un panel modificado. Esto está ligado a la capacidad de absorber energía y por ende al trabajo realizado por la lámina viscoelástica.

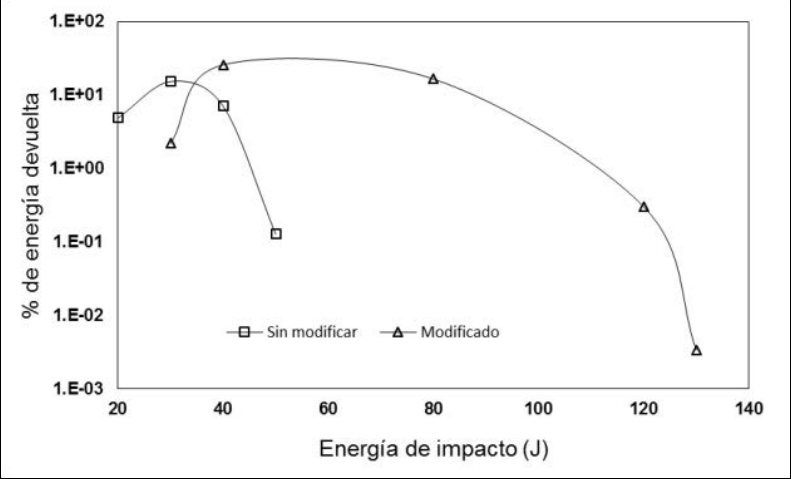

Figura 107 Comparación de energía devuelta tras impactos por caída de peso 


\subsection{Comparación entre el comportamiento frente a impactos repetidos de baja energía en ensayos de slamming de paneles GFRP sin modificar y modificados mediante la introducción de capas viscoelásticas}

La comparación realizada mediante la medición de la flexibilidad de los paneles, permitió ver en el ensayo realizado a similares condiciones de flexibilidad o de la pendiente de ingreso de la leva deformando el panel, permite observar que el comportamiento del panel modificado tiene una restitución con menor deformación luego del impacto de slamming tal como se observa en la Figura 108. Esta capacidad está directamente relacionada a la inserción de la lámina viscoelástica, en la repetición de los ciclos juega con las tensiones de tracción y compresión sobre ambas superficies del panel, disminuyendo el daño.

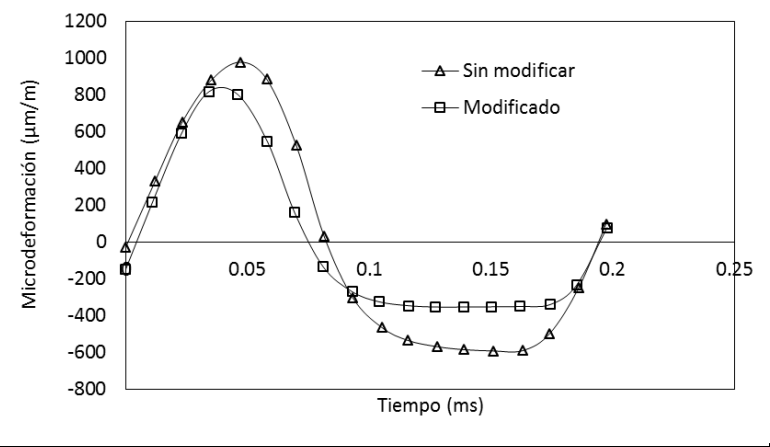

Figura 108 Comportamiento de la galga extensiométrica al slamming

Comparando el mismo ensayo, con los valores de flexibilidad obtenidos a lo largo de la escala de ciclos aplicados, observamos en la Figura 109 que sobre los $5 \times 10^{3}$ de la escala logarítmica, los paneles sin modificar y modificado comienzan a distanciarse en gran medida. Esto está asociado con la aparición de las primeras micro grietas que comienzan a enlazarse y van disminuyen la resistencia residual del panel. El panel sin modificado pierde rápidamente mucha flexibilidad de allí en adelante, mientras que el modificado se mantiene debido a la lámina viscoelástica que absorbe este impacto cíclico. La comparación realizada es muy buena, porque en el ensayo del modificado no hubo despegue de la lámina viscoelástica, manteniéndose el panel como un solo cuerpo. 


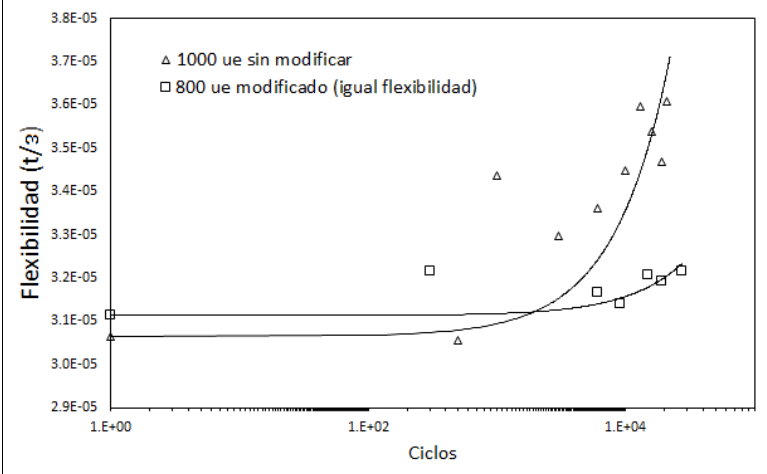

Figura 109 Comparación del cambio de la flexibilidad durante el ensayo de slamming con $2.7 \times 10^{4}$ ciclos 


\section{CONCLUSIONES Y RECOMENDACIONES}

1. El equipo reproductor de slamming construido para esta investigación, efectivamente reproduce las presiones que soporta el casco de una embarcación planeadora, controlando los parámetros del fenómeno de slamming en cuando a niveles máximos y mínimos de presión y frecuencia de los impactos aplicados.

2. El empleo en la investigación de la observación del daño cuantificado por el software ImageJ luego del barrido a las probetas con ultrasonido sumergido, permite tener una idea clara de lo que ocurre durante la deformación del material y su comportamiento para daños no observables visualmente durante los ensayos de slamming y su evolución siendo una fuerte herramienta de decisión para este tipo de experimento.

3. Las presiones de slamming sobre el compuesto y su relación con el porcentaje de daño producido por ciclo, tiene un aumento brusco de intensidad sobre un cierto valor de presión. Esto es porque las microgrietas que se alinean rápidamente con las fibras de mayor tensión se orientan para llegar a la fractura por la disminución de rigidez y aumento de fragilidad de preimpregnado.

4. El daño se cuantificó deteniendo la prueba después de bloques con un número especificado de ciclos y examinando los paneles por inspección de ultrasonido por inmersión, con representación $\mathrm{C}$-scan y procesamiento digital de las imágenes obtenidas. El daño microscópico ocurre cuando el material soporta deformaciones umbral por encima de cierto valor umbral, y este daño continúa creciendo hasta que forma daño macroscópico que conduce al fallo final de los paneles.

5. En relación con la evolución del daño se observa una degradación en el comportamiento mecánico de los paneles, que ha sido monitorizada realizando pruebas de compresión después del impacto. Combinación de la información generada experimentalmente que permite predecir la evolución del daño en función de los ciclos de frenado sufridos en diferentes zonas del casco del buque, con datos sobre la disminución de la resistencia 
residual de los paneles en función de los niveles de daño presentes, Es posible hacer estimaciones cuantitativas sobre la evolución de la integridad estructural del casco durante la vida útil de ciertas condiciones de navegación.

6. La metodología aplicada mediante la observación de daño por caída de peso microestructuralmente con luz ultravioleta, relacionada con la tendencia de las curvas de fuerza versus desplazamiento en el manejo matemático de los resultados, guardan una relación directa de comportamiento y magnitud, con lo cual es un indicativo de que los ensayos son consistentes con los resultados.

7. Los ensayos realizados y los resultados experimentales obtenidos permitieron observar varios modos de fallo interno dentro del laminado del material compuesto a partir de una perspectiva de la micromecánica. Esto permitió predecir la aparición de las mesogrietas, la microfisuración en la matriz, la desunión de las fibras, la retirada de la fibra, y la delaminación.

8. El equipo es adecuado para realizar ensayos de impactos de slamming de baja energía en la cual las microgrietas se van alineando en forma interlaminar, y pasar a impactos de mediano nivel de energía en la cual el daño interlaminar produce también daño intralaminar.

9. Al insertar una lámina viscoelástica en los paneles de GFRP (OoA pre-impregnado) es posible mitigar efectivamente el daño por impacto. La combinación de polímeros con alta capacidad de deformación formando pequeñas células hexagonales, con paredes de un segundo polímero más rígido, amortigua los impactos. Las deformaciones están parcialmente aisladas en la lámina protectora y protegen las capas de material compuesto por debajo de la zona afectada. De este modo, se controla la generación y propagación del daño, mejorando la disipación de la energía de impacto, protegiendo así la estructura del casco y aumentando la vida útil del barco. Este enfoque abre nuevas perspectivas en el diseño de embarcaciones rápidas, permitiendo la modificación de cuartones, ya que la 
introducción de las capas viscoelásticas cambia la forma en que las tensiones debidas al fenómeno de golpeo se distribuyen y se concentran en el casco.

10. El modelo viscoelástico de elementos finitos empleado no lineal empleado para comprobar los beneficios de la capa elastomérica en la modificación del material permite grandes elongaciones causando un amortiguamiento de la energía que se comprobó experimentalmente con los resultados de los ensayos por caída de peso.

11. La energía de impacto definitivamente fue absorbida por la lámina viscoelástica y esta concentró las tensiones dando lugar a un perfil de tensiones obtenidos mediante el modelo no lineal de elementos finitos presentado anteriormente.

12. La caracterización por tintas penetrantes fluorescentes, permitió observar físicamente como el daño no se propaga de igual forma bajo las capas de la lámina viscoelástica, mezclándose este daño entre el golpe de impacto y la tensión normal por la flexión del panel en la cara de tracción.

13. En el impacto del panel modificado viscoelásticamente, se observa que el nivel de daño en la parte superior del laminado donde fue el golpe vertical de impacto, tiene una diferencia de daño mucho mayor que la cara inferior donde las grietas interlaminares e intralaminares no pudieron llegar a enlazarse para formar los típicos escalones.

14. La comparación realizada mediante la medición de la flexibilidad de los paneles, permitió ver en el ensayo realizado a similares condiciones de flexibilidad o de la pendiente de ingreso de la leva deformando el panel, permite observar que el comportamiento del panel modificado tiene una restitución con menor deformación luego del impacto de slamming-

15. El panel sin modificado pierde rápidamente mucha flexibilidad de allí en adelante, mientras que el modificado se mantiene debido a la lámina viscoelástica que absorbe este impacto cíclico. La comparación realizada es muy buena, porque en el ensayo del modificado no hubo despegue de la lámina viscoelástica, manteniéndose el panel como un solo cuerpo. 


\section{TRABAJOS FUTUROS}

El método de reproducción propuesto para estudiar el fenómeno de slamming, emplea una carga seca para estudiar la aparición de los daños dentro del material y su evolución. Este puede ser mejorado desarrollando investigación que considere lo siguiente:

- Incluir el efecto viscoso del agua, ya que esto induce cargas por cavitación además de actuar como un refrigerante para disminuir el calentamiento de la placa y de la leva.

- Diseñar un sistema de lectura con acelerómetro, para obtener el comportamiento del laminado durante cada ciclo de slamming instalado en la cara contraria al impacto. Durante los ensayos se observó que el diseño de la leva no induce un impacto lateral inicial, sino que la presión ejercida es gradual soportable al tacto, lo cual permitiría acoplar este tipo de equipo. Las curvas de fuerza versus desplazamiento dieron una idea clara de la delaminación, y con un acelerómetro instalado se podría analizar la evolución del daño en el interior de forma cuantitativa.

La propuesta sobre la modificación viscoelásticas y los resultados obtenidos, abren un gran campo para continuar la investigación en esta línea con el propósito de optimizar las prestaciones transmitidas al material circundante así como su participación como parte de un todo en el material compuesto. Así, se tiene lo siguiente.

- Investigar sobre mejorar la adherencia de la capa viscoelástica con el preimpregnado, con el propósito de canalizar las energías superficiales de los polímeros en contacto de tal forma que el esfuerzo de cizalla sean iguales para ambos materiales. Como se observó en la experimentación, el desprendimiento de las capas introduce datos erróneos en los resultados y definitivamente disminuyen la vida útil del laminado en el casco de una embarcación.

- No se ha considerado el efecto de la curvatura del casco de la embarcación y de cómo se acoplaría la lámina viscoelástica.

- Es importante estudiar el efecto del espesor del material elastómero con relación a su bondad de absorber la energía. En la construcción de naves el espesor y el peso de la 
estructura tiene un rol importante en el diseño de las condiciones operativas como potencia, peso y capacidad de carga. 


\section{REFERENCIAS}

1. Von karman, t., "el impacto de los flotadores de hidroaviones durante el aterrizaje". Nota técnica naca 321, washington d.c., ee.uu. 1929

2. Wagner, h. "uber stoss- und gleitvergange an der oberflache von flussigkeiten. "zeitschrift für angewandte mathematik und mechanik, 12: 4: 193-235. 1932

3. Kabsenberg B., "Slamming or ships: where are we Now?". Philosofical Transactions of Royal Society, 20 de junio de 2011. Pág 2892-2897.

4. Matthias Tenzer, "Experimental investigation of impact loads during water entry". Ship Technology Research. Vol 62, pág 47-59. 2015

5. Rousset J., Pettinotti B., "Slamming experiments on a ship model. Hydrodynamics and Ocean Eng. Group, Fluids Mech. Lab. - UMR 6598 CNRS.

6. Faltinsen, O. M. "Colloquium for Ship and Offshore Hydrodynamics" In Advances in ship and offshore hydrodynamics (ed. V. Bertram)., Institut fur Schiffbau der Universität Hamburg, Germany. Report no. 561, 1996.

7. Kapsenberg, G. K., Veer, A. P., "Whipping loads due to aft body slamming". 24th Symposium. on Naval Hydrodynamics, Fukuoka, Japan, Washington, DC: National Academies Press, 8-13 July 2002.

8. Kvålsvold, J. \& Faltinsen, O. M. 1993 Hydroelastic modeling of slamming against the wet deck of a catamaran. In Proc. 2nd Int. Conf. on Fast Sea Transportation (FAST), Yokohama, Japan, 13-16 December 1993, pp. 681-697.

9. Zhao, R. \& Faltinsen, O. M. 1993 Water entry of 2-dimensional bodies. J. Fluid Mech. 246, 593-612. (doi:10.1017/S002211209300028X)

10. Lewis, S. G., Hudson, D. A., Turnock, S. R. \& Taunton, D. J. Impact of a free-falling wedge with water: synchronized visualization, pressure and acceleration measurements. Fluid Dyn. Res. 42, 1-30. (doi:10.1088/0169-5983/42/3/035509) 2010.

11. Hermundstad, O. A., Aarsnes, "Hydroelastic analysis of a flexible catamaran and comparison with experiments". 3rd International. Conference on Fast Sea Transportation (FAST), Germany, Schiffstechnische Gesellschaft. 25-27 September 1995.

12. Lavroff, J., Davis, M. R., Holloway, D. S. \& Thomas, G. 2007 The whipping vibratory response of a hydroelastic segmented catamaran model. In Proc. 9th Int. Conf. on Fast Sea 
Transportation (FAST), Shanghai, China, 23-27 September 2007. China Ship Scientific Research Center.

13. Drummen, I., Storhaug, G. \& Moan, T. 2008 Experimental and numerical investigation of fatigue damage due to wave-induced vibrations in a container ship in head seas. J. Mar. Sci.Technol. 13, 428-445. (doi:10.1007/s00773-008-0006-5)

14. McTaggart, K., Datta, I., Stirling, A., Gibson, S. \& Glen, I. 1997 Motions and loads of a hydroelastic frigate model in severe seas. In SNAME Annual Meeting, Ottawa, Canada. SNAME.

15. Dessi, D., Mariani, R., La Gala, F. \& Benedetti, L. 2003 Experimental analysis of the wave induced response of a fast monohull via segmented-hull model. In Proc. 7th Int. Conf. on Fast Sea Transportation (FAST), Ischia, Italy, 7-10 October 2003.

16. Iijima, K., Hermundstad, O. A., Zhub, S. \& Moan, T. 2009 Symmetric and antisymmetric vibrations of a hydroelastically scaled model. In Proc. 5th Int. Conf. on Hydroelasticity in Marine Technology, Southampton, UK, 8-10 September 2009. Washington, DC: National Academies Press.

17. ABS, "Rules for Building and Classing High-Speed Craft". American Bureau of shipping, Parte 3, capítulo 2, sección 2. 2015. Pág 61-65.

18. Bogaert, H., Leonard, S., "Sloshing and scaling: results from the Sloshel project". 20th Int. Offshore and Polar Engineering Conf. (ISOPE), Beijing. Pág 20-25. 2010

19. Selvaraju S., Ilaiyavel S., "Applications of composites in marine industry". Journal of Engineering Research and Studies E-ISSN0976-7916 JERS, Vol.II. Pág 89-91, 2011.

20. Recuero A. "Refuerzo de estructuras con composites avanzados". Informes de la Construcción, Vol. 49, n 452, España. Diciembre 1997

21. Smith, C., "Design of Marine Structures in Composite Materials", Elsevier Applied Science, 1990.

22. Shenoi, R., Wellicome J., "Composite Materials in Maritime Structures", Cambridge University Press, Vol. 1, Fundamental Aspects, Vol. 2 Practical Considerations, 1993.

23. Rehau, "Unlimited Polymer Solutions" revista de Empresa, No. 8. España, 2015Noury P., Hayman B., "Lightweight construction for advanced shipbuilding - recent development". Det norske veritas. 
24. Mouritza, A., " Review of advanced composite structures for naval ships and submarines", Elsevier Vol 53-1, 2001

25. Noury P., "Lightweight construction for advanced shipbuilding - recent development". Det Norske Veritas.

26. Buermann T., Della L., "Fiber glass reinforced plastics for marine applications", Spring meeting of the society of naval architects and marine engineers - SNAME, Pág 138-192, junio 1960.

27. Heller S., "The use of composite material in naval ships, mechanics of composite material", the fifth symposium on structural mechanics, Pág 69-111. Mayo, 1976.

28. Makinen K., Hellbrat S. "The envelopment of sandwich structure". Kluwer Academic publishers, Netherlands, page 13-28 5. 1998

29. Dixon R., Ramsey B., "Design and build of GRP hull of HMS". Royal institution of naval symposium on GRP ship construction, Pág 192, UK,1972 .

30. Wllicome F., "Composites in offshore structures". Composite materials in marine structures, Vol 2. Pág 199-228.

31. M/S Bluefin propiedad de Nye Bluefin AS en Nekkøy, construido en Sæbøvågen, Noruega, 2000.

32. The Lake Geneva Solar Ferry built by Decision Boatyard used ACG's ZPREG partial impregnation technology.

33. Johnson T., “What are prepregs?”. Composite Technical Paper. Noviembre 2016.

34. Centea T., Grunenfeldr L., "A review of out-of-autoclave prepregs - Material properties, process phenomena, and manufacturing considerations". Composite Materials, Elsevier Edition, volume 70, Pág 132-158, 2015.

35. Largber Y., "Deformability of Unidirectional Prepreg Materials". Licentiate Thesis Stockholm, Sweden 2009. KTH School of Engineering Sciences ISSN 1651-7660 SE-100 44 Stockholm,

36. Cytec Industries, "venta de productos prepreg para usos industriales y aeroespaciales". Magazine.

37. Schlimbach J, Ogale A., "out-of-autoclave curing process in polimer matrix composites". Manofacturin techniques for polymer matrix composites publishing. Cambrige 2012. 
38. Brosius D., "Economic comparison of autoclave and quickstep processes for high volume advanced composite automotive components"

39. Calder N, "Who needs the pressure and Composite material companies continue to develop resins designed for outof-autoclave (OOA) cures". Cytec reports. 2006

40. Hou T., Baghman J., "Evaluation of Sandwich Structure Bonding In Out-of-Autoclave Processing”. Technical Paper of NASA Langley Research Center, Hampton, VA 23681. USA, Octubre de 2010. 12 p.

41. Sutter J., Kenner W., "Comparison of Autoclave and Out-of-Autoclave Composites". Technical Paper of NASA Langley Research Center, Hampton, VA 23681. USA, Octubre de 2011. 15 p.

42. Umeco, “Umeco MTM@22S Polyester Prepreg”. Umeco industries product description. 2012

43. Hou T., "A theoreticalstudy of resin flows for thermosetting materials during prepreg processing”. Nasa Contractor Report, Kentron International Inc. Aerospace Technological Division, Hampton Virgina, USA. Julio 1984.

44. Hubert P., "New Materials and Out-of-Autoclave Manufacturing Technologies for Aircraft Structures". Associate Professor, Canada Research Chair in Advanced Composite Materials Department of Mechanical Engineering, McGill University. 2006.

45. Hubert P., “Aspects Of Flow And Compaction Of Laminated Composite Shapes During Cure”. Thesis submitted in partial fulfillment of the requirements for the degree of Doctor of, Department of Metals and Materials Engineering. the University of British Columbia July 1996.

46. Pelhman H., McKorcle L., "Face-sheet quality analysis and thermo-physical property characterization of ooa and autoclave panels". NASA Glenn Research Center, Cleveland, OH. 44135. 11p. Extraído el 19 de noviembre de 2012 a la $12 \mathrm{~h} 10$ desde:

47. Arafath, A.R.A., Fernlund, G. \& Poursartip, A. "Gas Transport in Prepregs: Model and Permeability Experiments." 17th International Conference on Composite Materials (ICCM17) Edinburgh, Scotland. UK 2009

48. Balckington R., "A call to shipbuilders for a new approach to composite hull fabrication". Composite Technology magazine, agosto 2014. 
49. Hayman B., "Response of sandwich structures to slamming and impact loads". Composite Materials in Marine Structures, vol. 2. Cambridge University Press, Cambridge, Great Britain (Chapter 9). 1993.

50. Hayman B., "Response of sandwich structures to slamming and impact loads". Composite Materials in Marine Structures, vol. 2. Cambridge University Press, Cambridge, Great Britain (Chapter 9). 1993.

51. Z. Qin, R.C. Batra, "Local slamming impact of sandwich composite hulls", International Journal of Solids and Structures 46 (2009) 2011-2035.

52. Chen JK, Sun CT., "Dynamic large deflection response of composite laminates subjected to impact”. Compos Struct 4:59e73. 1985

53. S. Lake, M. Eagle "Slamming of Composite Yacht Hull Panels". The 18th Chesapeake Sailing Yacht Symposium. Marylan 2007.

54. Pedro Tamayo-Meza1, Anatoly S. Ovchinsky, "Estudio de la Dinámica de los Procesos de Fractura y de Delaminación en Materiales Reforzados con Fibras”. Revista de la Facultad de Ingenieria de la Universidad de Antioquia N. ${ }^{\circ} 70$ pp. 119-131, marzo, 2014.

55. A. Turon a, J. Costa a, "Simulation of delamination in composites under high-cycle fatigue". AMADE, Spain November 2006. Pág 1.

56. Shim VPW, Yang LM.," Characterization of the residual mechanical properties of woven fabric reinforced composites after low-velocity impact”. Int J Mech Sci 47:647e65. 2005

57. Lopes C., Seresta O., "Low-velocity impact damage on disperse stacking secuence laminates. Part I: experiments”. Compos Sci Tenchol 69(2009) 926-936. 2009

58. Choi H., Downs R., "A new approach toward understanding damage mechanisms and mechanics of laminated composite due to low velocity impact: part i - experiment". Journal of Composite Material, 25: 992-1011. 1991.

59. Choi H., Chang F., "A model for predicting damage in graphite/epoxy laminated composites resulting from low velocity point impact”. Journal Composite Material 26: 2134-2169. 1992.

60. Ahmed A., "A numerical study on interacting damage mechanisms in FRP laminated composite plates". Heron journal 58-1. 2013.

61. Jang B., Wang C. "Impact resistance and energy absorption mechanisms in hybrid composites”. Composites Science and Technology, Vol 34-4, Pages 305-335, 1989 
62. Cantwell W., Morton J., "The impact resistance of composite materials - a review". The composite Journal Vol 22-5, Pág 347-362, 1991.

63. Lopes C., Cammanho P., "Low-velocity impact damage on dispersed stacking sequence laminates. Part II: Numerical simulations”. Composites Science and Technology 69 (2009) 937-947. 2009

64. Abrate S., "Impact on Laminated Composite Materials". Applications Mechanical, Rev 44-4, pág 155-190. 2009.

65. Belingardini G., Bador V., Low velocity impact tests of laminate glass-fiber-epoxy matrix composite material plates International Journal of Impact Engineering, Vol 27-2, 2002.

66. Baucoma J., Zikryb M., "Low-velocity impact damage progression in woven E-glass composite systems Composites Part A”. Applied Science and Manufacturing, Vol 36-5, Pages 658-664, 2005.

67. Svenson A., Hargrave M., "Data Analysis Techniques for Impact Tests of Composite Materials”. ASTM International, Vol 22-5, 1994.

68. Elavenil S., Knight S., "Impact response of plates under drop weight impact testing”. Daffodil International University Journal Of Science And Technology, Vol7-1, 2012.

69. Grasso M., Penta F. "Low Velocity Impact Response of Composite Panels for Aeronautical Applications". Proceedings of the World Congress on Engineering London, Vol 2, 2015.

70. Liu P., Zheng Y., "Recent developments on damage modeling and finite element analysis for composite laminates: A review", Materials and Design 31 (2010) 3825-3834.

71. Zhou G. "The use of experimentally-determined impact force as a damage measure in impact damage resistance and tolerance of composite structures”. Composite Structural 42:375e82. 1988

72. Brien TK. Analysis of local delaminations and their in uence on composite laminate behaviour. Delaminations and debonding of materials. ASTM STP 876 W.S. Jhonson ASTM 1985.

73. Shi Y., Swait T, "Modelling damage evolution in composite laminates subjected to low velocity impact”. Composite Structures 94 Pág 2902-2913, 2012.

74. Raimondo L., Lannuci L., “A progressive failure model for mesh-size-independent FE analysis of composite laminates subject to low-velocity impact damage". Composites Science and Technology 72, Pág 624-632, 2012 
75. Tomblin, J., Lacy, T., "Review of Damage Tolerance for Composite Sandwich Airframe Structures". Final Report, DOT/FAA/AR-99/49, 1999.

76. Zilong Z., Xiaoquan Ch., "An Investigation On The Impact Resistence And Residual Compressive Strength Of Composite Materials". Institute of Aeronautical Materials ID-115 Beijing.

77. Sanchez S., Barbero E., "Compression after impact of thin composite laminates". Department of Continuum Mechanics and Structural Analysis, España.

78. Varela T., Fernández E. "Material Compuestos Multifuncional con Intercapa Viscoelástica". Patente WO2012089884 A1, Airbus Operation Cl, 2012.

79. Maly R., Johnson D., “Cocured Viscoelastic Composite”. Smart Structures and Materials, doi:10.1117/12.239104, 1996.

80. Jayantha A. Epaarachchi, "An empirical model for fatigue behavior prediction of glass fibrereinforced plastic composites for various stress ratios and test frequencies. Department of Mechanical Engineering, University of Newcastle, Australia Composites: Part A 34 (2003) 313-326.

81. Blake J., Shenoi R., "Strength modelling in stiffened FRP structures with viscoelastic inserts for ocean structures" University of Southampton, UK Ocean Engineering 29 (2002) 849-869

82. House R., Grant J. "Viscoelastic Composite Materials For Noise Reduction And Damage Tolerance", Advance Performance Material, Vol 3-3, Pág 295-30, 1996.

83. Lavanya K., Vamsi P., "Analysis of the damping characteristics of glass fibre reinforced composite with different orientations and viscoelastic layers". International Journal of Conceptions on Mechanical and Civil Engineering. Vol. 1, Issue. 1, Dec' 2013; ISSN: 2357 2760

84. Rajesh S., Ramesh T., "A continuum damage model for linear viscoelastic". Composite materials. School of Aerospace Engineering, Georgia Institute of Technology, Atlanta

85. Crowther M., Wyatt R., "Creep-fatigue interactions in glass/polyester composites". Composites Science and Technology, 36:191-210. 1989

86. Reifsnider, K., "Some fundamental aspects of the fatigue and fracture response of composite materials. Proceedings of the Fourteenth Annual Meeting of the Society of Engineering Science, Lehigh University. 1977 
87. Moore, R., Dillard, D., "Time-dependent matrix cracking in cross-ply laminates". Composites Science and Technology 39, 1-12. 1990

88. Raghavan, J., Meshii, M., "Time-dependent damage in carbon fibre reinforced polymer composites". Composites Part A 27 (12), 1223-1227. 1996

89. Zocher, M., Allen D., "Stress analysis of a matrix-cracked viscoelastic laminate". International Journal of Solids and Structures 34 (25), 3235-3257. 1997

90. Zocher, M., Groves, S., “A threedimensional finite element formulation for thermoviscoelastic orthotropic media". International Journal for Numerical Methods in Engineering 40, $2267-$ 2288. 1997

91. Kumar, R., Talreja, R., "Linear viscoelastic behavior of matrix cracked cross-ply laminates". Mechanics of Materials 33 (3), 139-154. 2001

92. Arvin H., "Frequency response analysis of higher order composite sandwich beams with viscoelastic core", Transactions of Mechanical Engineering, Vol. 38, No. M1+, pp 143-155. 2014 
ANEXOS 

WE91-2

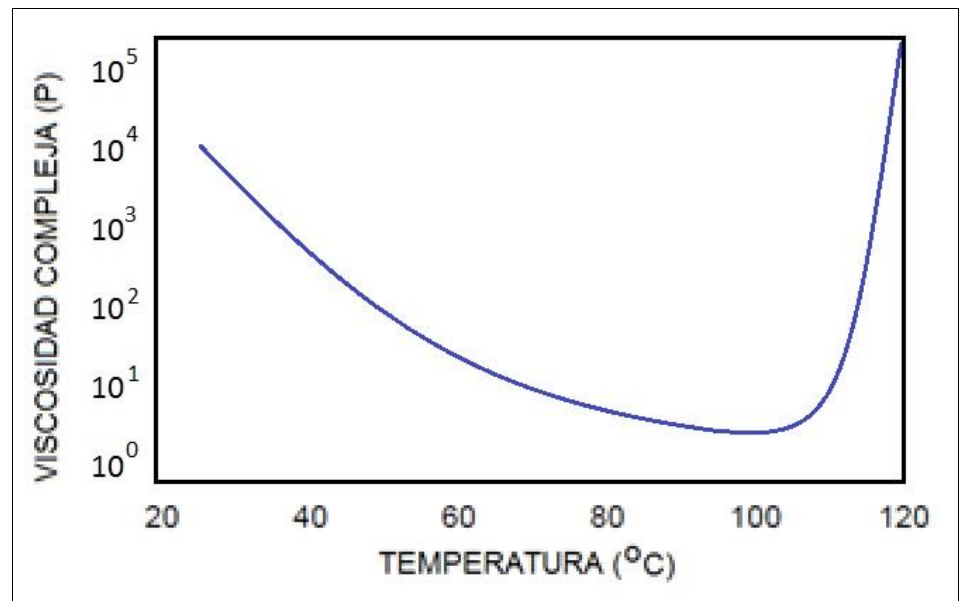

Figura 110 Viscosidad Compleja del Prepreg WE91-2

\begin{tabular}{|l|l|l|l|l|}
\hline PROPIEDADES & \multicolumn{2}{|l|}{ VALORES } & UNIDAD & MÉTODO \\
\hline Laminado típico & \multicolumn{2}{l|}{$\begin{array}{l}\text { 4 capas de laminado WE91-2 XE600 biaxial con 35\% de contenido } \\
\text { de resina }\end{array}$} \\
\hline $\begin{array}{l}\text { Rampa de } \\
\text { temperatura }\end{array}$ & $1-2$ & \multicolumn{2}{l|}{${ }^{\circ} \mathrm{C} / \mathrm{min}$} & - \\
\hline $\begin{array}{l}\text { Temperatura de } \\
\text { curado }\end{array}$ & 85 & 120 & ${ }^{\circ} \mathrm{C}$ & - \\
\hline Tiempo de curado & 600 & 90 & $\mathrm{~min}$ & - \\
\hline $\begin{array}{l}\text { Presión de curado } \\
\text { Temperatura de } \\
\text { desmoldado }\end{array}$ & 1 & Bar & - \\
\hline $\begin{array}{l}\text { Temperatura de } \\
\text { transición vítrea }\end{array}$ & $110-125$ & ${ }^{\circ} \mathrm{C}$ & - \\
\hline
\end{tabular}

Tabla 7 Condiciones de curado del WE91-2 


\begin{tabular}{|c|c|c|c|}
\hline PROPIEDADES & VALORES & UNIDAD & MÉTODO \\
\hline Restricción & \multicolumn{3}{|c|}{$4 \mathrm{~mm}$ de espesor curado en $90 \mathrm{~min} 120^{\circ} \mathrm{C}$} \\
\hline Resistencia a la tracción & 88 & $\mathrm{GPa}$ & ISO $527-2$ \\
\hline Módulo de tracción & 3.3 & $\mathrm{GPa}$ & ISO $527-2$ \\
\hline Resistencia a la compresión & 118 & $\mathrm{GPa}$ & ISO 604 \\
\hline Módulo de compresión & 3.9 & $\mathrm{GPa}$ & ISO 604 \\
\hline
\end{tabular}

Tabla 8 Características mecánicas de la resina WE91-2

\begin{tabular}{|c|c|c|c|}
\hline PROPIEDADES & VALORES & UNIDAD & MÉTODO \\
\hline Tipo de fibra & \multicolumn{3}{|c|}{$\begin{array}{l}1200 \mathrm{gr} / \mathrm{m} 2 \text { de armado triaxial con resina tipo E, con } \\
50 \mathrm{~g} / \mathrm{m} 2 \text { de vellón }\end{array}$} \\
\hline Porcentaje de resina & 43 & $\%$ & - \\
\hline Presión de curado & 1 & Bar & - \\
\hline Temperatura de curado & 90 & ${ }^{\circ} \mathrm{C}$ & - \\
\hline Tiempo de curado & 120 & $\min$ & - \\
\hline Temperatura de transición vítrea & $110-125$ & ${ }^{\circ} \mathrm{C}$ & $\begin{array}{ll}\text { ISO } & 671 \\
\text { (DMA) }\end{array}$ \\
\hline Espesor del laminado curado & 1.01 & $\mathrm{~mm}$ & $\begin{array}{l}\text { ASTM D3171 } \\
\text { Método II }\end{array}$ \\
\hline $\begin{array}{l}\text { Volumen de fibra a } 0^{\circ} \text { de la } \\
\text { dirección de tensión }\end{array}$ & 45.2 & $\%$ & $\begin{array}{l}\text { ASTM D3171 } \\
\text { Método II }\end{array}$ \\
\hline $\begin{array}{l}\text { Esfuerzo de tensión a } 0^{\circ} \\
\text { (normalizado al 60\%) }\end{array}$ & 656 & Мpa & ISO 527-4 \\
\hline $\begin{array}{l}\text { Módulo de tensión a } 0^{\circ} \\
\text { (normalizado al } 60 \% \text { ) }\end{array}$ & 24 & $\mathrm{GPa}$ & ISO $527-4$ \\
\hline $\begin{array}{l}\text { Volumen de fibra a } 0^{\circ} \text { de la } \\
\text { dirección de compresión }\end{array}$ & 44.5 & $\%$ & $\begin{array}{l}\text { ASTM D3171 } \\
\text { Método II }\end{array}$ \\
\hline
\end{tabular}




\begin{tabular}{|l|l|l|l|}
\hline $\begin{array}{l}\text { Esfuerzo de compresión a } 0^{\circ} \\
\text { (normalizado al 60\%) }\end{array}$ & 537 & MPa & $\begin{array}{l}\text { SACMA } \\
\text { SRM1-94 }\end{array}$ \\
\hline $\begin{array}{l}\text { Volumen de fibra a } 0^{\circ} \text { del módulo } \\
\text { de compresión }\end{array}$ & 46.4 & 5 & $\begin{array}{l}\text { ASTM D3171 } \\
\text { Método II }\end{array}$ \\
\hline $\begin{array}{l}\text { Módulo de compresión a } 0^{\circ} \\
\text { (normalizado al 60\%) }\end{array}$ & 31 & GPa & $\begin{array}{l}\text { SACMA } \\
\text { SRM1-94 }\end{array}$ \\
\hline $\begin{array}{l}\text { Volumen de fibra a de la } \\
\text { dirección del ensay ILSS }\end{array}$ & 45.4 & $\%$ & $\begin{array}{l}\text { ASTM D3171 } \\
\text { Método II }\end{array}$ \\
\hline \begin{tabular}{l} 
Resistencia ILSS a $0^{\circ}$ \\
\hline
\end{tabular} & 41 & MPa & ISO 14130 \\
\hline
\end{tabular}

Tabla 9 Propiedades del laminado WE91-2 ya curado 
ANEXO 2 ANALISIS DE LOS PANELES DE GFRP SIN MODIFICAR MEDIANTE ULTRASONIDO SUMERGIDO

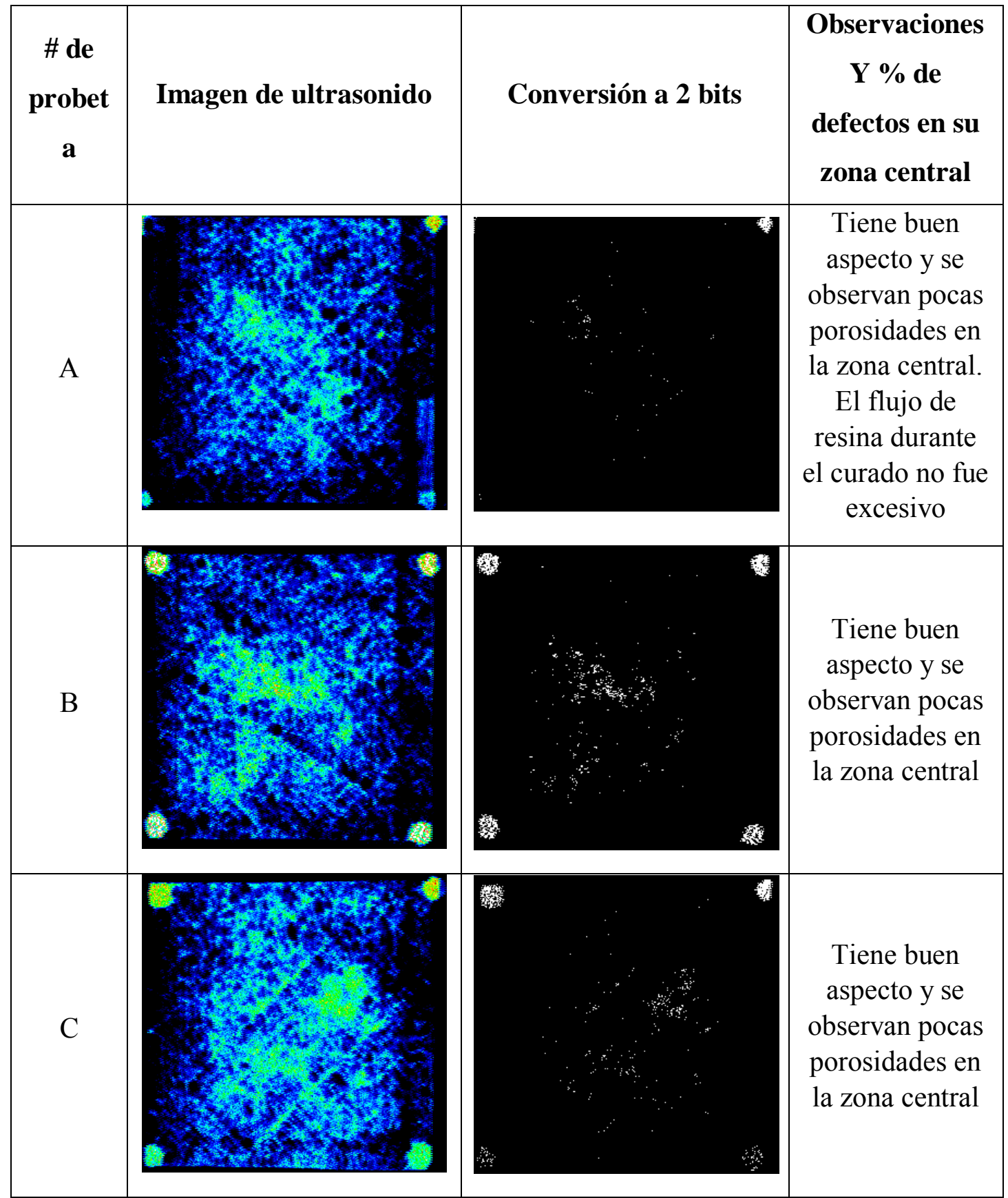




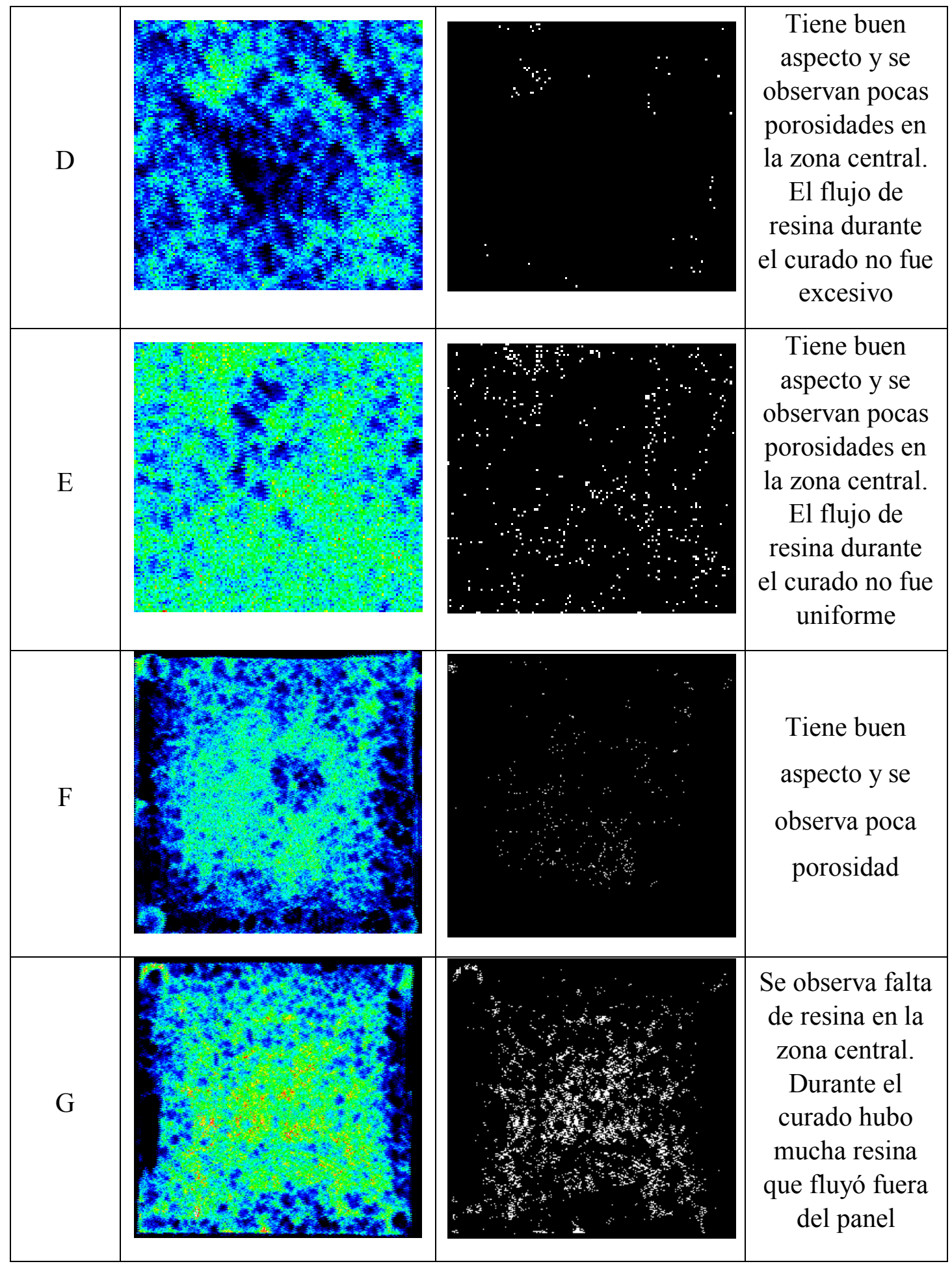




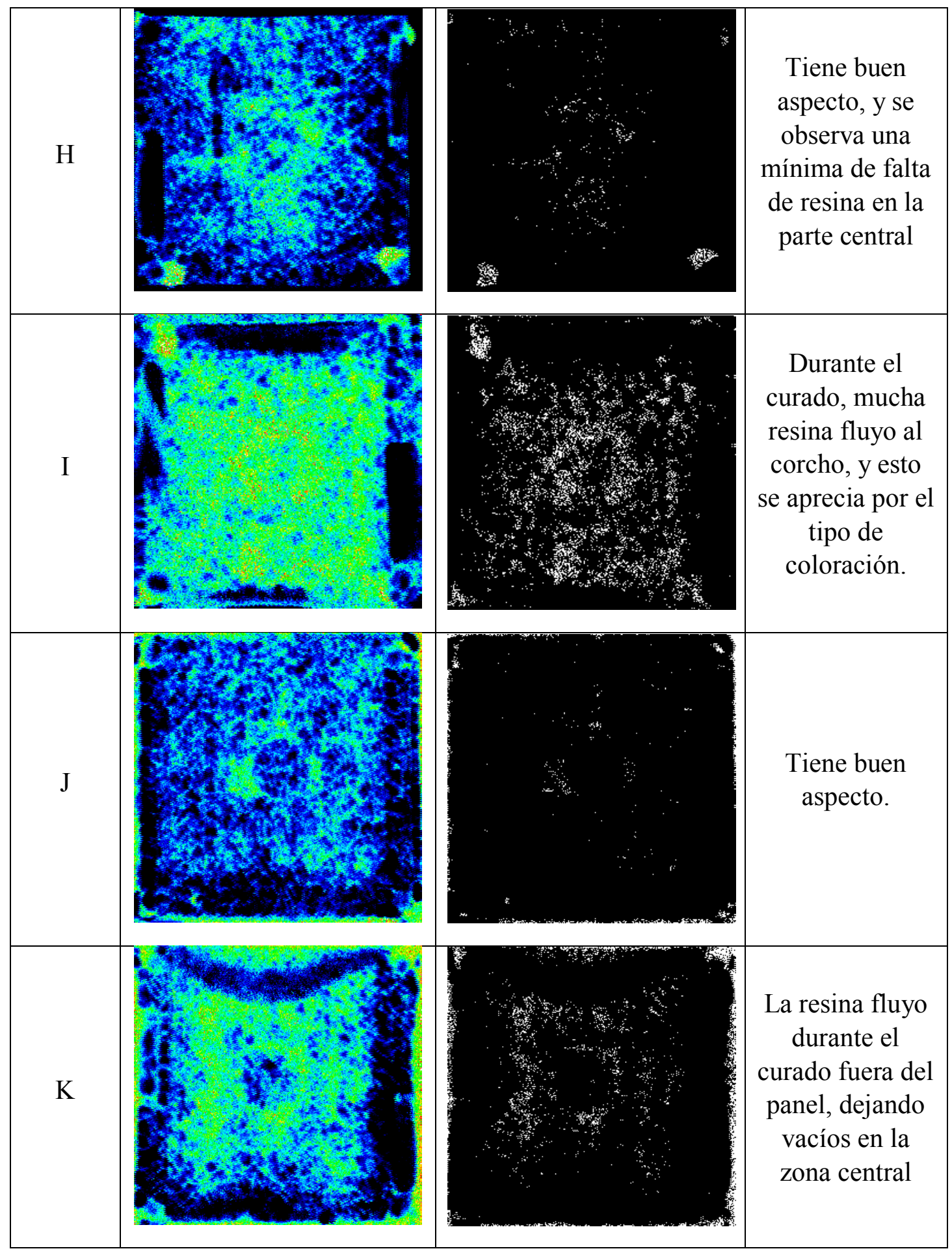




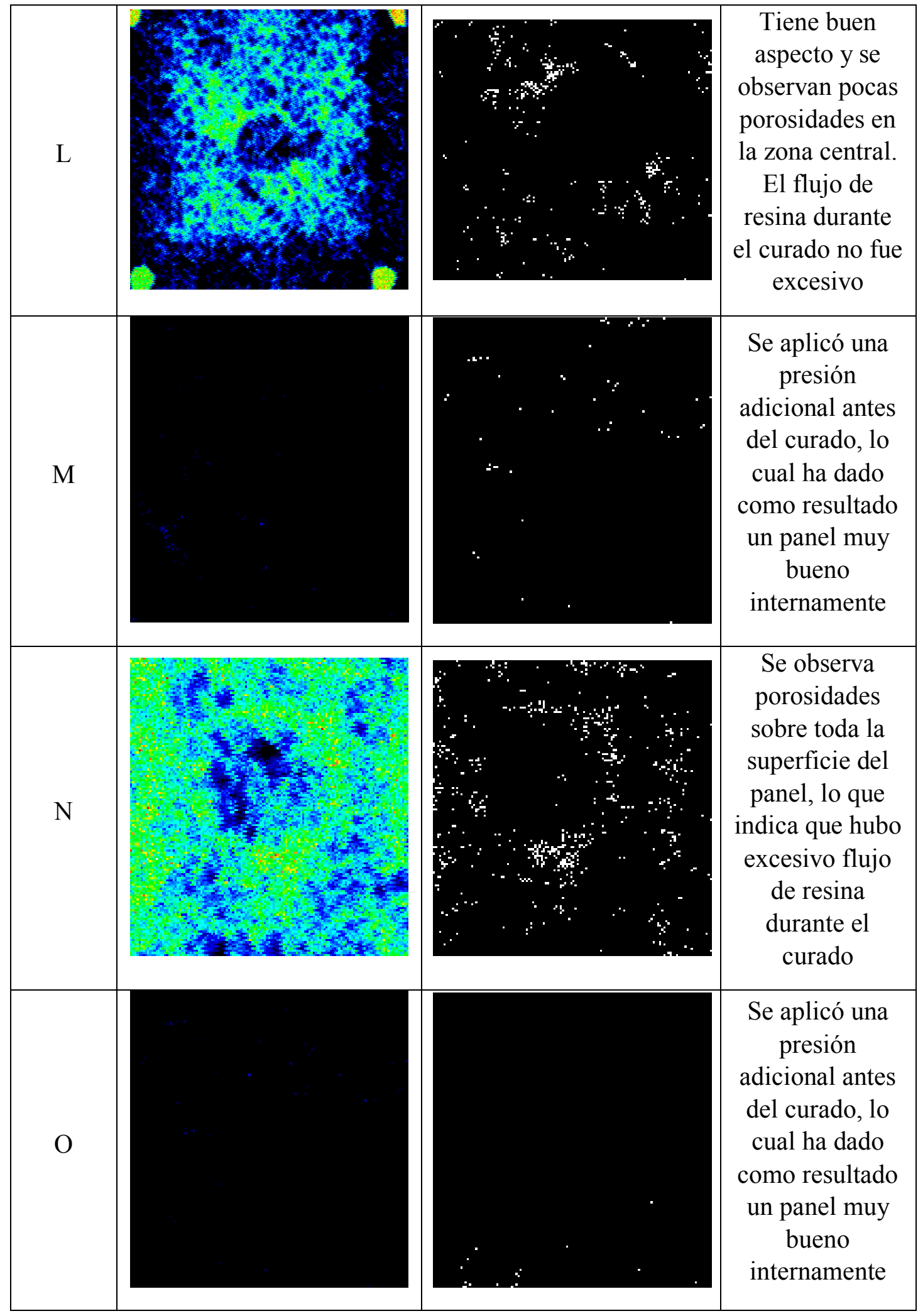




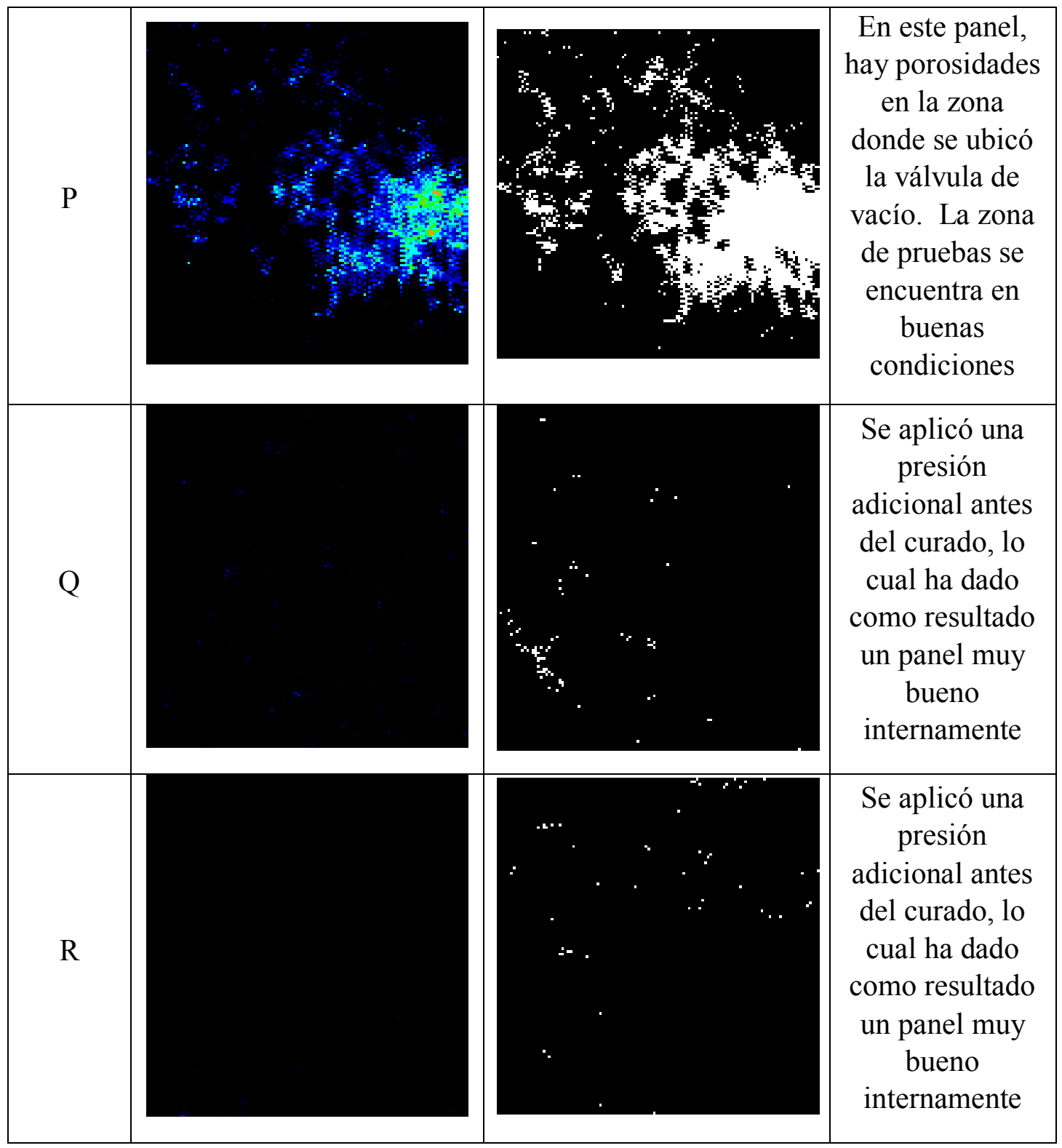

Tabla 10 Análisis de los paneles de GFRP con ultrasonido sumergido 
ANEXO 3 ANALISIS DE ENERGÍAS LUEGO DEL IMPACTO POR CAÍDA DE PESO DE PANELES NO MODIFICADOS

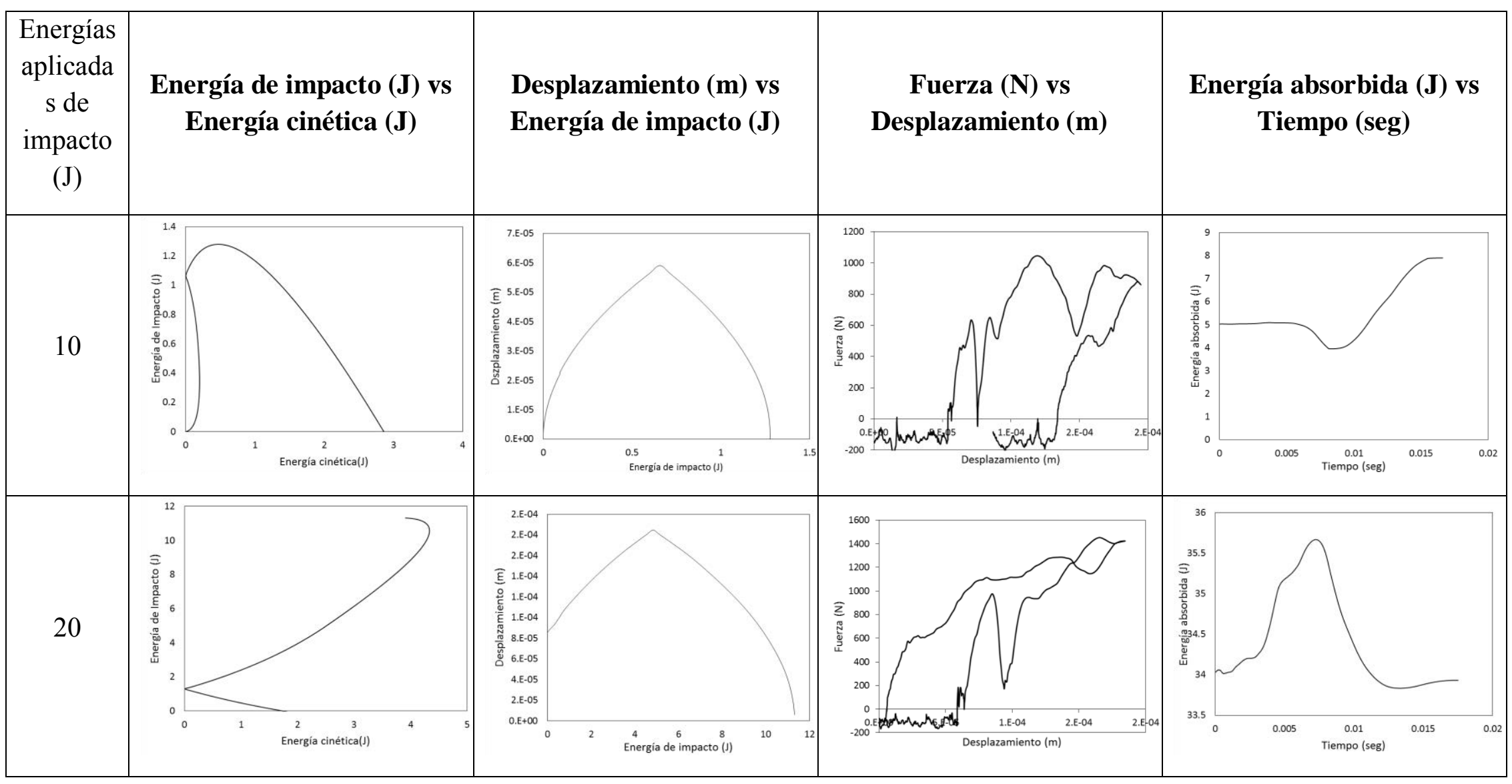




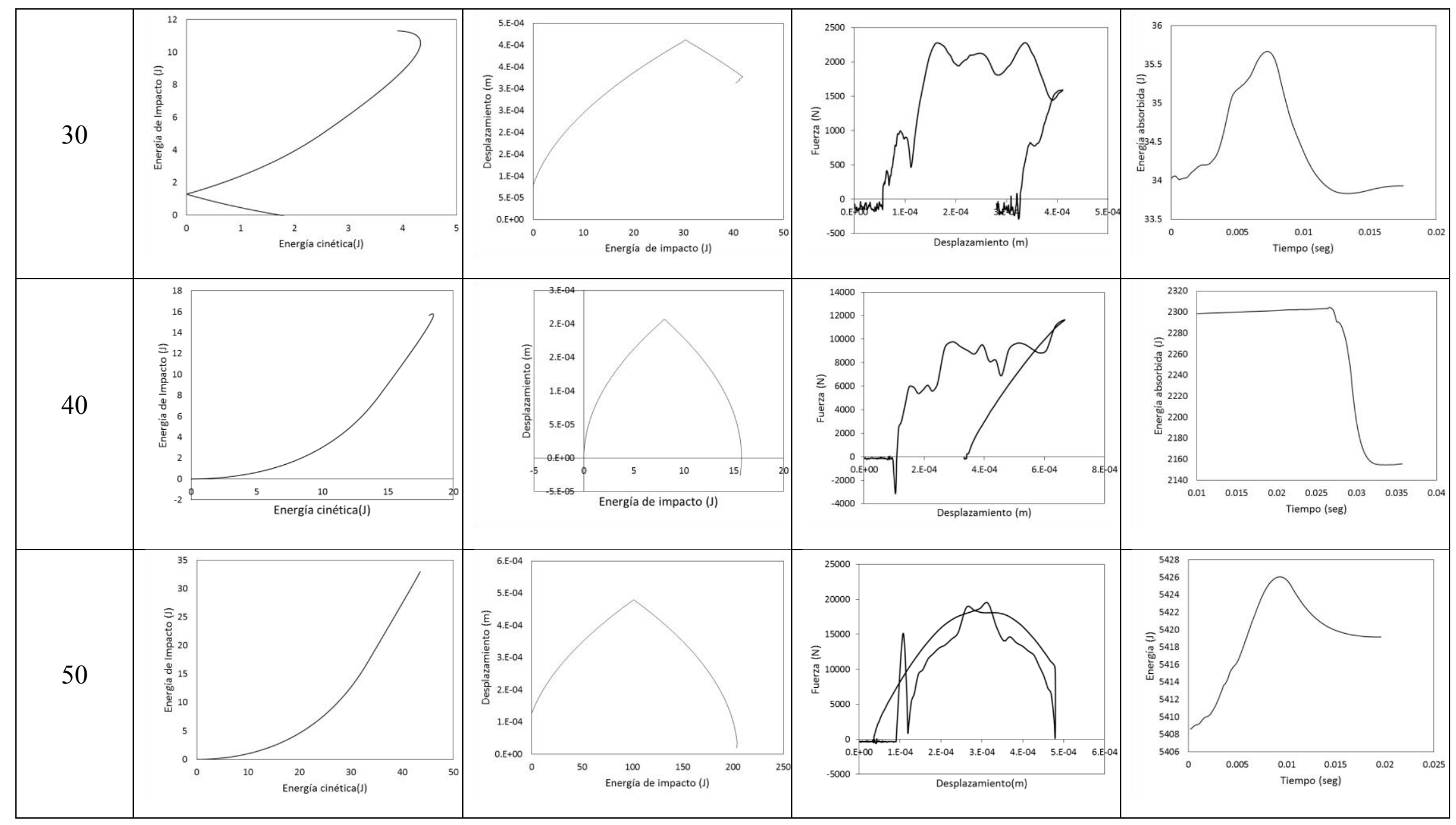




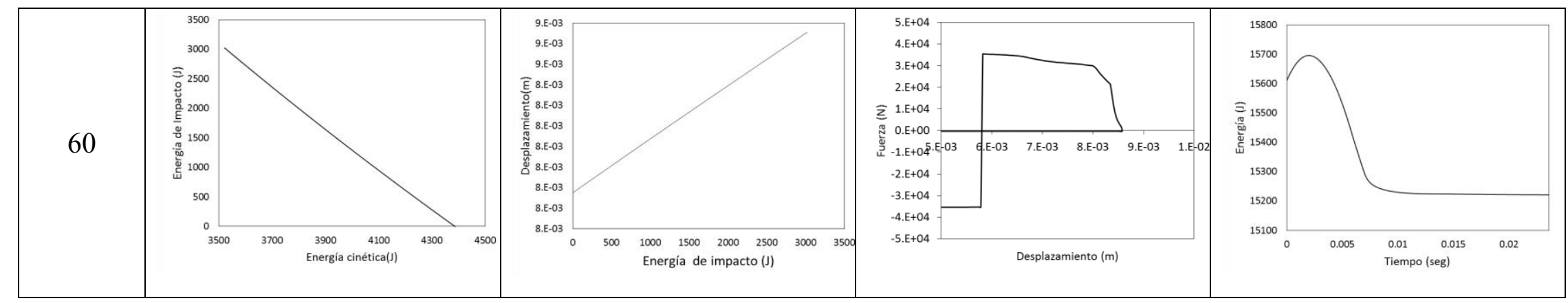


ANEXO 4 PANELES DE GFRP DE PREIMPREGNADO SIN MODIFICAR LUEGO DEL IMPACTO POR CAIDA DE PESO CARACTERIZADO CON LUZ Y TINTA PENETRANTE ULTRAVIOLETA

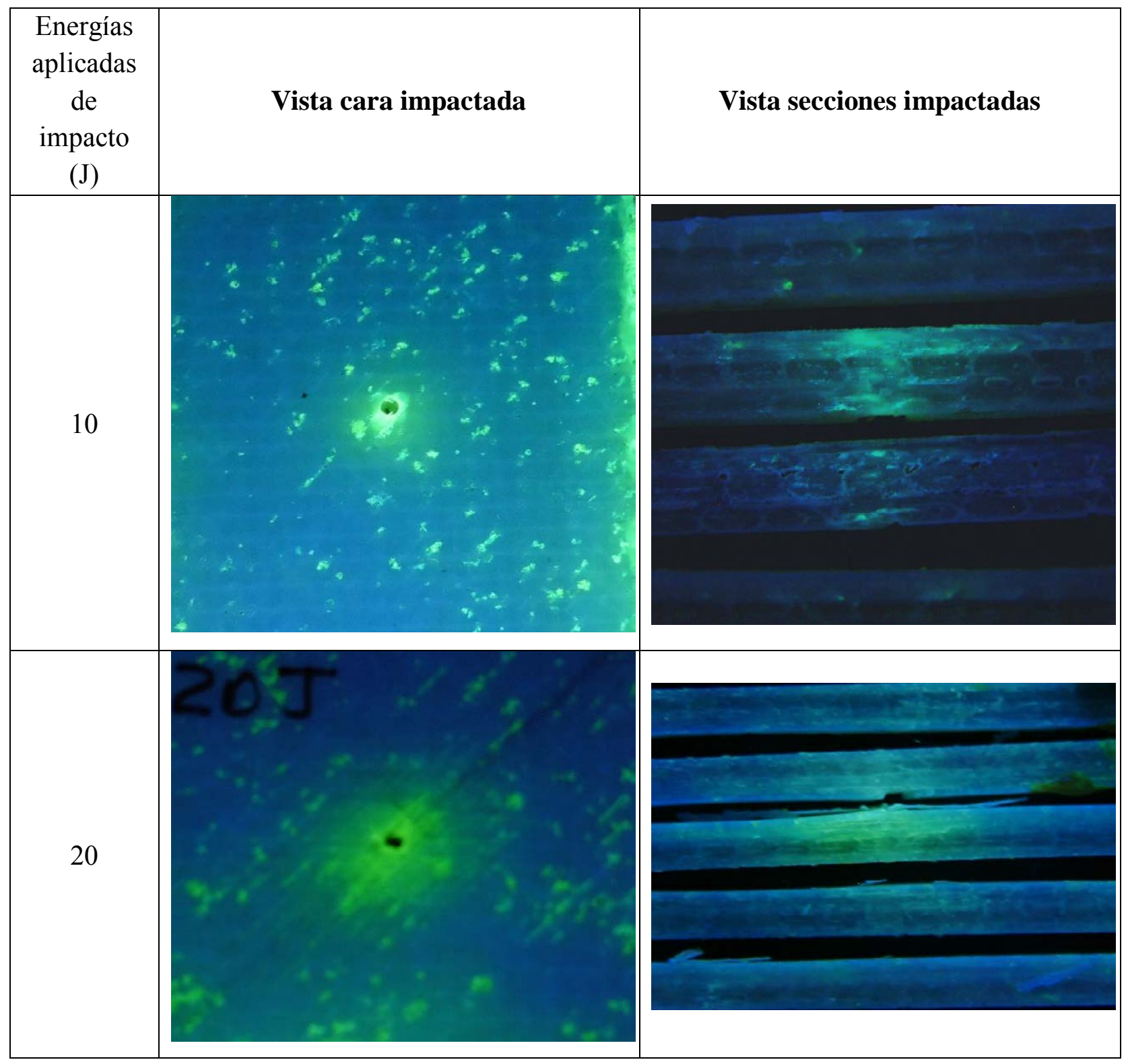




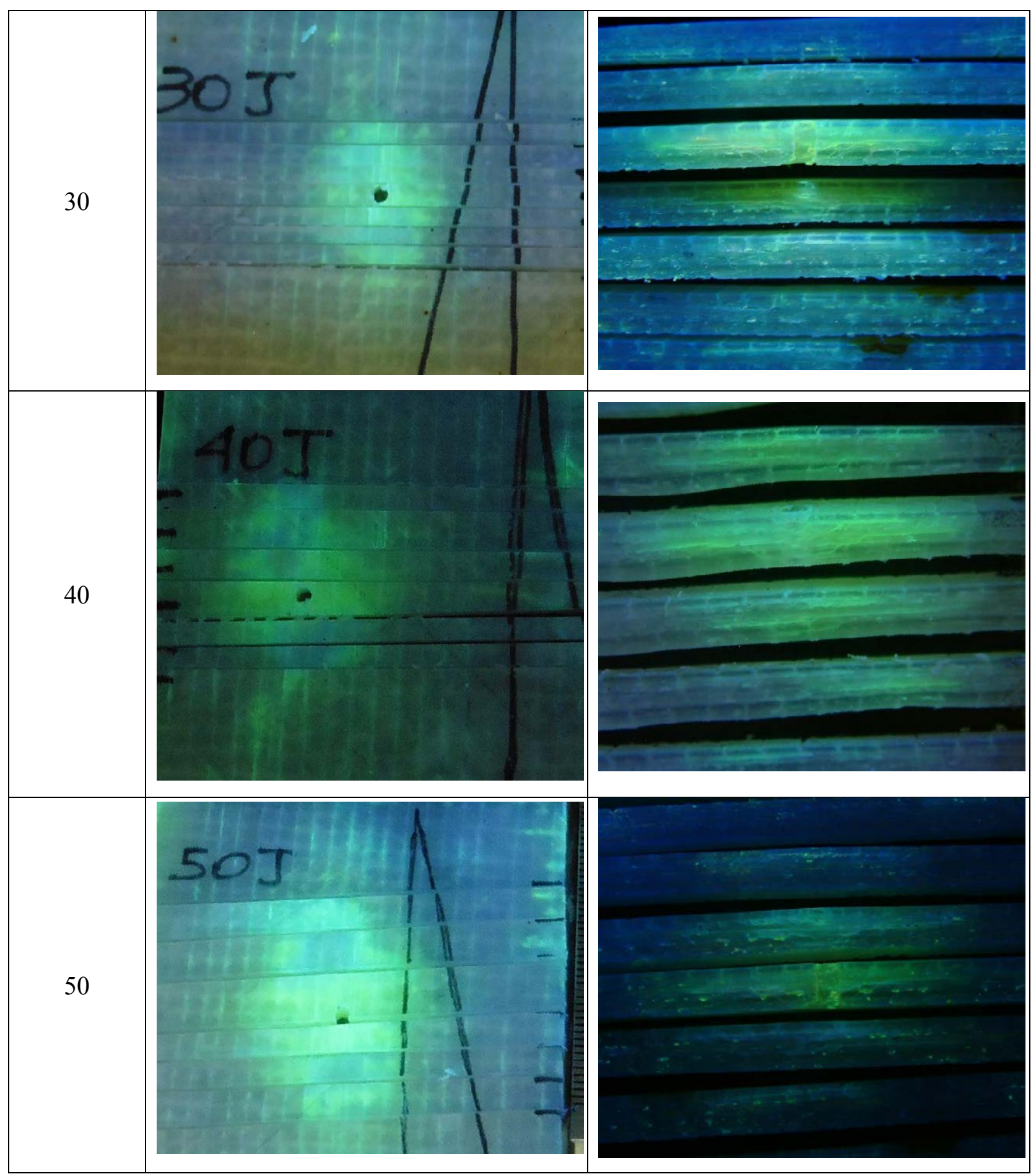




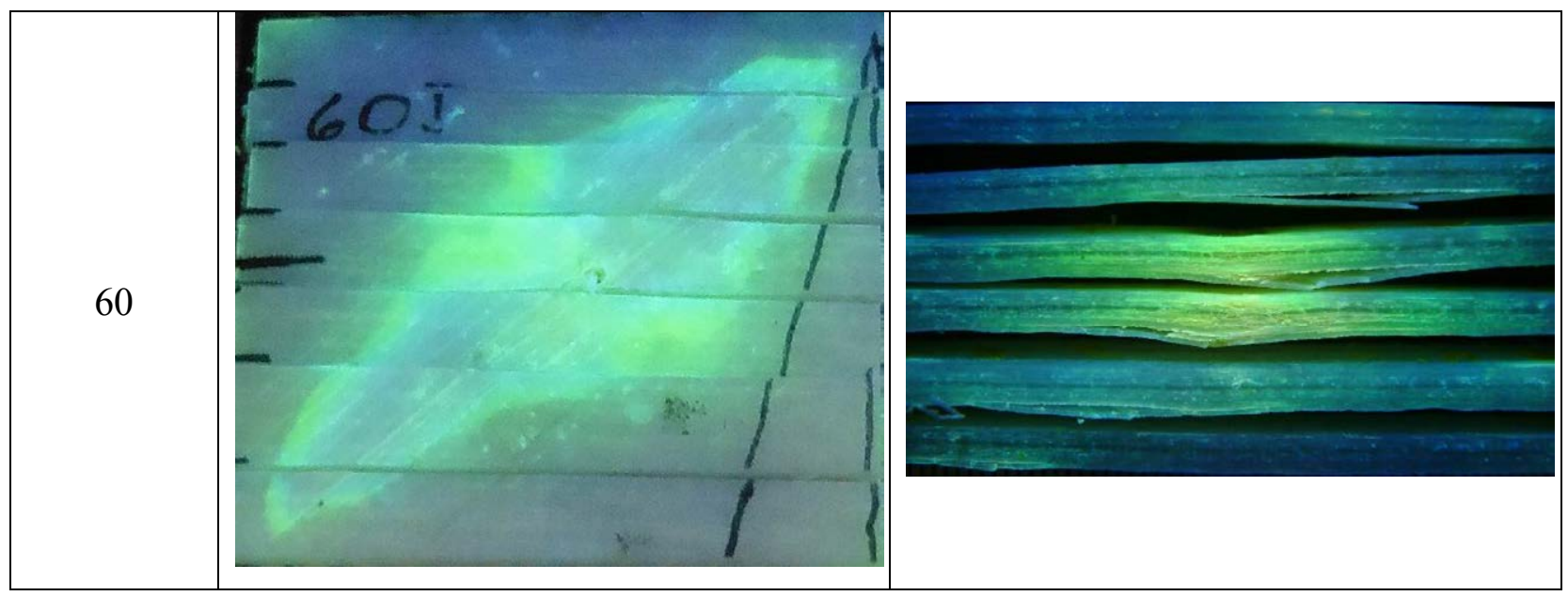


ANEXO 5 MODELADO 3D DE LAS DELAMINACIONES ENTRE CAPAS EN PANELES SIN MODIFICAR IMPACTADOS POR CAÍDA DE PESO

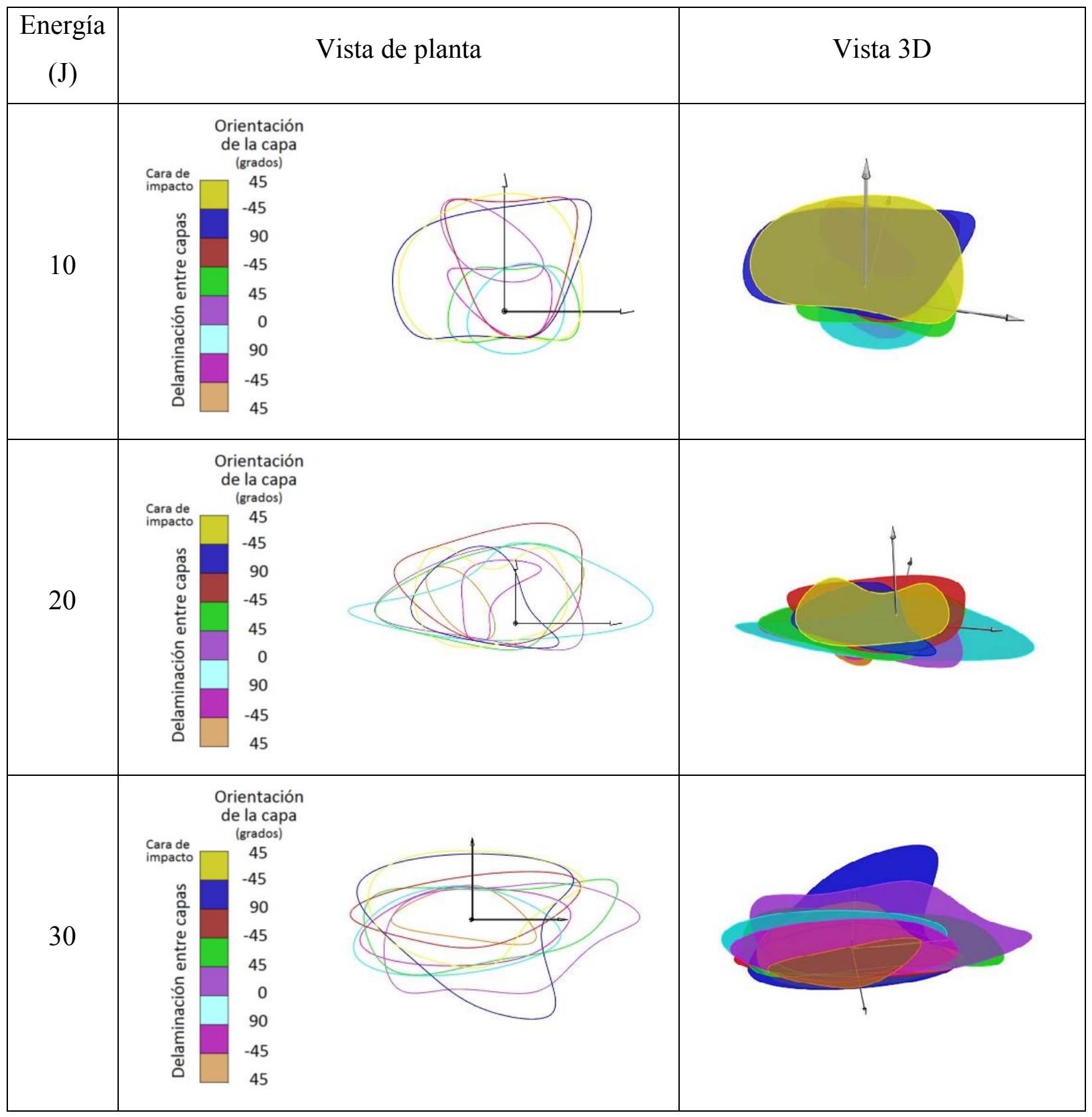




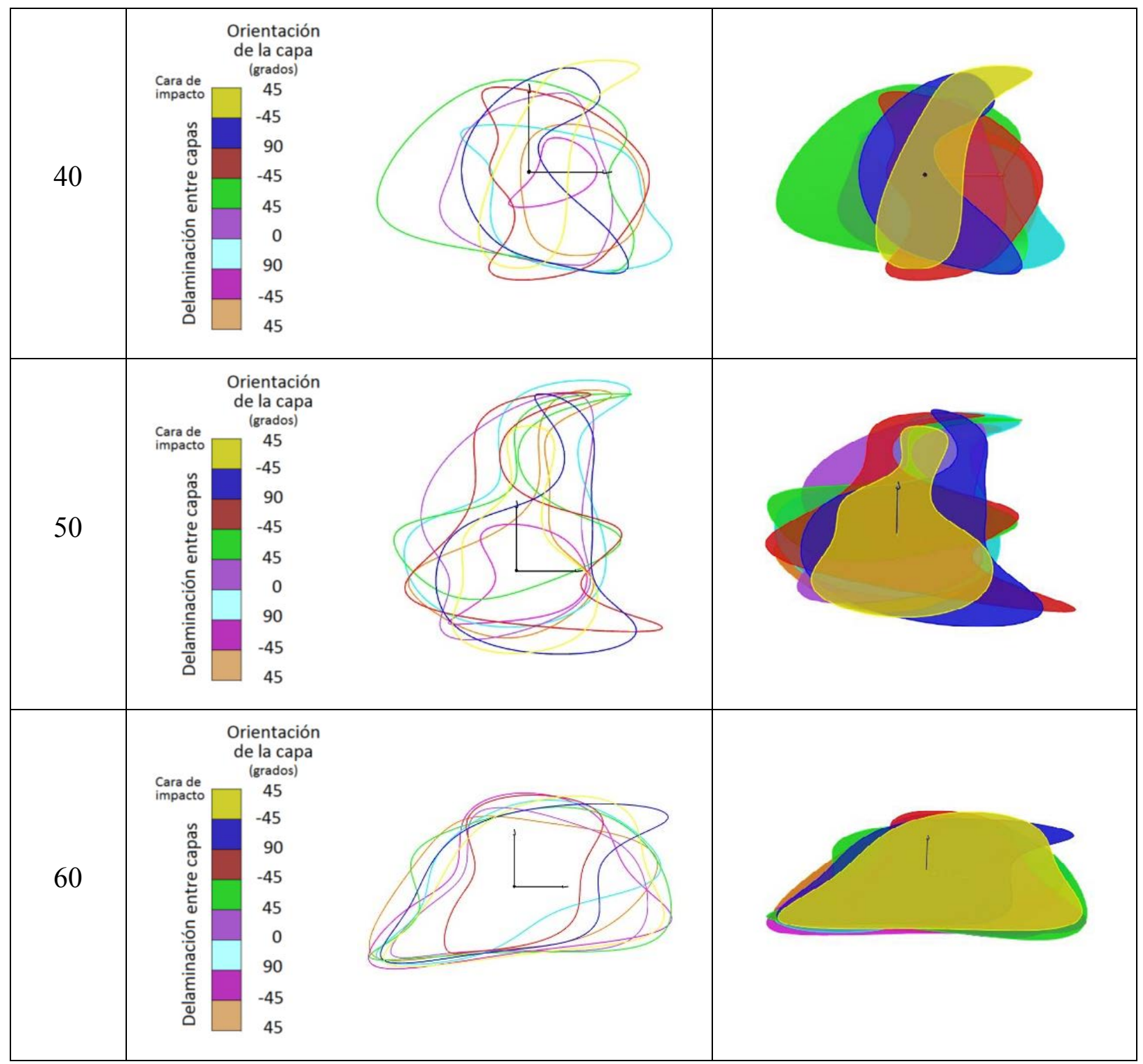


ANEXO 6 PANELES DE GFRP DE PREIMPREGNADO MODIFICADOS LUEGO DEL IMPACTO POR CAIDA DE PESO CARACTERIZADO CON LUZ Y TINTA PENETRANTE ULTRAVIOLETA

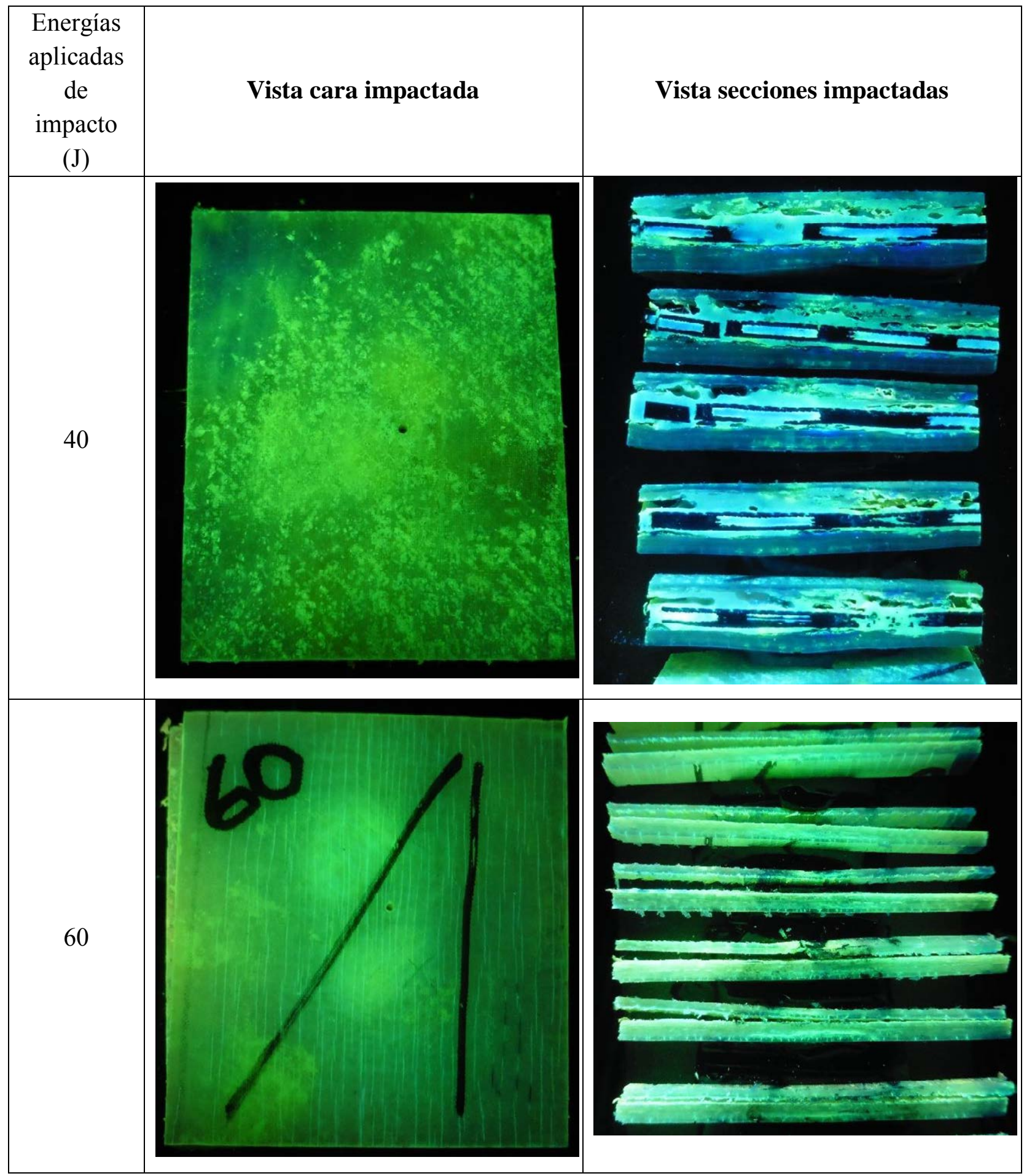




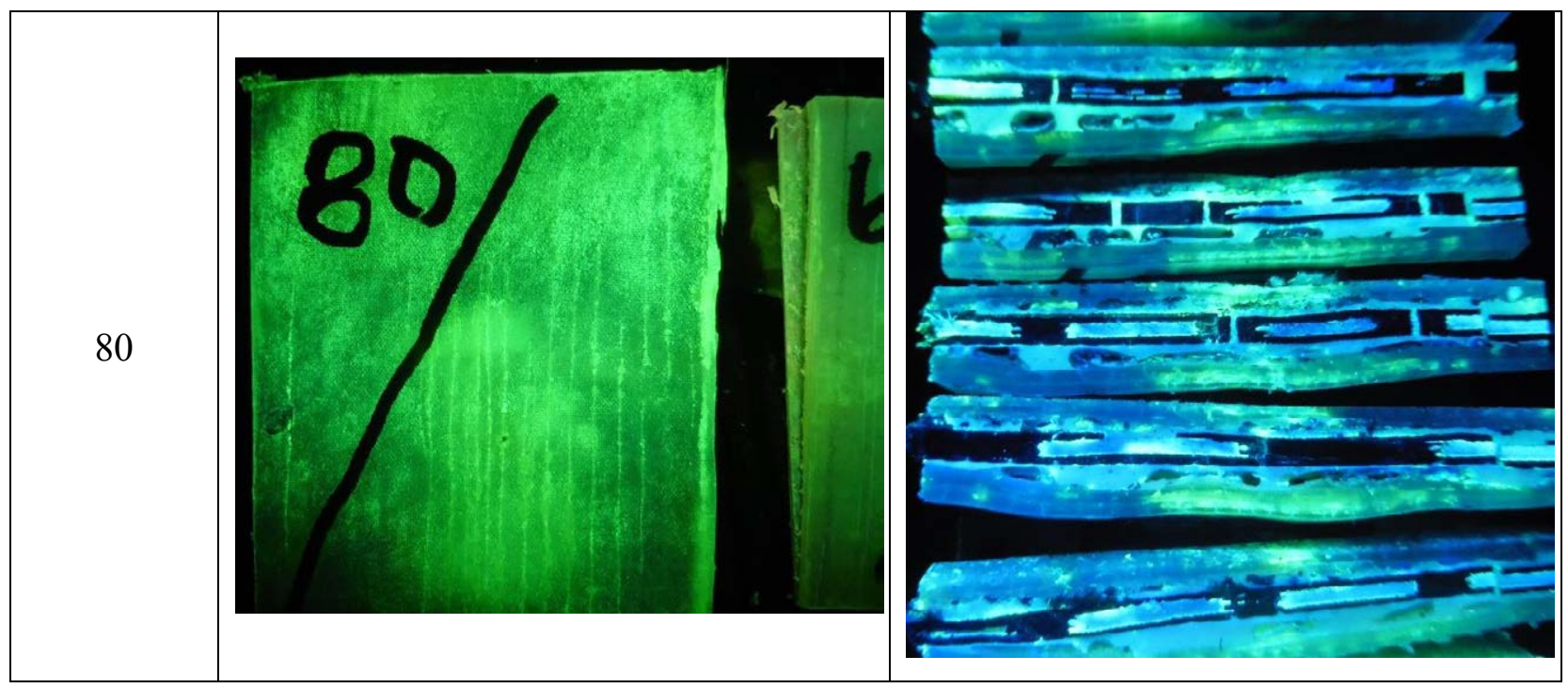


ANEXO 7 ANALISIS DE ENERGÍAS LUEGO DEL IMPACTO POR CAÍDA DE PESO DE PANELES NO MODIFICADOS

\begin{tabular}{|c|c|c|c|c|}
\hline $\begin{array}{c}\text { Energías } \\
\text { aplicadas de } \\
\text { impacto }(\mathrm{J})\end{array}$ & $\begin{array}{c}\text { Energía de impacto }(\mathbf{J}) \text { vs } \\
\text { Energía cinética }(\mathbf{J})\end{array}$ & $\begin{array}{l}\text { Desplazamiento }(\mathrm{m}) \text { vs } \\
\text { Energía de impacto }(\mathrm{J})\end{array}$ & $\begin{array}{c}\text { Fuerza }(\mathbf{N}) \text { vs } \\
\text { Desplazamiento (m) }\end{array}$ & $\begin{array}{c}\text { Energía absorbida }(\mathbf{J}) \text { vs } \\
\text { Tiempo (seg) }\end{array}$ \\
\hline $20(2)$ & 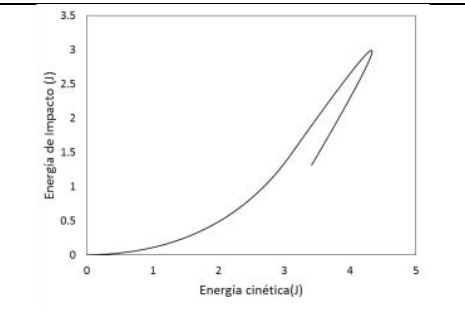 & 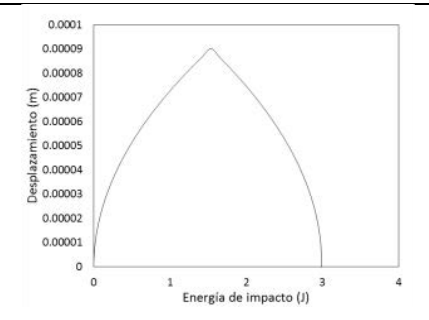 & (2) & D.e05 \\
\hline $30(2)$ & 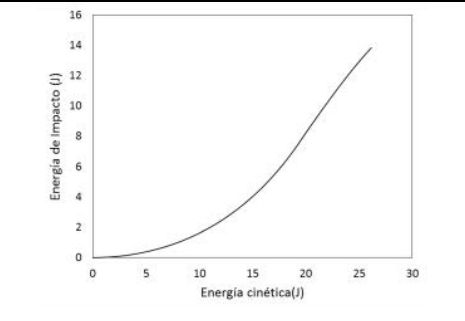 & 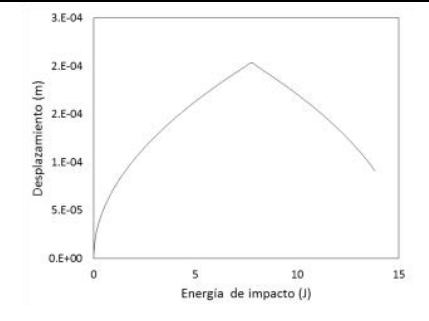 & 象 & ${ }_{\text {Tempoos (sege) }}^{0.011}$ \\
\hline $30(3)$ & 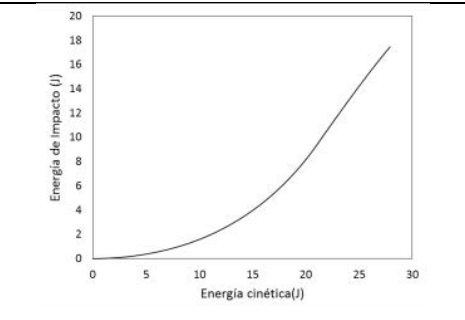 & 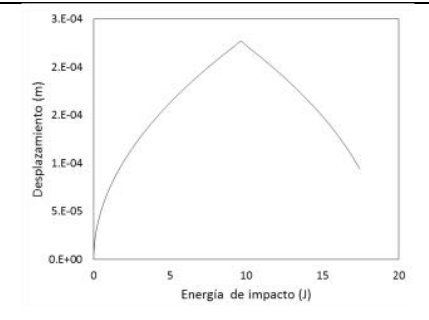 & Desplazmiento (m) & $\underbrace{0.011}_{\text {Tempo (seg) }} \quad$ 0.015 \\
\hline
\end{tabular}




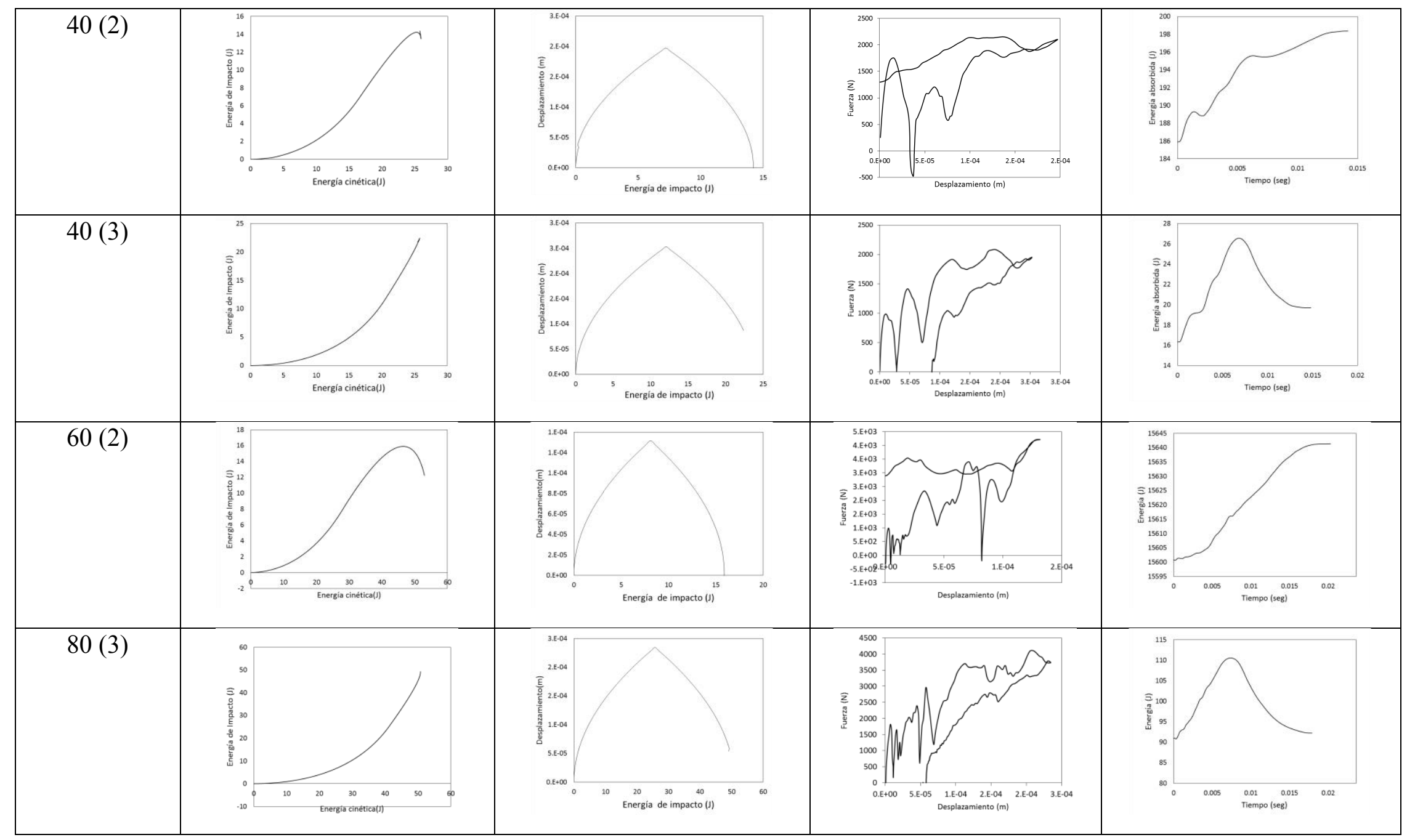




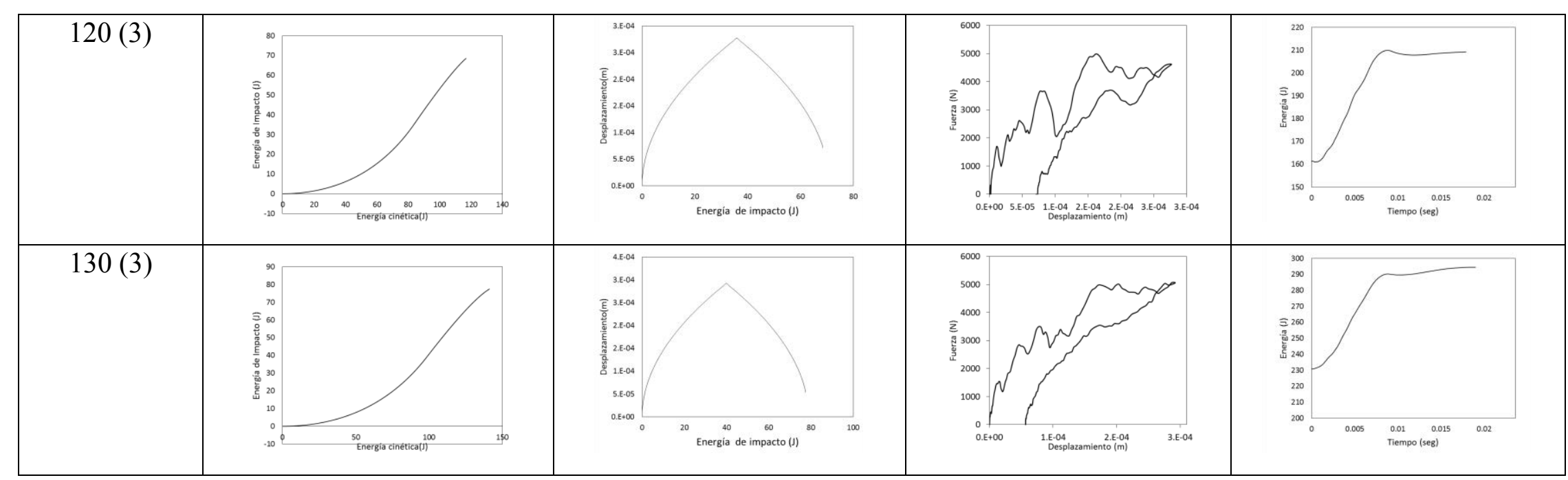


ANEXO 8 MODELADO 3D DE LAS DELAMINACIONES ENTRE CAPAS EN PANELES MODIFICADOS IMPACTADOS POR CAÍDA DE PESO

\begin{tabular}{|c|c|c|}
\hline Energía $(\mathrm{J})$ & Vista de planta & Vista 3D \\
\hline 10 & 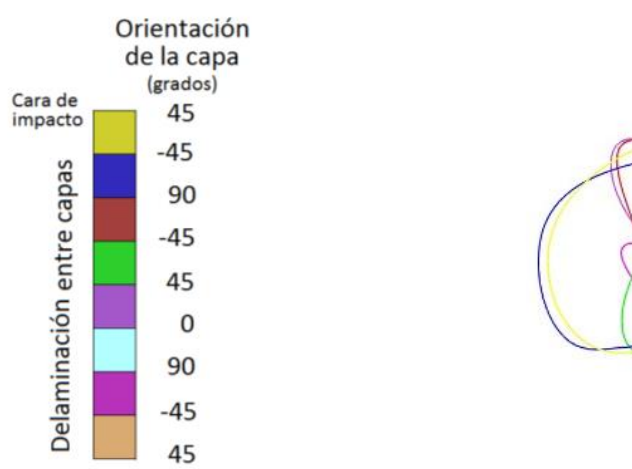 & 1 \\
\hline 20 & 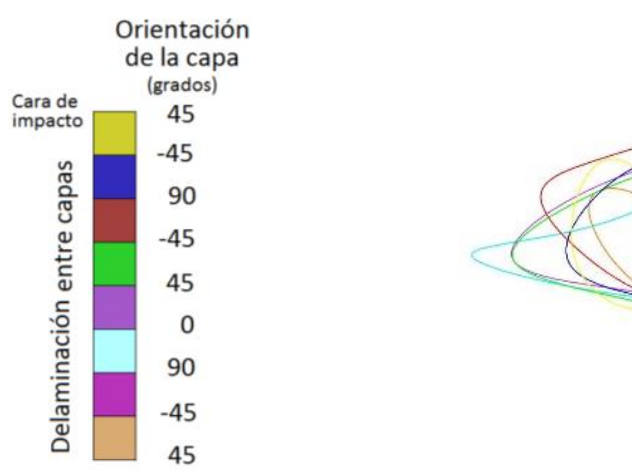 & \\
\hline
\end{tabular}


ANEXO 9 ENSAYOS DE SLAMMING DE PANELES SIN MODIFICAR

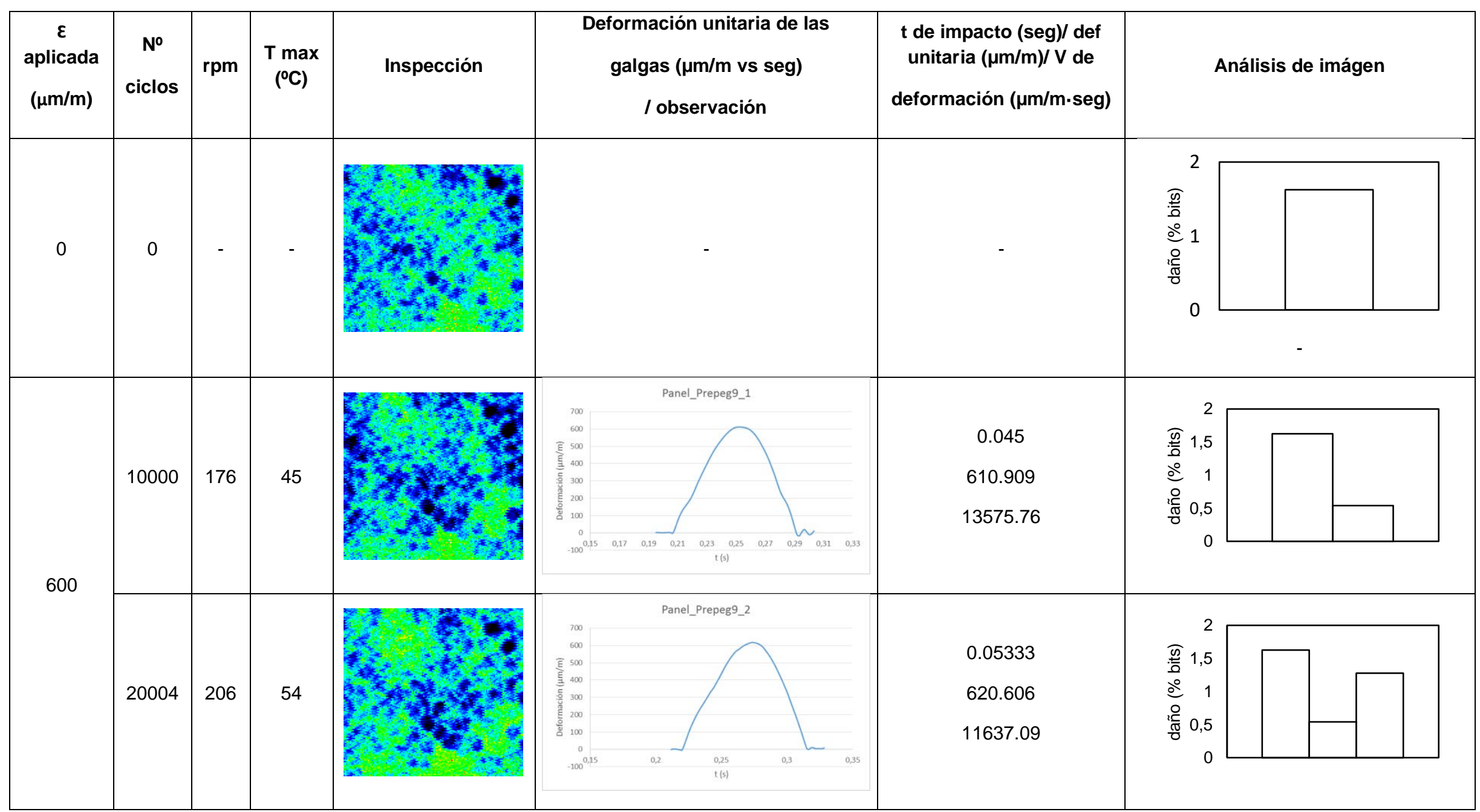




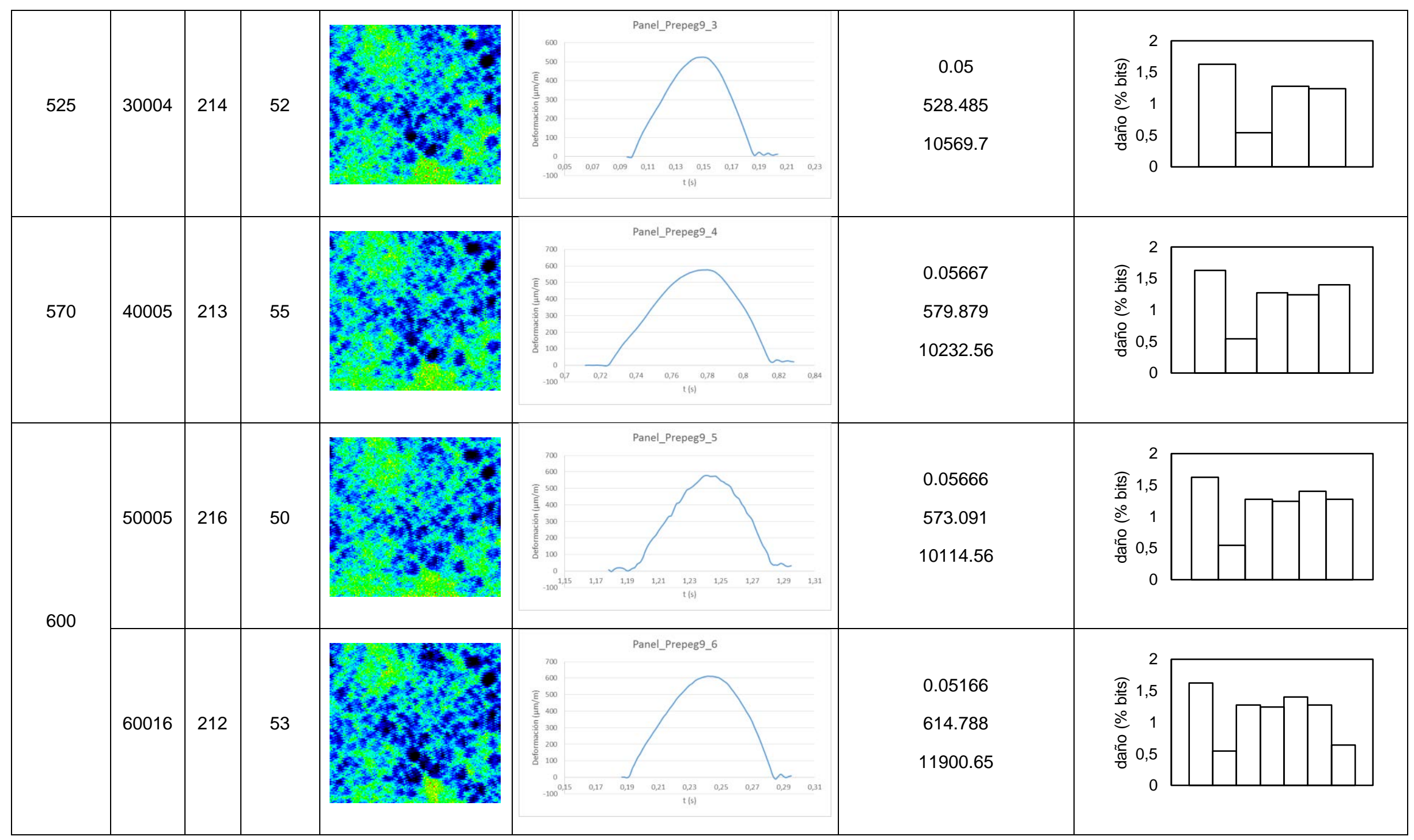




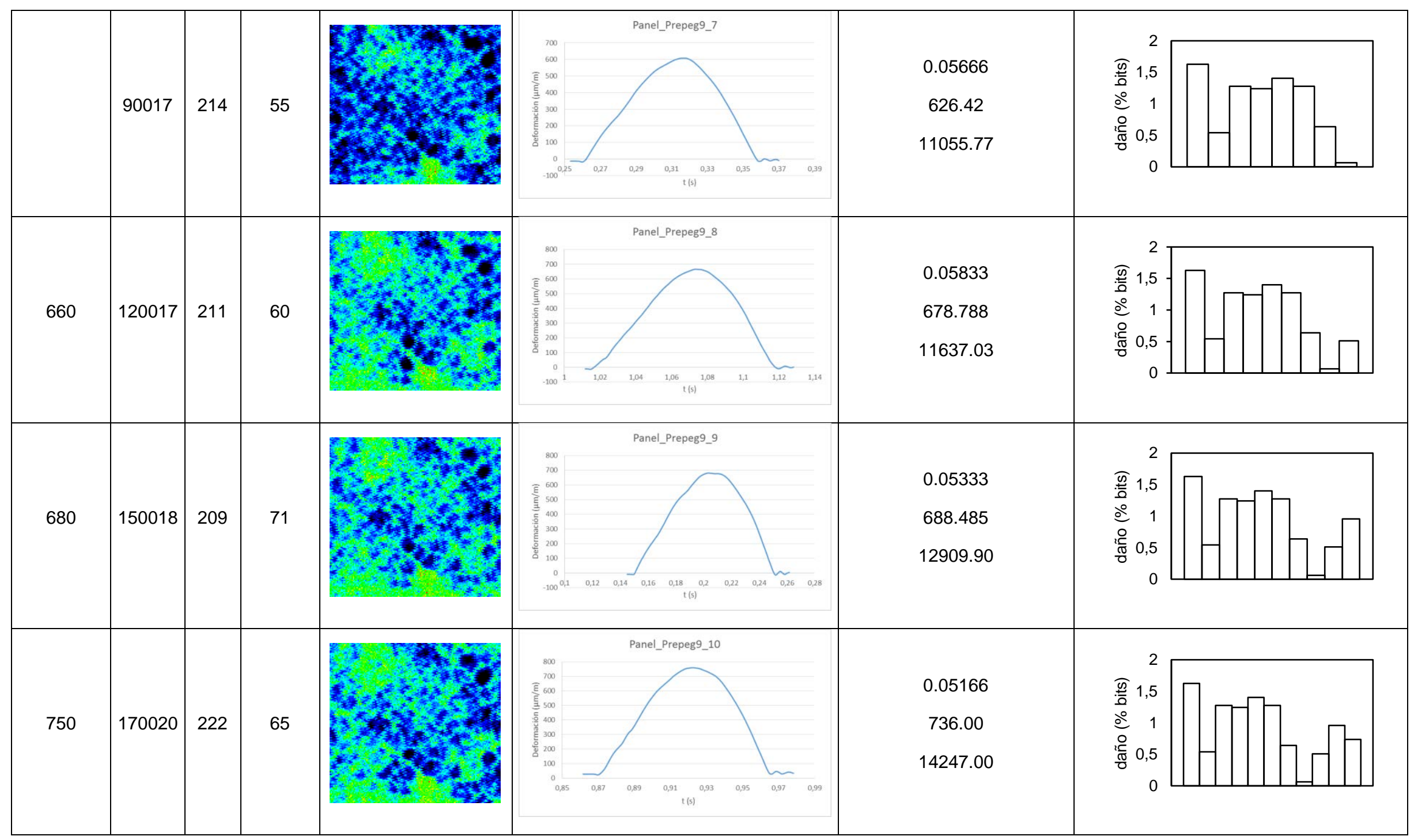




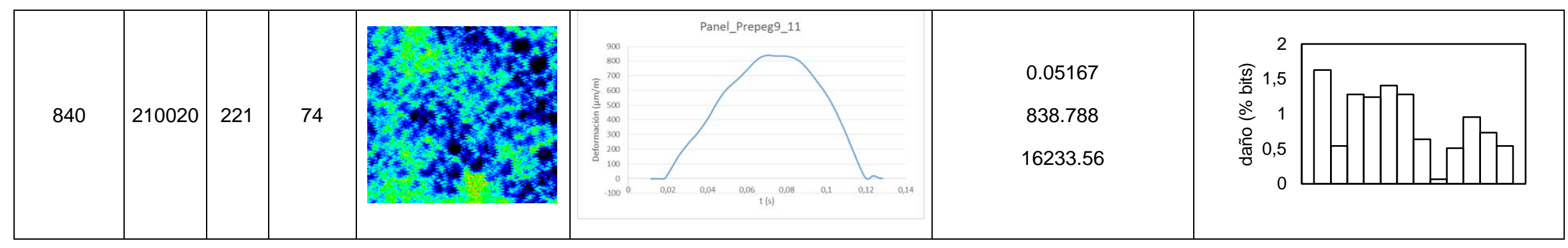

Tabla 11 Resultados de los ensayos de slamming sobre el panel \# A 


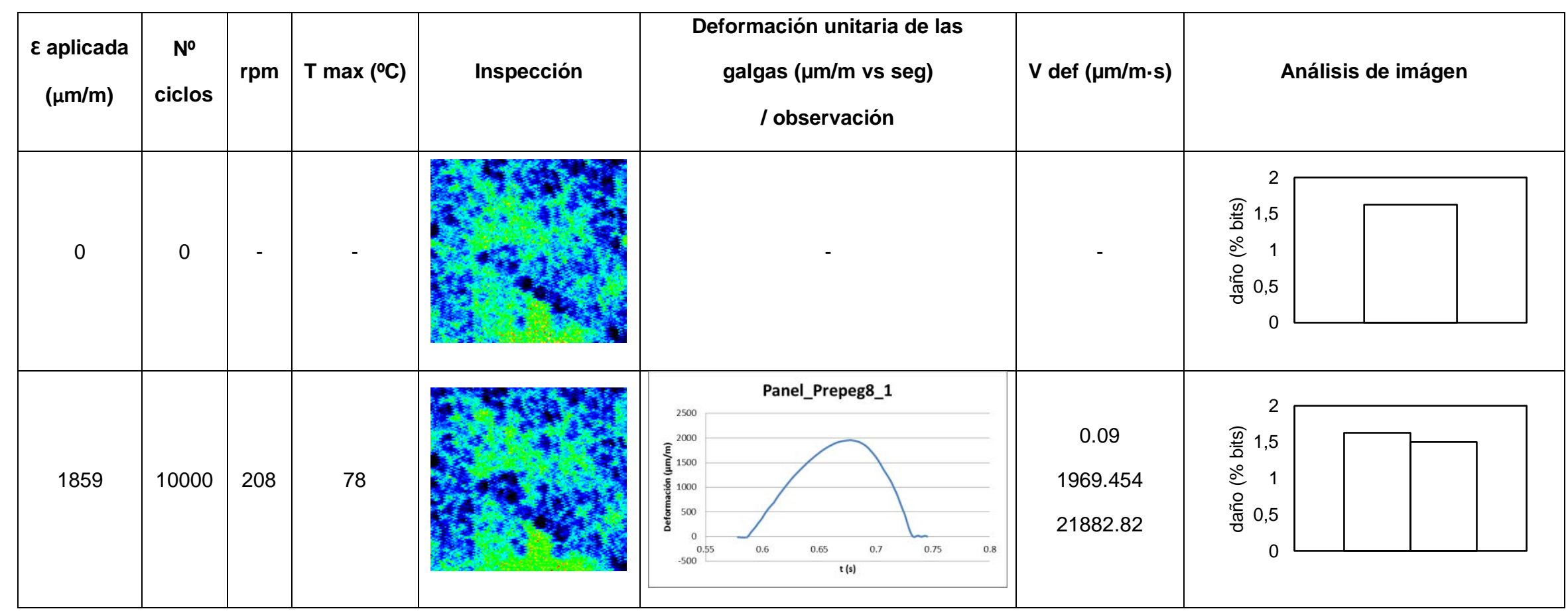




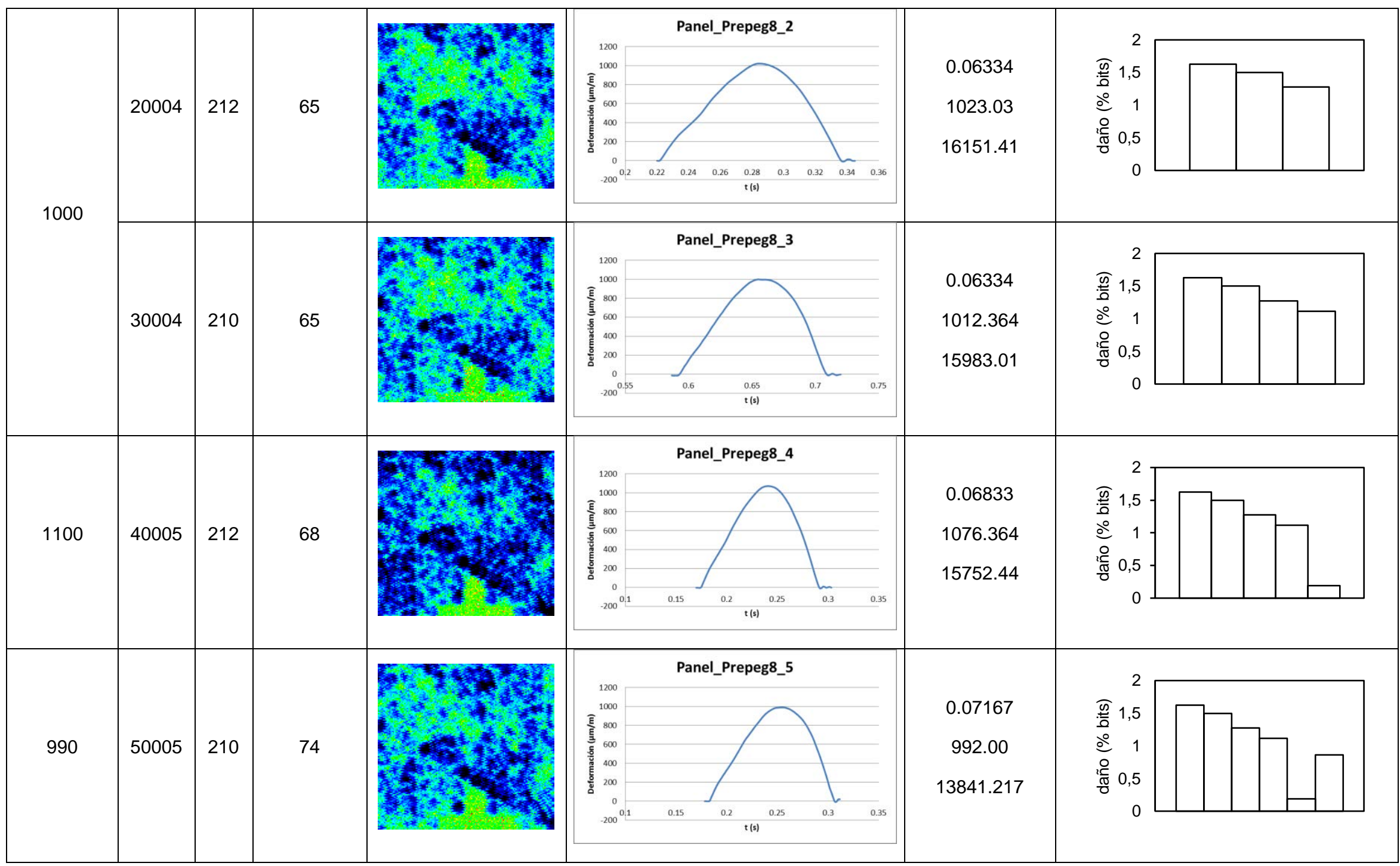




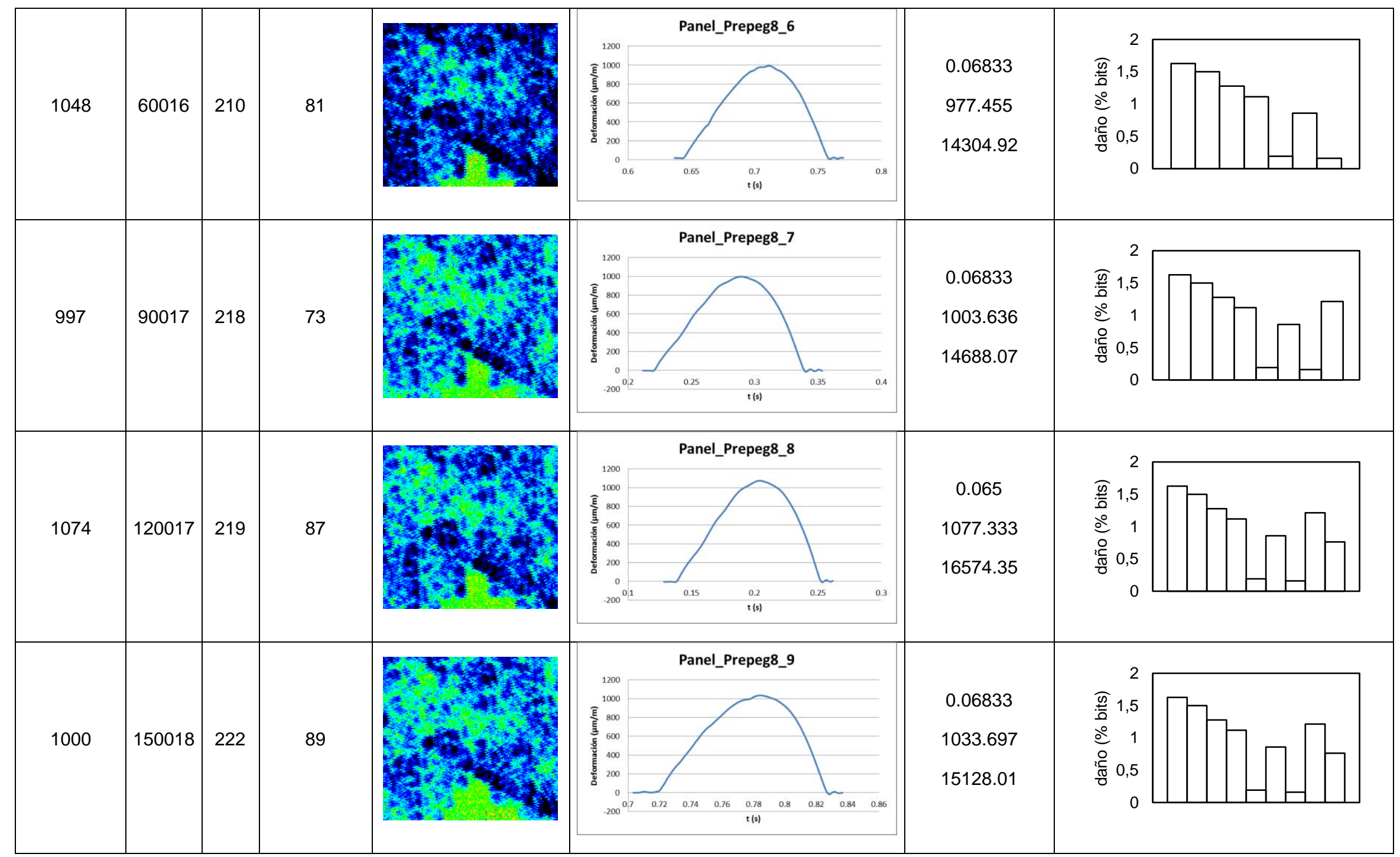

Tabla 12 Resultados de los ensayos de slamming sobre el panel \# B 


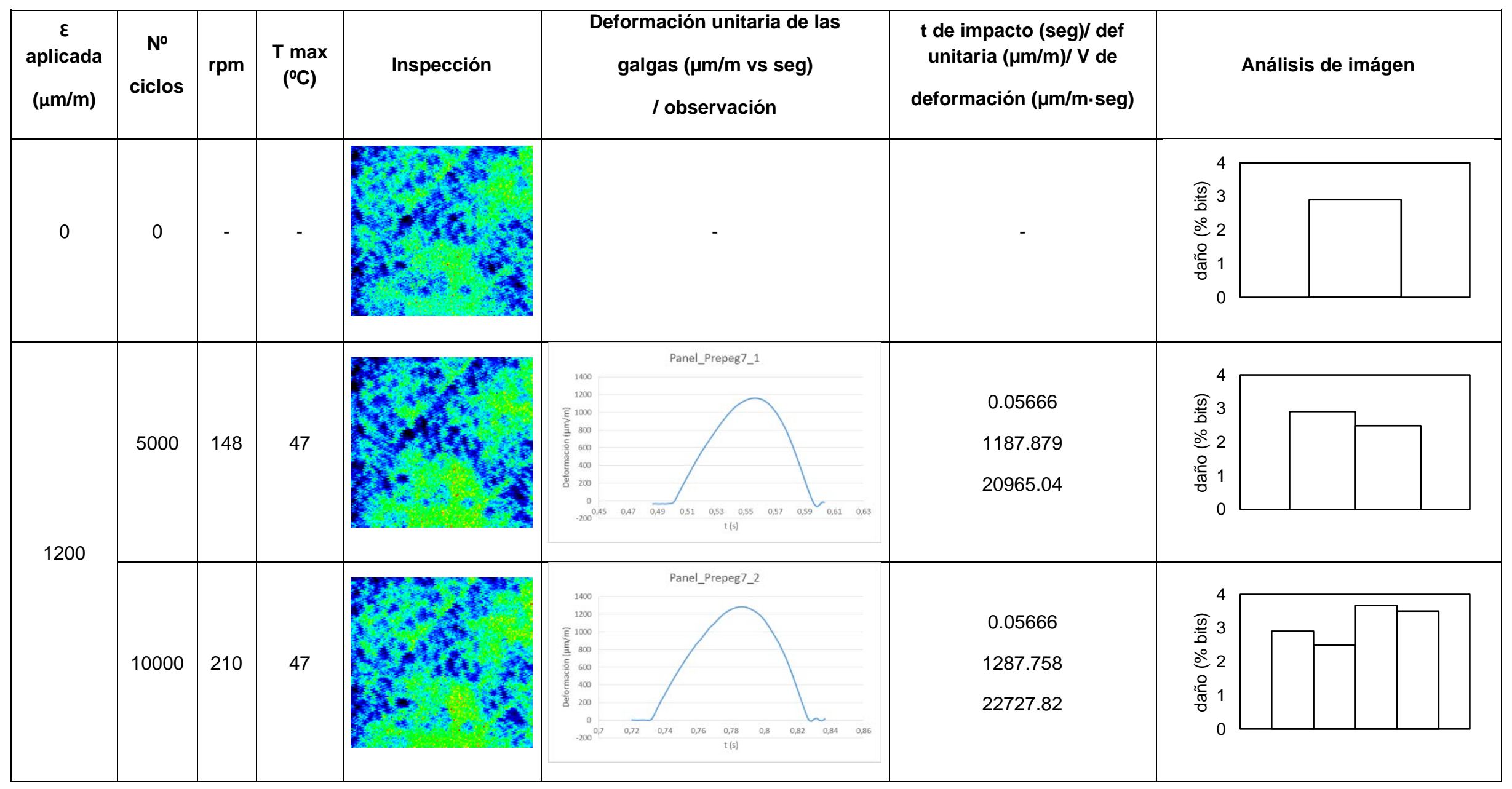




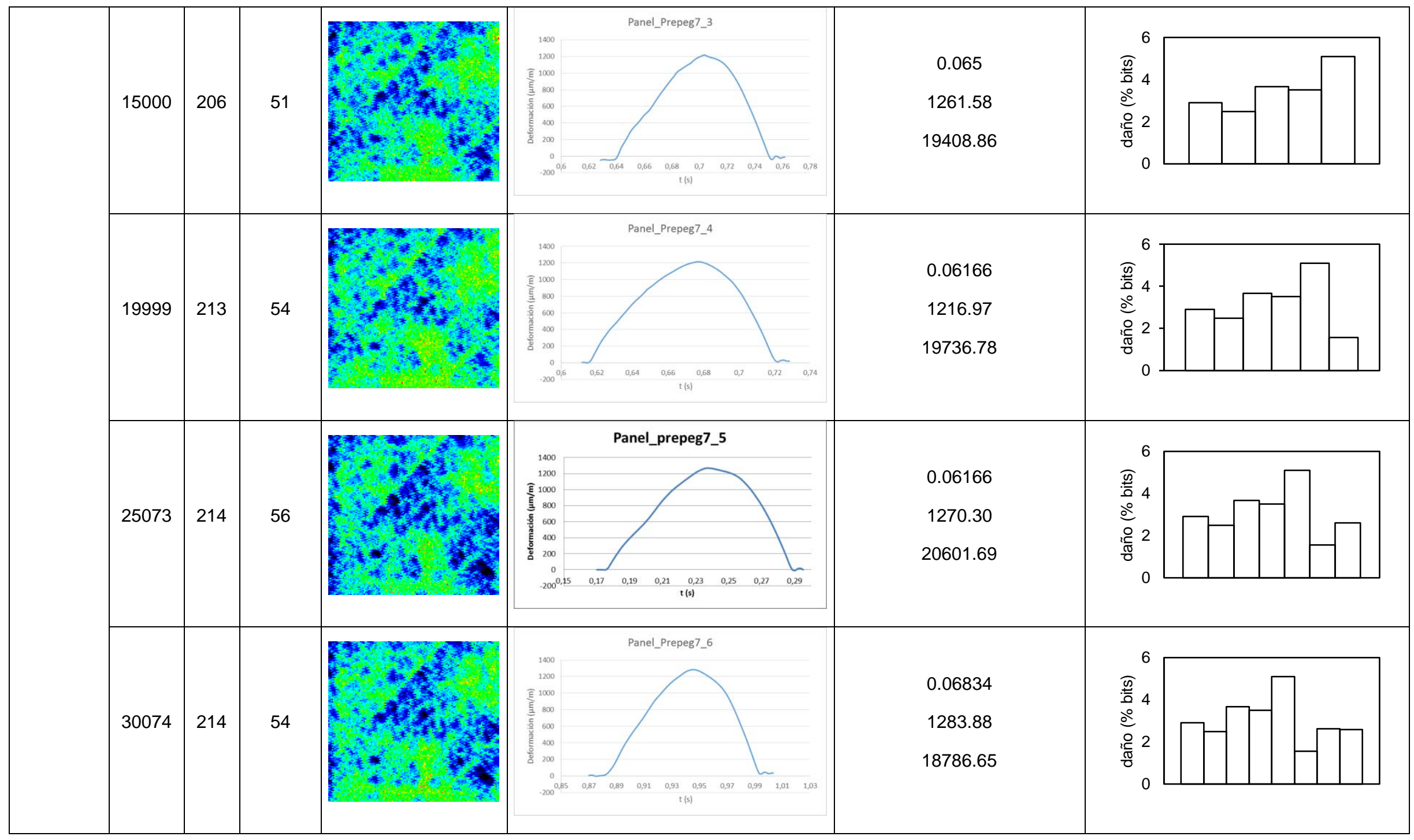




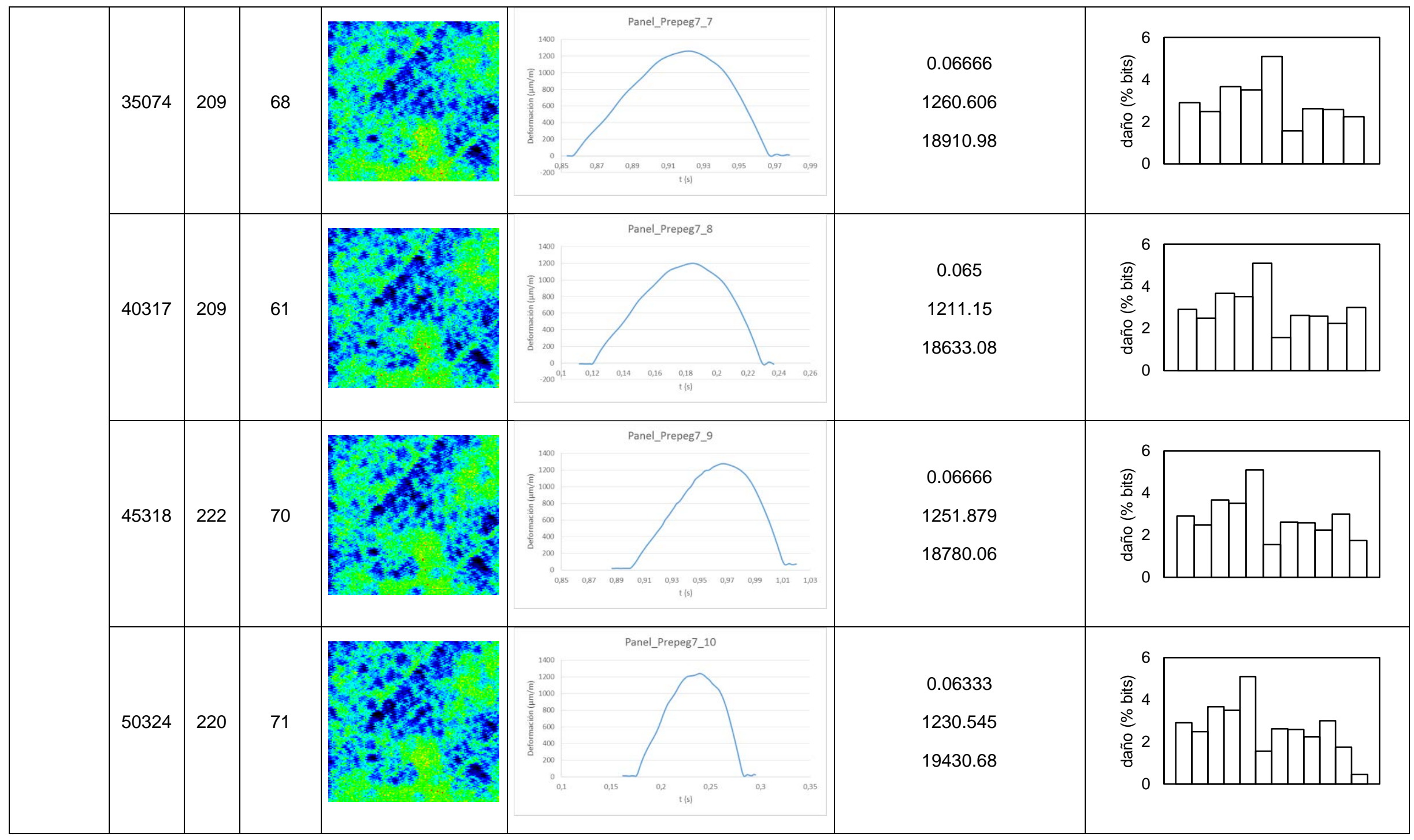




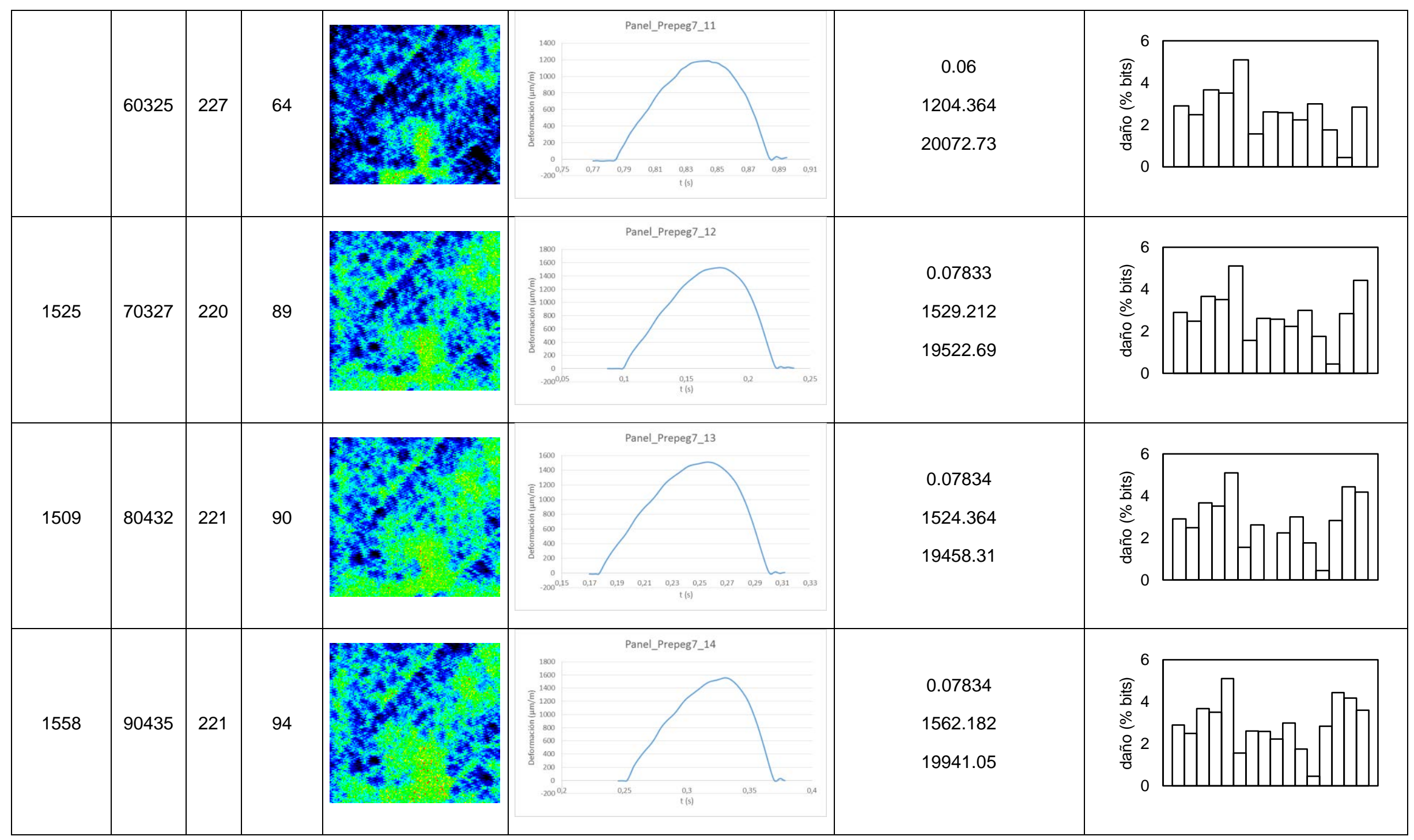




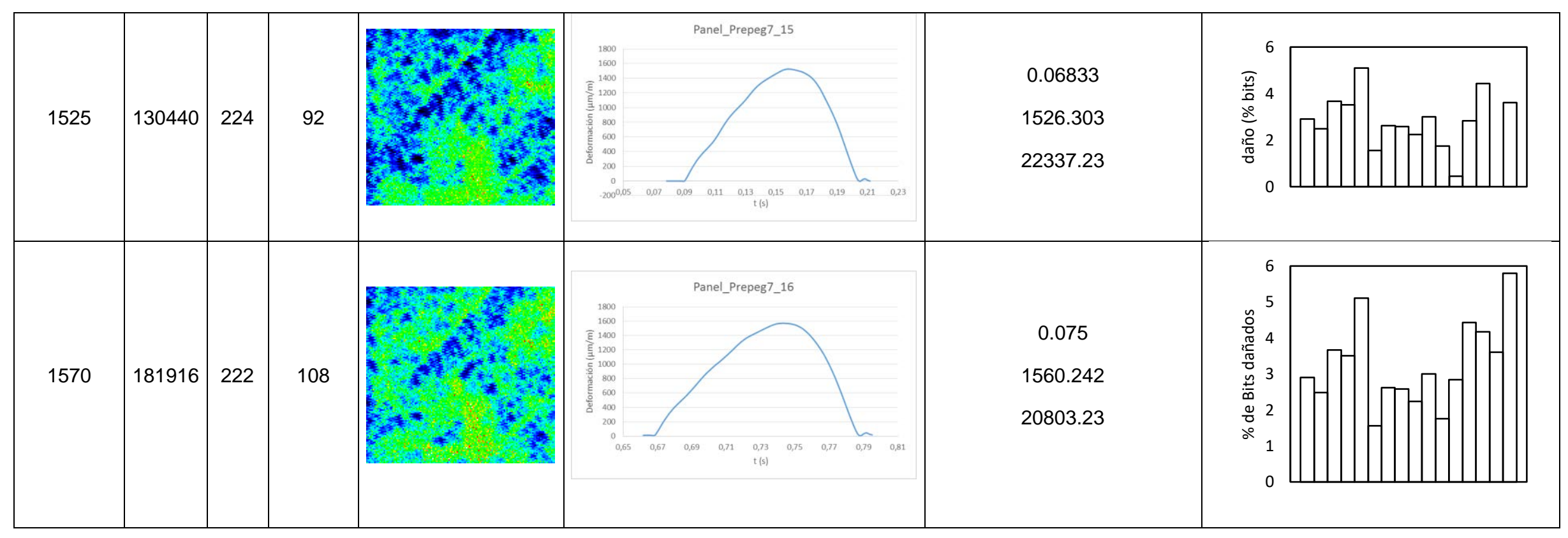

Tabla 13 Resultados de los ensayos de slamming sobre el panel \# C 


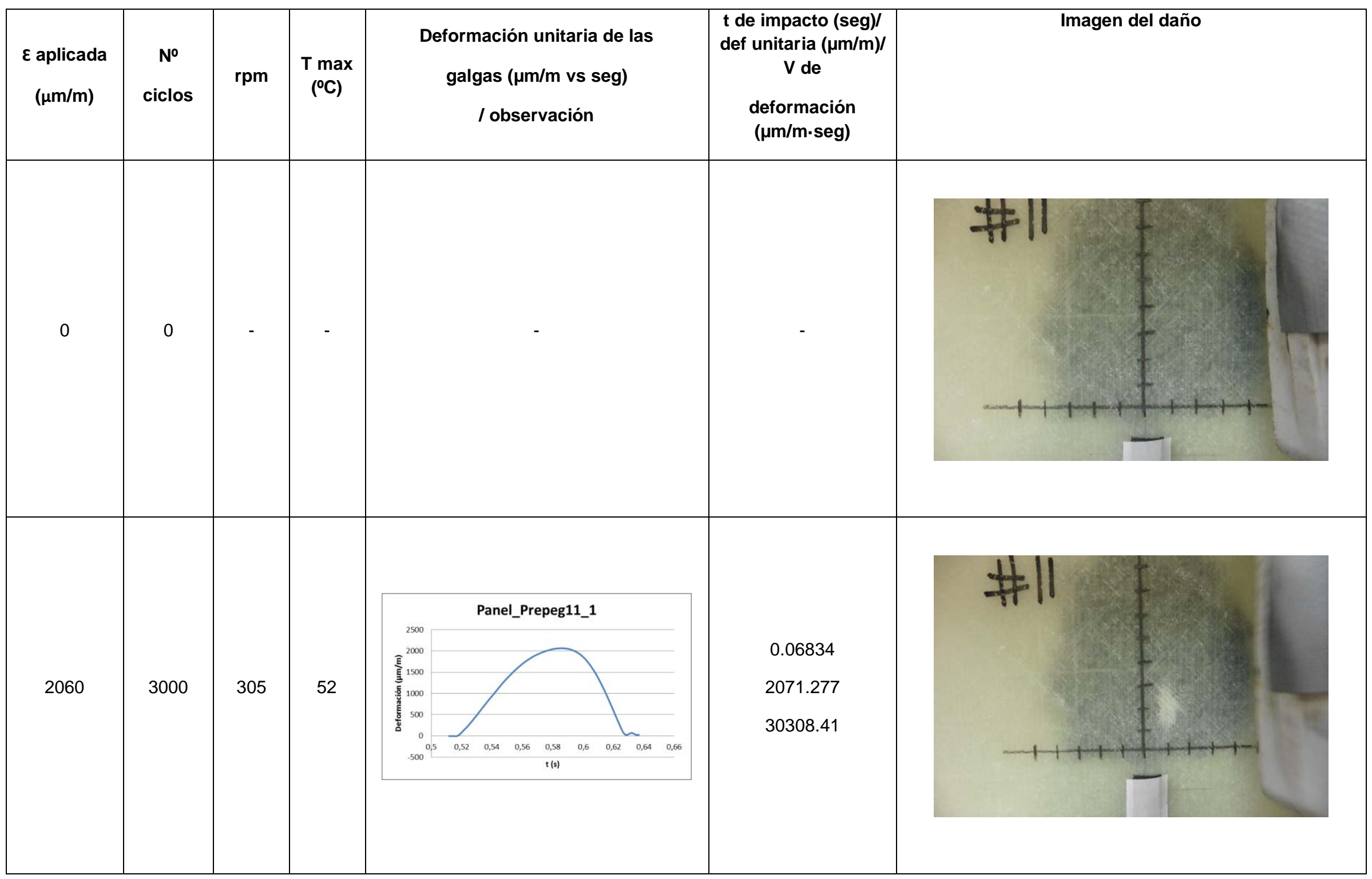




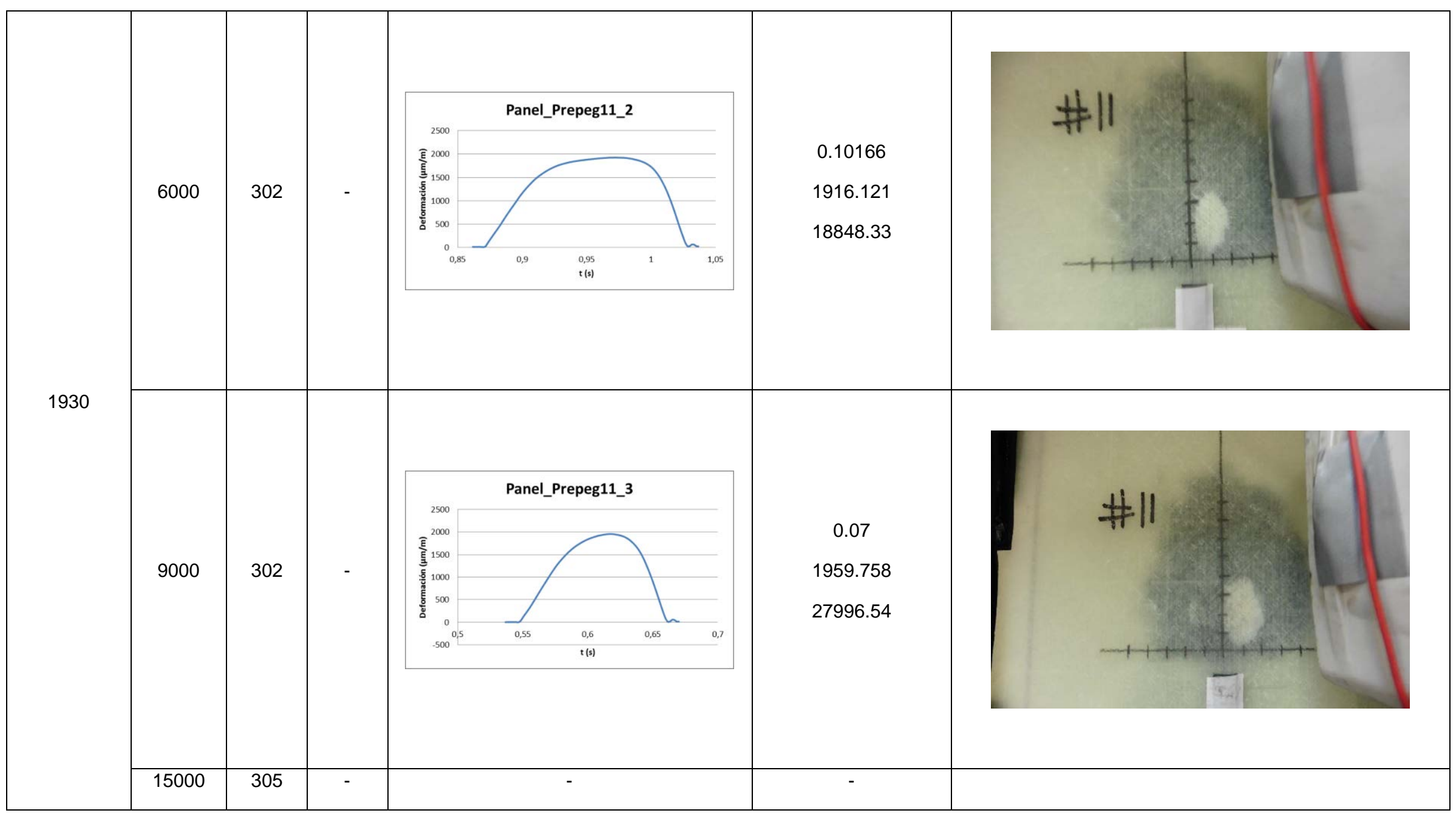




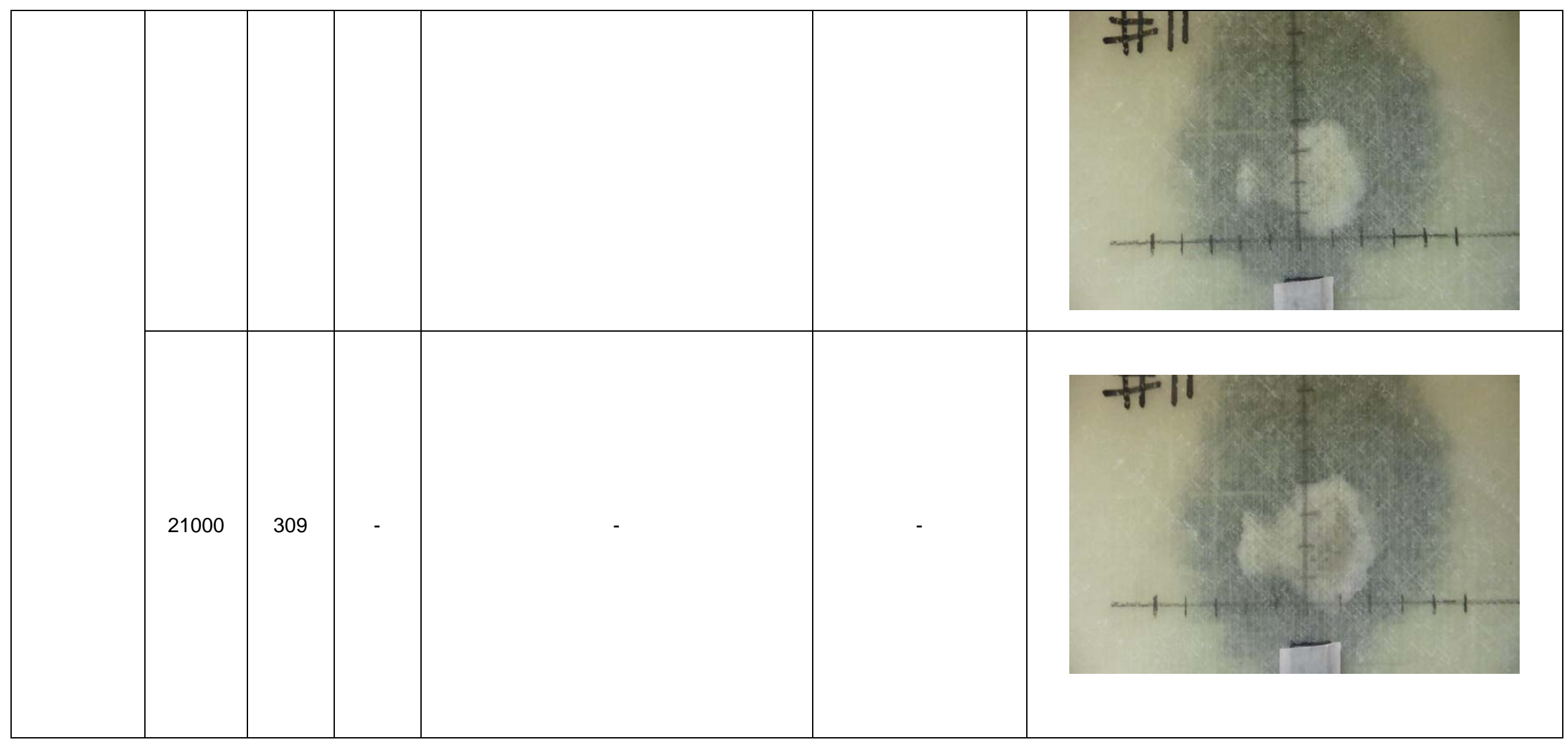

Tabla 14 Resultados de los ensayos de slamming sobre el panel \# D 


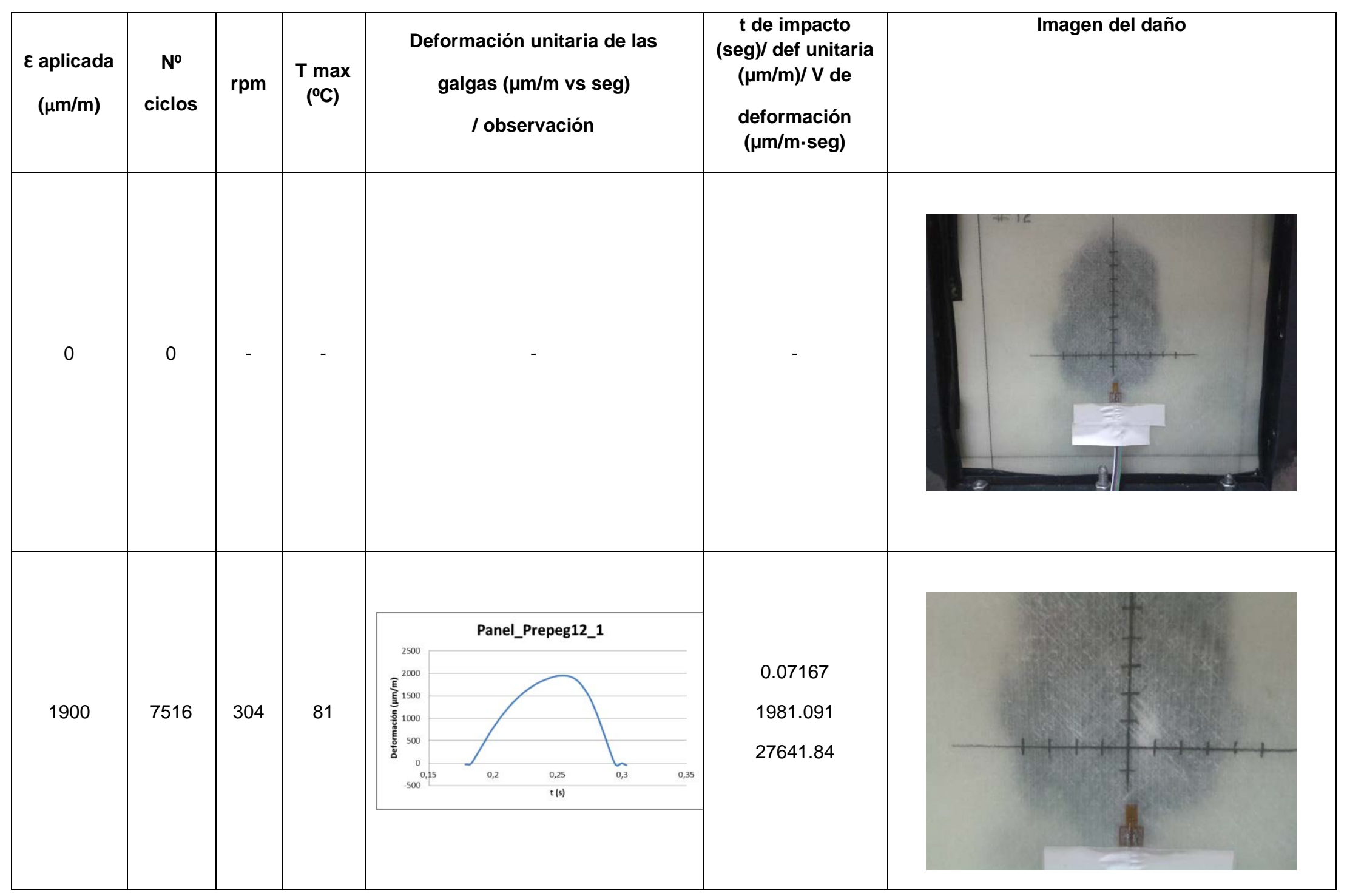




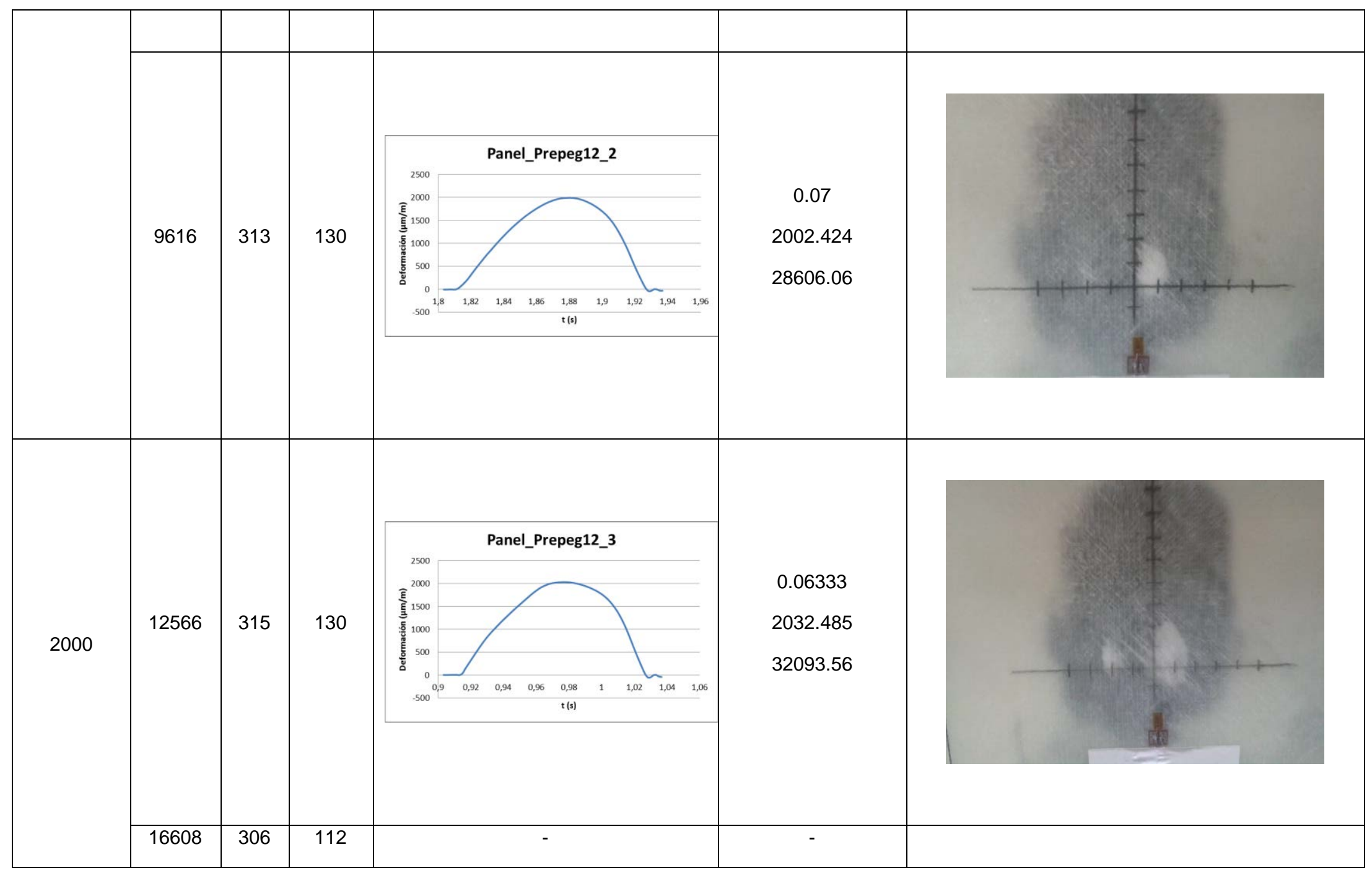




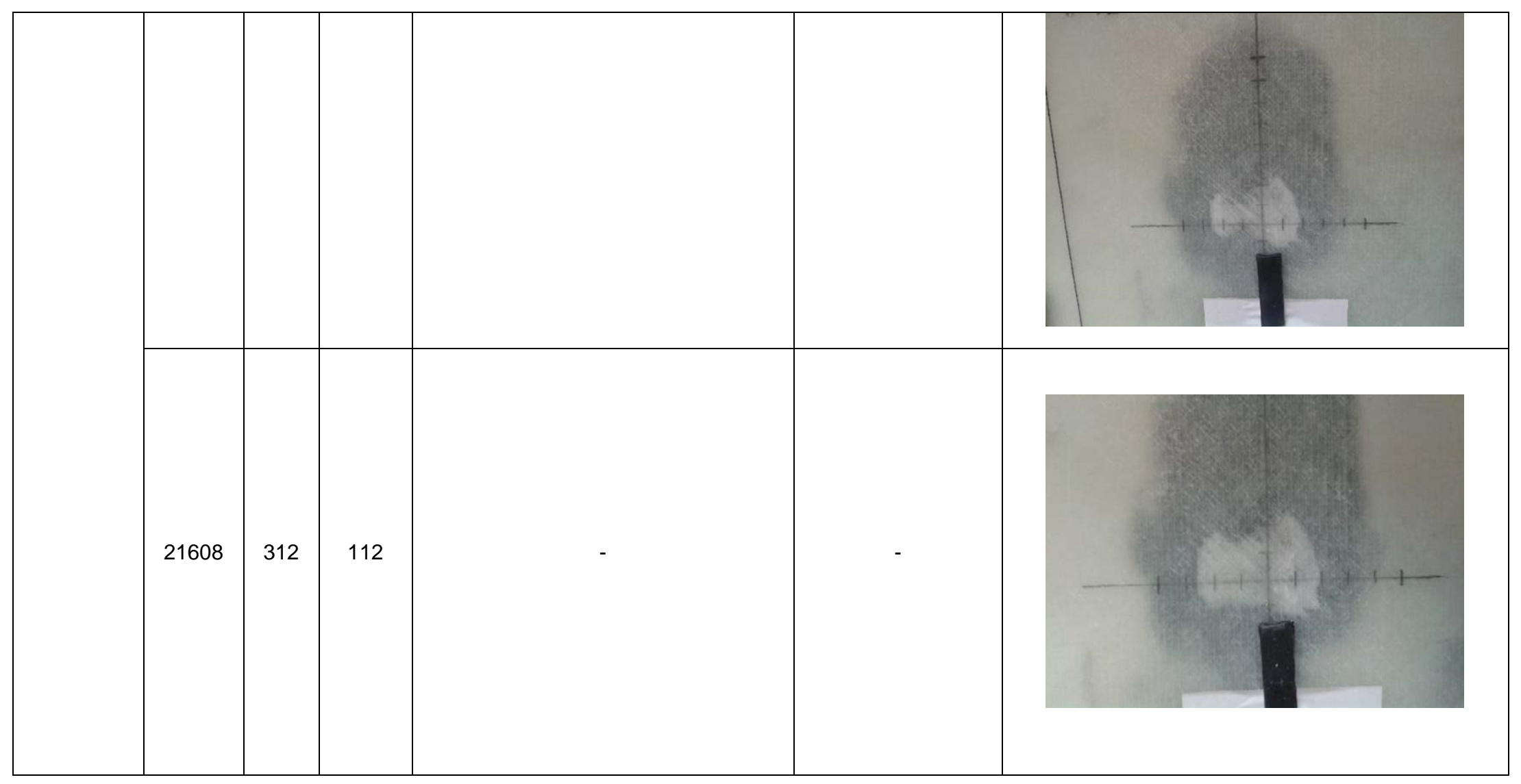

Tabla 15 Resultados de los ensayos de slamming sobre el panel \# E 
